\title{
adComunica
}

número 18 - julio $2019 \cdot 15 €$
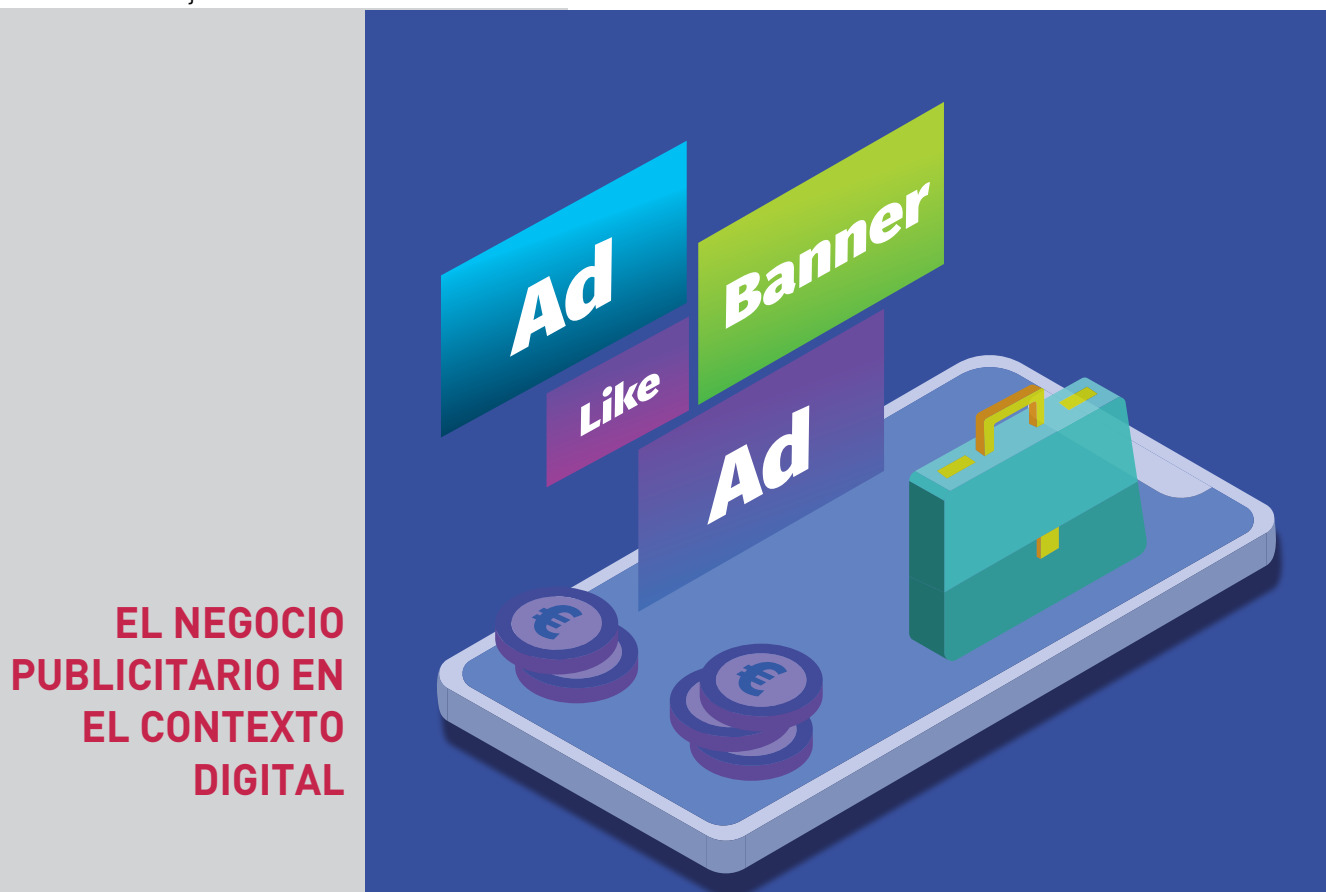



\section{EL NEGOCIO PUBLICITARIO EN EL CONTEXTO DIGITAL}

número 18 - julio 2019 
EDITOR - publisher

Departament de Ciències de la Comunicació, Universitat Jaume I

LUGAR DE EDICIÓN · publishing location

Castellón de la Plana, España.

DIRECIÓN DE CORREO ELECTRÓNICO y PÁGINA WEB · e-mail and website direccion@adcomunicarevista.com

www.adcomunicarevista.es

DISEÑO $\cdot$ original design

Marta Martín Núñez

MAQUETACIÓN E IMPRESIÓN · layout and printing

Martín Gràfic

ISSN

2174-0992

DEPÓSITO LEGAL

V-1606-2011 


\section{adComunica}

\section{EDITORES · editors}

Javier Marzal Felici, Universitat Jaume I, Castellón Andreu Casero Ripollés, Universitat Jaume I, Castellón

\section{EDITORES ADJUNTOS · assistant editors}

Jéssica Izquierdo Castillo, Universitat Jaume I, Castellón

Marta Martín Núñez, Universitat Jaume I, Castellón

Silvia Marcos García, Universitat Jaume I, Castellón Antonio Loriguillo López, Universitat Jaume I, Castellón 


\section{COMITÉ CIENTÍFICO · advisory board}

Eduardo José Marcos Camilo, Universidad de Beira Interior, Covilha, Portugal Jonathan Dovey, University of the West of England, Bristol, Reino Unido Paulina Beatriz Emanuelli, Universidad Nacional de Córdoba, Argentina

Pietsie Feenstra, Université Paul Valéry 3 Montpellier, Francia

Christian Fuchs, Univerisity of Westminster, Londres, Reino Unido

Tristan Mattelart, Université Paris 8, París, Francia

Gianpietro Mazzoleni, Università degli Studi di Milano, Italia

Claudia Mellado, Pontificia Universidad Católica de Valparaíso, Chile

Jean-Claude Séguin, Université de Lyon II - Louis Lumière, Francia

Carlo Sorrentino, Università degli Studi di Firenze, Florencia, Italia Jacques Terrasa, Université Paris-Sorbonne, París, Francia

Daya Kishan Thussu, University of Westminster, Londres, Reino Unido

Maximiliano Martín Vicente, Universidade Estadual Paulista UNESP, Bauru, Brasil

\section{COMITÉ EDITORIAL · editorial board}

Miguel de Aguilera Moyano, Universidad de Málaga José Ignacio Aguaded, Universidad de Huelva

José María Álvarez Monzoncillo, Universidad Rey Juan Carlos, Madrid Juan Benavides Delgado, Universidad Complutense, Madrid

María Rosa Berganza Conde, Universidad Rey Juan Carlos, Madrid

Enrique Bustamante Ramírez, Universidad Complutense, Madrid

Francisco Campos Freire, Universidad de Santiago de Compostela

María José Canel Crespo, Universidad Complutense, Madrid

Fernando Canet Centellas, Universitat Politècnica de València

María Victoria Carrillo Durán, Universidad de Extremadura

María Jesús Casals Carro, Universidad Complutense, Madrid

José María Casasús Gurí, Universitat Pompeu Fabra, Barcelona

José Luis Castro de Paz, Universidad de Santiago de Compostela

Josep Maria Català Doménech, Universitat Autònoma de Barcelona Giuliana Colaizzi, Universitat de València

Ubaldo Cuesta Cambra, Universidad Complutense, Madrid

José Luis Dader García, Universidad Complutense, Madrid

José Manuel de Pablos Coello, Universidad de La Laguna, Tenerife

Concha Edo Bolós, Universidad Complutense, Madrid

Raúl Eguizábal Maza, Universidad Complutense, Madrid

Rosa Franquet i Calvat, Universitat Autònoma de Barcelona

Emilio Carlos García Fernández, Universidad Complutense, Madrid Juan Antonio García Galindo, Universidad de Málaga

Francisco García García, Universidad Complutense, Madrid

José Vicente García Santamaría, Universidad Carlos III, Madrid, España

Jesús González Requena, Universidad Complutense, Madrid

Juan José Igartua Perosanz, Universidad de Salamanca

Margarita Ledo Andión, Universidad de Santiago de Compostela

Xosé López, Universidad de Santiago de Compostela

Marta Martín Llaguno, Universitat d'Alacant

Manuel Martínez Nicolás, Universidad Rey Juan Carlos, Madrid

Koldo Meso Ayerdi, Universidad del País Vasco

Josep Lluis Micó Sanz, Universitat Ramón Llull, Barcelona

Juan Carlos Miguel de Bustos, Universidad del País Vasco

Marcial Murciano, Universitat Autònoma de Barcelona Fernando Olivares Delgado, Universitat d'Alacant

José Luis Piñuel Raigada, Universidad Complutense, Madrid

Emili Prado i Picó, Universitat Autònoma de Barcelona Juan Rey Fuentes, Universidad de Sevilla

Eduardo Rodríguez Merchán, Universidad Complutense, Madrid

Xosé Soengas Pérez, Universidad de Santiago de Compostela

Jenaro Talens Carmona, Universitat de València, Université de Génève

Jesús Timoteo Álvarez, Universidad Complutense, Madrid

Victoria Tur Viñes, Universitat d'Alacant

Santos Zunzunegui Díez, Universidad del País Vasco 


\section{CONSEJO PROFESIONAL · professional editorial board}

José Beltrán Lamaza, Director Periódico Levante de Castellón Juan Carlos Enrique Forcada, Director Regional de Onda Cero Illes Balears Eduard Farrán Teixidor, Director Creativo Estratégico en Stragonoff, Valencia Francisco Fernández Beltrán, Director del Servei de Comunicació i Publicacions de la Universitat Jaume I Darío Ginestar, Presidente de AESAV, Asociación de Empresas de Servicios del Audiovisual Valenciano Luis Gonsálbez, Presidente de EAVF, Empresas Audiovisuales Valencianas Federadas

Alipio Gutiérrez Sánchez, Presidente de ANIS, Asociación Nacional de Informadores de la Salud, España José Carlos Gutiérrez Vigara, Presidente de AEDEMO, Asociación Española de Mercado, Marketing y Opinión Josep Lázaro Dobón, Director Cadena Cope, Castellón Gustavo Llach Mollón, Dircom de CajaMar, Castellón Jesús López Flor, Director Radio Castellón-Cadena Ser, Castellón

Eugenio Martín, AECPcv, Asociación de Empresas de Comunicación Publicitaria de la Comunidad Valenciana Ximo Pérez, Presidente de PAV, Productores Audiovisuales Valencianos

Enrique Pernía, Presidente de la AECPcv, Asociación de Empresas de Comunicación Publicitaria de la Comunidad Valenciana Ángel del Pino, Presidente de la Federación de Agencias de Publicidad de España Almudena Román Domínguez, Directora de Autocontrol de la Comunicación España Carlos Rubio, Director Asociación Española de Agencias de Comunicación Publicitaria

José Luis Serrano Fabregat, Secretario General de adComunica, Asociación para el desarrollo de la Comunicación Montserrat Tarrés, Presidenta de DIRCOM, Asociación de Directores de Comunicación, España José Luis Valencia Larrañeta, Director Periódico Mediterráneo, Castellón

\section{CONSEJO TÉCNICO · board of management}

Laura Alonso Muñoz, Universitat Jaume I, Castellón Roberto Arnau Roselló, Universitat Jaume I, Castellón María Consuelo Balado Albiol, Universitat Jaume I, Castellón María Teresa Benlloch Osuna, Universitat Jaume I, Castellón Estela Bernad Monferrer, Universitat Jaume I, Castellón Rocío Blay Arráez, Universitat Jaume I, Castellón Eva Breva Franch, Universitat Jaume I, Castellón Hugo Doménech Fabregat, Universitat Jaume I, Castellón Carlos Fanjul Peyró, Universitat Jaume I, Castellón Césareo Fernández Fernández, Universitat Jaume I, Castellón Pablo Ferrando García, Universitat Jaume I, Castellón Esteban Galán Cubillo, Universitat Jaume I, Castellón Samuel Gil Soldevilla, Universitat Jaume I, Castellón Cristina González Oñate, Universitat Jaume I, Castellón Lorena López Font, Universitat Jaume I, Castellón Pablo López Rabadán, Universitat Jaume I, Castellón Antonio Loriguillo López, Universitat Jaume I, Castellón Magdalena Mut Camacho, Universitat Jaume I, Castellón José Antonio Palao Errando, Universitat Jaume I, Castellón Aarón Rodríguez Serrano, Universitat Jaume I, Castellón Agustín Rubio Alcover, Universitat Jaume I, Castellón Emilio Sáez Soro, Universitat Jaume I, Castellón María Soler Campillo, Universitat Jaume I, Castellón Teresa Sorolla Romero, Universitat Jaume I, Castellón

La composición de los comités de la revista adComunica tendrá vigencia para el período 2016-2020, tras el cual se procederá a una renovación.
The composition of the committees of the journal adComunica will be effective for the period 2016-2020, being renewed by the end of it. 



\section{PRESENTACIÓN /}

11 El negocio publicitario en el contexto digital / Javier Marzal Felici y Andreu Casero Ripollés (Universitat Jaume I)

\section{INFORME / El negocio publicitario en el contexto digital}

Coordinación: Cristina González Oñate y Carlos Fanjul Peyró

17 El negocio publicitario en el contexto digital / Cristina González Oñate y Carlos Fanjul Peyró (Universitat Jaume I)

21 Hábitos de uso y consumo de la generación millennial en sus teléfonos móviles / Yolanda Cabrera García-Ochoa (Universitat de València)

41 Actitudes de los jóvenes hacia las comunidades virtuales y su vínculo con las marcas. Una aproximación a través de los estudiantes universitarios / Juana Rubio Romero y Gemma Barón Dulce (Universidad Antonio de Nebrija)

63 La incorporación de la figura del influencer en las campañas publicitarias: consecuencias para las agencias de publicidad españolas / Paloma Sanz-Marcos, Gloria Jiménez-Marín, Rodrigo Elías-Zambrano (Universidad de Sevilla)

87 Análisis de los perfiles profesionales en las webs de las agencias de publicidad en España / María del Mar Sánchez Moreno (Universidad Complutense de Madrid)

101 Publicidad de la publicidad. Las redes sociales como soportes de comunicación de las agencias de publicidad / Tatiana Hidalgo-Marí y Jesús Segarra-Saavedra (Universidad de Alicante) 
123 Comunicación de la sostenibilidad de las principales marcas de fast fashion españolas e italianas: Zara, Mango, Calzedonia y OVS. Diferencias entre el punto de venta online y el punto de venta físico / Raquel Martín López (Universidad CEU Cardenal Herrera)

\section{OTRAS INVESTIGACIONES /}

155 Gestión y comunicación de la cultura corporativa en empresas de las industrias creativas. Estudio de caso en el Arco mediterráneo en España / Eliseo Rodríguez Monteagudo y Fernando Olivares Delgado (Universidad de Alicante).

199 Actitud del menor ante la publicidad que recibe a través de los dispositivos móviles / Beatriz Feijoo Fernández (Universidad de los Andes, Chile) y Aurora García González (Universidad de Vigo)

219 Netflix, estrategia y gestión de marca en torno a la relevancia de los contenidos/ Santiago Mayorga Escalada (Universidad Europea Miguel de Cervantes)

245 Diez años de investigación en las principales revistas científicas de comunicación. Tendencias y temáticas en las publicaciones de mayor impacto en JCR y SJR / Ángel Vizoso, Sara Pérez-Seijo, Xosé López-García (Universidad de Santiago de Compostela)

271 El vínculo entre la marca España y la cultura en la prensa diaria / Fernando Carcavilla Puey (Universidad San Jorge) y Ricardo Zugasti Azagra (Universidad de Zaragoza) 


\section{TRIBUNA: INVESTIGACIÓN Y PROFESIÓN /}

297 Solo sé que no sé nada / Eugenio Martín Diéguez (Arquetipo)

301 El nuevo reto digital se llama creatividad / Laura Llopis (Weaddyou)

305 Dicen que el spot ha muerto, ¡larga vida al spot! / Josep Martí Prosper (KliperDvila)

309 Efectos de la transformación digital en la empresa publicitaria de la Comunidad Valenciana / Paloma Sanz-Marcos (Universidad de Sevilla)

313 Educación mediática en la era digital: hacia la formación de internautas exigentes / Alejandra Tirado García y María Rodríguez Arce

\section{CRÉDITOS /}

319 Acerca de los promotores de adComunica. Revista Científica de Estrategias, Tendencias e Innovación en Comunicación

321 About the promoters of adComunica. Journal of Strategies, Tendencies and Innovation in Communication

323 Normas de publicación

325 Submission guidelines 



\section{Editorial. El negocio publicitario en el contexto digital}

Javier Marzal Felici Universitat Jaume I

Andreu Casero-Ripollés Universitat Jaume I

\section{Referencia de este artículo}

Marzal Felici, Javier y Casero-Ripollés, Andreu (2019). Editorial. El negocio publicitario en el contexto digital. En: adComunica. Revista Científica de Estrategias, Tendencias e Innovación en Comunicación, (18), 11-16. DOI: http://dx.doi. org/10.6035/2174-0992.2019.18.1

\section{La centralidad de la publicidad en la sociedad digital}

Desde hace bastantes años venimos sosteniendo que la publicidad constituye el discurso hegemónico por excelencia de la sociedad de la información, al tratarse de un tipo de comunicación modélica en lo que a eficacia y capacidad persuasiva se refiere. En efecto, la información en prensa, radio y televisión responde cada vez más a una concepción más próxima al entretenimiento (Thussu, 2007), en la lógica de la «sociedad del espectáculo» (González Requena, 1990), que ya anticipó Debord en 1967. El cine mainstream contemporáneo, ejemplarmente representado por los films de la factoría Marvel / Disney, se pliega absolutamente a esta lógica de la espectacularización de las representaciones (Marzal-Felici, 1999; Bordwell, 2006), como también lo hacen las series de TV transnacionales, la narrativa de los videojuegos, buena parte del fotoperiodismo contemporáneo, etc. El auge de las narrativas transmedia también representa la revolución del modelo de financiación de la creación cultural y del sistema comunicativo actual. No podemos olvidar que la publicidad, en sus más diversas formas y modalidades, es la principal fuente de financiación del entretenimiento y de la información que consumimos en la actua- 
lidad. Por tanto, nuestra preocupación por la evolución y desarrollo del negocio publicitario es constante e, incluso, recurrente como lo acredita el hecho de hemos abordado el tema de comunicación publicitaria con bastante frecuencia en los últimos años: en el número 7 (mayo de 2014), «Los medios publicitarios en el contexto actual» o en el número 14 (julio de 2017), con la temática «Transmedia y comunicación publicitaria: retos, narrativas y emociones».

Si prestamos atención a la situación del sistema mediático español y, más especialmente, del sistema valenciano, hay muchos motivos para la preocupación. Seguimos constatando que nuestro sistema mediático está profundamente marcado por el desequilibrio entre medios privados y públicos. Las corporaciones públicas están cada vez peor financiadas y, asfixiadas por las deudas, disponen de muy poco margen para la innovación, lastradas además por el control político que nuestros gobernantes se resisten a ceder. En estos días ha sido noticia la falta de liquidez de la Corporación RTVE para asumir la compra de derechos de emisión de las Olimpiadas de Tokio 2020. Y no podemos olvidar que estamos a las puertas de un nuevo apagón digital, con la expansión de la tecnología 5G, que traerá transformaciones muy importantes en el panorama de los servicios OTT, con nuevos actores de la relevancia global de Disney, Apple y Amazon, entre otros.

En la Comunidad Valenciana, seguimos de cerca y con mucho interés el desarrollo de los nuevos medios de comunicación públicos que aglutina la Corporación Valenciana de Medios de Comunicación (CVMC) y su sociedad mercantil À Punt Mèdia. Está siendo un proceso de mucha complejidad y dificultades, porque la herencia recibida es, sin lugar a dudas, terrible. Tras un primer año de notable reactivación del sector audiovisual valenciano, nos encontramos ahora con una cierta parálisis, cuyas causas tienen que ver con una manifiesta infrafinanciación, pero también a errores de gestión que deben ser solucionados con urgencia. La Mesa Sectorial del Audiovisual Valenciano (MESAV) ha manifestado esta preocupación por la evidente disminución de la actividad del sector audiovisual desde diciembre de 2018, y la falta de comunicación con la dirección de À Punt Mèdia. Hay que destacar, como lo ha hecho la MESAV, que la recuperación de los medios de comunicación públicos está siendo fundamental para la promoción de la lengua y la identidad cultural de los valencianos, y que À Punt Mèdia es un motor esencial de las industrias culturales y creativas de la Comunidad Valenciana. En este contexto, es urgente que la Corporación Valenciana de Medios de Comunicación debe potenciar vías de financiación alternativas, que pasan por atraer a los anunciantes y aumentar notablemente los ingresos por publicidad, lo que tiene una relación directa con la mejora de los datos de audiencia. Pero debemos ser realistas: si no hay un esfuerzo inversor importante por parte de la Generalitat Valenciana, será imposible que el proyecto À Punt Mèdia pueda consolidarse a corto y medio plazo. El presupuesto anual de 55 millones en la actualidad es manifiestamente insuficiente, apenas once euros de gasto medio por habitante, nos coloca a la cola de las RTV públicas autonómicas, y hace imposible consolidar el proyecto. 
Todos querríamos que nuestros nuevos medios públicos fueran capaces de atraer una fuerte inversión publicitaria, pero esto no puede ocurrir tan fácilmente, sin un auténtico apoyo institucional.

Así pues, creemos que, una vez más, la elección del tema de nuestro Informe no puede ser más oportuno en estos momentos, gracias a la coordinación de los profesores Cristina González Oñate y Carlos Fanjul Peyró, que han conseguido reunir seis investigaciones que nos parecen muy relevantes y valiosas para conocer la situación del sector publicitario y de sus tendencias evolutivas en estos tiempos, y cuyo esfuerzo queremos agradecer desde aquí.

\section{La consolidación del proyecto editorial adComunica}

En estos últimos meses hemos recibido de la Fundación Española de Cienca y Tecnología (FECYT) el sello de calidad que concede a la calidad de edición de revistas. Para el equipo editorial de la revista adComunica es, sin duda, una gran noticia porque la FECYT es una institución que merece nuestro máximo respeto ya que tiene el reconocimiento de organismos como la Comisión Nacional de Evaluación de la Actividad Investigadora (CNEAI) y que se toma en consideración en los procesos de evaluación para la acreditación del profesorado universitario como el Programa Academia de la Agencia Nacional de Evaluación de la Calidad (ANECA).

Queremos reiterar que estos logros no serían posible sin el esfuerzo de nuestros editores, y el apoyo continuado de los investigadores y profesionales que participan en este proyecto editorial, sin cuyo trabajo sería imposible mantener esta revista. Nuestra más sincera gratitud a los coordinadores de los monográficos, a los autores y evaluadores de los manuscritos presentados, a los miembros de los comités científico y editorial y, en definitiva, a todas las personas que forman parte y alimentan el proyecto editorial de la revista adComunica.

\section{Referencias}

Bordwell, David (2006). The Way Hollywood Tells It: Story and Style in Modern Movies. Berkeley: University of California Press.

Debord, Guy (2007). La sociedad del espectáculo. Valencia: Editorial Pre-Textos. González Requena, Jesús (1990). El espectáculo informativo. Madrid: Akal.

Marzal-Felici, Javier (1999). Espectáculo y atracción fílmica. La mirada cautiva del cine de acción contemporáneo. En: Nos, Eloísa y Benet, Vicente (eds.), Cuerpos en serie. La representación del cuerpo en los medios audiovisuales. Castellón: Universitat Jaume I.

Thussu, Daya Kishan (2007). News as Entertainment: The Rise of Global Infotainment. London: Sage Publishing. 



\section{INFORME El negocio publicitario en el contexto digital}

Coordinación: Cristina González Oñate y Carlos Fanjul Peyró 



\section{El negocio publicitario en el contexto digital}

Cristina González Oñate

Universitat Jaume I

Carlos Fanjul Peyró

Universitat Jaume I

\section{Referencia de este artículo}

González Oñate, Cristina y Fanjul Peyro, Carlos (2019). El negocio publicitario en el contexto digital. En: adComunica. Revista Científica de Estrategias, Tendencias e Innovación en Comunicación, (18), 17-20. DOI: http://dx.doi.org/10.6035/21740992.2019 .18 .2

El siglo XXI se está definiendo por la globalización permitida por Internet y las tecnologías digitales de la comunicación. Este fenómeno ha supuesto que las estructuras tradicionales del negocio publicitario sean replanteadas en aras de conseguir una rápida adaptación del sector al panorama digital. El nuevo contexto comunicativo facilita la agrupación virtual de personas con afinidades, ideologías, gustos y preferencias similares. En definitiva, permite una segmentación mejor definida de públicos objetivos, un factor fundamental para la eficacia publicitaria (Gutiérrez, Sánchez y Galiano, 2018).

La Red y la proliferación de dispositivos electrónicos de comunicación (móviles, tabletas, smartwatches...) propician un cambio drástico en el comportamiento del consumidor, permitiendo un mayor protagonismo al receptor. La web semántica (o web 3.0) permite un uso más eficiente de los contenidos, utilizando un lenguaje más natural en las búsquedas y obteniendo información relevante para el usuario. Y la denominada web 4.0 promete una interacción mucho más eficiente y personalizada en el que las "máquinas" comprenderán mejor el lenguaje natural del ser humano. Además, la interactividad y participación que permite el nuevo medio digital ha 
provocado que la relación entre marca-clientes y marca-agencia adquiera nuevas dimensiones, buscando siempre la conversación y la adaptación de los mensajes a las demandas actuales (Santana, 2017; Lacalle y Gómez, 2017)

Debido a todos estos profundos cambios estructurales en el mercado, y a que el desarrollo de las tecnologías es más veloz que su propia definición, se establece en el entorno publicitario una necesidad constante de reajustarse y adaptarse. Dentro de la agencia han comenzado a proliferar equipos dedicados a entender a los anunciantes y que colaboran con ellos a tomar decisiones y recomendar. Y respecto al público objetivo, se consolida en la agencia cada vez más la necesidad de la simbiosis entre estrategia y creatividad. La figura del planner se establece como fundamental, ya que es el que mejor conoce a los potenciales receptores de los mensajes publicitarios y establece cuáles son las herramientas comunicativas más adecuadas en cada entorno para una mayor eficacia publicitaria (Valle y Tobar, 2017).

El número 18 de la revista adComunica presenta un monográfico con seis artículos que abordan, desde distintas perspectivas, algunos de los cambios producidos en este nuevo entorno digital en el ámbito de la comunicación publicitaria. Los dos primeros artículos, analizan las nuevas formas de relación y comportamiento entre las marcas y los consumidores. Exploran cuáles son las actitudes y motivaciones de uno de los principales públicos de interés de la publicidad; los jóvenes millennials. Y se estudia cómo éstos hacen uso de las nuevas tecnologías y de las comunidades virtuales con el objetivo de definir el papel que deberían desempeñar las marcas con ellos en su entorno online.

Los tres siguientes textos se centran en el análisis de las consecuencias que el panorama digital ha tenido para las agencias de publicidad desde tres perspectivas. En primer lugar, se estudia cómo han tenido que adaptar las agencias sus mensajes ante la aparición y consolidación de las redes sociales y los denominados influencers (nuevos líderes de opinión de gran interés para las marcas por su repercusión social y capacidad de persuasión). El siguiente texto, aborda cómo los anunciantes demandan nuevos perfiles profesionales especializados en el entorno digital y cuál es la realidad de la adaptación de las agencias ante esta nueva exigencia. Y el siguiente artículo analiza cómo las propias agencias de publicidad han encontrado en las redes sociales y los medios digitales un espacio virtual en el que poder trabajar su comunicación, haciéndose autopublicidad y consolidando sus propios valores de marca.

Finalmente, el último artículo de este monográfico está dedicado a un tema de especial relevancia social como es el de la preocupación por la sostenibilidad dentro del mundo de la moda, tanto en el ámbito online como en el offline (centrándose en el punto de venta físico).

Con estos seis artículos se pretende aportar una pequeña visión de cómo el rol del receptor se ha modificado en la nueva coyuntura digital y cómo el negocio publicitario está evolucionando y adaptándose a este nuevo contexto. 


\section{Referencias}

Gutiérrez Montoya, Guillermo Antonio; Sánchez Jiménez, Miguel Ángel; Galiano Coronil, Araceli (2018). Redes sociales como medio de promoción turística en los países iberoamericanos. En: RETOS. Revista de Ciencias de la Administración y Economía, vol. 8, no 15. Quito: Universidad Politécnica Salesiana, 135-150.

Lacalle, Charo y Gómez, Beatriz (2017). La recepción televisiva española en la era multipantalla. En: Comunicación y Sociedad, $\mathrm{n}^{\circ}$ 30. Pamplona: Universidad de Navarra, 197-216.

Santana, Eva (2017). Tapas de Publicidad. Barcelona: Promopress.

Valle, Alexandra Tatiana y Tobar, Guido Hernan (2017). El marketing relacional y la rentabilidad en los servicios prestados por tres concesionarios automotrices en la provincia de Tungurahua del Ecuador. En: Uniandes episteme, vol. 4, n ${ }^{\circ} 2$. Tungurahua: Universidad Regional Autónoma de los Andes, 1-15. 



\section{Hábitos de uso y consumo de la generación millennial en sus teléfonos móviles Habits of use and consumption of the millennial through their mobile phones \\ Yolanda Cabrera García-Ochoa Universitat de València}

\section{Referencia de este artículo}

Cabrera García-Ochoa, Yolanda (2019). Hábitos de uso y consumo de la generación millennial en sus teléfonos móviles. adComunica. Revista Científica de Estrategias, Tendencias e Innovación en Comunicación, (18), 21-40. DOI: http://dx.doi. org/10.6035/2174-0992.2019.18.3

\section{Palabras clave}

Millennials; Telefonía; Hábitos de uso; Internet; Género.

\section{Keywords}

Millennials; Telephony; Consumer uses and habits; Internet; Genre.

\section{Resumen}

El uso de la telefonía móvil ha experimentado en los últimos años un crecimiento insólito a nivel mundial. Esto ha tenido consecuencias que afectan a los hábitos de consumo, de entretenimiento, el intercambio de contenidos y ha obligado a los expertos de marketing y a las agencias de publicidad a poner el foco en un consumidor que se ha convertido en la generación clave que apuntalará las nuevas formas de consumo del siglo XXI. Se trata de la denominada generación Y, también conocidos como los millennials ${ }^{1}$. Aunque hay cierta discrepancia en torno a la franja

1 En España hay cerca de 8.153.428 personas nacidas baja la etiqueta de esta generación, según las últimas cifras del Instituto Nacional de Estadística. Y hay un poco más de 1.700 millones en todo el mundo. 
de años que aglutina a este grupo de edad, los demógrafos William Straus y Neil Howe, quienes acuñan el término, les definen como los nacidos entre 1982 y 2004 (1991). Una generación surgida en plena prosperidad económica pero que llega a su mayoría de edad haciendo frente a una fuerte recesión económica, lo que les lleva a estar mejor preparados que sus predecesores pero sin embargo, tener peores expectativas laborales y verse afectados por una alta tasa de desempleo.

Tomamos como muestra de nuestra investigación a este grupo de edad por ser nativos digitales para analizar los usos y las motivaciones que marcan la utilización de sus teléfonos móviles, analizar sus hábitos de consumo y ver qué características de uso definen a este grupo de edad y pueden verse afectadas en función de parámetros como el género, la formación o la edad de las personas encuestadas.

\begin{abstract}
The use of mobiles telephone has experienced exponential growth in recent years around the world. This has had consequences that affect consumer habits, entertainment, as well as the exchange of content thus forcing marketing experts and advertising agencies to focus on a consumer that has become the key generation in underpinning new forms of consumption in the 21st century. This consumer group is the so-called generation $\mathrm{Y}$, also known as millennials.

Although there is some discrepancy in the actual age of this group, the demographers who coined the term, William Straus and Neil Howe, define it as those born between 1982 and 2004 (1991). It is a generation that has emerged in times of full economic prosperity but which comes of age facing a bitter economic recession. Although this fact leads this age group to be better prepared than their predecessors, they have lower job expectations and suffer the throes of a high rate of unemployment.

We take this age group as a sample in our research due to them being digital natives. We analyse the forms and motivation behind their use of mobile phones, their consumption habits together with the observation of the usage characteristics which define this age group and in turn can be affected by parameters such as gender, education or age.
\end{abstract}

\footnotetext{
Autora

Yolanda Cabrera García-Ochoa [yolanda.cabrera@uv.es] es Doctora en Comunicación por la Universidad de Valencia. Ha trabajado en televisión, radio y agencias de publicidad. En su actividad científica destaca la participación en tres proyectos de Investigación del Ministerio de Economía, Industria y Competitividad y cinco proyectos internos de distintas universidades. Su producción científica se centra en cuestiones de género, estereotipos, publicidad y comunicación corporativa.
} 


\section{Introducción}

El auge en el desarrollo de las Tecnologías de la Comunicación e Información ha tenido múltiples consecuencias en la forma en que los miembros de la sociedad interaccionan, se comunican y ha afectado incluso a los hábitos y comportamientos sociales. El crecimiento exponencial de la telefonía móvil en el mundo ha hecho que en sólo una década el $68 \%$ de la población mundial posea un teléfono móvil. En el caso de España este porcentaje asciende hasta el $87 \%$ de la población total como refleja el informe Digital en 2018 (Hootsuite, 2019).

A esto han contribuido la bajada de las tarifas de telefonía y la reducción del precio de los terminales que ha permitido al sector de la telefonía acercarse a un consumidor cada vez más joven (Ling, 2002). Tanto las marcas de telecomunicaciones como muchas otras empresas tecnológicas han visto la gran rentabilidad comercial de captar a este nuevo consumidor con productos atractivos y actualización constante de sus servicios y aplicaciones. Lo que afecta de manera clara especialmente a los jóvenes llegando incluso a influir en sus estilos de vida que cada vez aparecen más ligados a esa nueva tecnología de la que son usuarios fieles (Tapscott, 1998; Chu, 1997).

El informe en España2 refleja que los usuarios de internet han aumentado en 2 millones durante el pasado año, lo que representa ya el $85 \%$ de la población. Además, casi el $60 \%$ de los ciudadanos hace uso de las redes sociales al menos una vez al mes, lo que supone un aumento del 8\% con respecto a 2017. Son indicadores que analizan el uso de, entre otros, los dispositivos móviles de 239 países, entre ellos España. De ahí se extraen indicadores que resultan relevantes como punto de arranque para esta investigación y que reflejan un aumento del uso de tecnología digital con una media diaria de 5,5 horas, de las cuales 100 minutos se pasan en redes sociales.

Tomamos estos indicadores como punto de arranque para comprobar si en el grupo de estudio se reproducen estos patrones de uso o si se ven de alguna manera afectados por las características de los participantes de la muestra seleccionada. Como novedad aportada a los trabajos ya existentes sobre esta temática se destaca el hecho de trabajar con una muestra que recoge la experiencia de uso en estudiantes de diferentes áreas de conocimiento, de universidades públicas y privadas para determinar si variables como el género, la formación, condición social o estatus afecta a sus rutinas de uso en los móviles y si coinciden o difieren de los obtenidos en estudios similares en otras comunidades. A diferencia de otros estudios (Carcelén, Mera e Irisarri, 2019) o (Martínez-Rodrigo, Martínez-Cabeza Jiménez y Martínez-Cabeza Lombardo, 2019) en esta investigación no se restringe el uso del móvil al ámbito académico sino que se amplía a las diferentes facetas de la vida de los universitarios encuestados.

2 Estudio realizado por la consultora Hootsuite, una plataforma web y móvil que gestiona redes sociales por parte de personas y organizaciones. 
La hipótesis general de partida sostiene que el uso de teléfonos móviles entre los jóvenes menores de 35 años ha sufrido un importante incremento en los últimos años y esto ha afectado sus hábitos de uso y consumo tanto académico, social, profesional y personal pasando a convertirse en una herramienta imprescindible en su día a día de la que cada vez existe una mayor dependencia.

Para comprobar la validez de dicha hipótesis se formulan unas preguntas que sirven de guía de la investigación y la relacionan con los datos obtenidos:

- ¿Qué uso hacen los jóvenes universitarios españoles de sus teléfonos móviles? ¿Cuáles son los servicios más valorados?

- ¿Tienen dependencia tecnológica? Y si la hay ¿Son conscientes de ella?

- ¿Existen diferencias en los hábitos de consumo o uso relativas al género, la formación cursada o la edad, posibles de identificar (si las hay)?

\subsection{Una generación conectada a internet y enganchada a la telefonía}

Si hay algo que se constata en la recogida de datos es que en la cotidianidad de los millennials el móvil es una herramienta fundamental. Esta gran dependencia se manifiesta en su forma de organizar su actividad diaria. Al ser preguntados por la primera y la última cosa que hacen al despertarse o al ir a dormir un $98 \%$ de los encuestados afirma que mira el móvil. En algunos casos, este hábito repetitivo es justificado por el hecho de utilizar el dispositivo móvil como alarma despertador y esa última mirada coincidiría con los momentos de final e inicio de la jornada.

En las entrevistas personalizadas se consigue información más detallada en la que se refleja que son muchas las personas que duermen con el móvil cerca de su cama y que lo consultan incluso de madrugada si lo oyen vibrar o si se desvelan.

En el caso de los estudiantes participantes en los focus group se constata la importancia del móvil como herramienta para mantener el contacto con familiares, amigos o parejas. Esto se acrecienta al producirse una distancia física porque muchos varían su lugar de residencia habitual para asistir a la universidad. El móvil se convierte así, tal y como ellos mismos lo definen en un «objeto de primera necesidad» para cumplir esos roles familiares y sociales e incluso para gestionar las emociones y darles cierta sensación de seguridad y protección al sentirse conectados con las personas más importantes de su entorno. Nos encontramos así con terminales que trascienden la función meramente tecnológica y se tornan en dispositivos socialmente destacados y cada vez más involucrados en todos los aspectos de la vida cotidiana, incluidos los aspectos simbólicos y los representativos (Chen y Katz, 2009: 180).

Para estos jóvenes, las tecnologías de la comunicación prevalecen y son esenciales en muchas áreas de sus vidas y han supuesto una revolución en sus relaciones interpersonales, el entorno laboral, los hábitos y el consumo de bienes y servicios (Bringué y Sádaba, 2009). Así mismo, el Pew Research Center concluyó en su es- 
tudio sobre los valores, las actitudes y las experiencias de uso del móvil en la población millennial que superaban a las generaciones anteriores en prácticamente todos los usos de Internet y telefonía móvil y concluyó que era una generación que producía sus propios contenidos, se conectaban a internet en cualquier espacio y situación y les gusta publicar vídeos y fotografías en los que ellos son los protagonistas (2014: 25).

\subsection{El móvil: un dispositivo multifunción}

Son los usuarios más jóvenes los que más explotan y destacan las posibilidades multifunción de sus dispositivos móviles (Hulme y Peters, 2001). Sus destrezas digitales y sus habilidades tecnológicas les permiten sacar el máximo partido de sus teléfonos y utilizarlos como cámara fotográfica, reloj despertador, plataforma de entretenimiento, reproductor de música y vídeos, conectarse a internet y como ordenador para trabajar, realizar reservas, compras on line entre otras opciones (Hulme y Peters, 2001; Aoki y Downes, 2003).

El móvil ha pasado de ser una herramienta que surge como instrumento de trabajo o de comunicación para convertirse, sobre todo en manos de los usuarios más jóvenes, en un instrumento de interacción social que parece otorgarnos el don de la ubicuidad al permitir contactar con cualquier persona, en cualquier momento y en cualquier lugar (Palen, Salzman y Youngs 2000).

Autores como Heisson (2001) y Albarran (2009) demuestran que los millennials prefieren sus teléfonos móviles antes que otros dispositivos como el ordenador o las tabletas digitales y eso ha modificado el consumo de contenidos audiovisuales o su forma de trabajar e informarse. Son usuarios habituales de la televisión a la carta y diseñan su propia programación en horarios compatibles con su actividad diaria, sus gustos y preferencias. Y las fuentes en las que más confían proceden de su círculo de contactos o de influencers a los que confieren alta credibilidad. Se produce así una especie de readaptación del fenómeno fan pero asociada a estos nuevos prescriptores que utilizan a su vez los dispositivos móviles y la red como escenario desde el que dirigirse a sus millonarias audiencias. Por el contrario, las fuentes menos valoradas son las marcas comerciales, partidos políticos e instituciones religiosas.

\subsection{Móvil como seña de identidad personal}

Los jóvenes perciben el móvil como un objeto íntimo e intransferible que además gracias a poder personalizarlo se convierte en una seña de identidad propia. El hecho de poseer cada vez más opciones de personalización bien a través de la elección del tono, el fondo de pantalla o la carcasa hace que sea considerado por algunos jóvenes un complemento de moda del que hay que cuidar su apariencia externa para que vaya acorde con la de su dueño/a. Se trata de su bien más preciado, más imprescindible y por el que están dispuestos a hacer sacrificios económicos que les 
permitan acceder a las novedades en telefonía en cuanto son lanzadas. Esto les lleva a ser unos consumidores muy exigentes que valoran sobre todo las prestaciones pero también factores externos como el diseño, el tamaño de pantalla y el material de la carcasa. Son unos consumidores muy interesados en las novedades del sector de la telefonía y muy propensos a cambiar de móvil cada 2-3 años y el motivo de comprar un nuevo teléfono es adquirir uno de gama superior, el robo, pérdida y averías.

Host (2010) realizó un estudio para analizar las ventajas principales que encontraban los jóvenes en el uso del móvil y destacaban en los resultados cuatro motivaciones diferentes: sociabilidad, relajación, estatus social y estar a la moda. Encontramos que aparece el móvil como un medio para estar informado de moda y tendencias y a la vez como un instrumento de moda en sí mismo. Otros autores, como Chan-Olmsted, Lee y Kim (2011), han determinado que la portabilidad, la conveniencia y la personalización son las gratificaciones más destacadas que los millennials identifican al usar sus teléfonos. En ambos casos estos estudios coinciden en asociar el móvil con beneficios que redundan en obtener información cada vez más rápida, un fácil acceso al conocimiento y un fomento de la interactividad con otros usuarios lo que en ocasiones no se traduce en una mejor comunicación.

\section{Metodología}

Este trabajo pretende analizar los hábitos de uso y consumo de contenidos de los usuarios denominados millennials a través de sus móviles y confirmar si existen diferencias significativas teniendo en cuenta variables como el género, los estudios cursados o la edad. Siguiendo la misma perspectiva metodológica llevada a cabo por Vaan Weezel y Benavides (2009) se utilizan métodos mixtos que combinan por una parte, datos cuantitativos y cualitativos. La mezcla de los resultados obtenidos nos permite responder de manera más detallada a las preguntas de investigación planteadas y extraer información para poder desarrollar las conclusiones. Señalan autores como Hernández, Fernández y Baptista (2003) que esta combinación aunque agrega complejidad al diseño del estudio contempla todas las ventajas de cada uno de los dos enfoques.

En el estudio se ha trabajado sobre una muestra final formada por 375 estudiantes universitarios de centros públicos y privados de la ciudad de Valencia. Siendo el $46,9 \%$ hombres y el $53,1 \%$ mujeres.

Se hace una división por rango de edad en función a los datos recogidos en el cuestionario que fraccionaba en dos categorías correspondientes mayoritariamente a la edad media del alumnado matriculado en estudios de grado y posgrado. La muestra se distribuye un $75,7 \%$ de 18 a 25 años y un $24,3 \%$ de 26 a 35 años. En todos los casos se encuentran dentro del rango de edad de la denominada generación millennial. 
Tabla 1. Composición de la muestra analizada

\begin{tabular}{|c|c|c|c|c|c|c|c|c|}
\hline Género & Edad & $\begin{array}{c}\text { Grado } \\
\text { Marke- } \\
\text { ting }\end{array}$ & $\begin{array}{c}\text { Grado } \\
\text { Derecho }\end{array}$ & $\begin{array}{l}\text { Grado } \\
\text { ADE }\end{array}$ & $\begin{array}{l}\text { Grado C. } \\
\text { Audiovi- } \\
\text { sual }\end{array}$ & $\begin{array}{l}\text { Grado } \\
\text { Enfer- } \\
\text { mería }\end{array}$ & $\begin{array}{l}\text { Posgrado } \\
\text { Máster }\end{array}$ & TOTAL \\
\hline \multirow{2}{*}{ Mujeres } & $18-25$ & 22 & 23 & 25 & 32 & 47 & 3 & \multirow{2}{*}{199} \\
\hline & $26-35$ & 2 & 1 & 1 & 3 & 4 & 36 & \\
\hline \multirow{2}{*}{ Hombres } & $18-25$ & 25 & 28 & 33 & 25 & 20 & 1 & \multirow{2}{*}{176} \\
\hline & $26-35$ & 5 & 3 & 3 & 4 & - & 29 & \\
\hline & 375 & 54 & 55 & 62 & 64 & 71 & 69 & 375 \\
\hline
\end{tabular}

Elaboración propia

Para realizar la recogida de datos cuantitativa se elabora un cuestionario de datos sociodemográficos que fue distribuido en persona por la propia investigadora a una muestra de estudiantes universitarios matriculados en estudios de grado y de posgrado en la Universidad Europea de Valencia y en la Universitat de València desde diciembre de 2017 a febrero de 2018. El diseño del cuestionario se trabajó en colaboración con el catedrático Dr. José Martí Parreño responsable de investigación de la Universidad Europea Valencia especializado en técnicas y metodologías de investigación quien aportó su conocimiento para seleccionar el tipo de pregunta más adecuada en cada bloque, el orden de los ítems y la redacción de los enunciados.

En cada una de las universidades, la selección de la muestra se realizó mediante la agrupación de equipos homogéneos (en edad, formación, intereses) surgidos de las diferentes aulas encuestadas. Las aulas y cursos participantes se seleccionaron al azar teniendo en cuenta la disponibilidad de la investigadora y del profesorado de los diferentes grados y posgrados participantes respetando el calendario académico y realizándose en todos los casos en horario escolar.

Se trabaja sobre una muestra total de 405 personas y finalmente, tras depurar la muestra y eliminar los cuestionarios incompletos, se analizan 375 cuestionarios. La encuesta está formada por 20 preguntas cuyo contenido se agrupa en varios bloques temáticos:

Una primera parte de preguntas, formado por 8 ítems, que recogen datos genéricos, (edad, género, estudios cursados, universidad, tipo de móvil, marca y antigüedad) y se centran en determinar el tiempo medio y la importancia del móvil en sus hábitos de uso y consumo.

En el segundo bloque, formado por 6 ítems, las preguntas se centran en saber qué servicios son los más utilizados por los universitarios encuestados

El último bloque, formado por 6 ítems, combina dos tipos de preguntas, de respuesta abierta para conocer el tipo de contenidos consumidos a través del móvil y 
unas últimas cuestiones que mediante una escala de Likert de 5 puntos piden la valoración de diferentes servicios

Una posterior fase cualitativa permitió explorar las actitudes de los millennials hacia sus teléfonos y profundizar en los aspectos más redundantes detectados en las encuestas a la vez que nos permitió indagar en los elementos diferenciadores de uso entre los hombres y mujeres encuestados e intentó detectar si se daban diferencias de hábitos asociadas a factores como la edad del usuario o la formación cursada. Los composición de los 3 grupos focales se realiza teniendo en cuenta dos características comunes, todos han respondido previamente al cuestionario y disponen de al menos un móvil del que hacen un uso regular.

La composición de los grupos participantes en las entrevistas es la siguiente:

Tabla 2. Composición de los grupos para las entrevistas

\begin{tabular}{|l|l|l|}
\hline \multicolumn{1}{|l|}{$\begin{array}{l}\text { Grupo focal 1 } \\
\begin{array}{l}\text { Universitat de València } \\
\text { (Pública) }\end{array}\end{array}$} & $\begin{array}{l}\text { Universidad Europea Valencia } \\
\text { (Privada) }\end{array}$ & $\begin{array}{l}\text { Universidad Europea Valencia } \\
\text { (Privada) } \\
\text { Universitat de València (Pública) }\end{array}$ \\
\hline $\begin{array}{l}\text { Alumnado de Grado Co- } \\
\text { municación Audiovisual }\end{array}$ & $\begin{array}{l}\text { Alumnado Grados Derecho } \\
\text { Grado ADE, } \\
\text { Comercial, } \\
\text { Grado en Enfermería }\end{array}$ & $\begin{array}{l}\text { Alumnado posgrado } \\
\text { Master en contenidos y formatos } \\
\text { digitales (UV) } \\
\text { Master en marketing digital y Big } \\
\text { Data (UEV) } \\
\text { Master Universitario en formación } \\
\text { del profesorado (UEV) }\end{array}$ \\
\hline $\begin{array}{l}20 \text { participantes 10 } \\
\text { hombres+ 10 mujeres }\end{array}$ & $\begin{array}{l}20 \text { participantes 10 hombres+ 10 } \\
\text { mujeres }\end{array}$ & $\begin{array}{l}20 \text { participantes 10 hombres+ 10 } \\
\text { mujeres }\end{array}$ \\
\hline
\end{tabular}

Fuente elaboración propia

Las reuniones con los 3 focus group se realizaron durante los meses de abril y mayo de 2018 y fueron registradas mediante la grabación en vídeo para poder posteriormente acceder y recuperar de manera precisa los datos.

Estos grupos nos han proporcionado información valiosa sobre los diferentes usos, valoración y rutinas que tienen los participantes con respecto a sus móviles y han servido para permitirnos complementar la información recogida mediante los cuestionarios. En los dos primeros grupos, formados por alumnado de grado, la mayoría eran estudiantes a tiempo completo y solo una pequeña parte era estudiantes a tiempo parcial que compaginaba esta actividad con un empleo. En el tercer grupo, la mayoría de estudiantes de posgrados son a la vez profesionales en activo, algunos/as empresarios/as. Este es uno de los rasgos que más diferencia la información y opiniones recogidas entre los estudiantes de la universidad pública y la privada. En el caso del centro público un menor coste en la matrícula y una mayor 
heterogeneidad en el entorno económico de procedencia del alumnado hacen que la mayoría de estos estudiantes se centren en sus estudios a jornada completa. Por el contrario, el alto coste de matrícula en la universidad privada hace que algunos de los estudiantes aquí matriculados trabajen para costear sus estudios. Muchos provienen de familias con negocios en marcha en los que ellos colaboran en sus últimos años de carrera. Se constata un mayor número de emprendedores asociados a los grados de Administración y Dirección de Empresas y Derecho, principalmente.

\section{Resultados}

Los teléfonos móviles se han convertido en asistentes personales, dispositivos inteligentes que generan entretenimiento e información pero cuya complejidad y rápido avance ha transformado la relación de los usuarios con sus teléfonos (Fullwood, Quinn, Kaye y Redding, 2017).

$\mathrm{Al}$ analizar los datos obtenidos de nuestra investigación se observa que en gran parte los hábitos de uso y consumo de contenidos en los hombres y mujeres encuestados presentan una gran similitud.

\subsection{Resultados cuantitativos}

El primer dato que nos sorprende en las encuestas es el elevado número de horas al día que utilizan el teléfono móvil. No se recogen respuestas en la franja de menos de 1 hora al día. Los que menos afirman utilizarlo señalan un mínimo que oscila entre 1-2 horas al día, 8\%, un amplio grupo sitúa su uso en torno a las 2-3 horas, $35 \%$, seguidos de un $28 \%$ que asegura estar en torno a las 3-4 horas. Traspasada la barrera de las 4 horas encontramos a un 17\% que asegura utilizar el móvil de 4 a 5 horas y por último un $12 \%$ asegura utilizarlo más de 5 horas al día. Prevalecen en las respuestas que justifican el constante uso del móvil destacar que es a la vez una herramienta de comunicación, de entretenimiento y de trabajo (académico o laboral). Por lo que el 96,7 \% de los encuestados asegura que no podría vivir sin su móvil y sólo un 38,3\% asegura que podría prescindir de él de manera puntual menos de 48 horas. 
Gráfico 1. Uso diario del móvil

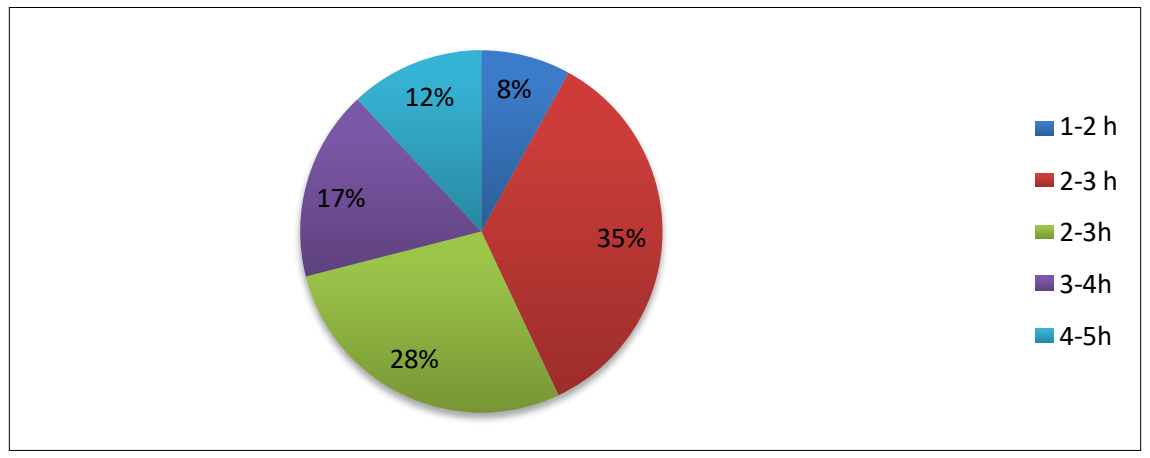

Elaboración propia

En este sentido, aunque cuentan con aulas informáticas en sus universidades, al $83,2 \%$ de las personas encuestadas les molesta tener que prescindir de sus teléfonos durante algunas clases por petición expresa del profesorado. En cuanto al lugar en el que se conectan y utilizan su móvil se detectan 3 espacios prioritarios: su hogar $(98,7 \%)$, la universidad $(98,1 \%)$ utilizando el móvil tanto en el aula como en las salas de estudio o bibliotecas, y espacios públicos o locales comerciales con wifi en abierto (67\%). Esta opción es muy valorada por los estudiantes más jóvenes que en ocasiones buscan ahorrar o no consumir datos accediendo a estas redes en abierto. El entorno laboral aparece como el cuarto espacio de conexión, pero solo para el $32,2 \%$ de los encuestados, esto debido a que dado el perfil de los encuestados (estudiantes universitarios) muchos no se hayan todavía inmersos en el mundo laboral. Los espacios mencionados en los que utilizan el móvil son muy variados e incluso inadecuados como el coche o la moto (cuando van conduciendo) y reconocen que llevan el móvil a todas partes. Los datos de nuestra muestra corroboran la información publicada por el Instituto Nacional de Estadística al evidenciar de manera clara que es en los grupos de edad en los que se incluyen los milénicos donde se produce un uso mayoritario de las TIC con porcentajes muy cercanos al $100 \%$ y apenas diferencias de uso entre hombres y mujeres. Entre las funciones más valoradas copan la cima las aplicaciones de comunicación personal utilizadas por el $98,9 \%$ de los encuestados. 
Tabla 3. Aplicaciones más utilizadas

\begin{tabular}{|c|c|c|c|c|c|c|c|c|c|c|c|c|}
\hline \multirow[t]{2}{*}{ Aplicación } & \multicolumn{2}{|c|}{$\begin{array}{c}\text { MUJERES } \\
18 \text { a } 25 \\
\text { años }\end{array}$} & \multicolumn{2}{|c|}{$\begin{array}{l}\text { HOMBRES } \\
18 \text { a } 25 \text { años }\end{array}$} & \multirow{2}{*}{$\begin{array}{l}\text { F. } \\
\text { ab- } \\
\text { so- } \\
\text { luta } \\
284\end{array}$} & \multirow{2}{*}{$\begin{array}{c}\text { F. } \\
\text { re- } \\
\text { lati- } \\
\text { va }\end{array}$} & \multicolumn{2}{|c|}{$\begin{array}{c}\text { MUJERES } \\
26 \text { a } 35 \\
\text { años }\end{array}$} & \multicolumn{2}{|c|}{$\begin{array}{c}\text { HOMBRES } \\
26 \text { a } 35 \\
\text { años }\end{array}$} & \multirow{2}{*}{$\begin{array}{c}\text { F. } \\
\text { ab- } \\
\text { so- } \\
\text { luta }\end{array}$} & \multirow{2}{*}{$\begin{array}{c}\text { F. } \\
\text { Re- } \\
\text { lati- } \\
\text { va }\end{array}$} \\
\hline & $\%$ & $\begin{array}{c}N \\
152\end{array}$ & $\%$ & N132 & & & $\%$ & N47 & $\%$ & N44 & & \\
\hline Snapchat & 64,4 & 98 & 43,9 & 58 & 156 & 54,9 & 34,1 & 16 & 20,4 & 9 & 25 & 27,4 \\
\hline Whatsapp & 98,1 & 149 & 97,7 & 129 & 278 & 97,8 & 100 & 47 & 97,7 & 43 & 90 & 98,8 \\
\hline YouTube & 95,3 & 145 & 96,9 & 128 & 273 & 96,1 & 89,3 & 42 & 88,6 & 39 & 81 & 89,1 \\
\hline Instagram & 65,1 & 99 & 64,3 & 85 & 184 & 64,6 & 57,4 & 27 & 50 & 22 & 49 & 53,8 \\
\hline Twittter & 44,7 & 68 & 38,6 & 51 & 119 & 41,7 & 27,6 & 13 & 25 & 11 & 24 & 26,3 \\
\hline Facebook & 23 & 35 & 21,2 & 28 & 63 & 22,1 & 40,4 & 19 & 38,6 & 17 & 36 & 39,5 \\
\hline Linkedin & 5,2 & 8 & 8,3 & 11 & 19 & 6,8 & 31,9 & 15 & 36,3 & 16 & 31 & 34,1 \\
\hline
\end{tabular}

Elaboración propia

Gráfico 2. Principales usos del móvil

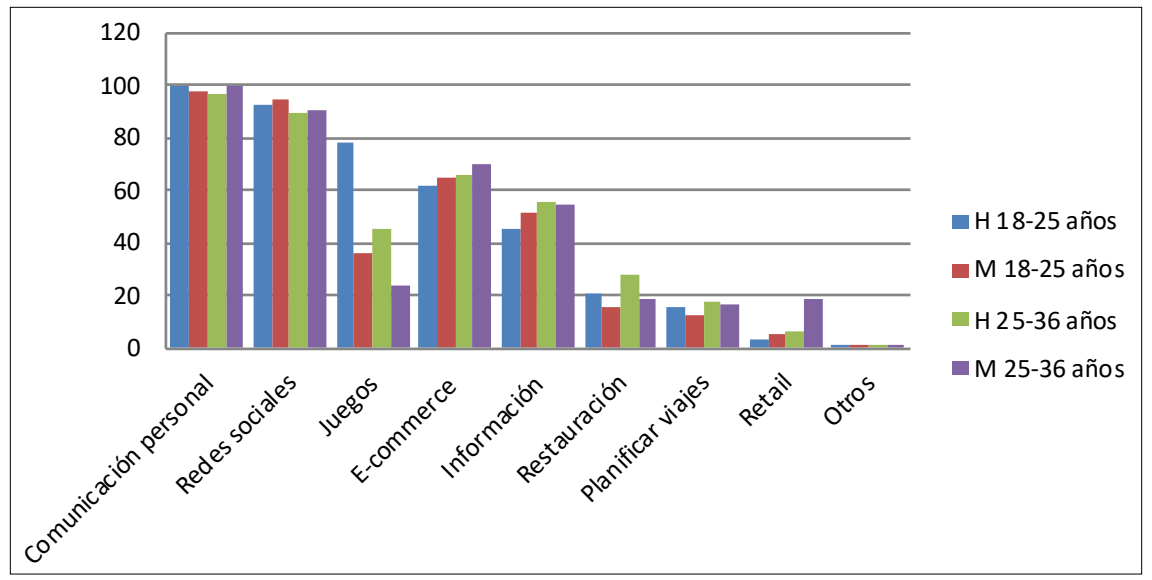

Elaboración propia 
Las más utilizadas son las aplicaciones de mensajería instantánea Snapchat y WhatsApp. Esta aplicación es más utilizada entre los usuarios millennials de la franja de 18 a 25 años en un 54,9\% frente a un $27,4 \%$ de la franja de 26 a 35 años. WhatsApp es utilizado por prácticamente la totalidad de las personas encuestadas mayores de 25 años, alcanzando un 98,5\%. Esta aplicación de mensajería instantánea es altamente valorada por los encuestados como herramienta que facilita la gestión de su vida social, familiar y también académica.

Gráfico 3. Redes y APP’s más utilizadas por edad y género

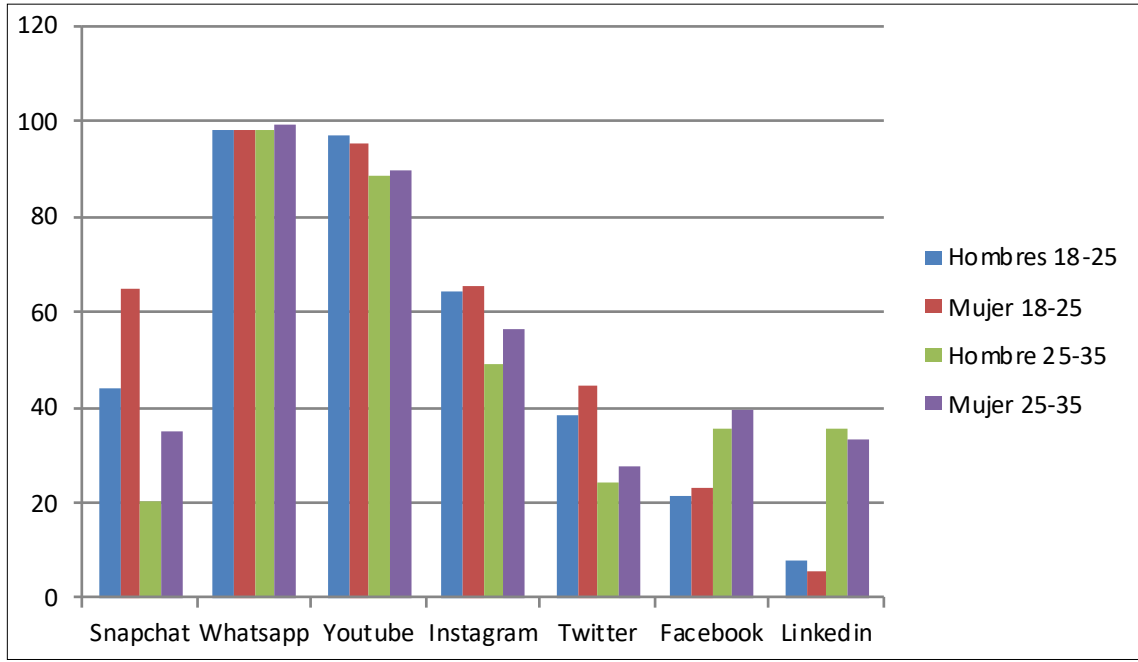

Fuente: elaboración propia

En segundo lugar, aparecen las redes sociales utilizadas diariamente por un 89,2\% de los encuestados. YouTube es la más visitada por los miembros de la generación millenium, seguida de Instagram, Twitter Facebook, y LinkedIn. El auge de este portal de vídeos se debe a que el $92,6 \%$ de los participantes de las encuestas utilizan sus teléfonos móviles para visionar, producir, descargar y almacenar contenidos audiovisuales.

Instagram es la segunda red más utilizada con un 59,3\% del total y aquí se produce una escisión en torno a los resultados. Los encuestados más jóvenes son quienes más la utilizan alcanzando el $64,6 \%$.

Twitter y Facebook se reparten a los millennials de manera complementaria, porque el uso de Twitter es mayoritario en las personas más jóvenes, a las que les gusta enterarse de qué se está hablando, o de ver opiniones sobre temas de actualidad 41,7\%. Una vez traspasada la treintena es Facebook la red social que acapara la atención de 
los estudiantes de nuestra muestra para retomar contactos con compañeros del colegio, instituto, la universidad o mantenerse en contacto con familiares $39,5 \%$.

La siguiente posición en el apartado de redes sociales más utilizadas, la ocupa LinkedIn, la red de contactos profesionales y networking. Encontramos aquí diferencias evidentes vinculadas a la variable edad, ya que hasta los 25 años solo un $6,8 \%$ de los encuestados es usuario habitual de esta red. Es en el segmento de edad de mayores de 25 años donde se incrementa el uso de la red LinkedIn hasta alcanzar el $34,1 \%$, lo cual coincide con el momento en el que la mayoría de los graduados acceden al mercado laboral.

Es en la tercera opción de usos del teléfono móvil donde se produce un primer cisma entre los datos recogidos en hombres y mujeres. Mientras el $62 \%$ de los hombres encuestados señala los juegos como uno de los servicios más demandados, en el caso de las mujeres esta posición la ocupan el acceso al e-commerce. Un 67,3\% de las mujeres encuestadas utiliza su móvil para realizar compras online de manera habitual. Los sectores en lo que más compran son: moda, servicios, libros y en la categoría varios muchas especifican regalos. También los hombres, sobre todo a partir de los 25 años, utilizan el móvil para realizar sus compras, aunque en un porcentaje algo menor $(65,7 \%)$. La opción de juegos cae hasta la quinta posición entre las mujeres y estos aparecen más asociados al advergaming como parte de algún tipo de campaña promocional en la que se ofrece una gratificación por jugar.

Avanzando en cuarta posición aparece el móvil como fuente primaria de información, tanto de actualidad, como a nivel profesional, académico y lúdico. Incluso en las encuestas recogidas entre estudiantes del Grado de Comunicación Audiovisual el móvil se utiliza como medio de información en cuarto lugar. A pesar de que sus estudios se enmarcan en la rama de Ciencias de la Comunicación no se registran valores muy diferentes al resto de universitarios encuestados. Ni consumen más medios, ni hacen un uso más selectivo.

En quinta posición, el móvil figura como plataforma de compra de productos y servicios cada vez más frecuente. No existe la barrera presente en otras generaciones ni la desconfianza ante la seguridad de la tecnología para efectuar transacciones económicas a través del móvil. Es muy utilizado en las compras retail siendo los principales supermercados en lo que realizan sus compras, Mercadona, Carrefour y Alcampo.

\subsection{Resultados cualitativos}

Las entrevistas realizadas a los grupos de discusión permiten completar las respuestas recogidas en el cuestionario y generar un foro de discusión sobre los temas expuestos en los diferentes bloques. Con respecto a la utilización diaria del móvil algunos participantes del focus group 1 y 2 modifican su respuesta al alza. Es decir, en algunos casos, las personas que aseguraron usar solo el móvil durante un par de horas, al hacer una estimación de uso detallado o compararlo con el de otros participantes ven que su respuesta ha sido inferior al tiempo real utilizado. 
A la hora de medir si el móvil puede ser una herramienta para mejorar el rendimiento académico o por el contrario un motivo de distracción la disparidad de respuestas es amplia. En lo que sí coinciden es en rechazar que se prohíba utilizarlo en clase. Este tipo de medidas represivas les incomoda aunque reconocen que mejora su atención y rendimiento. En algunas de las respuestas recogidas en el focus group 1 la participante 3 asegura «Es muy fácil saltarse la prohibición y aunque no nos permitan tener el móvil, con nuestros portátiles podemos seguir conectados y acceder a los contenidos».

Con respecto a las funciones más valoradas las aplicaciones de mensajería instantánea son las favoritas en todos los grupos de edad y WhatsApp la mejor valorada para cubrir sus necesidades comunicativas. Esta es una de las respuestas recurrentes recogidas entre los miembros de los tres focus group que aseguran que es habitual la creación de chats específicos para compartir información y gestionar tareas académicas lo que coincide con anteriores estudios centrados en el análisis de los pros y contras de WhatsApp en universitarios españoles en el que la totalidad de la muestra utiliza la aplicación con fines educativos (Fondevila-Gascón et al., 2019).

De Snapchat les gustan sobre todo sus opciones creativas y poder hacer vídeos divertidos. En el caso de las chicas lo utilizan porque les permite guardar y compartir momentos con sus amigos/as sin que estos permanezcan en el tiempo. El carácter efímero de los mensajes y el hecho de que no quede rastro del contenido enviado les permite sentirse más seguras a la hora de mandar fotos sexys o vídeos comprometedores sabiendo que no pueden verlos sus padres u otras personas porque desaparecen en el tiempo programado.

Los focus group nos desvelan cuál es su apartado favorito en algunas de las aplicaciones y destaca la popularidad de Instagram Stories cuya implementación, copiando de forma evidente las características de Snapchat, parece haber frenado el uso de esta aplicación entre los usuarios ya que estos vídeos también desaparecen pasadas 24 horas y posee herramientas de edición muy similares.

En las entrevistas algunos estudiantes de grado definen Facebook como una red «para viejos» donde están sus padres, sus tíos y reconocen que la mantiene porque así suben allí lo "políticamente correcto» y sus familias creen saber lo que hacen. Demuestran con sus respuestas y comentarios un amplio control de las TIC y una gestión, en ocasiones, selectiva de las redes donde suben diferentes contenidos e incluso algunos aseguran tener perfiles con identidades falsas.

LinkedIn es la red utilizada de manera preferente por los estudiantes de posgrado como lugar de encuentro con profesionales y empresas para mejorar su situación laboral, encontrar un empleo o generar contactos. Los estudiantes de grado empiezan a utilizarla con mayor frecuencia a partir del último año de carrera.

Muchos de los estudiantes tienen perfiles en todas las redes mencionadas, lo cual les genera cierto estrés al tener que dedicar tiempo a cuidar la información colgada, seguir a otros usuarios, contestar, generar contenidos. En los focus group algunas de las chicas encuestadas cuentan su experiencia como modelos e influencers y su 
relación con determinadas marcas para sacar un beneficio económico. También nos encontramos con dos chicos youtubers y dedican más de 10 horas semanales a generar contenido propio que interese a usuarios y a marcas.

El móvil aparece como una fuente de información primaria en todos los grupos de discusión y los participantes reconocen que a través del móvil solucionan muchas de sus dudas sobre cocina, bricolaje, mecánica, salud, sexo. Aunque valoran a sus padres como fuentes fiables les consultan en tercer lugar, en ocasiones por vergüenza o falta de confianza para hablar de ciertos temas. Las fuentes de consulta son, por orden de prioridad: el móvil, los amigos y en tercer lugar padres, familiares o profesores.

En las entrevistas grupales se declaran consumidores de medios generalistas y de prensa especializada sobre todo en temas deportivos ellos y cine, moda y sociedad ellas.

En los usos referidos a contratación de hostelería y gestión de viajes su teléfono se ha convertido en una especie de agencia de viajes virtual o gestión de reservas. Abanderados de la economía colaborativa son a la vez ávidos prosumidores de contenidos audiovisuales. Y hacen un uso habitual de aplicaciones que lo demuestran como B\&B, Wallapop o Blablacar. Estos servicios también distinguen y diferencian su forma de viajar con respecto a generaciones anteriores. Son confiados, sociables y la dependencia económica de sus familias les lleva a ser ingeniosos y resolutivos para poder viajar con pocos recursos. Por eso entre los usos destacados se incluyen la reserva o contratación de servicios de hostelería y gestión de viajes. Todas estas prácticas inciden en la importancia dotada a la movilidad así como la infidelidad que les define como clientes. Los resultados recogidos de sus respuestas nos permiten definirles como consumidores activos, dinámicos, abiertos al cambio, poco interesados en política y religión y muy interesados en temas sociales y medioambientales. Encarnan a la perfección el papel de prosumidores al ser a la vez consumidores y productores de contenidos. Valoran mucho la opinión de otros usuarios y consultan foros antes de efectuar la compra pero una vez decididos priman la rapidez para satisfacer sus necesidades en el menor tiempo posible. Son usuarios habituales de compra de comida y bebida a domicilio.

Es en el grupo de mayor edad de estudiantes de posgrado donde se evidencian las diferencias más significativas en torno a los cuidados del hogar y la conciliación. La mayoría de los encuestados viven ya emancipados de sus padres y algunas de estas personas ya tienen a sus propios descendientes. Los datos recogidos evidencian que en un $62,4 \%$ son las mujeres quienes se encargan de la compra de productos y servicios centrados en el cuidado del hogar y los menores, como son los procedentes del sector de la alimentación, puericultura o juguetes. Mientras ellos se encargan de compras más tecnológicas, gestión de pagos y seguros. Entre los estudiantes de posgrado, muchos reconocen en las charlas que son ellas las que soportan una doble jornada laboral dentro y fuera de casa y quienes más tiempo dedican a las labores del hogar o el cuidado de los hijos. En este caso el teléfono se ve como un aliado para gestionar la logística de la conciliación y los horarios. 
Los datos cuantitativos mostraban que hombres y mujeres en un $99,8 \%$ son prosumidores de contenidos audiovisuales a través del móvil, lo que difiere es el contenido de los vídeos a los que acceden o generan. Ambos géneros citan en primera posición el visionado de sus series favoritas. A partir de esta similitud, los hombres establecen un orden donde prevalecen los contenidos deportivos, musicales, informativos y vídeos divertidos. En el caso de las mujeres, encabezan el listado las series, seguidas de vídeos musicales, noticias de actualidad o sociedad, y tutoriales sobre moda, cocina, maquillaje y cierra el listado tráileres de películas o series nuevas. Muchas de las personas encuestadas visionan contenidos y aprovechan para informarse durante los trayectos de casa a la universidad o al viajar en transporte público. Aunque en sus respuestas coinciden en valorar negativamente la publicidad que llega a sus teléfonos móviles, reconocen que si el anuncio es divertido y original no lo saltan. De igual manera aguantan un anuncio no deseado para acceder al contenido que quieren ver, prefieren eso a tener que pagar por opciones Premium libres de publicidad.

En cuanto a hábitos relacionales gestionados a través del móvil, en las reuniones con los participantes en los focus group todos coinciden en que la mejor forma de hacer buenos amigos es fomentar y cuidar las relaciones personales. Sin embargo, como afirma Ortega, González Ispierto y Pérez Peláez «el joven universitario muestra una tendencia que se consolida en un consumo individual, multipantalla, multitarea, y con un pulso constante de interacción con sus contenidos audiovisuales preferidos a través de aplicaciones y redes sociales en movilidad (2015: 651). Lo que se traduce en una mayor atención y dedicación a sus dispositivos móviles y a las redes sociales que a sus amigos reales. Aseguran que cuando están con sus amigos pasan gran parte del tiempo mirando la pantalla del móvil o «hablando» con personas ajenas a la reunión. Esta situación lejos de sorprenderles, la viven como algo normal derivado de la gran dependencia tecnológica y la necesidad constante de compartir contenidos, novedades o siguiendo sus propias palabras de «estar conectados» y demostrar lo interesante que es su vida mediante el «postureo» o «evadirse de reuniones familiares que les agobian». Relacionan la cobertura telefónica con una suerte de integración social y el hecho de quedarse sin batería, cobertura o sin móvil les generan sentimientos que van desde la ansiedad, inseguridad, aburrimiento y soledad. Depositan un alto grado de confianza en ese objeto y en las amistades virtuales lo que les lleva a menospreciar a personas de su entorno más cercano, principalmente los padres.

No se aprecian diferencias significativas vinculadas al área de conocimiento de los estudios cursados. Sin embargo, las variables género y edad si muestran diferencias relevantes que permiten extraer conclusiones al respecto tras el análisis de los datos. Lo que difieren son las motivaciones que le dan a las diferentes necesidades que cubre su teléfono móvil. Así con respecto a las opciones de «estar en contacto con familiares y amigos» y «sentirme más seguro/a» son las mujeres quienes valoran sobre otros objetivos estos argumentos a la hora de justificar su utilización constante del móvil. Muchas chicas reconocen que el aumento de las noticias sobre agresiones sexuales, y violencia de género les ha condicionado y ahora llevan siempre el móvil encima para sentirse más protegidas en caso de ataque. 
No se detectan en esta investigación indicadores relevantes que hagan temer un uso adictivo del móvil o de servicios asociados a la navegación por internet como el juego, las compras y el teléfono móvil, siendo un grupo muy reducido de jóvenes los que sí se encuentran cercanos a tener un problema de adicción con este tipo de comportamientos.

\section{Conclusiones}

El móvil es el dispositivo más utilizado en España para acceder a internet y el dispositivo electrónico al que más tiempo dedican al día los españoles según los datos del Informe Mobile en España y en el mundo 2017 publicado por Ditrendia (2017). El $98,3 \%$ de las personas encuestadas confirman estos datos y utilizan el móvil como dispositivo de conexión habitual a internet.

Los usuarios millennials presentan una fuerte dependencia de sus dispositivos móviles utilizándolos más de 3,5 horas al día. Además, realizan conexiones a internet de manera regular durante toda la jornada, aunque esto afecte a su rendimiento académico y/o laboral. En el caso de los hombres, son los que más alargan la hora de desconexión hasta rebasar la madrugada por dedicar estas últimas horas del día a la utilización de aplicaciones de advergaming o acceder a páginas de juegos on line o de apuestas.

Las principales razones por las que los universitarios encuestados utilizan sus móviles se centran en la comunicación personal, la socialización, la independencia y el consumo de contenidos. Todos estos usos se vertebran entorno a tres variables principales: información, entretenimiento y seguridad que se convierten en los argumentos principales que definen las rutinas de uso que hacen los millennials.

Los hábitos de consumo más demandados se centran en acceso a herramientas de comunicación personal, redes sociales, juegos y el comercio online. Es aquí donde encontramos mayores diferencias que afectan tanto al género de los encuestados, como a su edad y formación. Mientras que por edad son los más jóvenes quienes mayor tiempo se conectan a las redes sociales (a veces no tanto para comunicarse sino solo por observar lo que hacen otros), son los treintañeros; hombres y mujeres quienes más utilizan el comercio electrónico. Valoran las facilidades de compra, el plazo de entrega y el servicio posventa.

Las redes sociales son visitadas de manera habitual por esta generación. Destaca aquí su faceta prosumer al generar y consumir muchos contenidos audiovisuales. Una de las coincidencias entre los grupos más jóvenes encuestados es que de manera general, tanto hombres como mujeres, se realizan selfies para compartirlos en sus redes sociales. Son los más jóvenes quienes realizan una mayor sobreexposición en las redes de contenidos, en ocasiones, personales y privados. Y llegan a exhibir de forma pública fotografías muy explícitas de sus planes de ocio, vacaciones, relaciones afectivas etc.

La gamificación y los contenidos que les suponen un reto, fomentan la diversión y ofrecen recompensas a su fidelidad son altamente valorados por los consumidores 
masculinos. Las mujeres valoran los contenidos más centrados en la información y los servicios que les ayudan a optimizar el tiempo, conseguir descuentos o promociones y son más indecisas y comparan precios antes de realizar una compra.

Los hombres utilizan sus teléfonos móviles más con fines laborales y de entretenimiento, mientras que las mujeres hacen un uso más social y una mayor utilización de las llamadas y éstas son de mayor duración. En el grupo focal 3, compuesto por alumnado de posgrado, se da una mayor analogía en la utilización de los dispositivos móviles entre hombres y mujeres. Esto se produce, en parte, por tratarse del grupo formado por personas mayores de 24 años que en su mayoría compatibilizan obligaciones laborales, domésticas y/o familiares de una manera más igualitaria. Es en este grupo de edad donde se reduce el uso de determinadas redes sociales muy centradas en lo que ellos denominan «el postureo» y se priorizan otras centradas en el ámbito laboral (LinkedIn), o familiar-social (Facebook).

Hombres y mujeres presentan motivaciones similares en el uso de sus teléfonos, pero, al igual que en otros estudios (Soto, Benavides Almarza y Wilkinson, 2017), las mujeres lo perciben como un elemento de seguridad personal que les mantiene conectadas a su entorno familiar. Genera sensación de protección por lo que la pérdida del dispositivo o quedarse sin batería o cobertura les genera malestar y en ocasiones cierta sensación de ansiedad.

La mayoría admite en las entrevistas que limita las llamadas realizadas a su entorno familiar y a sus parejas. Para contactar con amistades y compañeros optan por las aplicaciones de mensajería instantánea. Esto se justifica, en sus propias palabras, por el elevado coste que las llamadas tienen todavía en el mercado español y a las tarifas con condiciones limitadas contratadas por los usuarios más jóvenes.

En servicios como banca, viajes, consumo de contenidos y formatos audiovisuales e información de actualidad hacen un uso casi exclusivo a través de su móvil cuando están fuera de casa. Sus habilidades tecnológicas y digitales les llevan a confiar plenamente en las plataformas de pago tanto para sus transacciones comerciales como para la gestión de sus viajes, operaciones bancarias, gestiones académicas etc.

El 63,7\% de los encuestados reconoce no hacer un buen uso del móvil usándolo incluso en situaciones inapropiadas lo que les supone discutir con sus padres, parejas, compañeros de aula, amigos o profesores. El 46,3\% de los encuestados consideran que tienen una alta dependencia del teléfono.

\section{Futura línea de investigación}

El estudio se realiza con una muestra no aleatoria sobre un grupo muy concreto de la población lo que limita la interpretación o extrapolación de los resultados a jóvenes millennials de otros contextos. Por ello se propone una futura línea de investigación que amplíe la muestra de estudio incluyendo jóvenes con diferentes niveles formativos e incluso solo con la formación obligatoria. 
Se propone ampliar la investigación y establecer una comparación con la generación anterior y posterior a los millennials para analizar los puntos de coincidencia y divergencia y ampliarlo a otros países ya estudiados.

\section{Referencias}

Albarran, B. Alan (2009). Young Latinos' use of mobile phones: A cross-cultural study. En: Revista de Comunicación, $\mathrm{n}^{0}$ 8. Piura: Editorial Universidad de Piura, 95-108

Aoki, Kumiko y Downes, Edward (2003). An analysis of young people's use of and attitudes toward cell phones. En: Telematics and Informatics, Vol. 20, $\mathrm{n}^{\mathrm{o}} 4$. Tarrytown: Pergamon Press, 349-364.

Bringué, Xavier y Sádaba, Charo (2009). La generación interactiva en España: Niños y adolescentes ante las pantallas. Barcelona: Ariel.

Carcelén, Sonia; Mera, Montserrat e Irisarri, José Antonio (2019). El uso del móvil entre los universitarios madrileños: una tipología en función de su gestión durante el tiempo de aprendizaje. En: Comunicación y Sociedad, Tomo 32, n ${ }^{0} 1$. Pamplona: Universidad de Navarra, 199-211.

Chan-Olmsted, S. M., Lee, S. y Kim, H. (2011). Competitive strategies in Korea mobile television markets: A comparative analysis of mobile operators and television broadcasters. En: International Journal of Mobile Marketing, Vol. 6, $\mathrm{n}^{0} 1$. Nueva York: Mobile Marketing Association, 77-93.

Chen, Yi Fan y Katz, James (2009). Extending family to school life: College students' use of the mobile phone. En: International Journal of Human-Computer Studies, Vol. 67, no 2. Ámsterdam: Elsevier, 179-191

Chu, Julie (1997). Navigating the media environment: how youth claim a place through zines. En: Social Justice, Vol. 24, no 3 . San Francisco: Social Justice/Global Options, 71-85.

Fondevila-Gascón, Joan F.; Marqués-Pascual, Joaquín; Mir-Bernal,Pedro y PoloLópez, Marc (2019). Uses of WhatsApp in the Spanish university student. Pros and cons. En: Revista Latina de Comunicación Social, n ${ }^{\circ}$ 74. La Laguna: Sociedad Latina de Comunicación Social, 308-324. http://dx.doi.org/10.4185/RLCS-2019-1332en

Fullwood, Chris; Quinn, Sally; Kaye, Linda. K. y Redding, Charlotte (2017). My virtual friend: A qualitative analysis of the attitudes and experiences of Smartphone users: Implications for Smartphone attachment. En: Computers in Human Behavior, Vol. 75. Ámsterdam: Elsevier, 347-355.

Heisson, Enric (2001). Booty call: How marketers can cross into wireless space. Dublín: Puca.

Hernández, Roberto, Fernández, Carlos y Baptista, Pilar (2003). Metodología de la investigación. México: M Graw-Hill. 
Hulme, Michael y Peters, Samuel (2001). Me, my phone and I: The role of the mobile phone. En: http://www.cs.colorado.edu/ palen/chi_workshop/papers/HulmePeters.pdf (Consultado el 12-03-2019).

Hootsuite (2019). Informe Digital en 2018. En: https://hootsuite.com/es/pages/ digital-in-2018 (Consultado el 15-03-2019).

Ditrendia (2017). Informe Mobile en España y en el Mundo 2017. En: https://www. amic.media/media/files/file_352_1289.pdf (Consultado el 12-03-2019).

Ling, Richard (2002). Adolescent girls and young adult men: Two subcultures of the mobile telephone. En: Estudios de juventud, $\mathrm{n}^{\circ}$ 57. Madrid: Instituto de la Juventud, 33-58.

Martínez-Rodrigo, Estrella; Martínez-Cabeza Jiménez, Julia; Martínez-Cabeza Lombardo Miguel A. (2019). Análisis del uso de dispositivos móviles en las aulas universitarias españolas. En: Revista Latina de Comunicación Social, $\mathrm{n}^{0}$ 74. La Lagura: Sociedad Latina de Comunicación Social, 997-1013. http://dx.doi.org/10.4185/ RLCS-2019-1368

Ortega, Félix; González Ispierto, Beatriz y Pérez Peláez, María Esther (2015). Audiencias en revolución, usos y consumos de las aplicaciones de los medios de comunicación en tabletas y teléfonos inteligentes. En: Revista Latina de Comunicación Social, $\mathrm{n}^{\circ}$ 70. La Lagura: Sociedad Latina de Comunicación Social, 627-651. http:// dx.doi.org/10.4185/RLCS-2015-1063

Palen, Leisia; Salzman, Marilyn y Youngs, Ed (2000). Going wireless: Behavior and practice of new mobile phone users. En: Procedings of the Conference on Computer Supported Cooperative Work. New York: ACM Press, 201-210.

Pew Research Center (2014). Millennials Report. En: http://www.pewresearch.org/ topics/millennials (Consultado 20-02-2019).

Strauss, William y Howe, Neil (1991). Generations: The History of America's Future, 1584 to 2069. Nueva York: Harper Perennial.

Soto, Ricardo; Benavides Almarza, Cristobal y Wilkinson, Kenton T. (2017). Young Hispanics motivations to use smarphone: A three-country comparative study. En: Comunicación y Sociedad, Vol. 30, $\mathrm{n}^{\circ}$ 4. Pamplona: Universidad de Navarra, 13-24. Tapscott, Don (1998). Growing up Digital. New York: McGraw Hill.

Van Weezel, Aldo y Benavides, Cristóbal (2009). Uso de teléfonos móviles por los jóvenes. En: Cuadernos de información, $\mathrm{n}^{0} 5$. Santiago de Chile: Pontificia Universidad Católica de Chile, 5-14. 


\section{Actitudes de los jóvenes hacia las comunidades virtuales y su vínculo con las marcas. Una aproximación a través de los estudiantes universitarios de comunicación y de marketing de la Universidad Nebrija} Young people attitude towards vitrtual comunities and their relationship with brands. (An approach through the college students of communication \& marketing in Nebrija University)

Juana Rubio-Romero Universidad Antonio de Nebrija

Gemma Barón-Dulce Universidad Antonio de Nebrija

\section{Referencia de este artículo}

Rubio-Romero, Juana y Barón-Dulce, Gemma (2019). Actitudes de los jóvenes hacia las comunidades virtuales y su vínculo con las marcas. Una aproximación a través de los estudiantes universitarios de comunicación y de marketing de la Universidad Nebrija. adComunica. Revista Científica de Estrategias, Tendencias e Innovación en Comunicación, (18), 41-62. DOI: http://dx.doi.org/10.6035/2174-0992.2019.18.4

\section{Palabras clave}

Comunidad virtual; Comunidad de marca; Influencers; Investigación cualitativa; Jóvenes universitarios; Comunicación; Marketing

\section{Key words}

Virtual communities; Brand community; Influencers; Qualitative research; University students; Communication; Marketing 


\title{
Resumen
}

Las comunidades virtuales (CV) son formas de relación bastante asentadas desde hace tiempo, principalmente en las redes sociales. Para algunos, es debido al debilitamiento de los vínculos sociales en la vida real y para otros es una nueva forma de relación social. En medio de estas polémicas, las marcas han visto en ellas una oportunidad para relacionarse con sus consumidores, aprovechando el auge de los medios sociales, el interés de los consumidores convertidos en prosumidores y a que el foco de la comunicación publicitaria se ha puesto en los contenidos de marca y el marketing de influencia. En este contexto, las marcas están desplegando su arsenal de estrategias para crear contenidos ya sea para alimentar sus propias comunidades, las de sus influencers contratados o las comunidades de sus usuarios. Esta investigación se propone explorar las actitudes y motivaciones de los jóvenes universitarios de comunicación y marketing de la Universidad Nebrija hacia la forma de socialidad que representan las comunidades virtuales y cómo entienden el papel de las marcas en este escenario. La metodología utilizada es cualitativa a partir de grupos de discusión con estudiantes universitarios de titulaciones relacionadas con la comunicación y el marketing. Los resultados confirman que los vínculos comunitarios están muy arraigados en los jóvenes pero que, cuando se trata de comunidades de marca, la implicación no es tan intensa como para despertar un auténtico sentimiento de pertenencia, de compromiso y solidaridad tanto con los valores encarnados por la marca como con las personas que conforman esa comunidad virtual.

\begin{abstract}
Virtual communities are a new way of relationship quite steady for some time, mainly in the social networks. For some this is due to the weakening of the social links in real life; for others, it's just a newer form of social relationship. In the middle of this controversy, brands have found an opportunity to interact with their users, taking the advantage of the growth of social media, interest of consumers who have become prosumers and also due to the interest of publicity communication in branded content and the influence marketing. In this context, brands are deploying their strategies in order to create contents to feed their communities, their paid influencers' communities or their users' communities. This investigation aims to explore the attitudes and motivations of the young students in communication and marketing courses at Nebrija University towards this way of sociability through virtual communities and how they understand the role of the brands in this context. The applied qualitative methodology is based on discussion groups with young university students related with marketing and communication studies. The results confirm that communal links are truly ingrained into young people but, regarding brand communities, the feeling is not as intense to wake an authentic sense of belonging, commitment, and solidarity with both the embodied brand values and with the people which form this type of virtual community.
\end{abstract}




\section{Autoras}

Juana Rubio-Romero [jrubio@nebrija.es] es Doctora en Filosofía por la UCM y Licenciada en Psicología, por la Universidad Complutense de Madrid, acreditada como Profesora Contratada Doctora y Profesora Doctora de la Universidad Privada. Desde 1996 imparte docencia en la Facultad de Comunicación y Artes de la Universidad Nebrija y actualmente es investigadora e IP del Grupo INNECOM. Ha dirigido tres Tesis Doctorales.

Gemma Barón-Dulce [gbaron@nebrija.es] es Doctora en Comunicación, Licenciada en Publicidad y RRPP y Máster en DIRCOM. Experiencia previa en agencias y anunciantes, en España y Francia. Vinculada desde 2010 a la Universidad Nebrija, actualmente dirige el Grado en Marketing e imparte docencia en los grados de Publicidad y Marketing. Miembro del grupo INNECOM, Investiga sobre jóvenes y redes sociales, audiencia social e innovación docente. 


\section{Introducción}

\subsection{Las comunidades virtuales y sus tipologías}

A pesar del enorme desarrollo que han sufrido las comunidades desde el nacimiento de la web 2.0, se hace necesario especificar que las CV no siempre han estado enmarcadas en el entorno de Internet, pues los primeros estudios sobre comunidades que se han llevado a cabo estaban dirigidos a agrupaciones de aspectos sociales mucho más amplios que las comunidades en Internet, y más universales, incluso que el medio Internet en sí mismo, como son la religión o la raza. Rheingold (1994) ya habla de las CV como «los agregados sociales que surgen en la red cuando una cantidad significativa de gente lleva a cabo estas discusiones públicas durante bastante tiempo, con suficientes sentimientos humanos como para formar redes de relaciones personales en el espacio cibernético».

Por otro lado, mientras que los estudios sobre las RS se han estandarizado desde hace más de una década, debido al indiscutible interés que las mismas han generado en el conjunto de la sociedad y cuentan con la financiación y difusión por parte de instituciones y empresas gracias a la importante labor de apoyo que realizan a favor de la digitalización de la economía (Barón-Dulce, 2017: 237), las CV no cuentan habitualmente con estudios de seguimiento más allá de los que se realizan con el enfoque antropológico, y que emplean mayoritariamente, el método etnográfico.

Sí se puede apreciar un número significativo de estudios en torno a las comunidades y la comunicación asistida por ordenador desde 1996 por parte de investigadores sociales (Rheingold,1996; Negroponte, 1996; Smith y Kollock, 2003; Jones y Dages, 2003; Hine, 2003; Vayreda y Duran, 2004; Howard y Jones, 2004; Gálvez Mozo, 2005) provocando ciertos debates acerca de la influencia que tienen sobre la vida comunitaria offline y las dudas de si se podían considerar verdaderas comunidades dichos encuentros online o no (Ninova, 2008).

Pero es en los años 90 cuando ha tenido lugar el mayor y más visible desarrollo de las CV, en gran parte, influido por las comunidades en torno a una marca, definida como una comunidad especializada, no vinculada geográficamente, basada en un conjunto estructurado de relaciones sociales entre admiradores de una marca (Muniz Jr. y O’Guinn, 2001).

En esta línea, diversos autores, como es el caso de Pérez Chavarría y Rodríguez Ruiz (2012) evidencian la idea de que la web 2.0 no sólo transforma las interacciones, sino que también fortalece los vínculos ya creados o por crearse entre las personas y entre éstas y las marcas.

Por su parte, Muniz Jr. y O’Guinn (2001) identifican tres componentes para la formación de comunidad: por un lado, el sentimiento de pertenencia, definido como la conexión intrínseca que los miembros sienten unos hacia otros, así como el sentimiento colectivo de diferenciación de otros que no están en la comunidad. La segunda es la presencia de rituales y tradiciones, el hábito, entendido como lo que se ha convertido en lo habitual, ya que perpetúa la historia compartida de la co- 
munidad. La tercera es el sentido de la responsabilidad moral, entendido como un sentimiento de deber u obligación hacia la comunidad en su conjunto.

Anteriormente McMillan y Chavis (1986) investigaron sobre el sentimiento de comunidad y desarrollaron una definición, una teoría y un modelo. En la línea de otros autores ulteriores, destacan además de los tres componentes citados en el párrafo anterior, su propio constructo en el que encontramos de nuevo el sentimiento de pertenencia, la influencia, el sentido de la responsabilidad y, aportan los autores una nueva dimensión, como es la conexión emocional.

En este sentido y toda vez que se han identificado los principales componentes que favorecen la formación de comunidades, Porter identifica en 2012 los tipos de comunidades según el origen de su formación, concretando en dos tipos: las iniciadas por sus miembros o las iniciadas por la propia empresa.

También Susan Fournier y Lara Lee publicaron la sección Best Practice en Harvard Business Review (Fournier y Lee, 2009) un artículo sobre los mitos y realidades de las comunidades de marca y se centran en el desarrollo de una clasificación que se basa en las tres formas de asociación de personas en torno a una marca: En piscina (pools), en red (webs) y en ejes (hubs), donde las piscinas podrían encajar con la idea de las comunidades de marca de una forma más extendida, como reflejo del entusiasmo por una marca, que provoca esa identificación con la actividad y los valores de una compañía, las redes son las comunidades donde los miembros, además, establecen fuertes vínculos interpersonales entre ellos, y las comunidades en forma de ejes que, adaptándose al momento actual, podrían ser las establecidas en torno a los influencers que promocionan distintas marcas y actúan de recomendadores de productos pero cuya figura es el nexo de unión de todos los miembros de la comunidad. Pero también los autores Hagel y Armstrong (1998) habían identificado cuatro tipos de comunidades en función de los intereses de sus miembros, como son las comunidades de transacción, que son aquellas que facilitan la compra y venta de productos y servicios; las comunidades de interés, caracterizadas porque sus miembros están centrados en un tema específico; las comunidades de fantasía donde sus miembros crean nuevas personalidades, entornos o historias y las comunidades de relaciones sociales en las que grupos de personas, después de haber sufrido o estar sufriendo una situación dura e intensa, encuentran aquí dónde compartirlo, generalmente, enmascarando su identidad. No parece habitual encontrar estos tipos de comunidades en estado puro, sino que se combinan distintos tipos (Sanz, 2011), como es el caso de la mayoría de las comunidades de marca.

En relación con el modelo de negocio y concretando en los beneficios que pueden obtener las marcas a través de estas CM, Porter (2004) identifica: Aumento de ventas, WOM positivo, segmentación más efectiva, aumento del tráfico web, marcas más fuertes, mayor ROI, mejora de la atención al cliente y servicio post venta.

La aparición de comunidades en torno a una marca se puede entender como la última etapa del marketing relacional. El concepto de comunidad de marca ha evolucionado, ya que a principios de los años 2000 se partía de la idea de «lealtad 
intensa a una determinada marca comercial» (Muniz Jr. y O’Guinn, 2001) o «el interés destacable por un producto o servicio que ofrece una empresa» (García Ruiz, 2005), pero desde la llegada de las redes sociales (RS) al ecosistema se empiezan a dar otro tipo de afirmaciones en la línea de que la relación social entre los miembros de las comunidades proporciona un ambiente positivo para facilitar la comunicación y obtener confianza y lealtad de los consumidores (Algesheimer, Dholakia y Herrmann, 2005; Bagozzi y Dholakia, 2002; Habibi, Laroche y Richard, 2014; Labrecque, 2014; Laroche, Habibi, y Richard, 2013) y que sostienen que mantener, formar y extender relaciones con otrosen comunidades de RS es la principal razón del engagement (Jahn y Kunz, 2012; Mollen y Wilson, 2010).

Otro aspecto que han estudiado recientemente Hsieh, Tseng y Lee (2018) han sido los factores que determinan el empoderamiento psicológico y su impacto en los comportamientos de co-creación de valor en las CV en torno a una marca y los resultados han revelado que la receptividad percibida, la búsqueda de estado, la validación, el tamaño percibido de la red y la calidad de la información facilitan el establecimiento del empoderamiento psicológico, que a su vez promueve comportamientos de recomendación — advocacy —, de ayuda a los demás y de proporcionar retroalimentación.

Por otro lado, además de las habituales clasificaciones que categorizan las CM según el origen, el tipo de acceso, el soporte económico, el área de interés y el idioma, entre otros, el Estudio de Comunidades Virtuales de jóvenes llevado a cabo por un equipo de investigación de la Universidad de Barcelona también profundiza en el espacio en el que se inscriben, con el objetivo de comprender mejor el tipo de relaciones que se dan entre los miembros, concluyendo que algunas CM ocupan también espacios físicos y no solo virtuales (Bosco, Miño-Puigcercos, Rivera-Vargas y Alonso Cano, 2016).

Por su parte, Castells (2001) identifica dos importantes características culturales compartidas en las CM: por un lado estaría el valor de la comunicación horizontal y libre, defendido por sus usuarios y común a los valores generales de Internet y, por otro, se encuentra el valor de la «conectividad autodirigida», como instrumento para la organización social y la acción colectiva.

Así, la participación e implicación en las CM va a depender de los objetivos y fines de las mismas.

\subsection{La participación de los jóvenes en las redes sociales y las comunidades virtuales}

De acuerdo con Cruz y Mendelsohn (2010), los miembros de las comunidades online de marcas están más comprometidos y tienen tendencia favorable a la compra y a la recomendación de la marca, en comparación con los no miembros. También Becerra y Badrinarayanan (2013) determinan que los miembros de la comunidad 
online de una marca participan en la difusión de los contenidos y la información sobre dicha marca.

La idiosincrasia de los jóvenes estudiantes universitarios hace que sean un espectro de gran interés comercial para las empresas, para las marcas, pues se convertirán en los consumidores futuros, al estar cercanos a la independencia económica de sus familias con la llegada de su primer trabajo (Barón-Dulce, 2017).

Para entender el comportamiento de este colectivo en las redes sociales, Thomas, Briggs, Hart y Kerrigan (2017) identifican dos elementos que están especialmente presentes en las características de los jóvenes que transitan del instituto o colegio a la Universidad: la comparación social - social comparison- y la construcción de comunidad - community building-. En el estudio, hallaron que en un momento decisivo de sus vidas, como es este, los jóvenes universitarios noveles utilizan las RS para interactuar con iguales, lo que les ayuda positivamente en el ajuste social que se produce en esta transición. En cuanto a la construcción de comunidad en este contexto, los autores descubrieron que las RS tienen un papel relevante tanto en la creación de nuevas comunidades como en la integración en las ya existentes para estos alumnos en transición.

En la misma línea, y tomando como ejemplo el ensayo de Thomas, Briggs, Hart y Kerrigan (2017), se puede apreciar cómo en los últimos años han proliferado estudios que relacionan a los jóvenes con las $\mathrm{CV}$, pero siguen quedando espacios sin explorar, como la relación que establecen con las marcas en las RS, que sigue cambiando y evolucionando sin que, por el momento, los estudios realizados aclaren completamente cuál es el propósito de unos y otras.

El estudio más representativo en España sobre la evolución de las RS es el Estudio Anual de Redes Sociales de IAB Spain, que cada año se actualiza incorporando las novedades. Además, el estudio realiza un acercamiento más profundo en algunos aspectos, como es la relación entre las RS y las marcas (IAB Spain, 2018), la publicidad en RS, la relación de las RS y el ecommerce y los influencers. En su última edición, también dedica una atención especial a la Generación $\mathrm{Z}$ y la compara con la Generación Y en todos los ítems analizados.

En la edición 2018 del Estudio Anual de Redes Sociales, se constata que la tendencia de años anteriores en cuanto al seguimiento de las marcas en las RS, se mantiene, alcanzando un $81 \%$ del total los individuos que declaran seguir marcas en RS. Lo que sí se aprecia es un aumento de la intensidad de uso, pues un 39\% de la muestra declara utilizar «mucho» o «bastante» las RS para seguir marcas, respecto al $23 \%$ de la edición anterior del estudio. Esta cifra aumenta hasta el $44 \%$ en el caso de las mujeres y hasta el 47\% en el caso de los usuarios de 16-30 años en los que se enmarcarían los estudiantes participantes en nuestro estudio.

El surgimiento de los influencers como recomendadores de marcas tiene sentido desde el momento en que este rol del propio consumidor genera el impacto que las marcas han identificado en los últimos años (Miceli, 2018). Diversos autores y estudios resaltan el incremento del engagement en los post patrocinados de 
los bloggers o influencers en cuanto a las interacciones o los likes (Hughes, Swaminathan y Brooks, 2019), si bien, el grado de engagement depende del tipo de influencer y del tipo de post publicado (Kupfer, Pähler vor der Holte, Kübler y Hennig-Thurau, 2018). En este sentido, si bien el estudio de referencia en el sector a nivel internacional, CMO Survey (2017), revela una satisfacción media (3,3 puntos sobre $7^{1}$ ) en la eficacia de sus campañas en redes sociales, la mayor parte de los autores y estudios sí destacan la considerable incidencia económica, tanto en términos absolutos como relativos (Kupfer, Pähler vor der Holte, Kübler y Hennig-Thurau, 2018: 26).

\subsection{Hipótesis y Objetivos de la investigación}

Partimos de las siguientes hipótesis:

Hipótesis 1: los jóvenes estudiantes de comunicación, especialmente los que cursan grados relacionados con la publicidad y el marketing, están más motivados a participar y relacionarse a través de las comunidades de marca, dado que han elegido unos estudios afines con la comunicación en el ámbito de las marcas comerciales.

Hipótesis 2: el interés por las comunidades de marca varía en función del nivel de estudio de los estudiantes, entendiendo que los estudiantes de cursos más avanzados están más involucrados con las CM dado que tienen más cerca su horizonte profesional.

A partir de estas hipótesis iniciales, el principal objetivo de esta investigación ha sido explorar el interés de los jóvenes universitarios de Grado en las áreas de comunicación y marketing hacia las $\mathrm{CV}$ a la hora de relacionarse por Internet e indagar en este contexto sobre la notoriedad de las CM de marca y las actitudes que se suscitan.

Los objetivos específicos de nuestra investigación han sido:

- Explorar qué entienden por CV y las diferencias que observan con las redes sociales (RS)

- Analizar las motivaciones que lleva a los jóvenes a participar en las CV

- Indagar sobre las actitudes de los jóvenes investigados hacia las comunidades de marca (CM)

- Conocer el lugar que ocupa la participación en CM entre las prácticas en Internet de los jóvenes universitarios investigados.

- Descubrir los beneficios que les reporta el seguimiento de las marcas en RS y su nivel de involucración con las CM

\footnotetext{
1 Respondiendo a la pregunta: ¿En qué grado contribuye el uso de redes sociales a la mejora de resultados de su
} compañía? ( $1=$ nada en absoluto/ $7=$ mucho). 


\section{Metodología}

La metodología seguida ha sido la estructural o cualitativa que se ha desarrollado mediante grupos de discusión. Hemos utilizado esta herramienta por considerar es la más adecuada dada su capacidad de configurar marcos discusivos amplios, al mismo tiempo que dialécticamente estructurados. Esta técnica, tal y como señalan Canales y Peinado (1995), nos ha permitido entender el sentido social que se despliega en el contexto de una situación - grupal- discursiva.

Los temas para la conversación grupal se plantearon de forma totalmente abierta y amplia, a partir de las formas de relacionarse que practican los jóvenes en Internet. De ahí se fue descendiendo hacia las CV en general y las de marca en particular, según las temáticas iban surgiendo en el intercambio dialéctico entre los participantes (perspectiva emic).

La muestra de estudio han sido jóvenes universitarios, estudiantes de la Facultad de Comunicación y Artes de la Universidad Nebrija; chicos y chicas con edades comprendidas entre los 18/19 y los 22/23 años.

Se han realizado un total de 4 grupos de discusión aplicando el criterio homogeneidad/heterogeneidad. Todos los grupos han sido mixtos en cuanto al sexo y la titulación en la que están matriculados, dado que la mayoría de los estudiantes de la Facultad de Comunicación y Artes de la Nebrija realizan dobles grados, y las disciplinas de publicidad y marketing están entre las más elegidas en estos estudios. La única variable que se ha considerado para la segmentación ha sido el nivel de estudios de los estudiantes, y se ha realizado un grupo por cada nivel.

Así pues, en los grupos han participado los estudiantes de las distintas titulaciones relacionadas con la comunicación que se imparten en la FCA: Publicidad, Periodismo, Marketing y Comunicación Audiovisual.

Las dinámicas organizadas para los grupos de discusión ad-hoc se llevaron a cabo entre el $2^{\circ}$ semestre del curso 2018-19 y el $1^{\circ}$ de este curso 2019-20. A los grupos asistieron entre 6 y 9 asistentes y tuvieron una duración aproximada de 90 minutos cada una; todas ellas se llevaron a cabo en las dependencias de la universidad y fueron grabadas en audio para su posterior transcripción y análisis.

Por otro lado, contamos con las aportaciones de los alumnos de la asignatura de Métodos de Investigación en Comunicación, impartida por una de las autoras de este trabajo. En dicha asignatura los estudiantes, por grupos, tienen que llevar a cabo un trabajo de investigación empírica que en el curso 18-19 se centró en la temática «Jóvenes y comunidades virtuales». Los trabajos de investigación desarrollados por los propios estudiantes, así como los muchos debates mantenidos en clase, han sido de gran ayuda para comprender y profundizar en nuestra temática de investigación. Este tipo de aportes se inscriben en nuestra concepción de entender la docencia no solo orientada a la transmisión de conocimientos, sino como una oportunidad de experimentación y de producción de contenidos. De esta manera profesores y alumnos comparten e intercambian enseñanzas y aprendizajes, al mismo tiempo que los alumnos se involucran en las líneas de investigación de la Facultad de Comunicación y Artes. 


\section{Resultados de la investigación}

\subsection{Sobre qué entienden los jóvenes por comunidad virtual y qué características las definen}

Así como las redes sociales es lo primero que refieren los jóvenes en cuanto se comienza a hablar de Internet, las CV no es un asunto que tenga excesiva relevancia para ellos, ni siquiera en referencia a las actividades relacionales que llevan a cabo en este entorno.

Incluso, se observa un cierto rechazo hacia las CV entre los jóvenes que muestran actitudes menos participativas, posiblemente debido al grado de compromiso hacia los miembros de la comunidad que exige esta forma de relación. Incluso la propia denominación «comunidad virtual» parece desencadenar algunos conflictos emocionales entre estos jóvenes; como si el hecho de unir el término «comunidad» - entendida como la necesidad humana de vivir en sociedad - a «virtual» fuera algo artificioso. La mayoría de nuestros jóvenes se refieren a ellas denominándolas «foros» o «páginas».

Es de reseñar que este tipo de sentimientos no surgen en el caso de las RS, que ya se asumen como una nueva manera de vivir la sociabilidad en la era de Internet, y en este sentido el que sean virtuales se asume con absoluta naturalidad.

Se da incluso la paradoja de que uno de los asistentes a los grupos de discusión, que afirma con rotundidad no pertenecer a ninguna CV, durante la conversación grupal declara que desde hace un tiempo gestiona junto a otros dos amigos una página, «Futbol regional de Madrid», donde suben noticias sobre futbol regional y a la que están afiliados unos 1000 seguidores que también contribuyen con contenidos. Así pues, es uno de los administradores de lo que él llama "página» y no es otra cosa que una $\mathrm{CV}$ pero sin conciencia de serlo...

\footnotetext{
«No es que sea una comunidad porque no hablas con la gente directamente... escribes como en un muro de Facebook y ya la gente va escribiendo lo que quiere, resúmenes, videos, fotos. Nosotros lo que hacemos es que lo gestionamos por si se escribe algo que no viene a cuento, entonces se quita, o no se le permite...».
}

Aunque desde un punto de vista conceptual se tienen claras las diferencias entre una RS y una CV, a nivel funcional los límites entre ambas formas de relación social virtual son difusos. "¿Pero con comunidad te refieres a que si te abres una cuenta en Facebook estás ya en una comunidad o no?» «Ya solo por tener Facebook perteneces a una comunidad».

Teóricamente, una RS sería el ecosistema que alberga a las CV en las que se reúnen personas que comparten determinados intereses.

«Pero en Facebook se puede albergar una comunidad, páginas concretas sobre algo concreto, gustos concretos... Tengo un amigo que es de Las Rozas y se metió en una comunidad porque a sus amigos no les gusta salir por Madrid y él se metió en una página de Facebook donde hay gente que queda para hacer planes y eso aunque no se conozcan...». 
A diferencia de las RS, fundamentalmente orientadas a las relaciones entre personas, las CV están más centradas en los contenidos y los valores que se comparten, «En Facebook es más la amistad, no el interés por un tema en común... Los juegos en línea sí se pueden considerar más una comunidad. Un grupo de personas se reúne porque hay algo en común que les interesa...».

Pero no basta con compartir intereses para que se conforme una comunidad, también es necesario que se desarrolle un sentido de pertenencia, que se distinga claramente entre los que pertenecen a ella y colaboran entre si y los que simplemente recurren a ellas en busca de información puntual en un determinado momento: «Yo sí me meto en páginas especializadas para ver qué dice la gente sobre las películas y para elegir la que me interesa ver... Yo no colaboro en esas comunidades pero me viene muy bien para informarme».

Este sentimiento de pertenencia, si bien ayuda a los procesos de identificación, también obliga a participar activamente y colaborar con los miembros que componen esa comunidad.

Otra característica que diferencia una RS de una CV es que en las comunidades existe una jerarquía y una normativa que hay que cumplir para pertenecer a ella. A algunas de esas comunidades solo es posible acceder por invitación de algún miembro o haciendo alguna contribución económica, ya sea para una causa social, como una ONG por ejemplo, o para ser beneficiario de todos los servicios y no solo los de acceso abierto. En algunas comunidades, como las de videojuegos, hay que pagar una cuota anual.

Las relaciones jerárquicas entre los miembros de la CV son de dos tipos; de un lado son relaciones verticales, asimétricas, entre los gestores/administradores que lideran la comunidad y el resto de integrantes; los líderes son en última instancia los responsables de los contenidos que se suben para compartir, tal y como lo expresa un joven participante en nuestros grupos: «Nosotros lo que hacemos es que lo gestionamos por si se escribe algo que no viene a cuento, entonces se quita, o no se le permite...». Y de otro, se establecen relaciones horizontales, simétricas, entre todos los miembros que componen esa comunidad. "Al suscribirte a un canal de deporte o de ropa, si otro también está suscrito puedes hablar con él, puedes incluso crear un grupo de WhatsApp para hablar entre nosotros y comentar y puedes incluso tener feedback de la propia persona líder».

Pero estas relaciones horizontales también pueden llegar a convertirse en jerárquicas pues los miembros que más aportan consiguen mayor reconocimiento de la comunidad.

Los jóvenes mencionan distintos tipos de CV, pero sin duda la que consigue más notoriedad es la que se organiza alrededor de personas relevantes, ya sea porque han conseguido triunfar en los medios sociales, los llamados influencers, blogers, youtubers, o porque se hayan convertido en referentes mediáticos por méritos propios (músicos, actores...). 
Aunque nuestros jóvenes participantes dudan si el seguir a estas personas influyentes se puede considerar formar parte de una CV, máxime cuando en estos casos la interacción entre los seguidores es mínima pues parece que todo el interés gira alrededor de la figura líder que gestiona ese grupo. Unos opinan que no se puede considerar una comunidad...

«Sigo cuentas particulares y no sé si esto se puede considerar una comunidad... No es lo mismo seguir a una persona concreta que seguir en un foro... Entre los seguidores de una persona no nos comunicamos habitualmente entonces por eso no me parece que sea una comunidad».

Otros en cambio opinan que sí, que alrededor de un influencer o de un famoso se puede crear una comunidad... "es como pertenecer a un club de fans...». Un tipo de CV sobre la que hay menos dudas es la que se organiza alrededor de una temática de interés, que pueden ser de lo más variado.

\footnotetext{
«A mí me gusta mucho el mundo del deporte y sigo a mis ídolos, cómo les van las competiciones. O a gente de marketing interesante, por ejemplo, Roberto Alcalde, un profesor del ESIC que me gusta, o la página de Puromarketing, que está muy actualizada con las nuevas tendencias de marketing. Y a determinadas marcas».
}

Observamos entre nuestros universitarios actitudes diferentes hacia las CV según el nivel de involucración de los jóvenes; los más pasivos (observadores) expresan reacciones de cierto rechazo hacia las $\mathrm{CV}$, en cambio los más activos (participativos) expresan sentimientos muy positivos y hasta de cierto orgullo de pertenencia. «Pues yo sí pertenezco a varias comunidades y me encanta compartir y ayudar con información que puede ser útil a la gente...».

Finalizamos este epígrafe señalando que Facebook es la red más nombrada a la hora de referirse a las CV a las que siguen. Este dato es coherente con el carácter más emotivo e informativo que los jóvenes atribuyen a Facebook, frente a Instagram, «es más de postureo», o a Twitter, «para estar al tanto de las noticias».

\subsection{Motivaciones y frenos de los jóvenes hacia las CV}

Dado que las CV reúnen a personas que comparten intereses y están especializadas en alguna temática, cabe suponer que la información que circula en ellas es más selectiva, por lo que se llegan a entender como redes de «expertos».

Se da por hecho que para cualquier usuario/a de RS, conseguir más (nivel cuantitativo) y mejores (nivel cualitativo) seguidores es un objetivo principal pues ello significa conseguir prestigio (equivalente al capital simbólico de Bourdieu). En el caso de las CV este objetivo se amplifica, pues se proyecta tanto en el ámbito de la comunidad, que aspira a convertirse en referente de conocimiento de la temática que trata, como en el de los integrantes particulares, que también aspiran a que sus aportaciones conecten y empaticen con los intereses de los demás, contribuyendo así a engrandecer la comunidad y a potenciar su propia marca personal. 
Por ello en una CV el nivel de exigencia e implicación es mucho más alto emocionalmente que en una RS, pues de ella se espera que los miembros participen y colaboren de forma más activa, tanto para el bien de la comunidad, como para conseguir el reconocimiento de sus miembros. Un reconocimiento que siempre es bien recibido y que cuando proviene de los líderes que gestionan esa comunidad, o de alguien con prestigio, se eleva a la categoría de lo sublime:

«... te da un subidón, es como si Brad Pitt te saluda. A mí me pasó una vez, le puse a la Laura Escanes "estás superguapa", y a la tía le dio "Me gusta" a mi comentario y yo dije, ¡anda!..., pues esta chica que tiene tropecientosmil seguidores le da me gusta a tu comentario y no a otro..., no sé, hace ilusión».

En este contexto las motivaciones que subyacen a la hora de afiliarse a una CV son muchas y muy diversas: el poder tener acceso a un contenido más selectivo sobre el tema que interesa; el de relacionarse con gente con la que se supone es más fácil identificarse; el expresar y compartir opiniones sobre temáticas que interesan, por lo que es más fácil conseguir la interacción de los otros; el de colaborar y ayudar a los demás... «Te relacionas con gente con la que compartir dudas e inquietudes»,

«Un lugar en el que expresar las ideas, sean equivocadas o correctas, tienes esa ventana que te permite expresar tu opinión... Se aprende también un poco, consultas las opiniones de la gente antes de ir a un restaurante, por ejemplo, y luego pones tu opinión»

En el contexto del aislamiento social y el predominante individualismo que nos rodea, las CV parecen cumplir una función fundamental como facilitadoras de la convivencia y la integración: "Te sientes como una parte de una comunidad, que lo que te gusta a ti, no solo te gusta a ti, sino que gusta a más gente y entonces te sientes más integrado... Te sientes identificado».

También es un entorno en el que es más fácil la escucha y el desahogo, «Para desahogarse, la gente quiere ser escuchada siempre... No es mi caso, pero conozco a gente que con sus amigos no puede hablar de ciertas cosas o no se sienten a gusto y eso es una plataforma donde te puedes expresar libremente».

Más allá de que también pueden propiciar encuentros entre los afiliados en la vida real. «Mi padre por ejemplo estaba en un foro de la marca de su coche y se llegó a crear muy buen rollo y quedaban en la vida real y se hicieron muy amigos...».

«En mi caso entré en una comunidad relacionada con la música [...] Y pasó de ser una comunidad virtual a una comunidad real [...] incluso quedamos para encontrarnos en un festival que se hace en Asturias, así es que pasamos a conocernos en persona, contarnos nuestros problemas... Me pareció guay pero también me dio un poco de miedo si lo piensas».

Pero también se suscitan frenos a la hora de pertenecer a ellas, que se manifiestan tanto con respecto a las emociones, como en un ámbito más práctico.

Desde una perspectiva más emocional, la pertenencia a las CV puede estar indicando ciertas carencias e insatisfacciones en la vida real y en las que no gusta reconocerse. Esto mismo también se podría decir respecto a las RS, pero en las CV es 
más patente pues en ellas se despliega mayor carga emocional: el sentido de pertenencia está más arraigado y el compromiso de participar y colaborar con el resto de la comunidad es más fuere; la adscripción a una CV es voluntaria y reveladora de unos determinados gustos personales; también el nivel de compromiso e implicación es mucho más elevado. No tiene el mismo efecto no conseguir feedback en un RS, que en una $\mathrm{CV}$, pues se supone que se interacciona con gente con la que se comparten intereses y valores.

En un orden más pragmático, los jóvenes manifiestan restringir su participación en CV porque temen ver limitadas las posibilidades de estar informado de una amplia variedad de temas y de ampliar los intereses de tu perfil.

«Es que si interaccionas mucho con ese contenido, solo te llegan cosas relacionadas con esa temática o personas relacionadas con ella, influencers..., toda lo orienta hacia eso porque —el sistema - ha visto que te gusta, te manda mucha información sobre ese contenido y te cansas...».

Esto último se manifiesta sobre todo entre los universitarios de más edad que son los menos proclives a participar en estos entornos virtuales.

\subsection{El seguimiento de las marcas en las RS}

Como es bien sabido, la experiencia de consumo trasciende su sentido utilitario, para incorporar otros planos como el expresivo, el lúdico o el social. Lo podemos comprobar en las razones que declaran nuestros jóvenes para explicar el amplio seguimiento que hacen de las marcas en Internet.

Una de las razones principales que aducen es porque las adoptan sus amigos o personas de su entorno, lo cual nos habla de los aspectos identificatorios y socializadores que cumplen las marcas. Los jóvenes por Internet cotillean y exploran las marcas que siguen sus amistades y se suscita el interés por hacer lo mismo, reforzando así los vínculos que les unen.

«Por ejemplo vas a una marca de ropa y ves que también la sigue y dices, mira otra cosa más, otra cosa más (en común), vas cotilleando, como le digo yo, y al final tienes un montón de cosas en común y así tienes más cosas en común y siempre es un buen tema para charlar».

En muchas ocasiones es el propio sistema tecnológico el que se ocupa de informarles, tanto sobre las marcas a las que siguen sus amigos, como sobre otras que les sugiere por los datos de su perfil. «En Instagram, de forma automática te sale, Jaime sigue a éste, a éste y a éste». Otro factor de influencia para el seguimiento de las marcas son las opiniones de los influencers, blogers y youtubers, por más que se sepa que en la mayoría de los casos no se trata de una información desinteresada pues cobran por ello.

Por otro lado, también hay que tener en cuenta las estrategias de marketing que llevan a cabo las marcas en las RS, principalmente dirigidas a conseguir la interacción y participación de los jóvenes en la difusión de sus contenidos de marca. Son 
estrategias más de tipo lúdico, como sorteos o concursos, cuya principal finalidad es la de incrementar la atención y el seguimiento de usuarios: «... te dicen, sígueme, menciona 5 amigos, déjame un comentario y publica una historia, entonces con eso empiezan a tener más gente, más gente, más gente...».

A todo esto hay que añadir que algunas RS, como Instagram, o aplicaciones como 21 Buttons, han hecho posible una experiencia de compra similar a la de un centro comercial con las ventajas de la compra online: «Lo que yo digo..., últimamente te vas de compras por Instagram y cuantas más marcas sigas, pues más tienes como elegir, es como el centro comercial de antes, además ahora ves algo que te gusta, le das al link y te lo compras».

Los propios catálogos de las marcas disponibles en Internet para la compra online, sobre todo en el terreno de la moda, suscitan también el interés de los jóvenes; algunos tienen una gran calidad en cuanto a diseño, y se consultan como guías de estilo a la hora de seguir y compartir tendencias, llegándose a equiparar con las revistas de moda: «Por otra parte sigo a muchas marcas a nivel visual porque hay algunas marcas que hacen obras de arte..., como una película de cine, eso me hace feliz...».

En medio de esta inagotable oferta hay que estar muy bien informado sobre novedades y tendencias, sobre los precios y las ofertas, sobre los productos que ofrecen las marcas, sobre las opiniones de los consumidores...Y en este sentido, las comunidades de marca parecen cumplir una función primordial, como veremos en el siguiente epígrafe.

\subsection{El papel de las marcas en la formación de comunidades}

Los jóvenes reconocen un papel fundamental a las marcas en la conformación de las $\mathrm{CV}$, ya sean como creadoras de sus propias comunidades alrededor de intereses detectados entre los consumidores; ya sea como patrocinadoras de las comunidades de terceros, principalmente influencers, que por su temática, valores, número de seguidores y/o perfiles de consumidores sean afines a la marca. Se trata de personas a las que admiran, bien porque han conseguido atraer a multitud de seguidores, o por lo que representan como modelos de referencia

Se considera normal que las marcas utilicen los medios sociales para llegar a los consumidores y sean sus principales sostenedoras, como lo fueron en otros tiempos de los medios de comunicación tradicionales: «Son como las vallas publicitarias en el espacio virtual».

Mucho más cuando la publicidad intrusiva sufre una crisis radical y cuando las estrategias de branded content están en plena expansión.

En este contexto, las CM patrocinadas son mucho más numerosas, según los jóvenes, que las creadas y gestionadas por las propias marcas, y tienen más impacto social por la sencilla razón de que los intereses mercantiles están más diluidos. 
Entre las CM gestionadas directamente sobresalen algunas, como la de Redbull que se menciona de forma espontánea en los grupos de discusión. Se trata de una CM muy apreciada por la gran variedad de contenidos que trata relacionados con eventos deportivos y musicales. Se valora de esta comunidad tanto el contenido como la forma, así como los valores de superación y esfuerzo que transmite a través de su temática estrella, los deportes de riesgo. También gusta mucho que desde la marca se fomente y propicie las relaciones entre los integrantes de sus comunidades.

«Como deportista, la marca que a mí me encanta es Redbull, una marca de bebidas pero lo que me atrae son los eventos que tienen, los videos que hacen y la repercusión que tienen, y me encanta cómo los hacen y me identifico muchísimo con lo que hacen. Por ejemplo me gusta el snowboard y la mayoría están patrocinados por Redbull ... Tienen mucha adrenalina...Son situaciones de riesgo que no puedes hacer tú porque ellos son profesionales..., y piensas, por qué no puedo hacer yo eso, por qué no voy a la montaña y lo intento».

Otras marcas que también se mencionan en relación a las CV propias son Campofrío, por el mensaje de vida saludable que promueve en su comunidad, Tripadvisor, por la utilidad y servicio de su aplicación, o Dove cuya comunidad gira alrededor de la autoestima de las mujeres.

Todas estas marcas al parecer han sabido crear en sus respectivas comunidades un entramado de representaciones sociales, simbólicas y valores culturales que conectan con los intereses de los jóvenes.

A pesar de que estas iniciativas de las marcas se valoran muy positivamente, no deja de estar presente en el discurso de los jóvenes el impacto comercial que en última instancia pretenden, lo que siempre provoca un atisbo de sospecha: parecen altruistas pero no lo son.

Este aspecto mercantil se diluye en el caso de las CM patrocinadas y gestionadas por influencers, puesto que se solapa entre los otros contenidos de interés. Los mismos jóvenes se sienten concernidos en la actividad de los influencers pues también ellos aspiran a conseguir reputación social por su actividad en los medios sociales y si con ello consiguieran atraer a las marcas, sería la confirmación de su reconocimiento como personas influyentes, además de la remuneración económica que les reportaría. Los jóvenes también aplican estrategias similares en la promoción de su propia marca personal, imitando lo que ver hacer a los profesionales.

«...yo recuerdo el año pasado que me trabajaba mucho Instagram, mis amigos me decían, mira la bloguera, que yo nunca he sido bloguera, nada influencers, pero me llamaban bloguera de broma, y cuando me sigue alguien nuevo, ah, ya tienes tantos seguidores, cómo, quién eres... te hacen sentir un poco más... (admirada)».

En general se interacciona menos con los contenidos comerciales que con los de interés, y cuando se comparten se limita a los amigos, pues están en la esfera de los gustos personales

"Y sí que lo puedo compartir. No suelo hacerlo cada vez que veo algo que me gusta, a lo mejor hago captura y me lo guardo en mi móvil y se queda ahí hasta que un día voy a la tienda 
o me acuerdo y lo busco... O también lo de mencionar a gente para que le salga a ellos la publicación».

Este tipo de contenidos se comparte en las RS con un fin más utilitario, por ejemplo comunicar el interés por un determinado producto o para dar pistas a sus amistades de cara a posibles regalos... «Otra cosa que también hago es etiquetar las prendas que me encantan...Para que te la compren, eh?... (risas generales) ¿Oye me la compras para mi cumple? Es broma, es para que lo vean también ellas».

La información sobre novedades y tendencias son los contenidos comerciales que más interesan de las CVM: «Yo sigo a muchas marcas para enterarme de las tendencias, sobre cuál va a ser el futuro».

Con algunas marcas se llegan a establecer intensos vínculos emocionales, ya sea porque se compartan valores o estilos de vida: «yo sigo a marcas de surf porque lo practico, y me gusta también la ropa de surf..., pero también sigo a Nike, Adidas..., marcas básicas».

«Yo me identifico bastante con la marca Hollister, ropa de buena calidad, un poco informal pero formal.., un poco surferillo..., me gustan mucho sus valores..., lo que me inspira, que tú puedes ser una persona seria, pero luego a la hora de vestir puedes ir más libre».

Ya sea porque se trate de marcas de prestigio a las que se sigue porque representan un mundo aspiracional.

Las marcas de moda son sin ninguna duda las que más atraen el interés de los jóvenes, principalmente porque es una temática de mucha implicación, posiblemente debido a su conexión con asuntos de tanto calado emocional como la identidad. Y sobre ropa se conversa mucho en las RS y en todo tipo de comunidades en las que están los jóvenes.

\section{Discusión y conclusiones}

Compartir determinados contenidos es la principal razón de ser de las comunidades virtuales (CV), de igual forma que la de relacionarse socialmente es la de las redes sociales (RS), independientemente de que en las CV también se mantengas relaciones personales a partir de compartir determinados intereses. Pero se trata de formas de relación diferentes, pues en la RS son abiertas e igualitarias, mientras que en las CV son más selectivas y jerárquicas pues están gestionadas por quienes las lideran y tienen que ajustarse a la normativa que rige esa comunidad

También se diferencian en cuanto al sentido de pertenencia, más fuerte en el caso de las CV. En una RS la pertenencia procede de la marca de esa RS: cada marca de RS aporta a sus usuarios una identidad que le diferencia de los usuarios de otra RS (no es lo mismo ser de Instagram que ser de Snapchat). En las CV el sentimiento de pertenencia abarca más aspectos relacionales, como los que tienen que ver con la persona que lidera esa comunidad, las temáticas de las que trata y los usuarios afiliados. 
También el nivel de compromiso es mayor en una CV que en una RS pues se supone que la temática alrededor de la cual gira la conversación en una comunidad es un asunto de interés personal y por lo tanto se espera que todos participen con sus opiniones y experiencias. En las CV existe además un doble compromiso: el de colaborar para que la comunidad crezca y ocupe un lugar de referente experto en alguna temática, y el de participar activamente para conseguir cierta reputación dentro de esa comunidad.

Nuestros jóvenes consideran positivo el hecho de poder acceder a una selección de contenidos y el poder relacionarse con gente afín, pero también se observa que esta selección limita sus aspiraciones de estar al tanto de todo lo que ocurre a Internet y de conocer a gente diferente.

El hecho de compartir contenidos virtualmente con gente afín conlleva valores muy positivos como favorecer los procesos de identificación; beneficiar que se establezcan relaciones de confianza entre los miembros de una CV; facilitar el poder expresar las opiniones propias y el que puedan ser escuchadas. Pero también se movilizan ciertos temores, principalmente debidos a que alrededor de ellas se moviliza una mayor carga emocional que en las RS, pues por tratarse de relaciones con personas afines, se pueden sentir frustraciones más intensas cuando no consiguen respuesta a sus mensajes; incluso algunos relacionan la pertenencia a CV con carencias emocionales en la vida real e incluso perciben una cierta vulnerabilidad al depositar la confianza en desconocidos y compartir asuntos más personales.

De los resultados de nuestra investigación se desprenden actitudes diferentes según se trate de jóvenes más participativos o más observadores, advirtiéndose que los primeros son más proclives que los segundos a relacionarse mediante las $\mathrm{CV}$.

En lo que se refiere más en concreto a las comunidades virtuales de marca (CM) observamos que los jóvenes manifiestan un amplio seguimiento de las marcas a través de las RS, donde principalmente están alojadas estas comunidades, y parece que Facebook es la red social más proclive a esta forma de relación, posiblemente por su carácter más emotivo.

Así pues, la presencia de las marcas en los medios sociales se vive con absoluta naturalidad, conscientes de que desde siempre las marcas comerciales han sido las principales sostenedoras de los medios de comunicación. Por otra parte, tampoco se observan reacciones de rechazo hacia los contenidos comerciales de las marcas pues es una temática que resulta útil a la hora de estar informado de novedades y tendencias, a la vez que ayuda a orientarse en el universo de marcas que proliferan en Internet como consecuencia del auge actual de la compra online.

A la hora de referirse a las CM, nuestros jóvenes diferencian básicamente entre dos formas: las que gestionan directamente las marcas y las gestionadas por terceros donde las marcas son subsidiarias. Por más que en las primeras puede que los contenidos comerciales tengan menos presencia que en las segundas, el mensaje mercantilista tiene mayor relevancia y por ello, las CV gestionadas por terceros concitan más seguimiento. Principalmente si son gestionadas por influencers y ce- 
lebrities, que han sabido ganarse la confianza de los jóvenes; ya sea porque consideran lógico que las marcas sean las pagadoras del esfuerzo y trabajo que realizan para generar contenido interesante para la comunidad; ya sea porque los mismos jóvenes comparten este tipo de aspiraciones cuando participan de forma activa en las RS y aplican estrategias similares para promocionar su marca personal. Aun así, y tal y como se ha expuesto en el epígrafe 1.2 del presente documento, los estudios de referencia a nivel internacional, como es el ejemplo del CMO Survey (2017) anteriormente citado, reflejan una cierta desconfianza todavía por parte de las marcas más relevantes en la repercusión económica que puedan tener las acciones en redes sociales.

Con todo, cuando se trata de comunidades de marca, la implicación de los jóvenes no parece tan intensa como para despertar un auténtico sentimiento de pertenencia, de compromiso y de solidaridad tanto con los valores encarnados por la marca, como con las personas que conforman ese tipo de comunidad virtual. Y es por ello que se requiera de encuentros físicos en la vida real para reforzar estos vínculos, algo que parece bastante habitual.

En cuanto a nuestras hipótesis de partida, se confirma que los estudiantes con un perfil más orientado al marketing y la comunicación comercial (Hipótesis 1) manifiestan una actitud más favorable hacia las CV en general y a las CM en particular, mientras que son los estudiantes de periodismo los que se muestran más críticos. En cambio no se confirma la Hipótesis 2 pues el interés de los alumnos por las CM no está relacionado con el nivel de estudios y la cercanía de su horizonte profesional, más bien al contrario son los estudiantes de cursos menos avanzados los que parecen manifestar más interés por estas formas de relación virtual, posiblemente porque al ser más jóvenes son más sensibles al apoyo identitario y social que proporcionan las CV.

Consideramos que nuestra muestra de estudio es cualitativamente representativa en cuanto a que considera todas las relaciones que los estudiantes universitarios de comunicación pueden tener respecto al objeto de estudio, con la limitación de que se trata de estudiantes de una única universidad privada, lo que hace necesario que estos resultados se contrasten con estudiantes de comunicación de distintas universidades públicas y privadas para poder ser extrapolados.

También queremos señalar que comparando estos resultados con los de investigaciones similares que hemos realizado en el pasado, observamos que se empieza a vislumbrar entre los jóvenes universitarios de los grados en comunicación un cierto cansancio e incluso desconfianza hacia la excesiva presencia de los mensajes comerciales entre los contenidos de los influencers.

En cambio, no ocurre lo mismo en lo referente a la presencia de las marcas comerciales en las RS comerciales, que observamos menos crítica que en estudios

anteriores. A propósito de esto se nos ocurren algunas ideas, como el hecho de que la publicidad de las marcas es cada vez menos intrusiva y/o el predominio de las estrategias de branded content que están actualmente; también puede ser que, 
debido a la llegada al mercado de muchas marcas nicho desconocidas hasta hace poco y al auge de la compra online, los jóvenes consideren de utilidad la información comercial para orientarse y tomar decisiones. Son solo ideas en las que habría que seguir profundizando en futuras investigaciones.

\section{Bibliografía}

Algesheimer, René, Dholakia, Utpal M., y Herrmann, Andreas (2005). The social influence of brand community: Evidence from European car clubs. En: Journal of Marketing, Vol. 69, $\mathrm{n}^{0} 4$. Nueva York: SAGE Publishing, 19-34.

Becerra, Enrique P. y Badrinarayanan, Vishag (2013). The influence of brand trust and brand identification on brand evangelism. En: Journal of Product \& Brand Management, Vol. 22, n ${ }^{\circ}$ 5-6. Bingley: Emerald Publishing, 371-383.

Bagozzi, Richard P., y Dholakia, Utpal M. (2002). Intentional Social Action in Virtual Communities. En: Journal of Interactive Marketing, Vol. 16, $\mathrm{n}^{\circ} 2$. Ámsterdam: Elsevire, 2-21. https://doi.org/10.1002/dir.10006

Barón-Dulce, Gemma (2017). Una aproximación sobre la relación de los jóvenes con las marcas. Las redes sociales como escenario. Tesis doctoral. Madrid: Universidad Antonio de Nebrija.

Bosco, Alejandra, Miño-Puigcercós, Raquel, Rivera-Vargas, Pablo, y Alonso Cano, Cristina (2016). Comunidades Virtuales, jóvenes y aprendizaje. La complejidad de una categorización. En: Journal for Educators, Teachers and Trainers, Vol. 7, n ${ }^{0} 2$. Granada: Universidad de Granada, 25-37.

Canales. Manuel y Peinado, Anselmo (1995). Grupos de discusión. En: Delgado, J. M. y Gutiérrez Fernández, J. (coords.), Métodos y técnicas cualitativas de investigación en ciencias sociales. Madrid: Síntesis.

Castells, Manuel (2001). La Galaxia Internet. Reflexiones sobre Internet, Empresa y Sociedad. Barcelona: Plaza \& Janés.

Cruz, Brant y Mendelsohn, Josh (2010). Why Social Media Matters Matters to Your Business. Findings from Recent Research on Social Media from Chadwick Martin Bailey and Imoderate Technologies. Boston: Chadwick Martin Bailey.

Fournier, Susan y Lee, Lara (2009). Getting Brand Communities Right. En: https:// hbr.org/2009/04/getting-brand-communities-right (Consultado el 17-07-2019)

Gálvez Mozo, Ana $M^{\mathrm{a}}$ (2005). Sociabilidad en pantalla. Un estudio de la interacción en los entornos virtuales. En: AIBR. Revista de Antropología Iberoamericana, ${ }^{0}$ especial. Madrid: Antropólogos Iberoamericanos en Red, 1-29.

García Ruiz, Pablo (2005). Comunidades de marca. El consumo como relación social. En: Política y Sociedad, Vol. $42, \mathrm{n}^{\mathrm{O}}$ 1. Madrid: Universidad Complutense de Madrid, 257-272. 
Habibi, Mohammad Reza, Laroche, Michel, y Richard, Marie-Odile (2014). Brand communities based in social media: How unique are they? Evidence from two exemplary brand communities. En: International Journal of Information Management, Vol. 34, no 2. Ámsterdam: Elsevier, 123-132.

Hagel, John y Armstrong, Arthur (1998). Net Gain: Expanding Markets Through Virtual Communities. Boston: Harvard Business School Press.

Hine, Christine (2003). Etnografía Virtual. Barcelona: UOC.

Howard, Phillip N. y Jones, Steve (eds.) (2004). Society Online. The Internet in context. Thousand Oaks: SAGE Publications.

Hsieh, Sara H., Tseng, Timmy y Lee, Crystal T. (2018). Drivers of Online Brand Community Value Creation: The Role of Psychological Empowerment. En: http:// hdl.handle.net/10125/50153 (Consultado el 17-07-2019).

Hughes, Christian, Swaminathan, Vanitha, y Brooks, Gillian (2019). Driving Brand Engagement Through Online Social Influencers: An Empirical Investigation of Sponsored Blogging Campaigns. En: Journal of Marketing. Nueva York: American Marketing Association.

IAB Spain (2018). Estudio Anual de Redes Sociales. Madrid: IAB Spain.

Jahn, Benedikt, y Kunz, Werner (2012). How to Transform Consumers into Fans of Your Brand. En: Journal of Service Management, Vol. 23, no 3. Bingley: Emerald Publishing, 344-361.

Jones, John W. y Dages, Kelly D. (2003). Technology Trends in Staffing and Assessment: A Practice Note. En: International Journal of Selection and Assessment, Vol. 11, no 2-3. Malden: John Wiley \& Sons, 247-252.

Kupfer, Aann-Kristin, Pähler vor der Holte, Nora, Kübler, Raoul, y Hennig-Thurau, Thorsten (2018). The Role of the Partner Brand's Social Media Power in Brand Alliances. En: Journal of Marketing. Nueva York: American Marketing Association, 25-44.

Labrecque, Lauren I. (2014). Fostering Consumer-Brand Relationships in Social Media Environments: The Role of Parasocial Interaction. En: Journal of Interactive Marketing, Vol. 28, nº 2. Ámsterdam: Elsevier, 134-148.

Laroche, Michel, Habibi, Mohammad Reza, y Richard, Marie-Odile (2013). To be or not to be in social media: How brand loyalty is affected by social media? En: International Journal of Information Management, Vol. 33, $\mathrm{n}^{\mathrm{o}} 1$. Ámsterdam: Elsevier, 76-82.

McMillan, David W., y Chavis, David M. (1986). Sense of Community: A Definition and Theory. En: Journal of Community Psychology, Vol. 14, $n^{0} 1$. Malden: John Wiley \& Sons, 6-23. 
Miceli, Jorge (2018). El significado social de los precios. En: D. López y L. Lewkow, Análisis de redes y toma de decisiones económicas. Elementos conceptuales para su abordaje. Barcelona: Teseo Press.

Mollen, Anne, y Wilson, Hugh (2010). Engagement, telepresence and interactivity in online consumer experience: reconciling scholastic and managerial perspectives. En: Journal of Business Research, Vol. 63, nº 9-10. Ámsterdam: Elsevier, 919-925. Muniz Jr., Albert M., y O'Guinn, Thomas C. (2001). Brand Community. En: Journal of Consumer Research, Vol. 27, no 4. Oxford: Oxford University Press, 412-432.

Negroponte, Nicholas (1996). El mundo digital. Barcelona: Ediciones B.

Ninova, Maya Georgieva (2008). Comunidades, software social e individualismo conectado. En: Athenea Digital. Revista de pensamiento e investigación social, $\mathrm{n}^{\mathrm{o}}$ 13. Barcelona: Universitat Autònoma de Barcelona, 299-305.

Pérez Chavarría, Mariela, y Rodríguez Ruiz, Astrid A. (2012). Comunidades de marca: otra manera de sostener conversaciones y generar Relaciones Públicas. En: Revista Internacional de Relaciones Públicas, Vol. II, $n^{0} 3$. Málaga: Universidad de Málaga, 175-192.

Porter, Douglas R. (2012). Managing growth in America's communities. Washington: Island Press.

Porter, Michael E. (2004). Competitive advantage: creating and sustaining superior performance: with a new introduction. Brasilia: Elsevier.

Rheingold, Howard (1994). The virtual community: surfing the Internet. London: Minerva.

Rheingold, Howard (1996). La comunidad virtual: una sociedad sin fronteras. Barcelona: Gedisa.

Sanz, Sandra (2011). Comunidades de práctica. Barcelona: UOC.

Smith, Mark A. y Kollock, Peter (2003). Comunidades en el ciberespacio. Barcelona: UOC.

CMO Survey (2017). Highlights and Insights. En: https://cmosurvey.org/wp-content/uploads/sites/15/2017/08/The_CMO_Survey-Highlights_and_Insights-Aug-2017. pdf (Consultado el 17-07-2019).

Thomas, Lisa; Briggs, Pam; Hart, Andrew y Kerrigan, Finola (2017). Understanding social media and identity work in young people transtitioning to university. En: Computers in Human Behaviour, Vol. 76. Ámsterdam: Elsevier, 541-553.

Vayreda i Duran, Agnès (2004). Las promesas del imaginario Internet: Las comunidades virtuales. En: Athenea Digital. Revista de pensamiento e investigación social, primavera, $\mathrm{n}^{\circ}$ 5. Barcelona: Universitat Autònoma de Barcelona, 57-78. 


\section{La incorporación de la figura del influencer en las campañas publicitarias: Consecuencias para las agencias de publicidad españolas The influencer's power in strategic brand decisions: Consequences for Spanish advertising agencies}

Paloma Sanz-Marcos

Universidad de Sevilla

Gloria Jiménez-Marín Universidad de Sevilla

Rodrigo Elías Zambrano Universidad de Sevilla

\section{Referencia de este artículo}

Sanz-Marcos, Paloma; Jiménez-Marín, Gloria y Elías Zambrano, Rodrigo (2019). La incorporación de la figura del influencer en las campañas publicitarias: Consecuencias para las agencias de publicidad españolas. adComunica. Revista Científica de Estrategias, Tendencias e Innovación en Comunicación, (18), 63-86. DOI: http:// dx.doi.org/10.6035/2174-0992.2019.18.5

\section{Palabras clave}

Agencia de publicidad; Influencers; Digital; Estrategia; Profesión; Anunciante

\section{Key words}

Advertising agency; Influencers; Digital; Strategy; Occupation, Advertiser

\section{Resumen}

Las agencias publicitarias se ven afectadas por la necesidad de adaptarse a un fenómeno comercial que se encuentra presente en gran parte de las acciones de comunicación llevadas a cabo en redes sociales digitales de las grandes marcas, esto es, el 
influencer. Este perfil se presenta como un nuevo líder de opinión muy interesante para las marcas las cuales aprovechan el liderazgo de estas microcelebrities para atraer a nuevos consumidores. A través de veintiuna entrevistas en profundidad a agencias españolas y un panel Delphi de quince expertos, se constata un dominio complejo de las fuerzas entre anunciante y agencia. La repercusión mediática que tienen estas personalidades provoca que el anunciante posea un mayor control sobre las decisiones estratégicas resultando a su vez en un desafío estratégico para el profesional publicitario que ve afectadas las estructuras de las agencias, así como un aumento en la demanda de este tipo de estrategias.

\begin{abstract}
The advertising agencies are affected by the need to adapt to a commercial phenomenon that is present in a large part of the communication actions in digital social networks of major brands; the influencer. This profile is presented as a new opinion leader very interesting for brands which take advantage of the leadership of these microcelebrities to attract new consumers. Through twenty-one in-depth interviews with Spanish agencies and a Delphi panel of fifteen experts, a complex domain of forces between advertiser and agency can be found. The media impact of these personalities causes the advertiser to have greater control over strategic decisions, resulting in a strategic challenge for the advertising professionals that affects the structures of the agencies, as well as an increase in the demand of this type of strategies.
\end{abstract}

\title{
Autores
}

Paloma Sanz-Marcos [palomasanz@us.es] es Profesora del departamento de Comunicación audiovisual y Publicidad de la Universidad de Sevilla. Doctora en Comunicación (mención internacional por la UC Berkeley) y licenciada en Publicidad y Relaciones Públicas. Miembro del grupo de investigación IDECO, trabaja sobre branding y el comportamiento del consumidor. Ha trabajo en proyectos de investigación en universidades como UC Berkeley o la Pontificia Universidad Católica de Chile.

Gloria Jiménez-Marín [gloria_jimenez@us.es] es Doctora por la Universidad de Sevilla y Profesora en el área de Publicidad y RR.PP. en la Facultad de Comunicación de la misma universidad es Licenciada en Periodismo y Licenciada en Publicidad y RR.PP. Colabora, además, con la Universitat Oberta de Catalunya y es Máster en diseño publicitario. Su actividad investigadora se centra en el estudio de la comunicación publicitaria.

Rodrigo Elías Zambrano [rodrigoelias@us.es] es Licenciado en Comunicación AV, Máster en Gestión de Empresas AV y Experto en E-Learning por US, y Máster Oficial en Comunicación y Educación AV por la Universidad de Huelva, es Doctor por Universidad de Sevilla. Ha publicado diversos artículos relacionados con las estrategias de comunicación, la publicidad comercial y la comunicación audiovisual y su relación con la educación. Es miembro del Grupo de investigación SEJ420. 


\section{Introducción}

El entorno digital unido la llegada e instalación de las redes sociales han transfigurado la perspectiva del marketing y la comunicación influyendo tanto al ámbito comercial como a aspectos culturales. Esto mismo ya lo plantean autores como Pérez-Curiel y Sanz-Marcos (2019) o Jiménez-Marín, Elías Zambrano, Bellido Pérez y Sanz-Marcos (2019). En este sentido, internet ha logrado alcanzar la a priori utopía de «aldea global» que a finales del siglo XX planteaba McLuhan (1995). Así, el ecosistema digital en el que nos venimos desarrollando ha traído consigo un cambio radical donde ahora las redes sociales se presentan como herramientas de comunicación que apoyan al usuario y estimulan ciertas decisiones de compra (Kim y Ko, 2010).

En este panorama, el denominado Social Media Marketing ${ }^{1}$ puede definirse como una herramienta donde se utilizan las plataformas web de redes sociales como forma de hacer marketing y cuyo objetivo es crear contenido para que los usuarios lo compartan con su entorno social promoviendo la notoriedad de las marcas (Rouse, 2011).

Los consumidores son sujetos «cada vez más exigentes e informados», tal y como afirman Clavijo-Ferreira, Pérez-Curiel y Luque-Ortiz (2017). Se trata un cliente que «cada vez está más educado en publicidad» (López-Font, 2005: 114). Esto se debe, entre otras cuestiones, a la revolución digital en la que vivimos, que trae como consecuencia que estos mismos consumidores pasan a ser controladores de los mensajes empresariales. Y es ahí donde las empresas conciben estrategias (y tácticas) empresariales y de marketing global a través de redes sociales, tales como Instagram, Facebook o Twitter. El objetivo: Promover tráfico de la web y atraer a más usuarios.

El éxito máximo del marketing en redes sociales se consigue cuando las empresas crean cierto contenido (informativo, publicitario) y consiguen: 1) atraer a una audiencia determinada y 2) que esta audiencia lo comparta en sus redes ${ }^{2}$. El proceso de compartir con otros, el llamado boca-oído electrónico, se denomina eWoM.

El eWoM, Electronic Word of Mouth, consiste en explotar las redes sociales preexistentes para producir incrementos exponenciales en conocimiento de marca, denominada marketing viral. Supone compartir experiencias positivas o negativas (también neutrales), de consumidores o compradores acerca de un producto, un servicio, una marca o una empresa; ello se pone a disposición de una gran cantidad de personas e instituciones a través de Internet (Hennig-Thurau, Walsh y Walsh, 2004). Con esto se consigue una mayor audiencia y, por tanto, se obtienen mayores posibilidades de comunicación a través de internet. El eWoM es capaz de influir en cualquier decisión de compra, tal y como ya afirmase Dellarocas (2003). Las aplicaciones de SMM han sido un medio de comunicación para eWoM en el que los clientes expresan sus opiniones y pensamientos sobre productos y empresas. De

\footnotetext{
1 En adelante, SMM.

2 En adelante, SM
} 
este modo, el uso de redes sociales como herramienta de marketing ha aumentado de manera exponencial en los últimos años. De hecho, según una encuesta realizada por la consultora McKinsey \& Company, dos terceras partes de las grandes empresas multinacionales ya usan redes sociales $\mathrm{u}$ otras herramientas de la web 2.0 en su estrategia global de marketing.

Es aquí donde surge la figura del influencer.

\section{Objetivos}

El presente estudio parte de la base del cambio que vienen sufriendo las agencias en los últimos años debido a diversos factores externos como son la propia evolución de los mercados, el constante aprendizaje de los potenciales compradores, consumidores, usuarios y receptores, así como el papel de las nuevas tecnologías. En esta línea, Segarra-Saavedra e Hidalgo-Marí (2018: 323) ya planteaban que nos encontramos «en un proceso de cambio que modifica la planificación publicitaria y posibilita nuevas formas de contacto entre las marcas y sus públicos a través de la intermediación e influencia de personas en principio no interesadas en la industria publicitaria, y que invita, a su vez, a una investigación completa del fenómeno».

En este sentido, y tomando como punto de partida las afirmaciones de Mullaney (2012), quien ya planteaba que dos terceras partes de las grandes empresas multinacionales usan redes sociales u otras herramientas de la web 2.0 en su estrategia global de marketing, se propone como objetivo principal:

- Examinar los cambios que se han producido en las agencias con la introducción de influencers en sus estrategias publicitarias.

De este modo, se pretende conocer si la llegada de esta figura ha afectado de un modo general al trabajo de creación desarrollado por las agencias. Este objetivo se complementa con la concreción de los siguientes:

- Identificar si existe un incremento destacable en la aplicación del influencer en las campañas publicitarias y, en ese caso, examinar cómo su implementación afecta en el trabajo creativo y estratégico de los profesionales de las agencias.

- Analizar y valorar el poder de decisión estratégica que ejercen los planners de las agencias de publicidad en las campañas diseñadas para los influencers y en su caso, determinar si existe una tendencia hacia la pérdida de poder.

- Ofrecer una visión de la evolución del negocio publicitario a través del rol del influencer como paradigma estratégico de las nuevas acciones publicitarias.

El desarrollo de la investigación se basa en el análisis de los datos obtenidos de las agencias de publicidad: McCANN, Havas Media, Sra. Rushmore, Wunderman Thompson, TBWA, DDB, Ogilvy, Contrapunto, Young \& Rubicam, Comunica+A, 
Publicis, Grey, Leo Burnett, Lola Mullenlowen, Social Noise, Jumpers, Inn, Avantine, Good Company, Singular One, y La Caseta de Juan León.

El criterio de elección de las agencias responde al ranking elaborado por Infoadex (2017) que analiza la inversión publicitaria gestionada por las agencias. Asimismo, se han incluido varias agencias locales atendiendo a un criterio de proximidad y acceso.

\section{Metodología de la investigación}

Con objeto de entender cómo afecta la proyección de los/las influencers en el panorama publicitario actual, se ha elegido un enfoque metodológico de triangulación para analizar el papel actual de las/os influencers (celebrities o microcelebrities) como soporte publicitario y su relación con el desarrollo de una campaña. En este sentido, se ha empleado una metodología puramente cualitativa basada en el desarrollo de, en primer lugar, un profundo análisis bibliográfico con objeto de revisar la literatura existente; en segundo lugar, la realización de 21 entrevistas en profundidad a profesionales publicitarios la cual se ha completado con, una tercera fase, consistente en el desarrollo de un método Delphi con expertos del sector.

El análisis bibliográfico permitió obtener un marco teórico y conceptual adecuado para realizar una aproximación epistemológica al proceso de la investigación científica en el contexto de los conceptos influencer y agencia publicitaria. Supone la primera fase, la exploratoria, de esta metodología triangulada, cuyo objetivo es documentar la realidad que se analiza y planificar el encuadre más adecuado para realizar la investigación. De este modo, se revisa toda la documentación existente, pertinente y disponible sobre los conceptos en cuestión. Con ello se busca la profundización y familiarización con la realidad para realizar una aproximación acertada y eficaz.

Para la entrevista en profundidad se han seguido las indicaciones de Gaitán y Piñuel, y se realiza una entrevista pautada pero abierta, semiestructurada, es decir, «basada en preguntas que organizan la interacción, aunque en el curso de la entrevista pueden añadirse otras, incluso eliminarse algunas. Es una guía abierta de preguntas, de respuesta libre y de preguntas no absolutamente predeterminadas, aunque con guion preestablecido» (1998: 95). Esta técnica resulta adecuada ya que permite analizar la emisión en el objeto de estudio que nos ocupa debido a que el contacto directo con la fuente emisora permite obtener la información que subyace en los discursos estructurados resaltando opiniones, sentimientos, situaciones y perspectivas personales (Taylor, Bogdan y DeVault, 2015). En este sentido, otras técnicas como los cuestionarios de respuesta cerrada no aportan dichas ventajas dado que su objetivo principal es la obtención de datos cuantitativos. En este caso, consideramos que el empleo de esta técnica es adecuado para el registro de datos por parte de los profesionales publicitarios en tanto a que contribuye a la obtención de valiosas opiniones y evaluaciones personales que ofrecerán un punto de partida para tratar de resolver las preguntas de investigación planteadas. Asimismo, esta 
técnica permite obtener resultados más allá de un nivel factual, es decir, permite alcanzar un grado de profundidad en lo referido al nivel de significados (Kvale, 2011).

Partimos de las siguientes preguntas básicas:

- ¿Es común encontrar a clientes que soliciten expresamente realizar campañas publicitarias con influencers?

- ¿Dirías que ha habido un mayor número de implementación de este tipo de estrategias?

- ¿Cómo es el proceso de decisión a la hora de escoger a un determinado influencer? ¿Dirías que lo elige la agencia, o normalmente lo propone el anunciante?

- ¿Solicitan a celebrities concretas?

- ¿En algún caso se crean influencers para una campaña?

- ¿Encuentras que en este tipo de estrategias con influencers el anunciante suele tener más claro lo que quiere? ¿En qué medida se deja aconsejar por la agencia?

- ¿Crees que tu labor en la agencia se ha visto afectada por este tipo de estrategias?

- ¿Es común detectar la necesidad de emplear acciones con influencers en las estrategias publicitarias que requieren los anunciantes?

- ¿Crees que las acciones con influencers tienden a relegar a un segundo plano las decisiones estratégicas elaboradas o propuestas por la agencia?

Las cuestiones planteadas responden a la consecución de los objetivos propuestos en tanto a que, por un lado, recogen el análisis y valoración de la transformación de los profesionales de las agencias de publicidad, y, por otro, consideran el papel del influencer y su posible importancia en las campañas planteadas por el anunciante. Para la selección de los entrevistados se aplicó la técnica del muestreo no probabilístico por conveniencia. Se buscaron expertos con una experiencia consolidada en el trabajo de agencia, concretamente, en los perfiles de planner estratégico y cuentas para analizar en detalle el proceso de evolución en las decisiones estratégicas de las campañas publicitarias. Las entrevistas se realizaron durante los meses de marzo y abril de 2019 con la intención de obtener resultados de actualidad. Con objeto de preservar el anonimato y, a petición de los entrevistados, se ha protegido el nombre de todos los participantes.

Se ha creído conveniente hacer uso de la técnica del método Delphi debido a que, como señalan Gaitán y Piñuel (1998: 140): «Como técnica exploratoria puede utilizarse para desarrollar una construcción teórica relativa a un área de estudio o para realizar una aproximación aplicada al diseño definitivo de una investigación». Del mismo modo, y dado que el objetivo es la consecución de un consenso basado en la 
discusión entre expertos, siendo un proceso repetitivo, su funcionamiento se basa en la elaboración de un cuestionario que ha sido contestado por los expertos en varias ocasiones. Esto es: una vez recibida la información original, se ha vuelto a realizar otro cuestionario basado en el anterior para ser contestado de nuevo. Y de acuerdo a Landeta (1999) ha sido un proceso iterativo, que exponemos de forma anónima, con un feedback (o retroalimentación controlada) y con respuesta estadística de grupo.

La muestra quedó compuesta por un panel de 15 expertos. Al igual que en el caso de las entrevistas, su desarrollo tuvo lugar entre los meses de marzo y abril de 2019 .

\section{Marco teórico}

\subsection{La agencia de publicidad}

Las agencias de publicidad tienen un alto impacto económico en el sector general de la publicidad siendo uno de sus principales objetivos añadir valor a los bienes y servicios anunciados por parte de un cliente (Ferrer y Medina, 2014). Entre las funciones tradicionales que han venido realizando estas agencias, destacan la creación, producción, programación y control de campañas de publicidad (Soler, 2008; Kauffman-Argueta, 2014). No obstante, la ya consolidada digitalización de los medios viene provocando un cambio en la coordinación y control de los servicios hacia el cliente conduciendo a las agencias a «reflexionar sobre la efectividad de las campañas en medios de comunicación de masas» (Soler, 2008: 24) y abriendo camino a otras estrategias enfocadas hacia públicos más segmentados mediante medios especializados (López-Font, 2005; López-Vidales, 2005).

Lo cierto es que la agencia de publicidad es una entidad en evolución constante. Si bien, tradicionalmente se ha venido desarrollando en torno a formatos clásicos como el anuncio televisivo, la cuña radiofónica, el faldón o la valla publicitaria (Del Pino, 2007), en la actualidad el medio digital ha forzado una reinvención de los formatos publicitarios en el que la interacción con el con potencial consumidor es fundamental para el éxito comercial (González-Oñate, 2019). Siguiendo a Papí-Gálvez: «La estrategia se orienta hacia el público y no a la selección de medios y soportes concretos» (2014: 42).

Las exigencias de este entorno plantean importantes retos tanto a nivel estratégico como a nivel organizativo para este tipo de empresas (López-Font, 2005). El desarrollo de internet como medio de comunicación no solo ha favorecido que este se haya «consolidado como soporte publicitario en el mercado español, tanto en agencias creativas y de medios, donde forma parte del core business y se han creado unidades ad hoc [...]» (Castelló, 2013: 13) sino que, además, han aparecido nuevos profesionales especializados para hacer frente a las nuevas demandas (Fanjul-Peyró, González-Oñate y Arranz-Peña, 2018).

Asimismo, cuestiones como la posibilidad de medición de engagement con el usuario (Roca, 2015), la medición del impacto que facilitan las campañas digitales o 
el protagonismo del creciente contenido generado por los consumidores para las marcas (Del Pino, 2007), originan una relación cliente-agencia muy enfocada a la efectividad en torno a los resultados (Castelló, 2013). Esta destacada necesidad de obtener resultados positivos financieros por parte de los anunciantes obliga a los profesionales de las agencias publicitarias, a «innovar o morir en medio de un entorno sumamente cambiante» (Fernández Barros, 2014: 2).

Si bien es cierto que estas cuestiones vienen siendo parte de la lógica clásica del negocio publicitario (Flandin, Martin y Simkin, 1992), hay que añadir que la democratización del medio online ha generado una pérdida de valor y confianza en torno a creativos y planners que ven cuestionadas sus decisiones por parte del anunciante debido al fácil acceso a los medios digitales. Actualmente, crear y monitorizar campañas publicitarias en plataformas digitales como redes sociales es una práctica relativamente sencilla que no requiere de una especialización compleja. Esta perspectiva plantea que argumentos tradicionales como el presupuesto o el tiempo dejen de ser los únicos elementos que efectúen cierto control sobre la creatividad y la capacidad estratégica del profesional de la agencia (Hirschman, 1989). Hoy día existe una creciente dinámica que prioriza la visión estratégica propuesta por el anunciante, basada en la cotidianidad del medio, que amortigua la experiencia del experto publicitario y su valor como asesor estratégico (Del Río, 2007). En este sentido, la popularidad de los influencers propone un enfoque desafiante para las agencias publicitarias que encuentran un contexto en el que la interacción con el consumidor es clave para apoyar la marca además de para prescribirla a otros usuarios en las redes (Castelló-Martínez y Del Pino, 2015; Díaz, 2017). Un paradigma que plantea un cambio cultural que se integra en la vida de los consumidores y que tiene importantes consecuencias en la transformación del ecosistema mediático (Perlado-Lamo-de-Espinosa, Papí-Gálvez y Bergáz-Portolés, 2019).

\subsection{Los influencers en el panorama actual de la publicidad}

Murphy y Schran (2014) ya dejaban constancia del cambio de ciclo que estaba afectando a la publicidad, un hecho que, tal y como expresan Segarra-Saavedra e Hidalgo-Marí (2018), se agudizó a partir de la aparición de las redes sociales. Con ellas, la comunicación publicitaria se revolucionó para dar lugar a nuevas técnicas, ahora basadas en el social media.

Entre las distintas técnicas de SMM una de las más utilizadas por parte de las empresas comerciales es la contratación de una celebrity que haga las veces de influencer. Así, como indican Segarra-Saavedra e Hidalgo-Marí (2018: 315) «con la democratización de la información y la comunicación, este liderazgo de opinión ha ampliado su alcance de forma que personas en principio desconocidas que dieron el salto primero al blog y más tarde a las redes sociales se han convertido en nuevos prescriptores». De este modo, la aparición en la escena del marketing de estos nuevos prescriptores implica tanto la democratización del liderazgo de opinión 
como el replanteamiento de los tradicionales planes de marketing y comunicación (Monserrat-Gauchi y Sabater-Quinto, 2017).

Según el diario The Telegraph (2014), el top ten más popular tiene lugar en la red Instagram y lo componen personas que, además, son celebrities y que tienen aproximadamente unos 30 millones de seguidores a nivel mundial. Por tanto, cada vez que se asocia a una de estas figuras con una marca, se llega a un público objetivo de 30 millones de personas. Así, esta planificación de medios sociales es especialmente rentable debido a la influencia que genera. La importancia de estos influencers ha sido considerada por algunos autores como una nueva rama del marketing (Díaz, 2017), haciendo referencia a aquellas personas influyentes en las redes sociales que tienen la capacidad de dar forma a las actitudes de la audiencia a través de numerosas redes sociales (Freberg et al., 2011). En esta línea, el poder de los influencers reside en un alejamiento del modelo tradicional de marketing por el que la información es presentada de una manera objetiva e imparcial. Por el contrario, el modelo comunicativo que demuestran los influencers, se basa en su presentación como personas corrientes, cuyas valoraciones y opiniones despiertan la confianza entre los consumidores (Díaz, 2017), una influencia que reside en el reconocimiento que le otorga su liderazgo y una actividad digital que supera a la de la propia marca (Sábada y San Miguel, 2014).

Es interesante resaltar y tener en cuenta que un $84 \%$ de las marcas realizan campañas que implican a influencers, $y$ que el $81 \%$ de los profesionales considera que las relaciones con influencers son eficaces o muy eficaces (Augure, 2017). De este modo, parece que esta disciplina ya está más que implantada dentro del abanico de tácticas utilizadas por la comunicación y el marketing. Es más, Pino-Romero y Castelló-Martínez demostraron en un estudio realizado en 2017 que existen fuertes vínculos entre las marcas y los influencers, las estrategias publicitarias transmedia y el uso de acciones de marketing experiencial, branded content y SMM.

Otra técnica de marketing muy rentable y eficaz es la de mostrar a clientes reales en los 'stories'. Según Davoult (2014), cuando los clientes ven fotos de otras personas normales y similares que utilizan un producto, son más propensos a comprarlos. Esta opción supone una herramienta muy efectiva, pues se gana confianza al ver a personas cercanas y parecidas usando los productos que están a punto de usar o comprar. En este sentido también se pronuncia Polanski (2012) cuando afirma que los testimonios de clientes satisfechos muestran que las personas similares al público objetivo han disfrutado de su producto o servicio y, por tanto, es más probable que se conviertan en clientes. Siguiendo, pues, a Pérez-Curiel y Sanz-Marcos (2019), estos personajes influyentes suponen una revolución comercial que afecta a diversos sectores ya que son capaces de generar contenidos de interés para un público definido y muy segmentado por aficiones o estilos de vida. Así, Sáez-Barnet y Gallardo-Camacho (2017) plantean datos concretos sobre el poder de los influencers. De su estudio se desprende que el $61,8 \%$ de los encuestados declara haber conocido nuevas marcas tras visionarlas en YouTube (aunque, por el contrario, también el mismo porcentaje de personas revela que no consume ciertas marcas por haber sido aconsejadas por los youtubers). 
Aquí es interesante destacar una situación intermedia. Y es que desde 2005 viene desarrollándose, de manera paralela en varios países, el hecho de que muchos jóvenes han comenzado a utilizar los medios de comunicación social para crear personajes 'microcelebrities' como una carrera profesional. Senft (2008: 25) define la 'microcelebridad' como «un nuevo estilo de rendimiento online que implica que las personas aumentan su popularidad en la web utilizando tecnologías como vídeo, blogs y sitios de redes sociales». A diferencia de las celebrities de la industria del entretenimiento, que pueden convertirse en iconos públicos con seguidores a gran escala, la microcelebrity es «a state of being famous to a niche group of people» (Marwick, 2015: 114). Abidin (2016) resalta el incremento de la influencia social generada por estas microcelebridades, usando fundamentalmente los blogs y las redes sociales como canales de comunicación para dar a conocer su vida personal $\mathrm{y}$, de este modo, hacer las veces de prescriptores o vendedores.

\section{Resultados}

La revisión bibliográfica da muestra de la relación existente entre la figura del influencer y/o celebrity (o microcelebrity) y la planificación estratégica de la campaña. Autores/as como Abidin (2016), Monserrat-Gauchi y Sabater-Quinto (2017), Pino-Romero y Castelló-Martínez (2017), Sáez-Barnet y Gallardo-Camacho (2017), Segarra-Saavedra e Hidalgo-Marí (2018) o Pérez-Curiel y Sanz-Marcos (2019) muestran las relaciones e interrelaciones en dichas disciplinas.

No obstante, una vez planteado ese marco base, las técnicas con muestra aportan datos especialmente relevantes. En relación a las entrevistas en profundidad, las conversaciones mantenidas, de manera abierta (aunque guiada) con las distintas agencias españolas arrojan opiniones concluyentes con validez científica en tanto a metodología cualitativa. Si bien han destacado posturas diferentes en cuanto a las cuestiones conceptuales o estéticas, existe cierto consenso, de manera abierta, en elementos clave de la concepción de una campaña publicitaria.

De este modo, en relación a las entrevistas en profundidad, los resultados se estructuran siguiendo las siguientes categorías organizadas por bloques:

- Sobre la figura del influencer, de manera genérica (Bloque FI)

- Sobre la intencionalidad del anunciante (Bloque IA).

- Sobre la función de la agencia en relación a la estrategia con influencers (Bloque EI).

Esta organización de los datos recogidos, en relación a los temas por bloques a tratar, permite agrupar y confrontar las opiniones de los diferentes entrevistados sobre los mismos elementos de estudio así como identificar los hallazgos encontrados en relación a los objetivos propuestos. 


\section{Bloque FI:}

En cuanto a la cuestión capital de la investigación en torno a la figura del influencer, de manera unánime, los entrevistados afirman haber observado un incremento de la presencia del influencer en el diseño de las campañas publicitarias para las que trabajaban. Entre los principales motivos, estos profesionales señalaban que estos perfiles son muy interesantes para el diseño estratégico de las acciones publicitarias debido al cambio generacional y al incremento en el uso de las redes sociales por parte de los consumidores que, de manera generalizada, se observaba entre los entrevistados como un paradigma comunicacional sin precedentes. En este sentido, se destacaron algunas cuestiones como la reciente aparición de «agencias que se especializan en este tipo de servicio» (profesional agencia número 2) o la creciente preocupación por el interés y conocimiento del funcionamiento y negociación con este tipo de perfiles por parte de los propios profesionales de las agencias.

Ampliando estas afirmaciones, los participantes reflexionaron en torno a la posibilidad de la creación de microcelebrities en campañas concretas. En este caso, los expertos muestran posiciones diferenciadas como se observa en el gráfico 1. Por un lado, la tendencia generalizada, esto es, doce de las veintiuna agencias entrevistadas, afirmaban que se trataba de una práctica «muy habitual» (profesional agencia 10).

Gráfico 1. Resultados de las entrevistas en profundidad relativas al Bloque FI

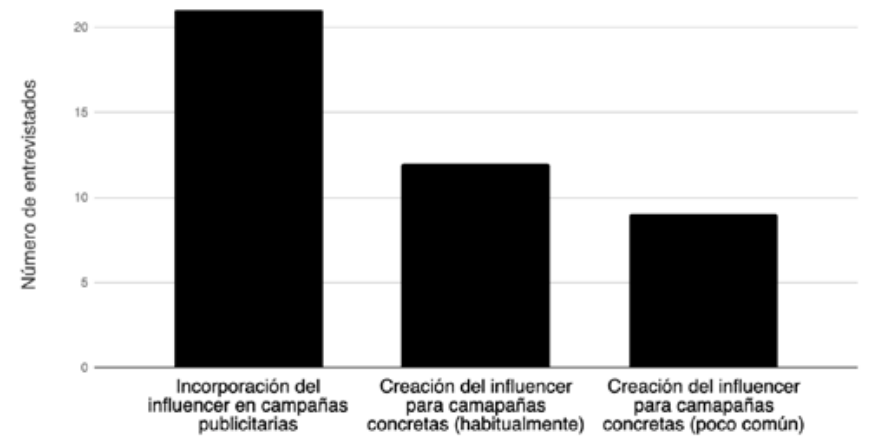

Elaboración propia (2019)

El desarrollo de personajes concretos para determinadas marcas, aumenta según los entrevistados, la probabilidad de éxito en las campañas. La posibilidad de crear un perfil personalizado para una acción concreta, supone un beneficio en términos de eficacia de la campaña, algo que según aseguraba el entrevistado número 4, se 
vincula con una consideración y valoración positiva de los profesionales de la agencia. De hecho, las apreciaciones de los responsables de las agencias número 7 y número 21, complementan estas percepciones en tanto a que aseguraban que se trataba de una solución para aquellos clientes con un menor presupuesto, reflejando así la posibilidad de asociar este perfil con una ventaja de carácter económico y por tanto, percepción de optimización de los recursos del cliente. Por otro lado, las nueve agencias restantes coincidieron en que la creación de estos perfiles resultaba una práctica poco común entre las agencias siendo, en algunos casos, una cuestión cuya responsabilidad recaía sobre el anunciante. Así lo expresaba el entrevistado de la agencia número 3 cuando señalaba que «desde el punto de vista de agencia [...] no, en caso de hacerse lo haría el cliente». Asimismo, la apreciación del entrevistado de la agencia número 5 revelaba que, a pesar de que «no se crean [...], a veces se buscan perfiles incipientes que crezcan con la marca», reflejando un leve interés por apoyar la creación y diseño de estos microcelebrities. Estas últimas perspectivas sugieren que las agencias entrevistadas manifiestan un nivel de competencia aun por desarrollar en la ejecución de estas funciones concretas.

\section{Bloque IA:}

Sobre la cuestión de la intencionalidad del anunciante, los profesionales expresaban que era bastante frecuente encontrar como mandatory del briefing de la campaña la incorporación de un influencer. Como se indica en el gráfico 2, esta cuestión ha dado lugar a una mayoría de posiciones cercanas a la idea de que esta figura es cada vez más demanda por el anunciante, el cual suele subordinar el éxito de la campaña a la implementación de las estrategias con influcencers.

Gráfico 2. Resultados de las entrevistas en profundidad relativas al Bloque IA

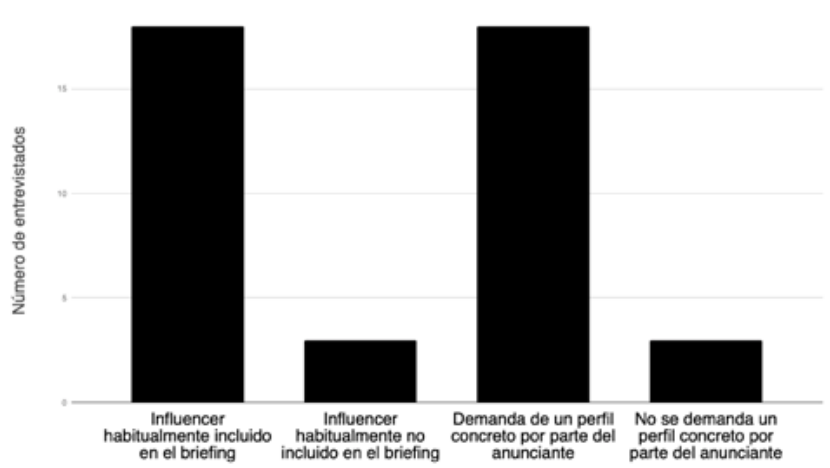

Elaboración propia (2019) 
Concretamente, el entrevistado de la agencia número 11 señalaba que un posible motivo de este creciente interés por parte del cliente, podría deberse a que el influencer "se ha convertido en un canal» planteando que dichos perfiles podrían estar siendo responsables de una fuerte revolución mediática. Es preciso destacar que las respuestas a estas apreciaciones han desvelado cierta resistencia con respecto al anunciante. La novedad de esta figura y su actual protagonismo en los medios parece provocar según estos entrevistados un auge arbitrario, y en muchas ocasiones injustificado, que antepone las recomendaciones de los profesionales de las agencias. No obstante, las agencias número 4, número 7 y número 8, negaban encontrar clientes que solicitaran tales servicios respondiendo a una cuestión de responsabilidad y coherencia con respecto a la estrategia. En palabras del entrevistado de la agencia número 4: «No, común no es. Nosotros lo proponemos en el plan de acciones si ayuda a conseguir los objetivos marcados». Esta apreciación se relaciona estrechamente con otras cuestiones como la de identificar el responsable de la decisión de incluir al influencer en el diseño de las campañas. La mayoría de los profesionales destacaban que la agencia, y no el anunciante, era la máxima responsable de incluir al influencer en la estrategia publicitaria. Así, el responsable de la agencia número 2 , señalaba que «lo elegimos desde la agencia en función a los KPIs que quiere cubrir el cliente y en función a la similitud del influencer con los valores del cliente» asumiendo que se trataba de una decisión que dependía de variables muy concretas y especializadas, en términos estratégicos, que son difícilmente identificables por el cliente. A este parecer, algunos profesionales destacaban que la agencia se encargaba de estudiar un «perfil, afinidad con la marca, y adecuación del target de seguidores al target de la marca» (profesional agencia 5). Una de las apreciaciones más destacables en esta línea es la del entrevistado de la agencia número 8, quien expresaba con vehemencia que «lo tiene que elegir la agencia. Para eso está. Porque primero evalúa si es el canal correcto para hablar de un producto o una marca, y luego estudia qué perfil es relevante para hablar de ello», subrayando así la idea de que se trata de una decisión que requiere de la intervención de un experto en la materia. Si bien es cierto que esta ha sido la tendencia generalizada en un total de doce agencias, los resultados muestran que ocho de los participantes contemplaban posiciones intermedias cuando señalaban que esta cuestión dependía del objetivo de la campaña y del tipo de cliente. Así, el entrevistado perteneciente a la agencia número 6 , representa claramente las apreciaciones de esta perspectiva cuando revelaba que dependía del «briefing que se le establezca», destacando que, concretamente, el presupuesto suponía un factor muy condicionante. Asimismo, es preciso añadir que este enfoque ha contado con un grupo de afirmaciones que proponían que la agencia asesoraría al cliente a través de un listado de influencers a partir del cual el anunciante elegiría. De este modo, se observa la posibilidad de un trabajo «conjunto» entre ambas partes como aseguraba el entrevistado de la agencia número 1. A pesar de esta mayoría, uno de los entrevistados afirmaba con rotundidad que: «Lo propone el anunciante», es el caso de la agencia número 1. Con todo, se subraya que las respuestas que han presentado mayor determina- 
ción, rotundidad y seguridad ante la supremacía del profesional de la agencia con respecto al anunciante en la decisión estratégica de estas cuestiones, han sido representadas por las agencias con mayor volumen de negocio.

En cuanto a la solicitud de perfiles concretos de influencers, se observa que, si bien la mayoría de los participantes, dieciocho agencias, suelen trabajar con clientes que parecen tener claro el tipo de perfil concreto que buscan, los entrevistados afirmaban que en algunas ocasiones el anunciante no demandaba un nombre concreto, pero sí un tipo de «estilo» o «perfil» determinado. Es el caso del profesional de la agencia número 6 quien expresaba que «[...] un estilo sí pero alguien en concreto no» o el de la agencia número 20 quien señalaba que: «Solicitan perfiles concretos pero no nombres, por lo general». Con todo, tres de las veintiuna agencias aseguraba que dependía de la «ocasión» (agencia número 15), «el cliente» (agencia número 7) o el «público que quieras alcanzar» (agencia número 8). Estas ideas vienen a reforzar la idea de que el cliente parece tomar parte activa en el proceso de campañas con influencers según qué tipo de agencia.

\section{Bloque EI:}

En cuanto al papel de la agencia y sus funciones en relación a la estrategia con influencers, existe una polarización equilibrada en las opiniones con respecto a la labor de sus profesionales. La implementación de estos perfiles sugiere para once de los entrevistados un cambio en sus labores diarias en la agencia. Para el participante responsable de la agencia número 21 , los cambios se relacionan con cuestiones de evaluación de los resultados: «Sí, es fundamental a día de hoy [...] es fundamental para tener unas buenas estadísticas en redes», algo que el experto de la agencia número 5 completaba con la siguiente: «Sin duda, ahora más que nunca hay que pensar como los influencers pueden ayudar a empujar nuestra campaña». Otro de los individuos manifestaba que su trabajo se veía afectado «en el sentido de que ahora es otro nuevo canal donde explotar el concepto de campaña agencia», subrayando así las reflexiones anteriores en torno a la consideración del influcencer como un nuevo canal.

Sin embargo, una cifra muy similar, diez de los entrevistados, aseguraban no verse afectados por estas estrategias. En este sentido la mayoría de respuestas en esta línea contemplaban que las estrategias con estos perfiles son «como cualquier otra, y que se tiene que incorporar a la propuesta si tiene sentido» (profesional agencia número 17). Contrastando con lo anterior, estas afirmaciones se amplifican con las opiniones acerca de la posible pérdida de poder en las capacidades de decisión estratégicas de la agencia. Tan sólo tres de los entrevistados manifestaba que sus decisiones estratégicas se veían negativamente afectadas cuando se ponían en práctica acciones con influencers. En el caso de la agencia número 14, su responsable afirmaba que se debía a que «hay anunciantes que miden la inversión a realizar por lo que podrían conseguir de influencers con ese mismo presupuesto». El participante de la agencia número 6 respondía que: «sí, y desde nuestra experiencia la mayoría de las veces no consiguen los resultados esperados, cuando por la misma inver- 
sión tendrían una repercusión en medios digitales infinitamente mayor». De esta manera, los profesionales añaden que esta situación puede comprometer el éxito de la campaña, ya sea por cuestiones de presupuesto, o repercusión. El resto de opiniones parte de que el trabajo de los profesionales de la agencia no se encuentra relegado a un segundo plano debido a, fundamentalmente, cuestiones como la experiencia y la capacidad en el desarrollo de estrategias. Así el participante de la agencia número 3 mantenía que es imposible prescindir de una «estrategia sólida» para comunicar o construir una marca siendo ésta una tarea de los expertos de la agencia. Al igual que se ha observado en respuestas anteriores, huelga destacar que esta polarización coincide con el prestigio y reconocimiento social de las agencias. De este modo, parece que en el caso de las agencias con un mayor volumen de clientes, la inclusión de estos perfiles se ha previsto con mayor precisión que en el caso de las agencias locales. Se observa que las grandes agencias cuentan con mayor capacidad a la hora de replantear y planificar las funciones y responsabilidades de sus profesionales. Hecho que también se ha manifestado en el modo personal de responder a las preguntas por parte de los entrevistados. Algunos profesionales pertenecientes a las agencias de menor reconocimiento, presentaban cierto resentimiento con respecto al incremento de la carga de trabajo sufrido.

Por último, en cuanto a la necesidad de emplear acciones con influencers bajo el punto de vista de estos profesionales, si bien es cierto que las agencias número 2 y número 10 establecían que es algo que depende de la marca, un total de trece entrevistados frente a seis, indicaban que es muy común detectar la necesidad de contar con estos perfiles en sus estrategias publicitarias. Algo que viene a destacar, una vez más, la relevancia que adquieren este tipo de campañas. Partiendo de las respuestas que manifiestan la necesidad de dichas estrategias, los argumentos se relacionan, principalmente, con aspectos como la notoriedad y la efectividad de las campañas. Para el experto de la agencia número 5 los influencers «dan mucha visibilidad y credibilidad», algo que se amplía con la apreciación del experto de la agencia número 12 cuando aseguraba que «son una manera más encubierta, real, y natural [...] de llegar a la audiencia», valorando así que su aplicación genera resultados positivos. Del mismo modo lo entiende el entrevistado de la agencia número 4 quien señalaba que «en este momento una buena estrategia con influencers, en nuestra opinión, es la inversión publicitaria que te reporta un mayor ROI».

Los resultados cualitativos de la aplicación del método Delphi se presentan, del mismo modo que las entrevistas, por categorías temáticas. Algunas de estas categorías atienden a las cuestiones analizadas, y las respuestas extraídas contribuyen también a su verificación. La aportación de los expertos figura identificada entre comillas y se atribuye a un código asignado previamente a cada uno de ellos, que aparece entre paréntesis, donde la E hace alusión al término experto, seguida del número que le corresponde según el orden secuencial atribuido.

De este modo, la presentación de la visión de los expertos sobre el objeto de estudio se desarrolla de la siguiente manera: 


\section{Bloque FI:}

Sobre la cuestión de la figura del influencer, la mayor parte de los expertos entrevistados, al igual que en el caso de los profesionales de agencia, coinciden en que ha habido un claro aumento de la figura del influencer desde el propio momento de creación y concepción de la campaña. De este modo, algunas de las reflexiones planteadas apuntan en esta línea: «Claro que ha habido un aumento de influencers. Es más, es que muchas de las campañas no tienen sentido sin un influencer» (E2). O «A ver, los famosos en publicidad han existido siempre... pero con la irrupción de internet masivo en nuestras vidas, los famosos se hacen casi imprescindibles en nuestras campañas, y ahora esos famosos no son famosos. Ahora son influencers» (E8). De hecho, incluso existen agencias especializadas en gestión de influencers, tal y como afirmaba uno de los expertos (E12) quien aportaba que «incluso ahora la gestión es máxima con la creación de agencias específicas para la profesionalización de los influencers». En el caso de estos expertos, se observa con mayor profusión una consideración del influencer como una figura completamente necesaria en el desarrollo de las estrategias actuales. Los motivos se relacionan principalmente con la novedad y éxito que han demostrado estos perfiles. No obstante, se advierte que, a diferencia de los profesionales de la agencia, destaca el interés meramente social que despiertan los influencers más allá de su eficacia estratégica. De hecho, algunos de los expertos en comunicación sostienen que los influencers ya son imprescindibles en casi cualquier campaña global o nacional, no así en acciones locales y puntuales. De este modo, «es que con frecuencia nos referimos a grandes cuentas, y ahí es que es casi necesario tener un influencer. Pero, ¿y si nos referimos a una cadena local de ferretería? No hablo de Leroy Merlin o de Bricomart. Me refiero a Ferretería Pepe, que también hace sus campañitas. Ahí ya hablamos de una cuestión bien diferente» (E5).

Este hecho hoy en día está estrechamente relacionado con los hábitos de consumo de marcas y tecnología, pues «ya es muy complicado encontrar a personas sin ningún tipo de tecnología. Y los influencers llegan por las tecnologías» (E9). De este modo, y en términos generales, se puede afirmar que para la mayoría de las personas consultadas, la percepción de la relación campaña - influencer es claramente existente, debido a «la cantidad de valores, características y similitudes que tienen los influencers con las personas de a pie. O lo que las personas de a pie quieren conseguir en sus vidas» (E4).

En este sentido, y como se ha expuesto en la revisión de la literatura, llegan a crearse expresamente influencers para campañas concretas. «O incluso 'microcelebrities', que son esos influencers pasajeros que desde las agencias de publicidad creamos para productos, marcas y campañas específicas» (E15). Y no es el único experto que plantea este punto de vista, pues son varios quienes afirman expresamente que se crean estas figuras en algunas campañas (E1, E3, E4, E9, E14, E15). «Sobre todo para campañas más pequeñas o microcampañas» (E13). Pero, tal y como afirma el experto 12 (E12) «no podemos olvidarnos del presupuesto, que es determinante para esta cuestión». 


\section{Bloque IA:}

En torno a la cuestión de la intencionalidad del anunciante, uno de los expertos planner de agencia- destacaba que por su experiencia en el mundo de los medios «a veces nos encontramos con anunciantes que incluso en el briefing te plantean directamente el uso de influencers. Es más, influencers concretos. Nos han llegado a pedir a Paula Echevarría para anunciar un producto bancario. (Y, obviamente, no sucumbimos a la petición)» (E2). En este sentido, el experto 4 (E4) se manifestaba en una línea similar cuando aportaba que «cada vez más nos viene casi impuesto en el briefing que debemos usar influencers. Incluso cuando no encaja en el eje ni en el concepto que tenemos de partida" (E8). Y de manera similar se pronuncian E1, E3, E5, E7, E9, E10 y E11. En concreto, el experto 11 (E11) afirmaba que «es que a veces, no solo se nos impone, sino que viene uno concreto, por lo cual ni escogemos. No hay proceso».

Gráfico 3. Resultados del panel expertos relativas al Bloque IA

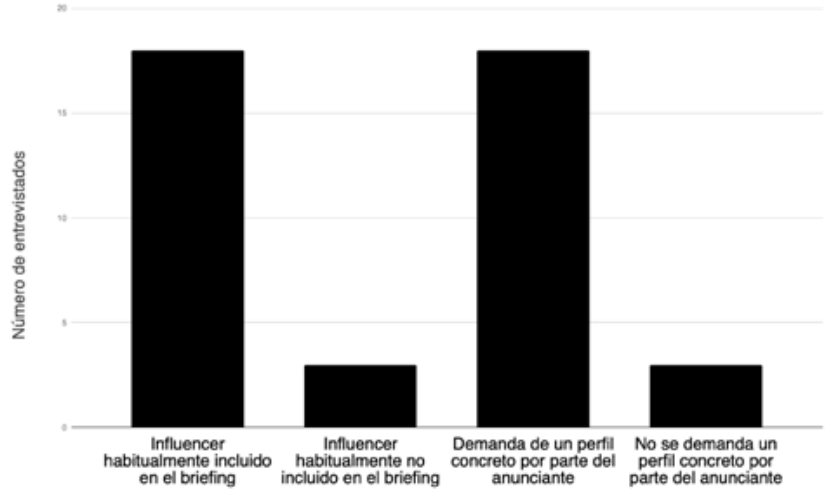

Elaboración propia (2019)

No obstante, encontramos opiniones diversas pues algunos de los expertos (E2, E3, $\mathrm{E} 4, \mathrm{E} 14, \mathrm{E} 15)$ aporta que entienden que los influencers deben venir propuestos por las agencias, mientras que otros se muestran más partidarios de que sean los propios anunciantes quienes, al menos, orienten (E1, E5, E6, E7, E10). Así, el experto 6 afirmaba que «no tengo muy claro si la figura del influencer debe venir impuesta pero sí es cierto que los anunciantes conocen casi mejor que nadie a su público, a su target, y aunque la estrategia viene de nuestra parte, de la agencia, también es cierto que tenemos que ponernos en mano y al servicio del conocimiento que tienen los anunciantes que, al fin y al cabo, llevan años vendiendo sus productos y no llevan años con la misma agencia» (E6). El experto 1 (E1) profundizaba un poco más cuan- 
do se refería a que «en algunos casos es más conveniente que sea el propio anunciante quien lo plantee... Pero siempre debe dejase aconsejar por la agencia, por el planner, y eso no siempre ocurre. Ahí a veces tenemos una lucha agencia-cliente que supone una barrera importante». Estas apreciaciones sugieren un predominio del anunciante con respecto a la agencia que, de manera generalizada, provocaba un descontento generalizado por parte de los expertos que mantenían esta visión.

Asimismo, se ha observado cierta coincidencia (E1, E2, E3, E6, E7, E8, E11) cuando estos afirmaban que, cuando existe una predisposición hacia un influencer, es difícil hacer cambiar al anunciante de opinión y «no es fácil que se dejen aconsejar» (E3). Ahí, podemos afirmar que, en línea con estos expertos, la mitad encuentran que en este tipo de estrategias con influencers el anunciante suele tener más claro lo que quiere y no suele dejarse aconsejar por la agencia. Algo que de manera generalizada se corresponde con las apreciaciones de los profesionales de las agencias publicitarias.

\section{Bloque EI:}

Sobre la función de la agencia en relación a la estrategia con influencers todos los expertos afirmaban tajantemente que su labor en la agencia se ha visto afectada por este tipo de estrategias, aunque no todos ponen el mismo énfasis en esta circunstancia. De hecho, los expertos E1, E3 y E14 se manifestaban aportando que si se trabajaba con clientes locales, les afecta poco: «Recuerdo un cliente muy local, de una farmacia que factura mucho (porque tiene tienda online y vende mucho a nivel nacional) que quería un influencer sí o sí. Y no venía propuesto en el briefing. Ni nosotros así lo planteamos. Y una vez ideada la estrategia y los cimientos de la campaña quiso que contratásemos a un influencer... Y no cuadraba. No encajaba. Y tuvimos que cambiar la estrategia por orden expresa del cliente. Claro que esta figura nos afecta. Y mucho. Yo creo que ha venido para quedarse». De este modo, se observa cierta sintonía con las perspectivas de los profesionales de las agencias entrevistados. Parece de especial importancia en todos los casos considerar la relevancia de las campañas. De esta manera, el enfoque se traslada no tanto a la pertinencia del influencer, como al alcance de la campaña.

En relación a la necesidad (o no) de emplear acciones con influencers y acudir a esta figura, todos se manifestaban en la misma línea: «En ningún caso hay necesidad de nada en publicidad. Es la función del departamento creativo construir con una base sólida que sustente una campaña con unos elementos equis... Pero esos elementos se configuran, se construyen, campaña a campaña, anunciante a anunciante y nada (y todo) es realmente necesario» (E2). De hecho, otro de los expertos mantenía lo siguiente: «¿Necesidad? No hombre, nunca hay necesidad de algo concreto. Solo es cuestión de establecer la estrategia y luego construir la campaña sobre esos cimientos» (E13). En este sentido, observamos cómo varios de los expertos consultados incluso utilizan expresiones como construir, como cimientos, o como base. Y es que todos parten de esa idea: De que nada es realmente necesario y que todo se hace ad hoc para los objetivos de campaña. 
En relación a la cuestión sobre si las acciones con influencers tienden a relegar a un segundo plano las decisiones estratégicas elaboradas o propuestas por la agencia, la mayoría se muestran en desacuerdo pues afirmaba que «la estrategia siempre es lo primero. O debería ser lo primero» (E8). También se manifestaba en esta línea el experto 3 (E3) al afirmar que «la estrategia existe por y para los objetivos de campaña y del anunciante. Todo lo demás, los medios, la planificación de soportes, la duración de la misma, los protagonistas... (todo) siempre es secundario». O el experto 10 (E10) quien exponía que «muchos influencers son el centro de todo. Pero eso no significa que las decisiones estratégicas queden en un segundo plano. Siempre han de estar en un primer plano. Siempre». A este parecer, consideramos oportuno destacar que dos de los expertos consultados hacían referencia expresa al nuevo modelo de agencia que puede surgir o que, de hecho, ya está surgiendo: «La globalización, la localización o el uso de internet y el abaratamiento de ciertos costes está ayudando, incluso a que en ciertas ocasiones la labor de la agencia quede relegada porque muchos clientes tienen sus ideas súper claras y básicamente necesitan un departamento de cliente o de tráfico que les ayude a terminar de concretar» (E6); o «Ya estamos viendo cómo están surgiendo nuevas agencias que tienen una estructura diferente a la clásica, pues ciertos anunciantes tienen su propio departamento de creatividad interno y lo que necesitan es contratar mediante outsourcing labores que se le escapan desde dentro. Saben lo que quieren, lo trabajan y solo necesitan una empresa que se lo gestione. Pero para ello no necesitan la clásica agencia de publicidad. Cambian las estructuras. Y no solo por el auge de los influencers, aunque ello afecte» (E13). Perspectiva que, en cualquier caso, pone de manifiesto la novedad que supone la implementación de estos perfiles por parte de los expertos como ya sugerían los profesionales de las agencias.

En ese sentido, es necesario destacar la afirmación generalizada de que «en una campaña publicitaria, sin estrategia, no hay consecución de objetivos», afirmación proveniente del experto 7 (E7) y que han compartido la totalidad de expertos consultados.

\section{Conclusiones}

La consolidación de las redes sociales ha supuesto una transformación del paradigma comunicativo que, de manera significativa, viene afectando a las estrategias publicitarias. La integración del influencer en las acciones comunicativas parece ofrecer resultados positivos que atraen cada vez más a los anunciantes, que identifican a estos perfiles con el éxito, aunque, de facto, no siempre sea así. En efecto, y tal y como se proponía en los objetivos de esta investigación, se ha evidenciado un destacable incremento del diseño de campañas publicitarias que integran la figura del influencer como protagonista. Esto se debe no solo a las exigencias del cliente, sino, además, a la potencialidad de esta herramienta, tal y como ha sido reconocido por los profesionales de las agencias de publicidad y los expertos consultados. Lo cierto es que tanto para anunciantes como para expertos, estos perfiles son necesarios en muchos casos para llegar (e impactar) al público objetivo y, de este modo, 
conseguir los objetivos de campaña, algo que se ha identificado por parte de los entrevistados desde el inicio del planteamiento de las campañas. No obstante, los resultados sugieren cierta cautela a la hora de establecer generalizaciones, ya que destacan las consideraciones del alcance y relevancia de las campañas, siendo éste el principal condicionante para asegurar el éxito de campañas con estas figuras.

Destaca la importancia subrayada por parte de los expertos en contraposición a los profesionales en torno a la novedad y auge de la inclusión de influencers en las campañas publicitarias como principal motivo de éxito. Es en el caso de estos expertos donde se advierte un mayor entusiasmo y consideración de las acciones con estos perfiles debido, principalmente, a la aceptación social de los mismos. Algo que en el caso de las agencias no se contempla con tal profusión. Se observa que los entrevistados de las agencias valoran en mayor medida la importancia de la estrategia por encima de cuestiones como las tendencias del sector o los anhelos del cliente.

En cuanto al diseño de las estrategias con influencers, se ha observado un dominio complejo de las fuerzas entre anunciante y agencia. Así, la repercusión mediática que tienen estas personalidades provoca que el anunciante tenga a su alcance un mayor control sobre las decisiones estratégicas, cosa que, en vista de los resultados obtenidos, no siempre es una cuestión favorable o apetecible para las agencias. Así, el cliente parece identificar con más claridad el tipo de acción comunicativa que desea implementar, reduciendo la labor de la agencia a una actividad de consultoría. En este sentido, la labor de los profesionales de la agencia se ve afectada en cuestiones de capacidad de decisión resultando, previsiblemente, un potencial cambio de las estructuras de las agencias tradicionales o incluso el incremento de otro tipo de agencias. Estas apreciaciones se hacen muy evidentes en los casos concretos del panel de expertos y en el de las agencias de menor reconocimiento ya que sus respuestas tienden a considerar la priorización del mantenimiento de una relación positiva con el cliente. Algo que, sin duda, pone en relieve la indeseada precarización que en estos casos caracteriza al sector.

Respondiendo al objetivo específico de este trabajo en relación al análisis de las consecuencias que la implementación de las acciones con influencers han suscitado en el trabajo de las agencias, se ha advertido en las entrevistas con expertos y en el panel Delphi, la consideración del surgimiento de agencias especializadas en nuevos servicios o la reducción departamentos. Esta cuestión merece especial atención debido a que, tal y como se advertía en la literatura científica comentada, esta figura viene a representar un papel de prescripción que ha sido ampliamente reconocido, desarrollado y aplicado en campañas publicitarias tradicionales. A este respecto, es posible cuestionar la necesidad de considerar la pertinencia de crear nuevas agencias o perfiles profesionales, que bien pueden ser ejecutados por profesionales en activo y ampliamente formados. Se ofrece por tanto, un debate acerca de la urgencia con la que las nuevas tendencias se incorporan al mundo profesional. Otro de los objetivos que se planteaban apuntaba hacia la valoración del poder de la decisión estratégica que ejercen los profesionales en este tipo de campañas. En 
esta línea, se advierte que la labor de los publicitarios mantiene su carácter experto. A pesar de que el cliente parece condicionar la campaña en mayor medida que en otro tipo de propuestas y que la relevancia tanto de la campaña como de la agencia son aspectos a considerar, la opinión y consejo del estratega es altamente considerada.

Entre las cuestiones que determinan la naturaleza de estas acciones, es preciso destacar que el presupuesto condiciona de manera importante este tipo de campañas. A pesar del planteamiento de los objetivos de la campaña y de la empresa o entidad, en el caso del panel de expertos, se destacaba que es preciso ceñirse a los datos reales con los que cuenta el anunciante, y ello pasa por tener un presupuesto acorde a los planteamientos tanto de anunciante como de agencia. A tales efectos, se advierte la necesidad de adoptar una reflexión crítica en torno a la consideración de las opiniones de los expertos y su profesionalidad. Si bien es cierto que el anunciante es un activo fundamental para la agencia y una pieza clave para el desarrollo estratégico, es necesario reivindicar la capacidad en la toma de decisiones creativas por parte de los expertos publicitarios.

Con todo, esta investigación contribuye a aportar una nueva perspectiva acerca de cómo evoluciona el sector publicitario destacando las inquietudes y preocupaciones de los profesionales ante el nuevo paradigma digital que comienza a consolidarse. Los influencers parecen protagonizar gran parte de los pronósticos que se han venido anunciando en las investigaciones sobre las redes sociales y el medio digital, llegando a conformarse como un nuevo canal publicitario que, como toda revolución, requiere de un periodo de acomodación tanto por parte de las audiencias como de los profesionales que gestionan dichos perfiles.

\section{Bibliografía}

Abidin, Crystal (2016). Visibility labour: Engaging with Influencers fashion brands and \#OOTD advertorial campaigns on Instagram. En: Media International Australia, Vol. Vol. 161, no 1. Londres: SAGE, 86-100. https://doi. org/10.1177/1329878X16665177

Augure (2017). Informe de Influencer Marketing 2017, En: https://www.augure. com/es/contenidos/whitepapers/informe-de-influencer-marketing-2017/ (Consultado el 16-07-2019).

Castelló-Martínez, Araceli y del Pino, Cristina (2015). La comunicación publicitaria con influencers. En: Redmarka: Revista académica de marketing aplicado, $\mathrm{n}^{\circ} 14$. Buenos Aires: CIECID, 21-50.

Castelló, Araceli (2013). Estrategias empresariales en la Web 2.0. Las redes sociales Online. Alicante: Editorial Club Universitario.

Clavijo-Ferreira, Lucía; Pérez-Curiel, Concha y Luque-Ortiz, Sergio (2017). Social Media y Comunicación Corporativa: Nuevo reto en las empresas de Moda. En: He- 
rrero, Francisco Javier y Mateos, Concha (coords.) Del verbo al bit. Madrid: Cuadernos Artesanos de Comunicación.

Davoult, Thibaut (2014). How to Get Customers to Post Instagram Pictures. En: https://bit.ly/2Dal1Cm (Consultado el 01-04-2019).

Del Pino, Cristina y Olivares, Fernando (2007). "Brand placament” y "advertainment”: integración y fusión entre la ficción audiovisual y las marcas. En: $Z E R-R e$ vista de Estudios de Comunicación, Vol. 12, $\mathrm{n}^{0}$ 22. Bilbao: Euskal Herriko Unibertsitatea, 401-424. DOI:10.4185/RLCS-2018-1262

Del Río, Jorge (2007). Gestión creativa de la agencia de publicidad. Madrid: Editorial Einsa.

Dellarocas, Chrysanthos (2003). The Digitization of Word-of-Mouth: Promise and Challenges of Online Feedback Mechanisms. En: Management science, Vol. 49, $\mathrm{n}^{\circ}$ 10. Catonsville: Informs PubsOnLine, 1407-1424.

Díaz, Luís (2017). Soy marca: quiero trabajar con influencers. Barcelona: Bresca.

Fanjul-Peyró, Carlos; González-Oñate, Cristina; Arranz-Peña, María (2018). Creatividad y eficacia en la comunidad valenciana la figura del planner en el proceso creativo. En: Revista Latina de Comunicación Social, Vol. 73, n ${ }^{0}$ 4. La Laguna: Sociedad Latina de Comunicación Social, 401-424. 10.4185/RLCS-2018-1262

Fernández Barros, María de la Luz (2014). Creatividad, innovación y trabajo en las agencias publicitarias en la era digital. En: Razón y palabra, Vol. 18, no 83. Quito: Editorial Razón y Palabra, 2-18.

Ferrer, Ignasi y Medina, Pablo (2014). Gestión empresarial de la agencia de publicidad. Madrid: Ediciones Díaz de Santos.

Flandin, M. P.; Martin, E.; y Simkin, L. P. (1992). Advertising effectiveness research: a survey of agencies, clients and conflicts. En: International Journal of Advertising, Vol.11, $\mathrm{n}^{\mathrm{o}}$ 3. Londres: Taylor \& Francis Online, 203-214. https://doi.org /10.1080/02650487.1992.11104495

Freberg, Karen et al. (2011). Who are the social media influencers? A study of public perceptions of personality. En: Public Relations Review, Vol. 37, $\mathrm{n}^{\mathrm{o}} 1$. Ámsterdam: Elsevier, 90-92. https://doi.org/10.1016/j.pubrev.2010.11.001

Gaitán, Juan Antonio y Piñuel, José Luis (1998). Técnicas de investigación en comunicación social. Elaboración y registro de datos. Madrid: Síntesis.

González-Oñate, Cristina (Coord). (2019). El negocio publicitario en la sociedad digital de la comunidad Valenciana. Barcelona: UOC.

Hennig-Thurau, Thorsten, Walsh, Gianfranco y Walsh, Gianfranco (2003). Electronic word-of-mouth: motives for and consequences of reading customer articulations on the Internet. En: International Journal of Electronic Commerce, Vol. 8, n ${ }^{\circ} 2$. Londres: Taylor \& Francis Online, 51-74. 
Hirschman, Elizabet (1989). Role-Based Models of Advertising Creation and Production. En: Journal of Advertising, Vol. 18, $n^{\circ}$ 4. Londres: Taylor \& Francis Online, 42-53. https://doi.org/10.1080/00913367.1989.10673166

Infoadex (2017). La inversión publicitaria gestionada en 2017 por las agencias de publicidad 2017, En: https://bit.ly/2UzsNR5 (Consultado el 9 de Marzo de 2019).

Jiménez-Marín, Gloria; Elías Zambrano, Rodrigo; Bellido-Pérez, Elena y Sanz-Marcos, Paloma (2019). Eficacia del endorsement marketing: La comunicación de las empresas de retail a través de Instagram. En: AA.VV. (2019). La investigación en comunicación audiovisual. Madrid: McGraw Hill.

Kauffman-Argueta, Jürg. (2014). De la Publicidad tradicional a la publicidad digital. Desafíos para agencias y profesionales. En: Actas del XV foro de Investigación en Comunicación. Pontevedra, Universidade de Vigo.

Kim, Angella Jiyoung y Ko, Eunju (2010). Impacts of Luxury Fashion Brand's Social Media Marketing on Customer Relationship and Purchase Intention. En: Journal of Gloval Fashion Marketing, Vol. 1, n 3 . Londres: Taylor \& Francis Online, 99-118. https://doi.org/10.5565/rev/qp.161

Kvale, Steinar (2011). Las entrevistas en Investigación Cualitativa. Madrid: Morata.

Landeta, J. (1999). El método Delphi. Una técnica de previsión para la incertidumbre. Barcelona: Ariel.

López-Font, Lorena (2005). Agencia de Publicidad: La reinvención constante. En: Questiones Publicitarias, Vol. I, $\mathrm{n}^{\circ}$ 10,. Barcelona: Universitat Autònoma de Barcelona, 99-118. https://doi.org/10.5565/rev/qp.161

López-Vidales, Nereida (2005). Los medios audiovisuales en el tercer milenio. Atrapados en la 'tela de araña'. En: Telos, $\mathrm{n}^{\circ}$ 62. Madrid: Fundación Telefónica España, 72-80.

Marwick, Alice E. (2015). You may know me from YouTube: (Micro)-Celebrity in Social Media. En: Marshall, P. D. y Redmond, S. (eds.), A Companion to Celebrity. Hoboken: John Wiley \& Sons.

McLuhan, Marshall (1995) La aldea global. Barcelona: Gedisa.

Monserrat-Gauchi, Juan y Sabater-Quinto, Federico (2017). Planificación estratégica de la comunicación en redes sociales. Barcelona: UOC.

Mullaney, Tim (2012). Social media is reinventing how business is done. En https:// blog.nowmarketinggroup.com/social-media-is-reinventing-how-business-is-done (Consulta en 16-07-2019)

Murphy, T. y Schran, R. (2014). What is it worth? The value chasm between brand and influencers. En: Journal of Brand Strategy, Vol. 3, $\mathrm{n}^{0} 1$. Oxford: Ingenta Connect, 31-40.

Papí-Gálvez, Natalia (coord.) (2014). Claves en la planificación de la publicidad online: fundamentos, herramientas y retos. Madrid: AIMC. 
Pérez-Curiel, Concha y Sanz-Marcos, Paloma (2019). Estrategia de marca, influencers y nuevos públicos en la comunicación de moda y lujo. Tendencia Gucci en Instagram. En: Prisma Social, $\mathrm{n}^{\mathrm{o}}$ 24. Madrid: Fundación iS+D para la investigación social avanzada, 1-24.

Perlado-Lamo-de-Espinosa, Marta; Papí-Gálvez, Natalia y Bergáz-Portolés, María (2019). Del planificador de medios al experto en medios: El efecto digital en la publicidad. En: Comunicar, Vol. 59, n ${ }^{\circ}$ 27. Huelva: Grupo Comunicar, 105-114. https://doi.org/10.3916/C59-2019-10

Pino-Romero, Cristina y Castelló-Martínez, Araceli. (2017). La estrategia publicitaria basada en influencers. El caso de SmartGirl by Samsung. En: Araceli CastellóMartínez y C. Pino-Romero (Coords.), Publicidad y Convergencia Mediática. Nuevas estrategias de comunicación persuasiva. Sevilla: Egregius Ediciones.

Polanski, Tom (2012). Dr. Robert Cialdini and 6 principles of persuasion, En: https://bit.ly/2X2Ur5Q (Consultado el 24-03-2019).

Roca, Meritxell (2015). La transformación de la industria publicitaria en la era digital. Percepciones de los profesionales en Estados Unidos: retos y oportunidades. En: Telos, no 99. Madrid: Fundación Telefónica España, 64-74.

Rouse, Margaret (2011). Social Media Marketing (SMM). En: What Is, TechTargert. https://bit.ly/2I TWXb8 (Consultado el 01-04-2019).

Sábada Garraza, Teresa y San Miguel Arregui, Patricia (2014). Revisión de los influentials en moda con la aparición de Internet: estudio del caso español a través de Stylelovely.com. En: Revista de comunicación, $n^{0}$ 13. Piura: Universidad de Piura, 60-83.

Sáez-Barnet, Gloria y Gallardo-Camacho, Jorge (2017). La relación de los youtubers con la publicidad y sus espectadores. El caso de YouTube España. En: Telos, n ${ }^{\circ} 107$. Madrid: Fundación Telefónica España, 47-57.

Segarra-Saavedra, J., e Hidalgo-Marí, T. (2018). Influencers, moda femenina e Instagram: el poder de prescripción en la era 2.0. En: Revista Mediterránea de Comunicación, Vol. 1, no 9. Alicante: Universidad de Alicante, 313-325. https://doi. org/10.14198/MEDCOM2018.9.1.17

Senft, Theresa (2008). Camgirls: Celebrity \& community in the age of social networks. New York: Peter Lang.

Soler, Pere (2008). El director de cuentas. Gestión de cuentas en marketing y publicidad. Barcelona: Universitat Autònoma de Barcelona.

Taylor, Steven J.; Bogdan, Robert y DeVault, Marjorie (2015). Introduction to qualitative research methods: A guidebook and resource. New Jersey: John Wiley \& Sons.

The Telegraph (2014). The ten most popular Instagram accounts: in pictures, En: https://bit.ly/2Ktxibp (Consultado el 24-03-2019). 


\section{Análisis de los perfiles profesionales en las webs de las agencias de publicidad en España Profile analysis of advertising practitioners in corporate webs of advertising agencies in Spain}

María del Mar Sánchez Moreno Universidad Complutense de Madrid

\section{Referencia de este artículo}

Sánchez Moreno, María del Mar (2019). Análisis de los perfiles profesionales en las webs de las agencias de publicidad en España. adComunica. Revista Científica de Estrategias, Tendencias e Innovación en Comunicación, (18), 87-100. DOI: http:// dx.doi.org/10.6035/2174-0992.2019.18.6

\section{Palabras clave}

Publicidad; Relación cliente-agencia; Comunicación; Profesional digital; Transformación; Adaptación empresarial

\section{Key words}

Advertising; Client-Agency Relationship; Communication; Digital Professional; Transformation; Business Adaptation

\section{Resumen}

El sector publicitario se ha transformado con la evolución de la comunicación digital. La atomización de los formatos y soportes ha llevado a una sobre-especialización de la comunicación para la que el anunciante demanda nuevos perfiles profesionales expertos, lo que ha ampliado el número de proveedores de servicios de comunicación. A pesar de que las agencias de publicidad tradicionales han integra- 
do servicios digitales en sus estructuras, encuentran dificultad para competir con el abanico de empresas especializadas en las nuevas formas de comunicación. La demostración de las capacidades profesionales es clave para la competitividad de las agencias, pero la transformación de las estructuras internas no evoluciona a la velocidad del mercado. Esta circunstancia deteriora la relación cliente-agencia, la base de la calidad del servicio donde la confianza entre los profesionales es clave para el éxito. Este artículo analiza cómo las principales agencias creativas españolas presentan el talento interno en sus webs corporativas, el canal propio donde la agencia proyecta su imagen. Se ha realizado un análisis de contenido de los apartados que hablan de talento en dichas webs. La principal conclusión indica que la adaptación de la estructura de las agencias a la comunicación digital, es parcial; sigue predominando la misma estructura organizativa que tenían a finales de los 90, antes de que la competencia de las grandes tecnológicas se planteara como la gran amenaza.

\begin{abstract}
The advertising sector has transformed with the digital communication. The atomization of formats and media has led up to an over-specialization of communication, where the advertiser demands new expert professional profiles. Thus, the number of communication suppliers has been widened. Despite the fact that traditional advertising agencies have integrated digital services into their structures, they find it difficult to compete with the range of companies specialized in new forms of communication. The demonstration of professional skills is key to the competitiveness of the agencies. However, the internal transformation does not follow the pace of the market demands. This circumstance deteriorates the client-agency relationship, the basis of service quality where trust among professionals is the key to success. This article analyses how the main Spanish advertising agencies present the internal talent in their corporate websites, their very own channel to project its image. The content analysis methodology has been applied to the agency web sections about talent. The main conclusion indicates a partial adaptation of the agencies to the digital communication and the dominance of the classical structure from the 90 s, before the competition of the big tech companies was posed as a great threat.
\end{abstract}

\begin{abstract}
Autora
María del Mar Sánchez Moreno [msanch39@ucm.es] es Doctoranda de Comunicación Audiovisual y Publicidad en la Facultad de Ciencias de la Información de la Universidad Complutense de Madrid. Profesional de la publicidad desde hace veinte años, actualmente es Brand Strategist en una agencia de publicidad multinacional donde trabaja para grandes marcas de automoción, telecomunicaciones y consumo.
\end{abstract}




\section{Introducción}

En las tres últimas décadas el sector de la publicidad viene experimentando una serie de cambios cuyo efecto acumulativo ha transformado el estatus quo del sector, poniendo en cuestión desde las formas de comunicación tradicionales hasta el modelo de negocio.

Las crisis económicas afectan directamente a la publicidad porque reducen la inversión y el tamaño del mercado, pero la crisis de la publicidad no es solo consecuencia de la recesión de la economía. Las causas de la profunda crisis que viven las agencias de publicidad son múltiples y de distinto calado; desde el rechazo del usuario a los mensajes y la pérdida de su eficacia por «inmunización por sobredosis» (Costa, 1992: 12) hasta la revisión de la relación anunciante-agencia con la introducción de acuerdos de nivel de servicio (SLAs) para garantizar el cumplimiento de expectativas (Turnbull y Wheeler, 2016: 599).

En los años 90 ya se apuntaba a la pérdida de confianza de los anunciantes por parte de las agencias y la transformación que éstas habían tenido que hacer a nivel organizativo y financiero para adaptarse a los cambios en los anunciantes y en los medios de comunicación (Mínguez, 1993: 71-72). Es decir, la crisis publicitaria es una crisis de transformación: supone la adaptación de su actividad y estructuras a un entorno que ha cambiado. La aparición de Internet se puede considerar el gran detonante de la transformación de la publicidad, ya que el desarrollo de la red ha ido paralelo a la pérdida de eficacia del sistema publicitario tradicional. Como en otros sectores, la tecnología ha afectado a las bases de la actividad al modificar la conducta del consumidor, quien como declaraba un ejecutivo de marketing a principios de este siglo "en internet el cliente es quien tiene todo el poder» (Roselló, 2002: 75-81). Un poder que, según los ejecutivos consultados por Roselló (2002), se traducía en la facilidad de acceso a los productos, la capacidad de información, de comparar precios y productos, y la comunicación bidireccional del canal entre otros aspectos.

Este poder ha aumentado para los anunciantes las formas de llegar a los clientes. Paralelamente, se han creado nuevas formas de comunicación comercial con nuevos códigos, formatos y dinámicas que van más allá de la publicidad convencional.

Uno de los aspectos que ha afectado estructuralmente a las agencias de publicidad convencionales es el cambio en los servicios solicitados por los anunciantes, quienes cada vez saben más de publicidad (López-Font, 2005: 114) y demandan numerosas formas de comunicación derivadas del desarrollo de la red, como la digitalización de los medios y las plataformas de compra online. Esta ampliación de demanda ha originado la aparición de nuevos servicios fuera del portfolio tradicional de las agencias, que éstas han tenido que incorporar a su oferta de manera improvisada y a menudo tardía. Además, se ha traducido en la ruptura de los límites del servicio publicitario, evolucionando a servicios de comunicación de diversos tipos, lo que ha provocado la llegada de nuevos competidores al mercado como consultoras estratégicas, empresas de comunicación digital, productoras audiovisuales y otras. 
En los últimos años se han realizado varias investigaciones tratando de conocer a fondo la naturaleza de la actividad publicitaria para anticipar su posible evolución teniendo en cuenta la influencia de Internet en la comunicación y el comportamiento del consumidor (Davies y Prince, 2010; Kim, 2014; Moeran, 2015; Turnbull y Wheeler, 2016).

El servicio publicitario es un servicio adaptado a las necesidades de cada anunciante con el fin de conseguir los resultados deseados. La mayor parte de lo que una agencia de publicidad produce son intangibles, creados desde un conocimiento tácito (Davies y Prince, 2010: 13). Se trata de un servicio complejo en el que la selección de la agencia se convierte en la primera dificultad para el anunciante como indican Turnbull y Wheeler: «la contratación de los servicios de una agencia de publicidad se considera una de las decisiones de compra más complejas para las compañías» (2016: 599 citando a Smeltzer y Ogden, 2002). En esta decisión, el perfil de los profesionales de la agencia es clave para que el anunciante le otorgue la confianza de crear y gestionar la comunicación de sus marcas. El estudio de Turbull y Wheeler (2016) encontró que los profesionales de una agencia son el segundo factor de decisión en la elección de una nueva agencia por parte de un anunciante. «Las investigaciones sugieren que la habilidad creativa, el equipo de la agencia, el coste y la experiencia son factores claves en la selección por parte del anunciante» (Turnbull y Wheeler, 2016: 599).

Es el talento profesional, entendido como las aptitudes y capacidades técnicas de los profesionales de la agencia, lo que aporta valor diferencial al resultado ofrecido por la agencia: «Los estudios revelan que los anunciantes esperan que la agencia aporte destreza, afinidad, funcionalidad y perspectiva.» (Turnbull y Wheeler, 2016: 599) Como se aprecia en la cita, las expectativas que el anunciante deposita en la agencia están relacionadas directamente con el talento profesional. La relación anunciante-agencia se refuerza cuando el cliente tiene conocimiento de primera mano de las capacidades de su agencia, lo que incrementa los encargos, pues los anunciantes suelen atribuir los éxitos al trabajo de sus agencias más que a causas externas (Davies y Prince, 2010: 18). A esto, hay que añadir el coste de cambiar de agencia, una decisión costosa para los anunciantes que incurren en un coste de salida derivados en gran medida por el capital humano (Davies y Prince, 2010: 13).

En 2007 la investigación llevada a cabo entre los anunciantes por Yuksel y SuttonBready indicaba que las tres principales razones para cambiar de agencia eran la insatisfacción con el rendimiento de la agencia, el desacuerdo con los objetivos de la campaña y la falta de atención sobre la cuenta por parte de los profesionales senior (Yuksel y Sutton-Brady, 2007: 36). Un estudio más que incide en la importancia del talento para mantener al anunciante vinculado a la agencia de publicidad.

Otro estudio reciente muestra nuevos matices en la relación cliente-agencia, si bien ahonda sobre la creatividad como valor principal en el desarrollo de la relación, las agencias deben desarrollar eficientes y efectivos procesos de gestión para mantener relaciones duraderas con sus clientes (Levin, Quach y Thaichon, 2019: 7). 
Nuestro análisis parte de la hipótesis que considera que las agencias tradicionales se han adaptado al cambio digital del mercado de una forma superficial, sin cambiar drásticamente sus estructuras. Estas agencias han integrado nuevos servicios y perfiles profesionales en su organización, pero no han realizado una transformación profunda en la adaptación del talento profesional ni en la organización del trabajo que les dote de competitividad en el mercado publicitario, dominado ya por las grandes empresas tecnológicas (IANS, 2018).

Una demostración de esta situación la encontramos en la forma de trabajar que transmiten las propias agencias de publicidad en sus páginas web corporativas; su tarjeta de presentación digital y uno de los canales de venta de sus servicios. Las webs corporativas son un objeto de estudio interesante para analizar algunos aspectos de las agencias de publicidad por dos razones: la principal es que son el punto de información de referencia para cualquier nuevo cliente que piense en trabajar con una agencia. La web corporativa actúa como catálogo que muestra las capacidades, filosofía de trabajo y personalidad de la agencia. Por todo esto, aunque una web no sea un elemento decisivo en la contratación, sí es un elemento importante en la imagen que la propia agencia quiere proyectar en sus clientes. La segunda razón tiene que ver con la evolución hacia la comunicación digital que las agencias tradicionales han tenido que realizar. Entre los servicios digitales que ofrecen, las agencias de publicidad diseñan, crean y mantienen webs corporativas y comerciales para sus clientes. Luego qué mejor tarjeta de visita que la web propia de la agencia para demostrar tus capacidades.

El análisis sobre cómo muestran las agencias los perfiles y capacidades de sus profesionales bien puede servir como indicio de la organización de las mismas y de su nivel de transformación respecto a las estructuras tradicionales.

\section{Metodología}

El objetivo principal de este trabajo es mostrar cuál es el grado de transformación de las capacidades de las agencias de publicidad respecto a la situación evolutiva del mercado en cuanto a cambios en los perfiles de sus miembros y en la organización de equipos.

También se pretende mostrar cómo, a pesar de la importancia que los anunciantes dan a los profesionales, las agencias no resaltan como valor comercial para atraer a los clientes el talento disponible en sus organizaciones.

Nuestra hipótesis considera que en las principales agencias de publicidad (las que gestionan las cuentas con mayor inversión) las estructuras tradicionales todavía dominan sobre nuevas formas de trabajo y capacidades a pesar de la transformación del sector.

Se ha analizado la información sobre los equipos y profesionales que aparece en las webs corporativas de las principales agencias de publicidad en España. La muestra analizada se ha seleccionado entre las 25 principales agencias del sector 
por inversión en publicidad gestionada (volumen de inversión en publicidad de las marcas-clientes) según el ranking de la consultora Infoadex para 2017. Los rankings de Infoadex - Agencias creativas, agencias de medios e inversión anunciantes - son informes de larga tradición y reconocimiento en el sector de la publicidad1. En dicho ranking aparecen tanto agencias pertenecientes a una red internacional como agencias locales, aunque como afirmaba el profesor López Lita «conviene recordar que en gran número de agencias de publicidad conviven rasgos globales y locales» (López Lita, 2004: 40)

Se ha optado por la metodología de análisis de contenido teniendo en cuenta que el objeto de estudio, las webs corporativas de las agencias de publicidad que operan en España, son productos de comunicación ya elaborados por las propias agencias como parte interesada. Son documentos naturales (Bardin, 1977: 23) porque surgen de una necesidad comercial y tienen la función de transmitir una intencionalidad a los posibles clientes. Las características de las webs corporativas como objeto se prestan a que se les pueda aplicar el análisis de contenido. Por otro lado, internet permite hacer visibles algunos fenómenos psicológicos que no existen en el entorno natural o que allí son difíciles de estudiar (De Marchis, 2012: 264)

El análisis de contenido es, pues, una técnica basada en las comunicaciones (Bardin, 1977: 23) y, como afirman Henry y Moscovici, «todo lo que se dice o se escribe es susceptible de ser sometido a un análisis de contenido» (Henry y Moscovici, 1968: 23). Nuestra intención es usar el análisis de contenido de las webs para inferir una situación para lo que esta metodología aporta utilidad porque «del interés no reside en la descripción de los contenidos, sino en lo que éstos, una vez tratados, [...] podrían enseñarnos relativo a «otras cosas» (Bardin, 1977: 29).

Se ha elaborado una unidad de registro ad-hoc (ver anexo I) para analizar el contenido de cada web de cada una de las agencias de la muestra.

Como afirma Bardin (1977) «la técnica del análisis de contenido adecuada al campo y al objetivo perseguidos, es necesario inventarla cada vez, o casi» (Bardin, 1977: 23).

En cada una de las webs de estas agencias se buscaron y analizaron aquellos apartados donde se hiciera referencia a las personas de la agencia; bien su equipo directivo, o bien sus equipos o toda la plantilla. Este contenido tiene unos espacios propios y delimitados dentro de la web que suelen denominarse «nosotros», «equipo directivo» o «acerca de». Se revisaron también los apartados de contacto, pues también se espera que aparezcan referencias personales en este contenido.

Una de las webs estaba «en construcción», reduciendo la muestra a 24 webs operativas.

Hay que mencionar que, de las 24 agencias, 2 de ellas (8\%) ni siquiera tienen web corporativa española, remitiendo a la web del grupo internacional, donde la única referencia hacia la agencia en España es su dirección y teléfono de contacto.

1 XIX Estudio Infoadex de Agencias de Publicidad en España 2018. Ranking elaborado a partir del volumen de inversión anual en publicidad de los clientes de cada agencia. 


\section{Resultados}

En febrero de 2019 se visitaron las webs de las 25 primeras agencias por inversión gestionada, según el informe de Infoadex (2018) mostrado en el siguiente cuadro:

Tabla 1. Ranking Agencias de Publicidad por volumen de inversión en publicidad 2017 de sus clientes.

\begin{tabular}{|c|c|c|}
\hline & Agencias de Publicidad & $\begin{array}{l}\text { Inversión controlada por IntoAdex, } \\
\text { gestiunadla en } 2017 \text { (€) }\end{array}$ \\
\hline 1 & MCCANN & 323.052 .490 \\
\hline 2 & HAVAS CREATIVE & 297.272 .685 \\
\hline 3 & SRA. RUSHMORE & 189.592 .852 \\
\hline 4 & TBWA & 181.030 .762 \\
\hline 5 & DDB & 178.023 .826 \\
\hline 6 & GRIIPO OGIIVY & 136.518 .38 .5 \\
\hline 7 & CONTRAPUNTO BBDO & 129.234 .115 \\
\hline 8 & YOUNG \& RUBICAM & 126.800 .098 \\
\hline 9 & COMUNICA MAS A & 112.901 .601 \\
\hline 10 & PUBLICIS ESPAÑ $\Lambda$ & 109.046 .131 \\
\hline 11 & GRLY & 75.766 .780 \\
\hline 12 & LEO BURNETT & 75.254 .206 \\
\hline 13 & SCPF & 55.886 .052 \\
\hline 14 & CHEIL & 48.556 .056 \\
\hline 15 & PAVLOV & 46.320 .029 \\
\hline 16 & PROXIMITY & 44.961 .717 \\
\hline $1 /$ & SHACKLETON & 44.502 .583 \\
\hline 18 & DOMMO & 30.599 .409 \\
\hline 19 & CHINA & 29.293 .811 \\
\hline 20 & EL RUSO DE ROCKY & 25.566 .318 \\
\hline 21 & TIEMP0 BBD0 & 25.139 .674 \\
\hline 22 & FCB & 21.865 .959 \\
\hline 23 & DARWIN SOCIAL NOISE & 14.874 .333 \\
\hline 24 & $\&$ ROSAS & 10.395 .654 \\
\hline \multirow[t]{2}{*}{25} & GROW COMUNICACIÓN & 3.426 .760 \\
\hline & Total 25 primeras agencias & 2.335 .882 .289 \\
\hline
\end{tabular}

Fuente InfoAdex

Información actualizada a 31/07/2018 
Conviene aclarar que el ranking de Agencias por inversión gestionada de Infoadex se publica en torno a mediados de año (mayo/junio) con los datos referentes al año anterior del año en curso. Así, en la fecha de realización del análisis de campo, febrero de 2019, todavía no ha aparecido el ranking de agencias por inversión publicitaria gestionada de 2018, por lo que se ha usado el ultimo ranking disponible, el de 2017, publicado en julio de 2018.

El primer dato a destacar es el tratamiento irregular que se hace del contenido sobre talento. Sólo 6 agencias tienen un apartado en el que muestran los perfiles profesionales de sus equipos y 8 muestran a los integrantes de su cuadro directivo. Curiosamente, solo 3 de todas ellas presentan a ambos perfiles; cuadros directivos y técnicos. En total, 13 agencias no presentan a ningún perfil profesional en su web, es decir, más de la mitad de la muestra (54\%). Este dato contrasta con la importancia de la relación personal en el negocio de la publicidad, como han demostrado los estudios comentados en este artículo y las propias prácticas profesionales.

En el análisis de la presencia de perfiles profesionales digitales, nos encontramos con que poco más de la mitad (7) de aquellas agencias que mencionan perfiles de cualquier nivel (11) presentan algún perfil digital, ya sea en la dirección o en los técnicos.

Se ha tenido en cuenta también cuántos de los perfiles mencionados incluían la experiencia de los profesionales como muestra del valor para el posible anunciante y solo en 5 casos se incluía contenido sobre la trayectoria de las personas.

Tabla 2. Presencia de perfiles profesionales.

\begin{tabular}{|l|c|}
\hline Contenido presente en la web & No de agencias \\
\hline Apartado específico sobre talento & 6 \\
\hline Apartado cuadro directivo & 7 \\
\hline Presencia de perfiles profesionales digitales & 5 \\
\hline Mención a la experiencia de los profesionales & 13 \\
\hline Ninguna referencia sobre personas en la web & 8 \\
\hline
\end{tabular}

Fuente: elaboración propia.

Abajo se muestra una nube de tags realizada con la herramienta NVIVO12 resultado del análisis cualitativo de los nombres de los perfiles mostrados en las webs de las agencias. 
Imagen 1. Nube de tags descripción perfiles profesionales.

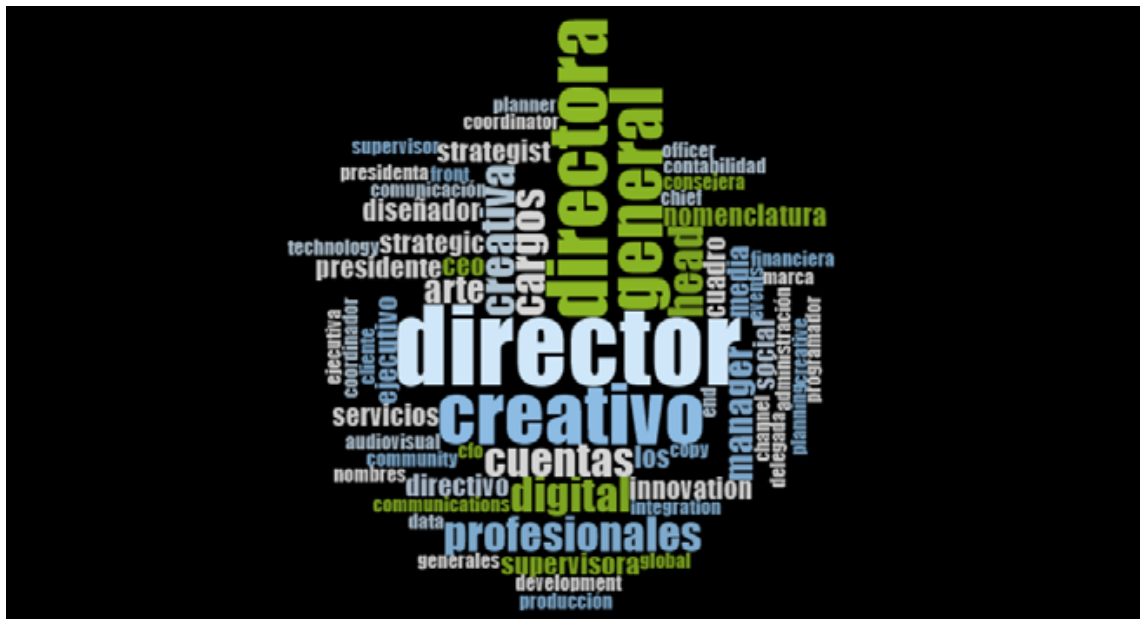

Fuente: Elaboración propia con el programa NVIVO12.

Como puede apreciarse los perfiles de dirección destacan sobre el resto; lógico, si tenemos en cuenta que la mayor parte de los perfiles reseñados son directivos. El perfil creativo destaca sobre los demás — también tiene sentido, pues es fundamental para la reputación de la agencia- seguido del de cuentas, que vemos que se aproxima a digital en genérico. Los perfiles más específicos vemos que su peso en la nube es menor - programador, community, data-.

También se ha analizado el peso de los perfiles digitales sobre el total de los perfiles presentados en cada agencia, siendo la media de presencia del $31 \%$. Es decir, un tercio de los profesionales de los equipos de las agencias que muestran las habilidades de su talento interno son digitales.

Por último, en el análisis de las relaciones personales que hacen las agencias también se considera si la invitación a contactar con ellas se hace de una forma impersonal - sin nombre de contacto- o con los datos de un profesional, que suele ser un directivo. Solo 4 de las 24 muestran el contacto con la agencia haciendo referencia a una persona con nombre y apellidos. Como se puede deducir, hay agencias que dedican un espacio a reseñar las personas de sus equipos, pero, curiosamente, no hacen referencia a ninguna persona en concreto en al apartado de contacto.

Retomando nuestro principal objetivo de averiguar el grado de transformación del talento interno de las agencias publicitarias, parece claro que se mantienen las estructuras tradicionales propias de las agencias de finales del siglo XX, a pesar de que se han integrado nuevos perfiles y se ha innovado algo en la organización de éstos. Se puede considerar que la reorganización de las capacidades de los equipos 
y la ampliación del perfil digital es todavía una asignatura pendiente en las principales agencias de publicidad creativas.

En cuanto al objetivo secundario sobre el uso del valor del talento interno de la agencia como reclamo comercial para los anunciantes en las webs corporativas, parece que la mayoría de las agencias no consideran un valor relevante mostrar los perfiles y capacidades de sus profesionales como aval de sus habilidades publicitarias.

Parece que se apunta la confirmación de nuestra hipótesis de que las estructuras tradicionales (organización del talento interno) se mantienen en la forma de trabajar de las principales agencias del país. No obstante, para llegar a confirmar tal situación sería necesario un análisis profundo de cada agencia, no solo a través de lo que ellas cuentan de si mismas en su web, sino conociendo a fondo su estructura a través de entrevistas a los responsables de éstas. Nuestro trabajo es un ejercicio demostrativo para apuntar que queda mucho por hacer para una transformación real del sector publicitario, empezando por la forma de presentar esa transformación por parte de las compañías de publicidad. No obstante, la metodología elegida tiene limitaciones por el carácter espontáneo del contenido y sus capacidades para extrapolar conclusiones.

\section{Conclusión}

Como se ha visto en los resultados del trabajo, las agencias no destacan el talento que poseen a través de sus profesionales, cuando estos son claves en la gestión y el mantenimiento de los clientes (de hecho, es típica la situación en la que un profesional reconocido abandona la agencia y se lleva a su cliente con él en sus nuevos proyectos).

También, analizando el contenido de las webs, se puede apreciar que las agencias adolecen de cierta incoherencia entre su oferta a los clientes — servicios $360^{\circ}$, servicios de publicidad digital, innovación, nuevos soportes - y las aptitudes y capacidades de su talento interno que muestran en su web para llevarlo a cabo, donde la presencia de profesionales especializados en comunicación digital y otras nuevas actividades no parece estar equilibrada (recordemos solo un $31 \%$ de perfiles digitales).

La circunstancia anterior nos muestra, además, la escasa evolución de los perfiles profesionales, en los que no se aprecia la incorporación de nuevas habilidades. También se observa que los cargos «clásicos» siguen teniendo mucho peso. Lo que se puede interpretar como una clara muestra de la escasa o deficiente integración de los nuevos perfiles digitales en las estructuras de las agencias.

Es reseñable la poca relevancia que las agencias dan a la demostración de las capacidades y aptitudes de su talento interno, y que puede apreciarse en varios resultados del análisis como la escasa referencia a la experiencia profesional o con otros anunciantes en los perfiles de los equipos (solo en 5 casos de la muestra). Llama la 
atención este dato, teniendo en cuenta que uno de los valores que preocupan a los anunciantes es la seniority de los profesionales con los que van a trabajar.

También puede interpretarse como una falta de compromiso por parte de las agencias con los potenciales clientes, el hecho de que no muestren las capacidades de sus equipos de forma más explícita, cuando el talento tanto creativo como de gestión son los factores más valorados por sus clientes. Esta falta de visibilidad puede afectar, incluso, a sus estrategias de comunicación interna ¿de qué sirve incentivar el talento en la agencia si después no se comunica al exterior? Los empleados pueden valorar su presencia en la web como un reconocimiento a su valía, acrecentando el grado de identificación de éstos con la organización, favoreciendo así la Opinión Publica Interna (Villafañe, 1999: 307).

Con este somero análisis realizado, se apuntan nuevos argumentos para investigar las estructuras de las agencias del siglo XXI y su preparación para las demandas de la comunicación hoy: creatividad, personalización, agilidad, transparencia. Así surgen cuestiones en las que sería interesante ahondar en otros estudios: ¿Por qué en un modelo de negocio basado en la relación entre profesionales no se destaca el valor del talento interno? ¿Por qué la integración de los perfiles digitales solo representa un tercio de los equipos técnicos cuando llevamos varias décadas con publicidad digital? ¿Cuál es el peso del talento personal en los nuevos modelos de negocio que se están creando a raíz de la transformación de la publicidad?

Estas cuestiones necesitan de una amplia investigación en el ámbito local, conectada con la evolución global del sector que debiera ser abordada en un futuro.

\section{Bibliografía}

Bardin, Laurence (1977). El análisis de contenido. Madrid: Ediciones Akal. Costa, Joan (1992). Reinventar la publicidad. Reflexiones desde las ciencias sociales. Madrid: Fundesco.

Davies, Mark y Prince, Melvin (2010). Advertising agency compensation, client evaluation and switching costs: An extension of agency theory. En: Journal of Current Issues and Research in Advertising, Vol. 32, $\mathrm{n}^{\mathrm{o}}$ 1. Londres: Taylor \& Francis Online, 13-31. https://doi.org/10.1080/10641734.2010.10505272

De Marchis, Giorgio (2012). La validez externa de las encuestas en la web. Amenazas y su control. En: Estudios Sobre El Mensaje Periodístico, vol. 18, número especial. Madrid: Servicio de Publicaciones de la Universidad Complutense, 263-272.

IANS (2018). Facebook, Google’s digital advertising dominance crushing ad firms: Report. En:

https://www.business-standard.com/article/management/facebook-google-s-digitaladvertising-dominance-crushing-ad-firms-report-118081300087_1.html (Consultado 15-07-2019). 
Henry, Paul y Moscovici, Serge (1968). Problèmes de l'analyse de contenu. En: Langages, $\mathrm{n}^{\mathrm{o}}$ 11. París: Larousse, 36-60. https://doi.org/10.3406/lgge.1968.2900

Infoadex (2018). La inversión publicitaria gestionada en 2017 por las agencias de publicidad. En: https://www.infoadex.es/home/la-inversion-publicitaria-gestionadaen-2017-por-las-agencias-de-publicidad/ (Consultado 02-2019).

Kim, Kwangmi Ko (2014). Research on Transnational Advertising Agencies. Cheng, Hong. En: H. Cheng (ed.). The Handbook of International Advertising Research. Chichester: Wiley-Blackwell. https://doi.org/10.1002/9781118378465.ch4

Levin, Elizabeth; Quach, Thu Nguyen y Thaichon, Park (2019). Enhancing clientagency relationship quality in the advertising industry - an application of project management. En: Journal of Business \& Industrial Marketing, Vol. 31, $\mathrm{n}^{\mathrm{o}}$ 2. Londres: Emerald Publishing, 463-473. https://doi.org/10.1108/JBIM-08-2017-0186

López-Font, Lorena (2005) Agencia de publicidad:La reinvención constante. En: Questiones Publicitarias, Vol. I, n ${ }^{0}$ 10. Cerdanyola del Vallès: Universitat Autònoma de Barcelona, 99-118.

López Lita, Rafael (2004). La agencia de publicidad local: hacia su conceptualización. En: Questiones Publicitarias, Vol. I, n ${ }^{\circ}$ 9. Cerdanyola del Vallès: Universitat Autònoma de Barcelona, 33-41.

Mínguez, Norberto (1993). Claves sociales y culturales de la crisis publicitaria. En: Benavides, J. (ed.). La crisis de la publicidad. Madrid: Edipo

Moeran, Brian (2015). Advertising Agencies. En: Smelser, N. J. y Balter, P. B. (eds.). International Encyclopedia of the Social \& Behavioral Sciences. Copenhague: Elsevier. https://doi.org/10.1016/B978-0-08-097086-8.95093-1

Roselló, Clemente F. (2002). Los negocios en internet. Madrid: Instituto Europeo de Marketing Comunicación y Publicidad.

Turnbull, Sarah y Wheeler, Collin (2016). Exploring advertiser's expectations of advertising agency services. En: Journal of Marketing Communications. Vol. 22, $\mathrm{n}^{\mathrm{o}}$ 6. Londres: Taylor \& Francis Online, 587-601. https://doi.org/10.1080/135272 66.2014 .920902

Villafañe, Justo (1999). La gestión profesional de la imagen corporativa. Madrid: Ediciones Pirámide.

Yuksel, Ulku y Sutton-Brady, Catherine (2007). From Selection To Termination: An Investigation Of Advertising Agency/Client Relationships. En: Journal of Business \& Economics Research (JBER), Vol. 5, no 1. Littleton: Clute Journals, 31-40. https:// doi.org/10.19030/jber.v5i1.2511 


\section{Anexo 1}

FICHA ANÁLISIS DE CONTENIDO

SOPORTE DE INFORMACIÓN: Webs corporativas agencias de publicidad

REGISTRO CONTENIDO SOBRE EL PERSONAL DE LA AGENCIA EN LOS

SIGUIENTES APARTADOS:

- Dirección

- Equipo

- Contacto

\begin{tabular}{|l|l|}
\hline Nombre de la agencia & \\
\hline URL analizada & \\
\hline$N^{*}$ ranking lnfoadex 2017 & \\
\hline Fecha campo & \\
\hline
\end{tabular}

\begin{tabular}{|l|l|l|l|}
\hline Soporte & Positivo & Negativo & Observaciones \\
\hline Web local & & & \\
\hline Web internacional & & & \\
\hline
\end{tabular}

\begin{tabular}{|l|l|l|l|}
\hline Apdo. Direceión & Positivo & Neqativo & Observaciones \\
\hline Ref Cuadro Dirección & & & \\
\hline Experiencia Cuadro D. & & & \\
\hline Cargos D' digital & & & \\
\hline
\end{tabular}

\begin{tabular}{|l|l|l|l|}
\hline Apdo. Equipo & Positivo & Negativo & Observaciones \\
\hline $\begin{array}{l}\text { Ref. Equipo } \\
\text { profesional }\end{array}$ & & & \\
\hline $\begin{array}{l}\text { Ref. nombres } \\
\text { profesionales }\end{array}$ & & & \\
\hline $\begin{array}{l}\text { Ref. Cargos } \\
\text { profesionales }\end{array}$ & & & \\
\hline $\begin{array}{l}\text { Ref. Experiencia de } \\
\text { profesionales }\end{array}$ & & & \\
\hline Ref. Carges digitales & & & \\
\hline
\end{tabular}

\begin{tabular}{|c|c|c|}
\hline $\begin{array}{c}\text { Cuando hay } \\
\text { Cargos digitales }\end{array}$ & $\begin{array}{c}\mathrm{N}^{*} \text { cargos digitales } \\
\text { referidos }\end{array}$ & $\%$ sobre total perfiles referidos \\
\hline & & \\
\hline
\end{tabular}

\begin{tabular}{|l|l|l|l|}
\hline Apdo. Contacto & Positivo & Negativo & Observaciones \\
\hline Persona de contacto & & & \\
\hline $\begin{array}{l}\text { Cargo de persona } \\
\text { contacto }\end{array}$ & & & \\
\hline $\begin{array}{l}\text { Contacto genérico-sin } \\
\text { persona }\end{array}$ & & & \\
\hline
\end{tabular}

Observaciones: 



\section{Publicidad de la publicidad. Las redes sociales como soportes de comunicación de las agencias de publicidad Advertising about advertising. Social networks as communication supports for advertising agencies}

Tatiana Hidalgo-Marí Universidad de Alicante

Jesús Segarra-Saavedra Universidad de Alicante

\section{Referencia de este artículo}

Hidalgo-Marí, Tatiana y Segarra-Saavedra, Jesús (2019). Publicidad de la publicidad. Las redes sociales como soportes de comunicación de las agencias de publicidad. adComunica. Revista Científica de Estrategias, Tendencias e Innovación en Comunicación, (18), 101-122. DOI: http://dx.doi.org/10.6035/2174-0992.2019.18.7

\section{Palabras clave}

Agencia de publicidad; Autopromoción; Autopublicidad; Comunicación publicitaria; Publicidad; Redes sociales.

\section{Key words}

Advertising agency; Self-promotion; Self-advertising; Advertising communication; Advertising; Social networks.

\section{Resumen}

La naturaleza de la actividad publicitaria trae consigo una dedicación centrada en el anunciante, para el cual, las agencias de publicidad definen, planifican y ejecutan estrategias de comunicación a todos los niveles. Sin embargo, poco se ha hablado de cómo las propias agencias de publicidad trabajan y perfilan su comunicación, en aras de captar y conseguir tanto clientes como su posicionamiento de marca en 
el mercado. La comunicación de las agencias se ha limitado, tradicionalmente, a obtener posicionamiento y reconocimiento en festivales y certámenes destinados a valorar su trabajo, evitando anunciarse en medios convencionales, para no entrar en conflicto con sus propios clientes. Sin embargo, con el surgimiento de las redes sociales y los medios digitales, el escenario de comunicación ha cambiado significativamente y las agencias han encontrado un espacio virtual en el que poder trabajar su comunicación, hacer autopublicidad y trabajar sus valores de marca. El presente trabajo realiza un análisis descriptivo sobre la presencia y uso de redes sociales de las agencias españolas de publicidad asociadas a la Asociación Española de Agencias de Comunicación Publicitaria (AEACP), que se complementa con una revisión de los mensajes difundidos por las mismas en redes sociales. Los resultados apuntan a que las agencias buscan su presencia en redes sociales, a pesar de que todavía no se están explotando todas las posibilidades que ofrecen estos canales. Además, se detecta un proceso de cambio tímido pero existente en base al uso de las redes sociales como soportes corporativos para las agencias.

\begin{abstract}
The nature of advertising activity brings with it a dedication focused on the advertiser, for whom advertising agencies define, plan and execute communication strategies at all levels. However, little has been said about how advertising agencies themselves work and profile their communication, in order to capture and get both customers and their brand positioning in the market. The communication of agencies has traditionally limited to obtain positioning and recognition in festivals and contests aimed at valuing their work, avoiding advertising in conventional media, so as not to come into conflict with their own customers. However, with the emergence of social networks and new digital media, the communication scenario has changed significantly and agencies have found a virtual space in which to work their communication, make self-advertising and work on their brand values. This work includes a descriptive analysis of the presence, use and situation of social media of Spanish advertising agencies associated with the Spanish Association of Advertising Communication Agencies (AEACP), which is complemented by a review of the content disseminated by them on social networks. The results indicate that agencies are looking for their presence on social networks, even though they are not yet exploiting all the possibilities offered by these media. In addition, a timid but existing process of change is detected based on the use of social networks as corporate supports for agencies.
\end{abstract}

\title{
Autores
}

Tatiana Hidalgo-Marí [Tatiana.hidalgo@ua.es] es Doctora por la Universidad de Alicante (2013), Máster en Comunicación e Industria Creativa (UA, 2012) y Licenciada en Publicidad y RR.PP. (UA, 2007). Profesora de Semiótica en el Grado en Publicidad y RR.PP. de la UA y docente en el Máster en Comunicación e Industrias Creativas (UA). 
Jesús Segarra-Saavedra [jesus.segarra@ua.es] es Premio extraordinario de Doctorado, Doctor y Licenciado en Publicidad y Relaciones Públicas por la Universidad de Alicante. Acreditado como Profesor Contratado Doctor por ANECA y la AVAP. Docente y profesor en UA y UNIR. Investigador en el grupo Comunicación y Públicos Específicos (COMPUBES). Editor técnico adjunto de Revista Mediterránea de Comunicación, editor adjunto de Revista Health and Addictions y colaborador de Revista Latina de Comunicación Social. 


\section{Introducción}

La forma en la que las agencias de publicidad consiguen captar y conseguir clientes se entiende como un tabú estratégico si se tiene en cuenta su escasa presencia en medios convencionales. Desde prácticamente los orígenes estandarizados de la profesionalización del sector y la industria, no ha sido común que las agencias ocupen espacios publicitarios en un intento de autopublicitarse o autopromocionarse.

Que las agencias de publicidad como sujetos responsables de la emisión de mensajes hicieran publicidad de sí mismas es un fenómeno que Ogilvy, en su libro Ogilvy y la publicidad (2001) explicaba bajo la expresión «médico, sánate a ti mismo», en un intento por identificar la escasa responsabilidad deontológica que mostraría este uso.

Hubo una época en la que «los nombres de las agencias representaban una filosofía publicitaria y una personalidad distinta como los productos de marca» (Russell y Lane, 1994: 125), sin embargo, los escasos estudios existentes sobre la autopublicidad, autopromoción o self advertising de las agencias coinciden en que estas formas publicitarias se han llevado a cabo en medios específicos tales como revistas del sector de la publicidad, anuarios del sector y similares (Ferrer Roselló, 1998; Quintas y Quintas, 2009) pero que no han trascendido a los medios y soportes generalistas.

Según Aprile (2010), es habitual y común que el discurso de las agencias de publicidad se centre en autoproclamarse como expertas de la promoción, no obstante, resulta evidente que son poco efectivas en promocionarse a ellas mismas. En general, se autopromocionan los/as creativos/as mediante agencias en festivales, concursos y rankings de inversión, pero no hay una planificación estrategia que pretenda llegar a un público objetivo con un mensaje contundente basado en valores de marca (Bravo, Cambra-Fierro y Melero, 2017).

El motivo puede ser, en primer lugar, no competir en los espacios que deben ocupar sus potenciales clientes, evitando conflictos de intereses en cuanto al medio y soporte se refiere. Sin embargo, esta apreciación genérica se vuelve mucho más compleja si se tiene en cuenta que el propio discurso publicitario que habla de la agencia entraría en conflicto con la creatividad expuesta en las piezas de clientes, anunciantes, y más aún, si la pieza no obtiene los resultados esperados, no solo se estaría ante una publicidad poco efectiva, sino que supondría un ejercicio inverso: la propia decadencia de la actividad de la agencia. No se puede olvidar que las agencias de publicidad deben construir su propia marca, al mismo tiempo en que construyen la marca de sus clientes (Quintas y Quintas, 2009: 5) puesto que de este escenario autopublicitario pueden surgir nuevas oportunidades de captación de nuevas cuentas, nuevos anunciantes y nuevos clientes.

En el contexto de la comunicación en general y de la publicidad en particular, la dimensión que ha adquirido el proceso entre anunciantes y agencias y las exigencias del propio mercado digital han forzado unas lógicas y procesos de trabajo que han alterado las relaciones convencionales entre medios, marcas y creativos. El escenario digital fuerza una especie de darwinismo tecnológico (Vollmer, 2009) que 
implica la adaptación de todos los sujetos de la actividad publicitaria a las normas y decretos del mundo online: la red es quien marca el ritmo y el tono comunicativo, y la propia estrategia creativa se convierte en un susurro dentro del concierto del entorno 2.0. En este contexto cabe preguntarse: ¿Cómo ha afectado la revolución digital a las agencias de publicidad? Más allá de la necesidad de adaptar su negocio a satisfacer unas necesidades digitales de sus clientes, ¿cómo utilizan estos nuevos portales comunicativos para autopublicitarse a ellas mismas?

Estudios recientes han analizado la postura de las agencias de publicidad frente a las necesidades digitales de los nuevos anunciantes. Según Martín-Guart y Fernández (2014: 14) «se ha criticado a las empresas una falta de adaptación difícil de justificar en un negocio que hace de la creatividad su razón de ser» que se ha limitado a trasladar parte del presupuesto de los clientes al medio Internet (Pérez-Latre, 2009) o apostando por las redes sociales (Mangold y Faulds, 2009). Sin embargo, a pesar de las críticas recibidas, de los cuestionables procesos convergentes o de la interiorización del propio darwinismo digital, las agencias de publicidad han encontrado en las redes sociales algo más valioso que el título de homologación digital de su labor o que un nuevo soporte que ofrecer a sus clientes: un espacio en el que autopromocionarse.

El fenómeno de la autopromoción de las agencias de publicidad es algo que ha estado cuestionado, informalmente, desde prácticamente los orígenes de la publicidad. Existía un saber popular que recogía que las agencias no debían hacer publicidad de sí mismas, ya que para ello estaban los festivales y reconocimientos a su labor (Ogilvy, 1990). Sin embargo, Internet lo ha cambiado todo: página web, redes sociales, bitácoras, canales de YouTube, aplicaciones móviles y un sinfín de recursos interactivos digitales en los que las agencias de publicidad encuentran su espacio personal y sin ser juzgado para autopromocionarse.

El presente trabajo pretende llevar a cabo un estudio del uso de la publicidad llevada a cabo desde la propia industria publicitaria, es decir, cómo se comunican las agencias de publicidad con sus públicos en el escenario digital. De forma descriptiva, se busca conocer el uso que las agencias hacen de las redes sociales como soportes propios para autopromocionarse, sin entrar a competir con sus propios clientes, sin colapsar espacios mediáticos, dando lugar a una nueva posibilidad de crear y mantener vigente su propia marca, su propio sello de identidad en un contexto online, requisito indispensable para asegurar la supervivencia de las empresas.

\section{Autopublicidad: una aproximación terminológica}

Alrededor de la actividad publicitaria existen numerosos conceptos que, en muchas ocasiones, generan controversia o confusión cuando pretenden ser aplicados. Es lo que ocurre con el término autopublicidad, self advertising, autopromoción, utilizado comúnmente como sinónimo de metapublicidad y metatextualidad publicitaria. Antes de seguir con el estudio, resulta necesario aclarar terminológicamente el alcance del término que lo sustenta. 
Existen pocos estudios que hayan analizado estos conceptos dentro de la disciplina publicitaria. No obstante, es necesario referenciar la aportación de Feliu y Fernández-Poyatos (2006) en la que se exponen diferencias significativas entre autopublicidad, endopublicidad y metapublicidad. Según los autores, la self advertising estaría reservada para anuncios de una cadena de televisión o una emisora de radio en los que dan a conocer algún programa propio que emitirán en breve mientras que el concepto de autopromoción se acotaría en el momento en el que se resaltan las bondades de la marca, el estilo y la personalidad del canal (citando a Echezuría, 1999).

El segundo término interrelacionado es la endopublidad, definida como la publicidad entre los sujetos creadores de la publicidad, que generalmente se inserta en medios especializados, a saber, lo que las agencias dicen de sí mismas (Feliu y Fernández-Poyatos, 2006) mediante propios discursos publicitarios tanto en contenido como en forma.

Cuando la esencia de una campaña reside en la propia publicidad, es decir, la publicidad supone el objeto que hay que ensalzar, alabar o corregir, se estaría ante el fenómeno que Adam y Bonhomme denominaron «contraconnotación» (Adam y Bonhomme, 2000). En este sentido, el término se aproxima a una dimensión más propiamente metapublicitaria, en la que la publicidad habla de ella misma, sin más dilación que hacer de la idiosincrasia de su discurso un producto apetecible para la sociedad (Feliu García, 1996), próximo también a la metatextualidad que Genette (1989) acuñó haciendo referencia a las posibles relaciones entre los textos y sus intertextos.

A pesar de que el concepto endopublicidad supone una aproximación fidedigna a la actividad comunicativa de las agencias de publicidad sobre sí mismas, lo cierto es que este concepto expuesto por Feliu y Fernández-Poyatos (2006) no ha trascendido en la investigación académica de la disciplina. Ante la escasa incidencia del término, se han impuesto los términos autopublicidad, self advertising o metapublicidad como totalizadores genéricos para hacer referencia al discurso que la publicidad lleva a cabo para hablar de sí misma.

Siguiendo las ideas de Lipovetsky y Roux (2004) la publicidad, antes de llevar a cabo su finalidad de incitar al consumo, se designa como publicidad, se muestra como un discurso comercial-publicitario, el medio publicitario tiene como primer mensaje el propio medio, la publicidad es, en ese sentido, metapublicitaria. Sin embargo, si se extrapola esa meta-relación discursiva entre dos textos a una tarea funcional propia de la publicidad, se estaría en una situación en que la agencia, en su lógica objetiva, pretende trabajar por y para un anunciante, convirtiéndolo en algo grandioso. A su vez, la propia agencia de publicidad necesita, de forma intrínseca, promocionarse y venderse a sí misma, ¿cómo sino iban a llegar los clientes? Se trata de la exposición máxima de la funcionalidad: la agencia como generadora de clientes a sus clientes Vs. la necesidad de obtener clientes para sí misma. 
Dentro de este bucle extraño, a modo de mise in abyme, se puede decir que la metapublicidad, por tanto, hace referencia a esa transgresión inmediata que la actividad publicitaria hace de su propia naturaleza funcional: dejar de servir a un cliente/anunciante para servirse a sí misma, siendo la agencia la empresa a la que hay que servir, el concepto autopublicidad resulta más apropiado en este contexto.

No obstante, puesto que el discurso de las agencias para venderse a sí mismas difiere de la propia naturaleza abstrusa de la disciplina y se condensa en un espectro mucho más funcional y teniendo en cuenta que los prefijos auto-, endo- o meta- hacen referencia a un significado de origen griego similar (por sí mismo, dentro o más allá, respectivamente), se entenderá, desde este momento que la actividad global de comunicación que las empresas de publicidad llevan a cabo supone un ejercicio de comunicarse por sí misma, haciendo uso de sus propias herramientas, definiciones y características, por lo que se utilizará el concepto autopublicidad. Todo esto, enmarcado en un contexto fundamentado por la comunicación corporativa de las empresas que encuentra, en las redes sociales, un nuevo escenario de comunicación, promoción y publicidad entre sus públicos directos y con la sociedad en general (Flores Vivar, 2009; Castelló-Martínez, 2013; Nicolás Ojeda y Grandío Pérez, 2013).

\section{La autopromoción tradicional de la agencia de publicidad}

Como se ha comentado anteriormente, la autopublicidad es un concepto poco estudiado dentro de las empresas del sector, a pesar de presentar una controversia popular que ha corrido entre los discursos de muchos publicitarios reconocidos. El concepto de autopublicidad, que se ha definido de distintas formas, entre ellas, como: «espacio publicitario en el que cada soporte (cadena de televisión, emisora radiofónica, etc.) anuncia su programación» (Gutiérrez González, Pedreira Sánchez y Velo Miranda, 2005) ha sido más relevante en los estudios propios del medio televisivo (Fernández-Vázquez, 2001; López Font y González-Oñate, 2005; López-Lita y González-Oñate, 2008; Moreno Fernández, 2007; Pérez-Sánchez, 2012; Valderrama Santomé, 2005).

Otros estudios han considerado la autopublicidad como «el relato constante de los medios acerca de sí mismos, la competencia o la comunicación en general» (Barranquero Carretero, 2012: 243) e incluso se ha llegado a establecer su naturaleza como una estrategia de cross-promotion (De Lara González, Rodríguez Ferrándiz y Sánchez Olmos, 2013: 25). Más allá de la televisión, Quintas y Quintas (2009) en un estudio muy acorde con el presente trabajo, analizan las autorreferencias de las agencias de publicidad en las revistas especializadas del sector mientras que Requejo Alemán y Herrera Damas (2012) llevan el estudio de la autopublicidad a las redes sociales, concretamente a Twitter y al uso que las emisoras de música en España hacen de la red social de los 280 caracteres con los mismos fines.

Las empresas de publicidad tienen su particular medio de difusión en los certámenes o festivales dedicados íntegramente a la creatividad publicitaria. Los reconocimientos y premios logrados tendrán repercusión principalmente en el sector pues- 
to que sus marcas protagonizarán la información profesional inmediata (Quintas y Quintas, 2009). Así, como se ha concebido tradicionalmente, la importancia de la comunicación de las agencias para el público general es más bien escasa, ya que tiene un objetivo mucho más industrial, si bien es cierto que esta mentalidad limita las posibilidades de comunicación de las agencias, el acceso a nuevas cuentas e impide de algún modo, alcanzar el concepto de marca integral, en su máxima expresión.

Según Quintas y Quintas (2009: 47), a pesar de que las agencias de publicidad son los únicos elementos del proceso publicitario cuya subsistencia depende de la publicidad, su interés en la propia publicidad es escaso, ignorando el potencial comunicativo de la autopublicidad como reflejo de los trabajos que pueden realizar para sus clientes. Cabe conocer, por tanto, cómo las agencias de publicidad han trasvasado sus estrategias comunicativas en el contexto digital, puesto que este escenario ha supuesto un cambio de paradigma en la idiosincrasia propia de la autopublicidad. Las redes sociales se convierten, en este contexto, en un escenario propicio para autopromocionarse, así como en el altavoz necesario para conseguir viralizar contenidos, conseguir seguidores/as y trabajar el branding, explotando los recursos creativos de cada agencia y compitiendo por conseguir ser el mejor, no solo en los festivales, concursos de agencias y premios de reconocimiento a la labor publicitaria, sino también, ser la mejor marca haciendo lo que, teóricamente, mejor sabe hacer: comunicar.

\section{Objetivos y metodología}

Este es un trabajo de corte descriptivo que pretende aportar una visión general sobre el uso que las agencias de publicidad españolas hacen de las redes sociales. Por ello, el presente trabajo tiene como objetivo analizar y conocer cómo las redes sociales sirven de escenario promocional y publicitario para las agencias de publicidad. En base a este objetivo principal, surgen otros objetivos específicos a los que se pretende dar respuesta:

(OE1) Detectar qué redes sociales son más comunes en la labor comunicativa autopublicitaria de las agencias.

(OE2) Identificar qué redes sociales son más prolíficas a la hora de generar comunidad alrededor de la agencia de publicidad.

(OE3) Reflexionar sobre el contenido de los materiales publicados por las agencias en las redes sociales generalistas de mayor uso.

La muestra de análisis (tabla 1) se basa en el estudio de los perfiles en redes sociales de las agencias adheridas a la Asociación Española de Agencias de Comunicación Publicitaria (AEACP), fundada en 1977, por considerarla entidad de carácter empresarial sin ánimo de lucro formada por las principales agencias de publicidad españolas, tal y como ellos mismos se definen en su página web (2018). 
Tabla 1. Muestra de agencias analizadas

\begin{tabular}{|c|c|}
\hline Agencia de publicidad & URL \\
\hline $360^{\circ}$ MARKETING Y COMUNICACIÓN & www.360gradosmc.es \\
\hline ARNOLD MADRID & http://arnoldmadrid.com/ \\
\hline BAP \& CONDE & http://www.bapconde.com/ \\
\hline C14TORCE & http://www.c14torce.com \\
\hline CHEIL SPAIN & http://cheil.com/es \\
\hline CONTRAPUNTO BBDO & https://www.contrapuntobbdo.es/ \\
\hline DDB & http://ddb.es/ \\
\hline DEC & https://dec-bbdo.es/ \\
\hline PS21 & https://www.ps21.team/ \\
\hline EL RUSO DE ROCKY & http://www.elrusoderocky.com/ \\
\hline ESTRESA COMUNICACIÓN & http://estresacomunicacion.com/ \\
\hline FCB\&Fire SPAIN & http://www.fcbandfire.com/ \\
\hline GREY GROUP & http://grey.com/spain \\
\hline HAVAS WORLDWIDE SPAIN & https://havas.com/ \\
\hline INNOCEAN WORLDWIDE & http://www.innocean.com/ww-en/ \\
\hline J. WALTER THOMPSON & https://www.jwt.com/es/ \\
\hline LA FÓRMULA & http://laformula.es/ \\
\hline LEO BURNETT & https://leoburnett.com/ \\
\hline M\&C SAATCHI MADRID & http://www.mcsaatchimadrid.com/ \\
\hline LOLA MULLENLOWE & http://lola-mullenlowe.com/ \\
\hline MANIFIESTO & https://manifiesto.biz/es \\
\hline McCANN & http://www.mccann.es/ \\
\hline OGILVY \& MATHER & http://www.ogilvy.es/ \\
\hline PUBLICIS COMUNICACIÓN & http://www.publicis.es/ \\
\hline SAATCHI \& SAATCHI & http://www.saatchi.es/ \\
\hline SHACKLETON & https://www.shackletongroup.com/ \\
\hline TIEMPO / BBDO & https://www.tiempobbdo.com/es \\
\hline VCCP & http://www.vccp.es/ \\
\hline Y\&R & https://www.yr.com/ \\
\hline
\end{tabular}

Fuente: elaboración propia a partir de AEACP (2018) 
A pesar de que en una fase inicial del proyecto se valoraron otros directorios, el juicio del equipo investigador decidió que, con el objetivo de aplicar un muestreo no probabilístico, el soporte seleccionado reunía los requisitos para poder ser objetivo, coherente y extensivo a la profesión en general en España, debido a la envergadura y la popularidad de muchos de los miembros adscritos a la asociación estatal. Esta decisión se apoyó en datos estadísticos, como la facturación global de las agencias adscritas a AEACP, que supone el $85 \%$ de la facturación global de agencias de publicidad de España (según AEACP, 2018; Infoadex, 2019).

El presente trabajo se caracteriza por presentar una metodología mixta que conjuga un método descriptivo de corte cuantitativo con una reflexión cualitativa sobre los posts publicados. En la fase inicial del trabajo (OE1), se ha trabajado en base a una tabla de recogida de datos creada ad hoc en la que se ha tenido en cuenta la presencia de las agencias de publicidad en las redes sociales generalistas con más usuarios/as, así como la promoción que se hace de estos perfiles sociales desde sus páginas web (ver Tabla 2).

Tabla 2. Variables analizadas por red social

\begin{tabular}{|c|c|c|c|}
\hline Facebook & Google+ & Pinterest & YouTube \\
\hline $\begin{array}{l}\text { Presencia o ausencia } \\
\text { en red social }\end{array}$ & $\begin{array}{l}\text { Presencia o ausencia } \\
\text { en red social }\end{array}$ & $\begin{array}{l}\text { Presencia o ausencia } \\
\text { en red social }\end{array}$ & $\begin{array}{l}\text { Presencia o ausencia } \\
\text { en red social }\end{array}$ \\
\hline $\begin{array}{l}\text { Tipo perfil (Fanpage/ } \\
\text { Perfil) }\end{array}$ & URL & URL & URL \\
\hline URL & $\begin{array}{l}\text { Fecha última } \\
\text { publicación }\end{array}$ & Número de seguidores & $\begin{array}{l}\text { Número de } \\
\text { suscriptores }\end{array}$ \\
\hline $\begin{array}{l}\text { Fecha de creación del } \\
\text { perfil }\end{array}$ & \multirow{2}{*}{ Número de seguidores } & \multirow{2}{*}{ Número de seguidos } & $\begin{array}{l}\text { Número de } \\
\text { visualizaciones }\end{array}$ \\
\hline $\begin{array}{l}\text { Número de } \\
\text { seguidores/Me gusta }\end{array}$ & & & $\begin{array}{l}\text { Fecha de } \\
\text { incorporación }\end{array}$ \\
\hline Twitter & Linkedln & Instagram & Vimeo \\
\hline $\begin{array}{l}\text { Presencia o ausencia } \\
\text { en red social }\end{array}$ & $\begin{array}{l}\text { Presencia o ausencia } \\
\text { en red social }\end{array}$ & $\begin{array}{l}\text { Presencia o ausencia } \\
\text { en red social }\end{array}$ & $\begin{array}{l}\text { Presencia o ausencia } \\
\text { en red social }\end{array}$ \\
\hline URL & URL & URL & URL \\
\hline $\begin{array}{l}\text { Fecha de creación del } \\
\text { perfil }\end{array}$ & \multirow{4}{*}{ Número de seguidores } & $\begin{array}{l}\text { Número de } \\
\text { publicaciones }\end{array}$ & Número de vídeos \\
\hline Número de seguidores & & Número de seguidores & Número de seguidores \\
\hline Número de seguidos & & \multirow{2}{*}{ Número de seguidos } & \multirow{2}{*}{ Número de likes } \\
\hline Número de tuits & & & \\
\hline
\end{tabular}

Fuente: elaboración propia 
La muestra sobre la que se ha aplicado el análisis se compone de la totalidad de agencias asociadas a AEACP, aportando un total de 29 casos de estudio analizados, que han sido sometidos al análisis de contenido a partir de la base de datos en cuestión. Para obtener una muestra objetiva y equitativa en tiempo y forma, la recogida de información se realizó en la semana del 28 de enero al 03 de febrero de 2019. Para la selección y localización de los perfiles en redes sociales se ha aplicado el criterio de la inclusión y vinculación en la web, por considerar que la web es el portal de referencia inicial de las agencias. Por tanto, se han analizado los perfiles en redes sociales siempre y cuando se vinculen desde la web corporativa de la agencia.

Para la segunda fase del trabajo (OE2) se han tenido en cuenta las variables que aportan información sobre el engagement, viralidad e interacción de los públicos con los contenidos publicados por las agencias en sus perfiles sociales. Para ello, se han tenido en cuenta variables relacionadas con el número de seguidores/as y la viralidad o número de veces que ha sido compartido (en aquellas redes sociales que permiten conocer esa información) y el engagement que se ha obtenido desde los orígenes del perfil social, en base a las métricas ofrecidas por cada una de las redes sociales analizadas.

En una tercera fase, de corte exploratorio (OE3), se ha realizado una reflexión cualitativa de los últimos cinco contenidos publicados por cada una de las agencias en las redes sociales generalistas Facebook y Twitter, con el fin de identificar el tono comunicativo y la finalidad con la que usan las redes sociales, con un enfoque más cualitativo, que complemente los datos descriptivos obtenidos en fases previas. Se han seleccionado estas dos redes sociales para aportar una reflexión sobre el contenido por considerar que son las redes sociales más prolíficas, puesto que son las que presentan un mayor volumen de uso por parte de las agencias analizadas. El estudio reflexivo sobre los contenidos se ha aplicado sobre las tres agencias con más seguidores/as en las redes generalistas mencionadas, con el fin de eliminar problemas representativos derivados de la poca o nula actividad de otras agencias en el periodo de recogida de datos seleccionado. Cabe destacar que este tercer objetivo, por su naturaleza, pretende aportar una respuesta sobre si los contenidos muestran alguna vinculación estratégica y merecen ser analizados en profundidad, abriendo nuevas líneas investigadoras si así se confirmara en los resultados.

\section{Resultados}

\subsection{Presencia, engagement y situación de las agencias de publicidad en redes sociales}

De los 29 casos de estudio analizados, todos ellos aplican la vinculación a sus redes sociales desde sus páginas web excepto tres casos (Cheil Spain, Satchi y Satchi y Oglivy y Matters), algo curioso, si se tiene en cuenta la envergadura de estas agencias a nivel internacional. 
Facebook es, junto a Twitter, la red social más popular entre las agencias de publicidad analizadas, con 22 casos frente a 7 que no la vinculan a sus webs (ver gráfico 1). El promedio de seguidores/as en Facebook es de 13.598, destacando el caso de INNOCEAN WORLDWIDE con 41.883 seguidores/as, muy superior a la media. Además, destaca que todas las agencias utilizan Fan Page, y ninguna de las analizadas presentan perfiles de usuario-a. En términos generales, el número de seguidores/as no es muy elevado en las Fan Page de Facebook, sin embargo, es necesario destacar que algunas agencias, como DEC o Estresa Comunicación, apenas acumulan 107 y 310 seguidores/as, respectivamente.

Gráfico 1. Presencia en Facebook de las agencias

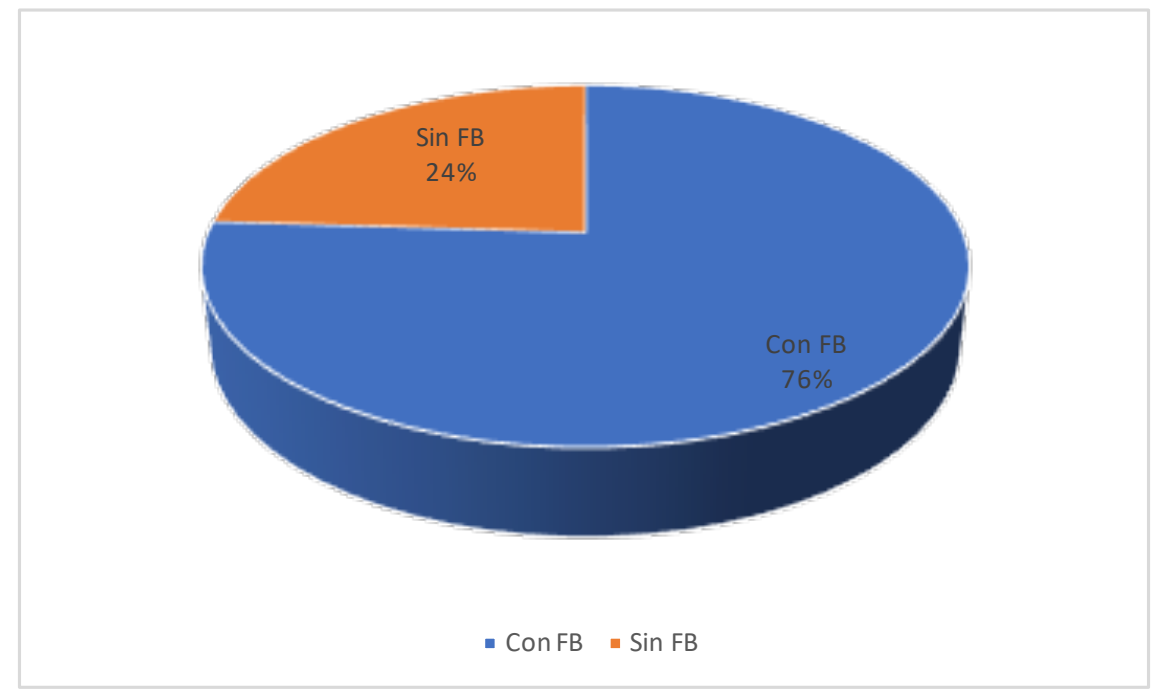

Fuente: elaboración propia.

El caso de Twitter (ver gráfico 2) presenta una radiografía similar a la de Facebook: un $75.8 \%$ de las agencias analizadas ( 22 casos) tienen un perfil abierto en esta red que promocionan desde su web. Solo 7 agencias $(24.2 \%)$ prescinden de Twitter o no lo publicitan desde sus websites. En términos generales, las agencias han publicado 80.993 tuits desde su creación hasta la fecha de cierre de recogida de datos de este trabajo. Sin embargo, a pesar de que el promedio de tuits es de 4.049 tuits por agencia, si se analizan de forma particular los datos, se detectan usos muy dispares de Twitter: 
Gráfico 2. Presencia en Twitter de las agencias

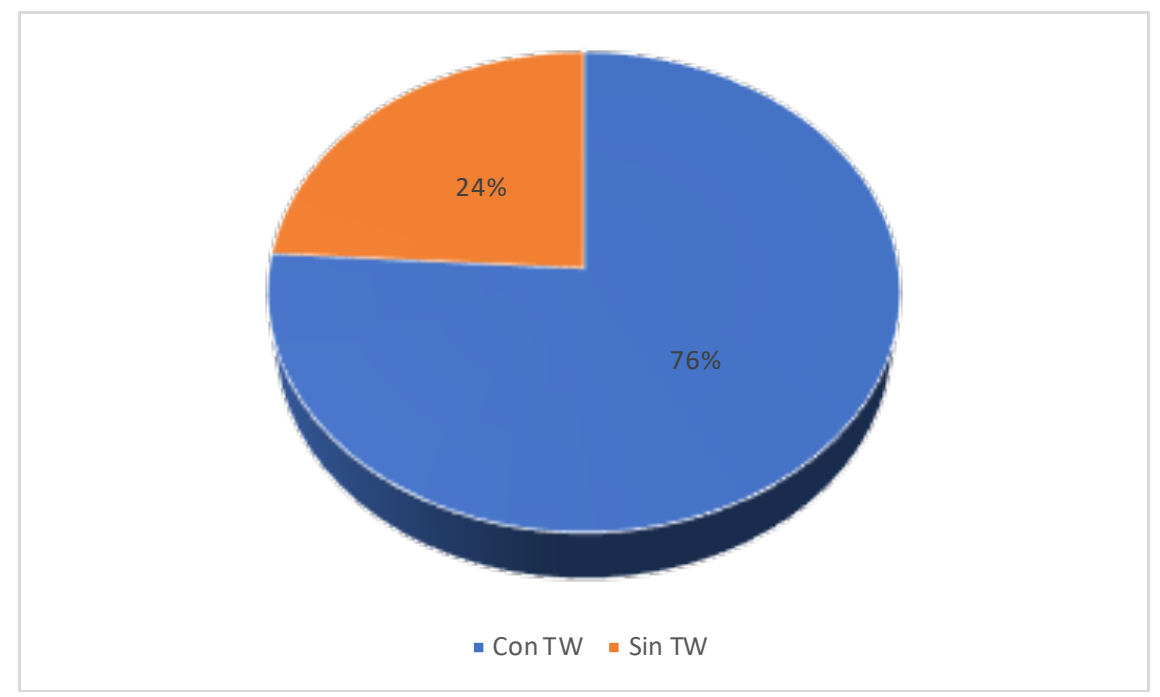

Fuente: elaboración propia.

Havas Wordlwide Spain y Lola Mullenlowe son las agencias punteras en el uso de Twitter, con alrededor de 14.000 y 12.000 tuits publicados, respectivamente. El caso de Lola Mulenlowe además, puede justificarse por ser el perfil más longevo de la muestra, en funcionamiento desde marzo de 2007, mientras que el perfil de Havas WordlWide Spain, fue abierto en marzo de 2009. En contra, las agencias $360^{\circ}$ Marketing y Comunicación y Contrapunto BBDO son las menos activas, con 782 y 948 tuits publicados de forma respectiva. En estos casos, la fecha de creación resulta determinante si se tiene en cuenta que Contrapunto BBDO mantiene su perfil desde enero de 2010, $360^{\circ}$ Marketing y Comunicación, sin embargo, lo estrenó cuatro años después, en marzo de 2014. Más allá de estos datos desiguales entre unas agencias y otras, se ve que hay casos en los que la actividad resulta inusual, por ejemplo, en el perfil de $Y \& R$, que solo ha publicado dos veces desde su creación (01/11/2018) o el perfil de La Fórmula, que, a pesar de estar en funcionamiento desde febrero de 2017, no ha compartido ningún contenido en su muro.

Mientras que los/as usuarios/as a los que siguen no resultan un dato relevante en este trabajo, sí lo es el número de seguidores/as de cada agencia. En términos totalizadores, las agencias albergan una media de 258.743 seguidores/as. En este sentido, destaca la agencia Leo Burnett que despunta con 102.803 seguidores/as, muy por encima del promedio de seguidores/as del resto de agencias, seguida, muy de lejos, de Havas Wordlwide Spain con 50.125 seguidores/as o Mccan, con 24.208. 
En cuanto a Google+ (ver gráfico 3) solo la utilizan un $17,5 \%$ de las agencias analizadas, correspondiente a cinco casos (Leo Burnett, Mccan, $360^{\circ}$ Marketing y Comunicación, SHACKLETON y VCCP). El resto prescinde del uso de esta red y tampoco la incluyen en sus páginas web, algo lógico si se tiene en cuenta la escasa incidencia social de esta web y sus malas previsiones de futuro. Los datos de penetración son de dudoso éxito, puesto que más allá de Leo Burnett que recoge 2.332 seguidores/as en Google+, el resto no supera en ningún caso los/as 300 seguidores/ as, e incluso se detecta algún caso con tres y once seguidores/as $\left(360^{\circ}\right.$ Marketing y Comunicación y VCCP, respectivamente). Algo similar ocurre con Pinterest, que solo es utilizada por la agencia Leo Burnnet y que, a pesar de la escasa incidencia de esta red social, cuenta con 2.229 seguidores/as en ella.

Gráfico 3. Presencia en Google+ de las agencias

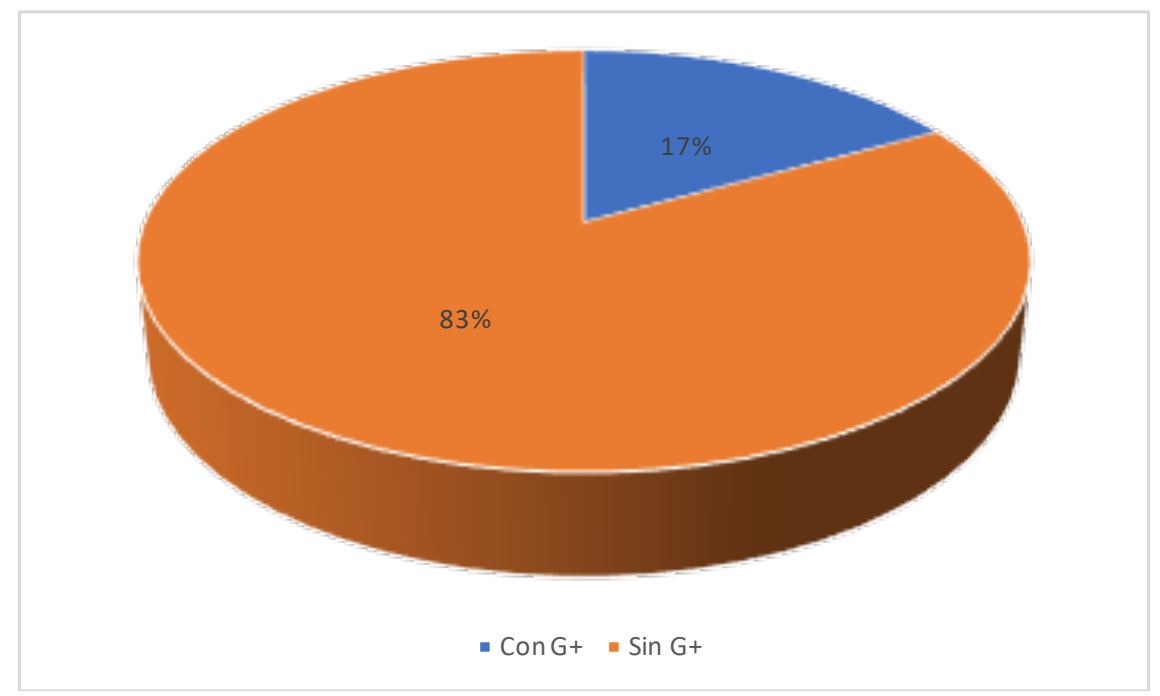

Fuente: elaboración propia.

Al analizar el uso de YouTube (ver gráfico 4) se detecta que esta red social tampoco supone un modelo de comunicación compartido y recurrente entre las agencias analizadas, puesto que solo un $44,8 \%$ de las agencias la utiliza (13 casos), a pesar del creciente potencial audiovisual de esta red social y plataforma audiovisual en los últimos años. Aunque el total de seguidores/as que acumulan las agencias es de 67.610, se detectan datos muy dispares: mientras que Contrapunto BBDO acumula 47.825 seguidores/as, seguida, muy de lejos, de Leo Burnett, con 10.974 seguidores/as, el resto de los perfiles de agencia en YouTube apenas alcanzan los dos mil seguidores/as. Contrapunto BBDO, además, mantiene un récord de visualizaciones 
superior a los cincuenta y cuatro millones en la totalidad de sus contenidos, algo comprensible si se tiene en cuenta que es el perfil más longevo (abierto en septiembre de 2007). Leo Burnett, por su parte, recoge 23.321.280 visualizaciones, con un perfil abierto dos años más tarde (mayo de 2009). Sin embargo, la longevidad del canal parece no tener demasiada incidencia al relacionarla con el número de visualizaciones, puesto que otras agencias, como BAP \& CONDE o TIEMPO / BBDO, también abrieron sus perfiles en 2007, al igual que la agencia con más relevancia en visualizaciones y apenas alcanzan 489.198 y 1.830 .304 visualizaciones, respectivamente. Por su parte, Vimeo, como red social audiovisual solo es utilizada por tres agencias: FCB\&Fire SPAIN, Manifiesto y Leo Burnett y el impacto de datos es poco relevante si se tiene en cuenta que apenas acumulan 28,42 y 989 , respectivamente, siendo el uso también escaso, puesto que Leo Bunett, por ejemplo, solo ha compartido 282 contenidos, frente a los 135 de Manifiesto o los 23 de FCB\&Fire.

Gráfico 4. Presencia en YouTube de las agencias

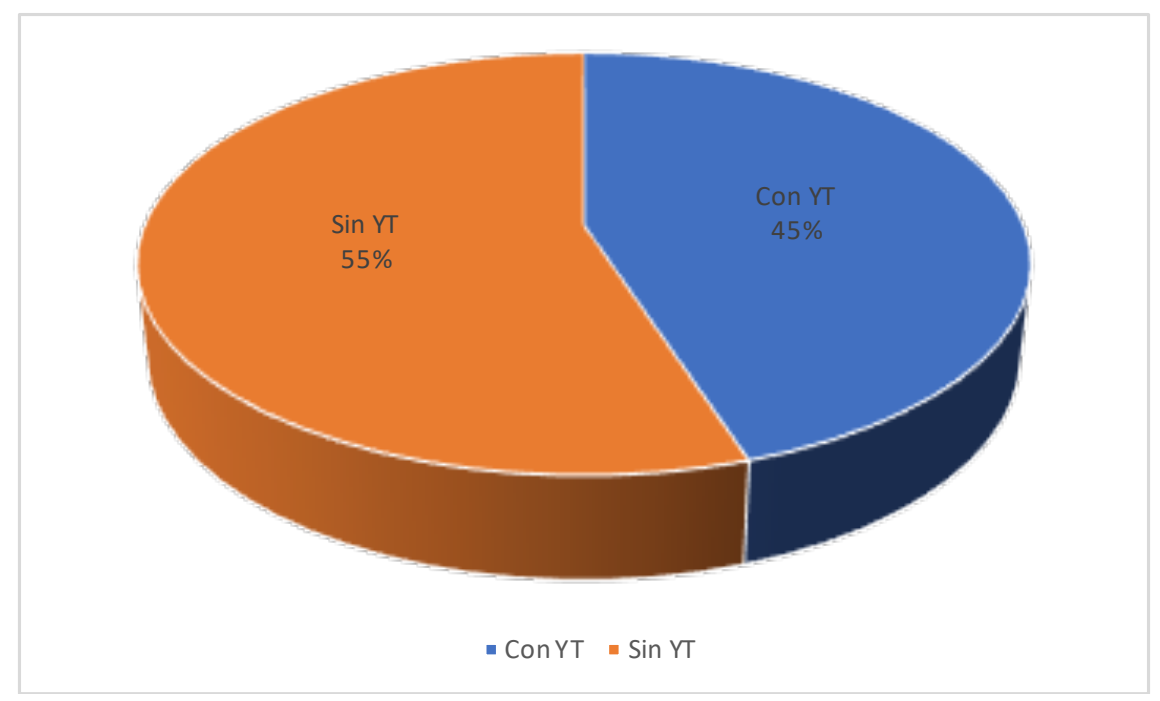

Fuente: elaboración propia.

Si se centra la atención en la red social profesional por excelencia, LinkedIn (ver gráfico 5), los datos siguen sin ser esperanzadores para la aplicación de la comunicación en redes sociales de las agencias: el $51 \%$ de las agencias (15 casos) mantiene un perfil abierto. En este caso, vuelve a destacar el volumen de seguidores/ as de Leo Burnett, que asciende a 327.686, seguida de Y\&R con 201.590. El resto de las agencias con LinkedIn se mantiene por debajo de los dos mil seguidores/as, 
con casos, además, muy significativos por su poco tráfico, como es el caso de La Fórmula, con apenas 383 seguidores/as. Resulta destacable el perfil de la agencia $360^{\circ}$ Comunicación y Marketing que, a través de su página web, vincula a un perfil de LinkedIn con 500 seguidores/as que se corresponde con el perfil personal del director de la agencia. Algo destacable por su carácter distinto y que no acaba de encajar en la política de posicionamiento y comunicación que las redes sociales pueden aportar a las empresas y tampoco resulta coherente con la estrategia seguida por esta agencia en otras redes sociales.

Gráfico 5. Presencia en LinkedIn de las agencias

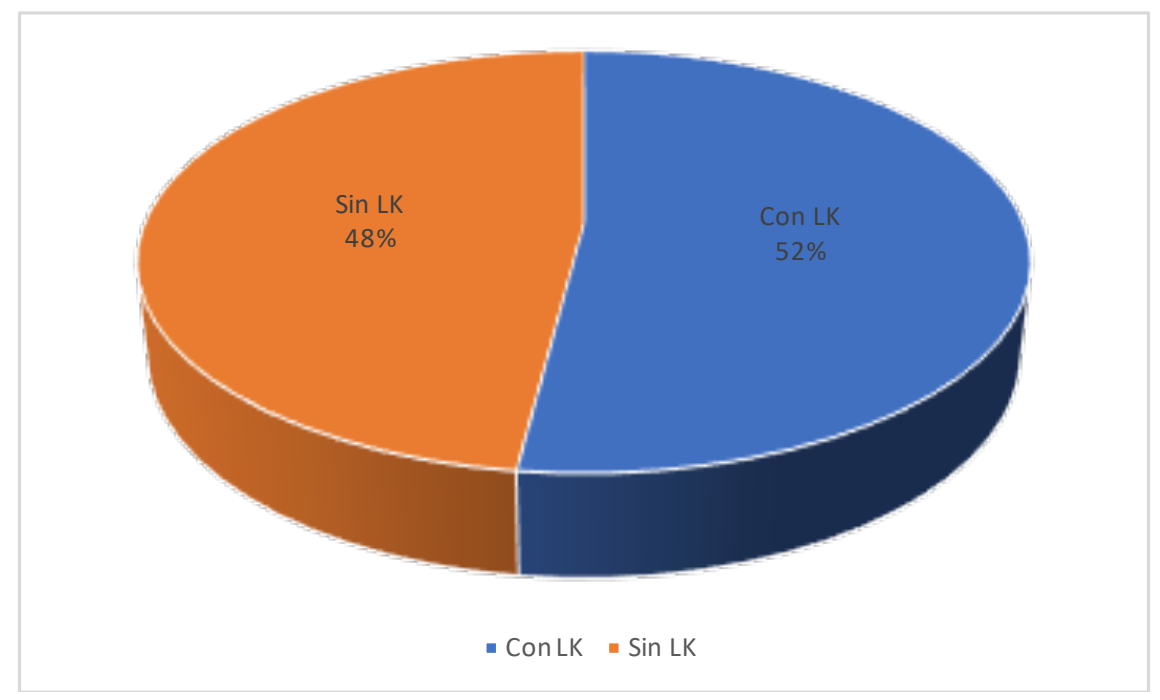

Fuente: elaboración propia

El caso de Instagram (ver gráfico 6) devuelve unos datos en línea a lo analizado previamente. Solo el $38 \%$ de las agencias mantiene un perfil abierto en esta red social (11 casos) a pesar de ser una de las redes sociales más visuales y con mayor penetración (IAB Spain, 2018), sobre todo, entre la población joven en los últimos años. En esta red destaca de nuevo Leo Burnett, con 112.303 seguidores/as y 794 publicaciones, seguida de lejos de Lola Mullenlowe con 12.988 seguidores/as, a pesar de que esta agencia ha duplicado prácticamente el número de publicaciones (1.363). Algunas, con solo tres publicaciones, apenas acumulan 62 seguidores/as, como es el caso de La Fórmula. El resto de los perfiles en Instagram, apenas superan los dos mil seguidores/as, algo que demuestra la poca incidencia de la comunicación de las agencias en esta red social. 
Gráfico 6. Presencia en Instagram de las agencias

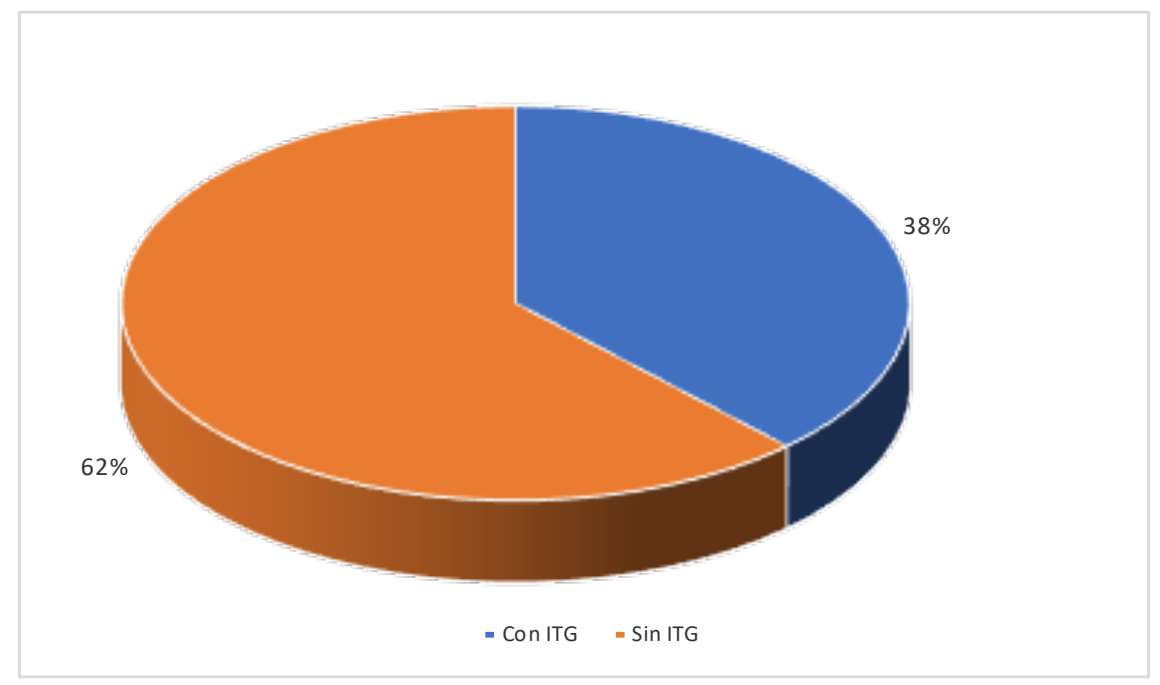

Fuente: elaboración propia.

4.2. Contenidos publicados y usos de las redes sociales por parte de las agencias de publicidad

El contenido que comparten las agencias de publicidad analizadas en sus perfiles sociales resulta peculiar, si se tiene en cuenta la naturaleza y contenido de las publicaciones que han sido analizadas cualitativamente. Teniendo en cuenta que se han tenido en cuenta los últimos cinco posts publicados por las tres agencias con mayor número de seguidores/as en las redes sociales Facebook y Twitter, se detecta que el uso que se hace de las redes sociales no muestra, inicialmente, una estrategia de comunicación definida.

En ese sentido, al analizar las publicaciones de Leo Burnett, por ser la agencia con mayor incidencia en redes sociales, se observa que las últimas cinco publicaciones en Facebook se corresponden con posts destinados a promocionar una nueva campaña desarrollada por la marca. Esta estrategia sirve como escaparate para mostrar el nivel de trabajo y el resultado de la agencia, sin embargo, se debe destacar que el post supone una promoción indirecta al propio anunciante de la campaña que, de un modo u otro, diluye la autopromoción de la propia agencia. Si se abre el abanico temporal, se puede encontrar otro tipo de publicaciones en el perfil de Facebook de Leo Burnett, como la comunicación de los premios recibidos por la agencia o la incorporación de nuevos cargos directivos, estrategias que, de algún 
modo, sí que responden a una estrategia corporativa de autopromoción de la agencia. En cuanto a la actividad en Twitter, se destaca que supone un calco de las publicaciones en Facebook, por lo que objetivos, usos y estrategia se corresponden con las mencionadas.

Havas Creative, por su parte, destaca por utilizar el muro de Facebook para aplicar una estrategia mixta que conjuga el escaparate de sus últimas aportaciones al entorno publicitario con las noticias propias de la agencia. Al centrar la atención en las últimas cinco publicaciones, se detecta un equilibrio entre mensajes que benefician directamente a la corporación (como nuevas incorporaciones o entrevistas a los/as trabajadores/as), combinado con la exposición de resultados de campañas. Este equilibrio acerca a los/as usuarios/as a un uso más estratégico que el del caso anterior, puesto que permite, no solo transmitir en redes sociales la capacidad publicitaria y los resultados de la agencia, sino que apuesta por un mensaje mucho más corporativo, que hace sólidos los pilares de la corporación y trabaja su branding core de forma explícita. Si se amplía el abanico temporal, se puede confirmar que esta estrategia detectada sigue utilizándose más allá de los últimos posts que conforman este análisis por lo que todo apunta a que la red social se utiliza con un fin comunicativo y publicitario de forma coherente. Al igual que ocurría con el caso de Leo Burnett, las publicaciones de Havas Creative en Twitter suponen una réplica de lo expuesto en Facebook, si bien es cierto que destaca el uso de recursos propios de Twitter como son los hashtags o los retuits a sus propias publicaciones. Además, se detecta que no existe una estrategia transmedia (Scolari, 2013) ni un mapa transmedia (Segarra-Saavedra y Hidalgo-Marí, 2018).

El tercer caso se corresponde con Innovean WordWeb, que, a pesar de ser una agencia de las que más seguidores/as en redes sociales presenta, no aporta un valor significativo si se habla del uso que hacen de los posts y contenidos compartidos, puesto que sus publicaciones muestran, de forma muy descriptiva, resultados puntuales de sus trabajos que, además, no presentan relación temporal con la fecha de publicación. Resulta curioso cómo, a pesar de la gran cantidad de seguidores/as que presentan en Facebook, su estrategia es poco publicitaria y, además, no existe relación en otras redes sociales puesto que no disponen de ellas.

\section{Conclusiones}

Como se ha podido observar en el estudio presentado, el uso que las agencias de publicidad hacen de las redes sociales es escaso y no muestra, en términos generales, una gran incidencia estratégica que vincule a los social media con las agencias de publicidad y comunicación.

Los datos descriptivos demuestran que las redes sociales generalistas, en concreto Facebook y Twitter, son las preferidas por las agencias para comunicarse con sus seguidores/as, puesto que el resto de redes sociales apenas presentan, en términos generales, actividad ni un esfuerzo por conseguir seguidores/as. Instagram, a pesar de ser la red social con más crecimiento (IAB Spain, 2018), apenas tiene peso en 
el desarrollo comunicativo de las agencias analizadas. Además, se constata que las redes sociales audiovisuales natas, como pueda ser YouTube o Vimeo, no parecen ser recursos promocionales que interesen a las agencias, a pesar del gran alcance de las mismas, su alto posicionamiento y las posibilidades audiovisuales, vinculadas con la publicidad que ofrecen.

En cuanto a las redes sociales profesionales, en concreto LinkedIn, se ha constatado que no existe demasiado interés en vincularla a la agencia, a pesar de que se ha detectado algún caso puntual, en el que se utiliza para vincular la agencia al perfil personal de su directivo o director.

Si se retoma el segundo objetivo de este trabajo, que pretendía identificar qué redes sociales son más prolíficas a la hora de generar comunidad alrededor de la agencia de publicidad, se observa que siguen siendo Facebook y Twitter las que mayor número de fans o seguidores recogen. Esta afirmación es coherente con el uso generalista de sendas redes sociales, si bien es cierto que sorprende la poca comunidad creada alrededor de otras redes muy visuales, como pueden ser YouTube o Instagram y que, sin duda, encajarían perfectamente como difusoras del mensaje de la agencia de publicidad.

En lo relativo al OE3, es decir, reflexionar sobre el contenido de los contenidos publicados por las agencias en las redes sociales generalistas de mayor uso, si se habla en términos de uso, se ha podido comprobar que no existe una estrategia clara que explique el empleo que las agencias hacen de las redes sociales, ni cuáles son los objetivos esenciales que las sustentan. Los contenidos suelen corresponderse con la publicación de campañas realizadas para otros clientes y sus resultados, con lo que la agencia muestra su capacidad y su estilo de trabajo pero su autopromoción se diluye en aras de la promoción del cliente. O lo que es lo mismo, se demuestra el planteamiento que otras autoras han afirmado sobre las agencias (Quintas y Quintas, 2009): que la agencia depende de la publicidad porque necesita apostar por la publicidad creada por el cliente para no entrar en conflicto con los mismos.

Todo lo expuesto lleva a volver al origen del documento en el que se comentaba que las agencias de publicidad tienen sus espacios de promoción en los festivales y certámenes destinados a tal fin, evitando su autopromoción en soportes mediáticos que, de alguna forma u otra, pudieran inducir a un conflicto de intereses o competencia con sus clientes. Se partía de la premisa de que las redes sociales podrían ser el escenario perfecto para que las agencias de publicidad hablaran de ellas mismas y así es, sin embargo, hablan de ellas mismas en la sombra, poniendo siempre al frente al cliente, al anunciante para el que trabajan y su estrategia corporativa pasa a segundo plano.

A modo de síntesis, se plantea el tímido, pero existente empoderamiento de la agencia de publicidad en redes sociales, gracias a la publicación de noticias internas, cambios en los puestos directivos o premios recibidos. Este es el camino que, a nuestro parecer, deben empezar a tomar las agencias de publicidad, aprovechan- 
do la idiosincrasia de las redes sociales y, a pesar de que apenas se detecta, todo parece apuntar que estamos ante el principio de un nuevo funcionamiento de la comunicación y de la publicidad de las agencias de publicidad.

\section{Bibliografía}

Adam, Jean Michel y Bonhomme, Marc (2000). La argumentación publicitaria. Retórica del elogio y de la persuasión. Madrid: Cátedra, 2000.

Aprile, Orlando C. (2010). La agencia de publicidad. En: Reflexión Académica en Diseño y Comunicación, Vol. 13. Buenos Aires: Universidad de Palermo, 16-17.

Asociación Española de Agencias de Comunicación Publicitaria [AEACP] (2018). La inversión publicitaria gestionada en 2017 por las agencias de publicidad. En: https://bit.ly/2U5rDrD (Consultado 16-07-2019).

Barranquero Carretero, Alejandro (2012). Teoría de la autorreferencia mediática. Un balance crítico de los primeros estudios. En: Estudios sobre el mensaje periodístico, Vol. 18, $\mathrm{n}^{\mathrm{o}}$ 1. Madrid: Universidad Complutense de Madrid, 243-258. http:// dx.doi.org/10.5209/rev_eSMP.2012.v18.n1.39368

Bravo, Rafael; Cambra-Fierro, Jesús; Centeno, Edgar y Melero, Iguácel (2017). The Importance of Brand Values in Family Business. En: Journal of evolutionary studies in business, Vol. 2, $\mathrm{n}^{\mathrm{o}}$ 2. Barcelona: Universitat de Barcelona, 16-43. http://dx.doi. org/10.1344/jesb2017.2.j029

Castelló-Martínez, Araceli (2013). Estrategias empresariales en la Web 2.0. Las redes sociales Online. Alicante: Editorial Club Universitario.

De Lara González, Alicia; Rodríguez Ferrándiz, Raúl y Sánchez Olmos, Cande (2013). El medio en el mensaje: La autorreferencia en la televisión generalista. En: Pensar la publicidad: revista internacional de investigaciones publicitarias, Vol. 7, $n^{0}$ 1. Madrid: Universidad Complutense de Madrid, 25-46.

Echezuría, Sonia (1999). Promocionarte. En: Razón y palabra, no 16. Quito: Editorial Razón y Palabra.

Feliu García, Emilio (1996). La negación (metadiscursiva) de la publicidad. En: Mitos, Actas del VII Congreso Internacional de la Asociación Española de Semiótica. Zaragoza, Departamento de Lingüística general e Hispánica. Recuperado de: https://bit.ly/2IcfpvP

Feliu, Emilio y Fernández-Poyatos, María Dolores (2006). Reflexiones Autopublicitarias. En: Losada Vázquez, A.; Plaza Sánchez, J. F., y Huerta, M. Á. (coords.). Comunicación, Universidad y Sociedad del Conocimiento. Actas del IV Congreso Internacional. Salamanca: Universidad Pontificia de Salamanca, 909-924.

Fernández-Vázquez, Jessica (2011). Autopromoción comparativa de la televisión en España: Antena 3 vs Telecinco. En: Pensar la publicidad: revista internacional 
de investigaciones publicitarias, Vol. 5, $\mathrm{n}^{\circ}$ 2. Madrid: Universidad Complutense de Madrid, 277-298.

Ferrer Roselló, Clemente Gabriel (1998). La publicidad de la A a la Z. Madrid: Edimarco.

Flores Vivar, Jesús Miguel (2009). Nuevos modelos de comunicación, perfiles y tendencias en las redes sociales. Comunicar, Vol. 17, n ${ }^{0} 33,73-81$. http://dx.doi. org/10.3916/c33-2009-02-007

Genette, Gerard (1989). Palimpsestos: la literatura en segundo grado. Barcelona: Taurus.

Gutiérrez González, Pedro Pablo; Pedreira Sánchez, David y Velo Miranda, Miriam (2005). Diccionario de la publicidad. Madrid: Editorial Complutense.

Interactive Advertising Bureau Spain [IAB Spain] (2018). Estudio anual de redes sociales 2018. En: https://bit.ly/2J95UhE (Consultado 16-07-2019).

Infoadex (2019). Resumen del estudio Infoadex de la inversión publicitaria en España 2019. En: https://bit.ly/2F6mHNx (Consultado 16-07-2019).

Lipovetsky, Gilles y Roux, Elyette (2004). El lujo eterno: de la era de lo sagrado al tiempo de las marcas. Madrid: Anagrama.

López Font, Lorena y González-Oñate, Cristina (2005). El posicionamiento en 20”: las autopromociones de las cadenas de televisión. En: Comunicar: Revista científica iberoamericana de comunicación y educación, Vol. 25, $\mathrm{n}^{\circ}$ 2. Huelva: Grupo Comunicar.

López-Lita, Rafael y González Oñate, Cristina (2008). Estrategia de intangibles en el medio televisivo. En: Pensar la Publicidad, Vol. 2, n ${ }^{\circ}$ 22. Madrid: Universidad Complutense de Madrid, 159-169.

Mangold, W. Glynn y Faulds, David J. (2009). Social media: The new hybrid element of the promotion mix. En: Business Horizons, Vol. 52, $\mathrm{n}^{\mathrm{o}} 4$. Indiana: Indiana University, 357-365.

Martín-Guart, Ramón, y Fernández Cavia, José (2014). La publicidad y la agencia de medios frente al cambio en el ecosistema mediático. En: Cuadernos.Info, $\mathrm{n}^{\mathrm{o}}$ 334. Santiago de Chile: Pontifica Universidad Católica de Chile, 13-25. https://doi. org/10.7764/cdi.34.572

Moreno Fernández, María de los Ángeles (2007). El discurso de identidad de la televisión pública. En: Telos, n ${ }^{0}$ 71. Madrid: Fundación Telefónica, 11-20.

Nicolás Ojeda, Miguel Ángel y Grandío Pérez, María del Mar (2013). Estrategias de comunicación en redes sociales. Barcelona: Gedisa.

Ogilvy, David (1990). Confesiones de un publicitario. Barcelona: OIKOS-TAU. Ogilvy, David (2001). Ogilvy y la publicidad. Barcelona: Folio. 
Pérez-Latre, Francisco Javier (2009). Advertising fragmentation: the beginning of a new paradigm? En: Powell, H.; Hardy, J.; Hawkin, S. y Macrury, I. (eds.). The advertising handbook. London: Routledge.

Pérez-Sánchez, Javier (2012). Las autopromociones desde el punto de vista de la continuidad y la comunicación publicitaria en televisión. En: Estudios sobre el mensaje periodístico, Vol. 18, $\mathrm{n}^{\circ}$ 2. Madrid: Universidad Complutense de Madrid, 713720. http://dx.doi.org/10.5209/rev_PEPU.2011.v5.n2.37873

Quintas Froufe, Eva y Quintas Froufe, Natalia (2009). La publicidad de los publicitarios: estudio de la autopromoción de las agencias de publicidad en revistas especializadas (2000-2007). En: Pensar la Publicidad, Vol. 2, n ${ }^{0}$ 1. Madrid: Universidad Complutense de Madrid, 191-220.

Requejo Alemán, José Luis y Herrera Damas, Susana (2012). La autopromoción, principal uso que las emisoras musicales españolas están haciendo de Twitter. En: de Haro de San Mateo, M. V.; Grandío, M. M. y Hernández, M. (coords.). Historias en red: impacto de las redes sociales en los procesos de comunicación. Murcia: Universidad de Murcia.

Russell, Thomas J. y Ronald Lane, W. (1994). Kleppner: Publicidad. Madrid: Pearson. Scolari, Carlos Alberto (2013). Narrativas transmedia: cuando todos los medios cuentan. Barcelona: Deusto.

Segarra-Saavedra, Jesús y Hidalgo-Marí, Tatiana (2018). Influencers, moda femenina e Instagram: el poder de la influencia en la era 2.0. En: Revista Mediterránea de Comunicación, Vol. 9, $\mathrm{n}^{\mathrm{o}}$ 1. Alicante: Grupo COMPUBES, 313-325. https://www. doi.org/10.14198/MEDCOM2018.9.1.17

Valderrama Santomé, Mónica (2005). De la paleo a la neotv a través de la autopromoción y la identidad televisiva: el caso de TVG. En: Área abierta, $\mathrm{n}^{0} 10$. Madrid: Universidad Complutense de Madrid, 1-17.

Vollmer, Christopher (2009). Darwinismo digital. En: Gestión, Vol. 14, no 5 . Buenos Aires: World of Business Ideas, 62-73. 
Comunicación de la sostenibilidad de las principales marcas de fast fashion españolas e italianas: Zara, Mango, Calzedonia y OVS. Diferencias entre el punto de venta online y el punto de venta físico Communication regarding corporate sustainability of the main Spanish and Italian fast fashion brands: Zara, Mango, Calzedonia and OVS. Difference between the online point of sale platform and physical point of sale

Raquel Martín López Universidad CEU Cardenal Herrera

\section{Referencia de este artículo}

Martín López, Raquel (2019). Comunicación de la sostenibilidad de las principales marcas de fast fashion españolas e italianas: Zara, Mango, Calzedonia y OVS. Diferencias entre el punto de venta online y el punto de venta físico. adComunica. Revista Científica de Estrategias, Tendencias e Innovación en Comunicación, (18), 123-152. DOI: http://dx.doi.org/10.6035/2174-0992.2019.18.8

\section{Palabras clave}

Moda; Fast Fashion; Comunicación; Merchandising; Greenwashing; Sostenibilidad corporativa

\section{Key words}

Fashion; Fast Fashion; Communication; Merchandising; Greenwashing; Corporate Sustainability.

\section{Resumen}

La preocupación por la sostenibilidad ha adquirido importancia en los últimos años en la industria de la moda, tras la tragedia del derrumbe del Rana Plaza en 
Bangladesh en 2013, donde se puso de manifiesto las posibles deficiencias en las memorias de sostenibilidad de los grandes grupos del sector. El objetivo principal de la investigación es verificar si las principales marcas de fast fashion españolas e italianas, incorporan criterios de sostenibilidad corporativa, tanto en el punto de venta físico, como en el online. La investigación ha sido llevada a cabo mediante dos técnicas cualitativas. En primer lugar, el análisis de contenido de la tienda online o web corporativa en Italia de Zara, Mango, Calzedonia y OVS. En segundo lugar, un estudio descriptivo del punto de venta físico en la capital italiana de las marcas seleccionadas. Los resultados revelan que las marcas Zara, Mango y OVS realizan una mayor inclusión de su sostenibilidad corporativa en sus canales de comunicación: en la web corporativa en el caso de Zara y OVS, y en la tienda online en el caso de Mango. El merchandising no es explotado por las marcas analizadas.

\begin{abstract}
Concern for the corporate sustainability has become important in recent years in the fashion industry after the tragedy of the collapse of Rana Plaza in Bangladesh in 2013, which revealed possible deficiencies in sustainability reports from the largest groups of the sector. The main objective of this research is to verify if the main Spanish and Italian fast fashion brands incorporate corporate sustainability criteria, both at their physical and online points of sale. The research has been carried out using two qualitative techniques: content analysis and a descriptive study. Firstly, the content analysis of the online store or corporate website in Italy of Zara, Mango, Calzedonia and OVS. Secondly, a descriptive study of the physical point of sale of the selected brands in Rome. The results reveal that Zara, Mango and OVS brands make a greater inclusion of their corporate sustainability in their communication channels: in the corporate website in the case of Zara and OVS, and in the online store in the case of Mango. Merchandising is not exploited by the brands analysed.
\end{abstract}

\title{
Autora
}

Raquel Martín López [raq.martin.ce@ceindo.ceu.es] es Graduada en Dirección de Empresas y Marketing por la Universidad CEU Cardenal Herrera. Máster en Moda, Gestión del Diseño y Operaciones realizado de forma conjunta en la Universidad CEU Cardenal Herrera y el Instituto Textil AITEX. Tres años de experiencia como Marketing Manager. Desarrollando los estudios de Doctorado en la Universidad CEU Cardenal Herrera con una tesis de Comunicación Social.

\section{Créditos}

La investigación fue desarrollada durante la movilidad internacional de la autora en la Sapienza Università di Roma (Italia), financiada por el Banco Santander. 


\section{Introducción}

Informes de organismos científicos, organizaciones no gubernamentales y medios de comunicación advierten diariamente del «efecto depredador de los seres humanos: cambio climático, pérdida de recursos marinos, modificaciones de los registros de las enfermedades infecciosas y parasitarias» (Muñoz, 2008: 197). En un contexto de crisis ambiental, con la lucha contra el cambio climático como uno de los grandes desafíos a los que se enfrenta la humanidad, es pertinente analizar cómo las grandes marcas de moda comunican a través de los medios de comunicación propios y del punto de venta físico su preocupación por la sostenibilidad ambiental, en línea con el concepto definido en 1987 en el conocido como Informe Brundtland: aquella que «satisface las necesidades de la generación presente sin comprometer la capacidad de las generaciones futuras para satisfacer sus propias necesidades» (World Commission on Environment, 1987: 59).

La preocupación por la sostenibilidad en la industria de la moda ha ido adquiriendo importancia en los últimos años, sobre todo, tras el derrumbe del Rana Plaza en Bangladesh en 2013. La tragedia puso de manifiesto las posibles deficiencias que no eran visibles en las memorias de sostenibilidad de grandes grupos empresariales del sector textil y de la confección. Tras las noticias publicadas desde ese momento, en las que se informaba de cómo las empresas del sector han provocado grandes impactos medioambientales, las empresas han optado por empezar a transformar los procesos (a medio y largo plazo) hacia sistemas más responsables con las personas y con el medioambiente. Pelta (2011: 1) señala que la industria de la moda es altamente problemática, en la medida en que se ha convertido en una de las más nocivas para el medioambiente y también "para las condiciones de vida de muchos trabajadores de todo el mundo que se encuentran sumergidos en un régimen de precariedad y explotación laboral».

Según Moorhouse y Moorhouse (2018: 7), la moda es ampliamente considerada como la segunda industria más destructiva para el medioambiente (por detrás de la petrolífera), con una cadena de suministro global que emplea a 58 millones de personas en todo el mundo. Los mismos autores exponen que «la presión de ONG, diseñadores, marcas y consumidores ha aumentado para desarrollar prácticas más sostenibles dentro de la industria del diseño de moda» (2018: 8).

Es importante reseñar que ante la creciente presión social para que las empresas informen sobre los impactos ambientales, «algunas revelan de manera selectiva impactos relativamente benignos, creando una impresión de transparencia al mismo tiempo que ocultan su verdadero desempeño» (Marquis, Toffel y Zhou, 2016: 483), como señalaban Lyon y Maxwell (2006) al hablar del greenwash (ecoimpostura en castellano $^{1}$ ), cuando «una empresa informe sobre los resultados de proyectos exitosos, mientras se mantiene en silencio obre su desempeñado agregado», especifi-

1 Se opta por el anglicismo greenwashing frente a la expresión correspondiente en castellano ecoimpostura debido a su mayor uso en el ámbito académico y laboral. El buscador de la Web of Science recomienda comprobar la ortografía de la consulta con el término "ecoimpostura". Comprobación realizada el 12 de abril de 2019. 
cando que el «greenwash no es lo mismo que simplemente no informar de información negativa, sino que implica el paso adicional de elegir selectivamente reportar información positiva» (Lyon y Maxwell, 2006: 6).

\subsection{El sector fast fashion y la RSC}

En los últimos veinte años, la industria de la moda ha evolucionado significativamente. Hasta mediados de los años 80 , los estilos estaban estandarizados y no cambiaban frecuentemente debido a las restricciones de diseño de las fábricas, donde el patrón básico de las temporadas consistía en Primavera/Verano y Otoño/Invierno. Los consumidores, aparentemente, eran menos sensibles hacia el estilo y la moda, prefiriendo moda clásica. Hacia principios de los 90, se añadieron más fases a las temporadas, donde los minoristas comenzaron a ampliar su gama de productos, con productos actualizados y teniendo una respuesta más rápida a la novedad de las tendencias. Como consecuencia de los cambios en el estilo de vida de los consumidores, se satisfacía la necesidad de prendas de moda para ocasiones específicas. Fue a partir de 1999, cuando los desfiles y pasarelas de moda se convirtieron en un fenómeno público, donde las fotografías de los últimos desfiles se podían ver en revistas y en la web, conduciendo a la desmitificación del proceso de la moda. Lo que hizo que los consumidores tuvieran acceso visual a los diseños exclusivos y así obtener estilismos inspirados en las pasarelas. Esta situación provocó que minoristas como Zara, H\&M, Mango, New Look y Top Shop adaptaran los diseños de los grandes diseñadores a sus prendas y así atraer a los consumidores a sus tiendas en un mínimo de tres a cinco semanas (Bhardwaj y Fairhust, 2010).

La industria de la moda apostó por dar una respuesta rápida, pasando de predecir tendencias futuras a usar información en tiempo real para crear necesidades y deseos en los propios consumidores. Estas marcas lo que hicieron fue ofrecer el producto que querían los consumidores en el momento adecuado en el mercado, es decir, ofrecer fast fashion.

Fletcher (2010: 260) afirma acerca del sector fast fashion:

\footnotetext{
Diseñada para ser barata, fácil y rápida de producir; se basa en material y mano de obra de bajo coste, plazos de entrega cortos y producción eficiente de gran volumen, creada para ser distribuida, vendida y consumida en cantidades cada vez mayores, con un bajo precio y comercialización rápida.
}

Esta respuesta rápida conlleva un desafío para los minoristas. Según afirman Bruce y Daly (2006: 340) en la conclusión de su estudio: «estos minoristas han tenido que adaptar sus procesos internos para administrar el ciclo del fast fashion y revisar la base de suministros para cumplir con las demandas de los costes y tiempos del fast fashion». 
La estrategia llevada a cabo por el fast fashion ${ }^{2}$ es redefinida por Byun y Sternquist (2008: 135) al sintetizar las definiciones de Guercini (2001) y Moore y Fernie (2004) «como un enfoque de marketing para responder a las últimas tendencias de la moda actualizando frecuentemente los productos con un ciclo de renovación corto y convirtiendo el inventario a un ritmo rápido». Además, añaden que «un corto ciclo de renovación y un suministro limitado se identifican como los dos componentes más importantes de estrategia del fast fashion».

Analizar cómo encara el sector fast fashion esta problemática es relevante en la agenda de investigación actual relacionada con la sostenibilidad y la Responsabilidad Social Corporativa (RSC), «un tema de gran interés en la actualidad que constituye una respuesta a la demanda social, cada vez más grande de propender por un desarrollo sostenible» (Avendaño Castro, 2011: 46).

Tal y como exponen Porter y Kramer (2006: 1), «la RSC se ha convertido en una prioridad ineludible para los líderes empresariales de todos los países». Dichos autores (2006: 5), además, exponen que:

\footnotetext{
El buen gobierno, el imperio de la ley y los derechos de propiedad son esenciales para la eficiencia y la innovación. Sólidas normas regulatorias tanto de los consumidores como de las empresas competitivas de explotación. En última instancia, una sociedad sana crea una demanda creciente de negocios, a medida que se satisfacen más necesidades humanas y crecen las aspiraciones. Cualquier negocio que persiga sus fines a expensas de la sociedad en la que opera encontrará que su éxito es ilusorio y, en última instancia, temporal.
}

La RSC se define como un concepto multidimensional. Carroll (1991) estableció cuatro dimensiones: la económica, la legal, la ética y la filantrópica. Posteriormente, Schawartz y Carroll (2003), conceptualizaron la RSC como una combinación de las dimensiones económica, legal y ética de la responsabilidad, clasificando las actuaciones de RSC en función de las relaciones entre las dimensiones citadas. En 2010, Visser observaba mejoras en la RSC a nivel micro, en términos de proyectos y prácticas específicas, mientras que a nivel global los indicadores referentes a salud social, ambiental y ética estaban en declive.

La mayoría de las teorías acerca de la RSC, según Garriga y Melé (2004), se centran en cuatro aspectos que han sido denominados teorías: las instrumentales, las políticas, las integradoras y las éticas. En la actualidad, tal y como expone Suárez Serrano $(2013 ; 5)$, «la responsabilidad de la empresa no sólo debe limitarse a su existencia, sino que se trata de una responsabilidad intergeneracional». En este sentido, los índices Dow Jones, que evalúan las dimensiones de la llamada «triple cuenta de resultados», atienden al plano económico, al social y al medioambiental: «la ecoeficiencia y la información medioambiental de las empresas determinan su grado de implicación y respeto por el medioambiente» (Suárez Serrano, 2013: 5).

2 El anglicismo fast fashion se utiliza en la presente investigación en lugar de la expresión española moda pronta al ser el más utilizado en el ámbito académico y profesional. En la búsqueda realizada el 12 de abril de 2019 en la Web of Science se encontraron 1.444 artículos sobre fast fashion y 0 sobre moda pronta. En Scopus (Social Sciences), 453 artículos se referían a fast fashion y 1 a "pronta moda" (expresión italiana) en vez de "moda pronta". 
Ramus y Montiel (2005: 378) sostienen que:

Las corporaciones tienen un incentivo para publicar declaraciones de política ambiental, ya que las declaraciones pueden influir positivamente en las percepciones públicas sobre el compromiso de la empresa con la protección ambiental y el desarrollo sostenible, lo que posiblemente resulte en una mayor participación de mercado y mejores relaciones con los interesados.

Los procesos de producción llevados a cabo como resultado de una deslocalización que busca costes bajos han provocado que durante la producción de las prendas del fast fashion se genere una gran contaminación, con los tintes y residuos de tejidos que están destruyendo ecosistemas. Según el Observatorio de la Moda Española (2016: 10) las empresas españolas del sector «cuentan con stakeholders muy concienciados con el impacto de la industria de la moda en el medioambiente, la economía y el conjunto de la sociedad».

«La correcta identificación de las expectativas y demandas de los grupos de interés, así como la integración de los mismos en la estrategia de la empresa, es una de las herramientas más poderosas para el éxito de un posicionamiento socialmente responsable» (Granda Revilla y Trujillo Fernández, 2011: 72).

Como solución alternativa, a una forma de producir poco sostenible, han surgido alrededor del mundo diferentes marcas y diseñadores que se encargan de fabricar prendas responsables con el medioambiente, apostando por acercarse a la economía circular. Según Carrera-Gallissà (2017), el gran reto de la industria textil y de la confección es producir más con menos, alargar la vida útil de las prendas y reintroducirlas en la cadena textil mediante la lógica circular cuando finalice su vida útil. Zara o Mango, entre otras marcas de fast fashion, comenzaron a realizar colecciones consideradas respetuosas con el medioambiente apoyando la sostenibilidad, poniendo en el mercado prendas realizadas con materiales tales como el algodón orgánico o el bambú que llevan el concepto sostenibilidad al mass market.

El problema surge al preguntarse si la sostenibilidad de las prendas de estas líneas/ colecciones suponen una evolución hacia un modelo de negocio más ético o son una estrategia de marketing para satisfacer la demanda existente, la cual corresponde según Broshdahl y Carpenter (cit. por González, 2015: 83) a «un aumento considerable de la aceptación de los productos ecológicos en el sector textil, registrado por parte de los consumidores». Sin embargo, según afirma González (2015: 83) «no está claro si la preocupación declarada por el medioambiente se traduce directamente en el comportamiento de compra real de productos ecológicos entre los consumidores». De hecho, existen resultados contradictorios en investigaciones previas acerca del factor sostenibilidad en la decisión de compra del consumidor.

La investigación de Market \& Opinion Research International (cit. por Bigné, Andreu, Chumpitaz, y Swaen, 2006: 166) confirma que «el 70\% de los consumidores europeos indican que el compromiso de una empresa a la responsabilidad social es importante cuando compran un producto/servicio». En el caso de las investigaciones de Boulstridge y Carrigan (cit. por Bigné et. al, 2006: 166), la Responsabilidad 
Social Corporativa (RSC) «está lejos de ser el principal criterio dominante en las decisiones de compra del consumidor». Mientras que en el caso de las investigaciones de Beckmann, Christensen y Christensen (cit. por Bigné et. al, 2006: 166) «los criterios tradicionales como precio, calidad y familiaridad de marca parecen mantenerse como los criterios de selección más importantes».

A pesar de la importancia que tenga el factor sostenibilidad en la decisión de compra, existe un problema adicional, el escepticismo existente en los consumidores según González (2015: 83):

Hay una brecha entre lo que los consumidores dicen que están dispuestos a pagar por productos sostenibles y lo que en realidad pagan, motivados por el escepticismo que existe acerca de las declaraciones ambientales engañosas y sin verificar.

Según Granero Castro y Ferrando Sánchez (2012: 90), en las organizaciones generalmente hay ciertos recelos respecto a la comunicación debido a la posible fuga de información sensible. Sin embargo, «es necesario que la organización decida cómo responder formalmente a partes interesadas externas, cuando estas soliciten información acerca de temas relacionados con los aspectos ambientales, política ambiental o gestión».

Según Trujillo y Vélez Bedoya (2006: 297) «el reconocer la inclusión de la variable medioambiental en la gestión empresarial es un aspecto que ha adquirido peso y por ende el medioambiente se ha convertido en un factor de competitividad y de perdurabilidad».

El consumidor es el que tiene la última palabra a la hora de comprar y determinar si la sostenibilidad puede ser una idea o una realidad en el sector moda. Como expone De la Cuesta González (2004: 51) «trasladan al consumidor final la responsabilidad de que el planeta se deteriore social y medioambientalmente».

En el nuevo paradigma de marketing «el esquema de funcionamiento es el siguiente: el consumidor/cliente y la marca establecen una relación en la que cada uno de ellos percibe al otro como proveedor de valor» (Aguilera Moyano y Baños González, 2017: 5). Esta relación ha sido acelerada exponencialmente gracias a internet, «aumentando las posibilidades de interactividad y de diálogo entre una marca y sus clientes. Los medios sociales, desde las redes sociales hasta los blogs y microblogs, se han convertido en una herramienta esencial de diálogo» (Aguilera Moyano, 2014: 176).

\subsection{La moda en Italia}

La industria textil-confección italiana consiguió imponerse como una de las más relevantes del mundo en la década de los 80 , «debido a la creación de la etiqueta del Made in Italy» (Quintas y Quintas, 2011: 205). Según Corbellini y Saviolo (cit. por Quintas y Quintas, 2011: 205) «probablemente el impacto de la industria de la moda italiana en el mundo no habría sido tan significativo si no estuviera apoyado en un sistema mediático muy fuerte». 
La industria de la moda constituye una actividad con gran peso en la economía de un país. Su estructura está compuesta por todas aquellas empresas que se dedican o colaboran en la creación de los 'productos de moda'; abarca firmas especializadas en la alta costura, prêt à porter o 'pronto moda', y aquellas otras que contribuyen directa o indirectamente a la elaboración del producto moda (Quintas y Quintas, 2011: 202).

La marca-país en Italia no ha sido comunicada del mismo modo en España, ya que «España, a diferencia de países como Francia o Italia, todavía no ha sabido crear el Made in Spain en este campo, a pesar de los intentos que los diversos Gobiernos han plasmado en varios planes de promoción de la moda» (Quintas y Quintas, 2011: 210). Además, Italia destaca por ser la cuna del Manifiesto Slow Design presentado en 2006 en Milán, en el Slow Design. En dicho manifiesto se describió «un enfoque de producción lento, donde se ofrece tiempo para producir, apreciar y cultivar la calidad» (Ozdamar Ertekin y Atik, 2015: 57).

«Slow fashion es un término acuñado por Kate Fletcher del Center for Sustainable Fashion (Reino Unido) en 2007, tomando prestado del Movimiento Slow Food, iniciado en 1986 por Carlo Petrini en Italia» (Ozdamar Ertekin y Atik, 2015: 57). Dicho movimiento en la gastronomía según expone Hadden (cit. por Ozdamar Ertekin y Atik, 2015: 57) «es reflejado en el sector de la moda, donde une el placer y la moda con conciencia y responsabilidad».

El Movimiento Slow Food, es un movimiento en contra de la comida rápida que comenzó en Roma como defensa de los placeres de cocinar y comer tranquilos. «Reemplaza el énfasis distorsionado sobre el consumo y la producción por la economía convencional con un conjunto más amplio de objetivos que valoran las tradiciones, la diversidad ecológica, la salud, el placer, el empleo y la seguridad del futuro» (Fletcher, 2010: 261). De tal forma que según Fletcher (2010: 262), la slow fashion «representa una flagrante discontinuidad de las prácticas del sector actual; un descanso de los valores y objetivos de la fast fashion. Es una visión del sector de la moda construido desde un punto de partida diferente».

A partir de la crisis del 2008, el sector moda en Italia, a pesar de ser uno de los más fuertes en la economía del país, ha sufrido una recesión frente a los años previos (ICEX, 2018; 3):

La disminución del número de empresas y trabajadores en pos de nuevas localizaciones más económicas para su producción en países en vías de desarrollo, donde los bajos costes de mano de obra, impuestos y/o tasas han creado nuevas vertientes productivas muy diferentes.

En referencias a la crisis de 2008, Mortara (2015: 19) expuso que «el Made in Italy ha sido citado en varias ocasiones como una oportunidad extraordinaria para revivir la economía del país».

Italia es el primer exportador de moda de la Unión Europea y cuarto en el mundo, después de China, Bangladesh y Vietnam. Mientras que España es el tercer exportador de la Unión Europea, después de Alemania, y el noveno a nivel mundial con una cuota del 2,6\% sobre el total. Ambos países centran la mayor parte de sus ventas ex- 
teriores en el continente europeo debido a la cercanía entre territorios, suponiendo el $67 \%$ de las exportaciones italianas y el 71\% de las españolas (ICEX, 2017).

El Observatorio de la Moda Española (2016: 9) apunta que «así como Francia tiene la alta costura e Italia cuenta con el prêt-à-porter, España es el país exportador del fast fashion gracias a Inditex, y, en los últimos años, también a Mango, que continúa con su desarrollo económico». Además, el informe añade que:

\footnotetext{
España cuenta con una cantidad de compañías equiparable a Italia, que se caracteriza por la polarización: existe un grupo de siete grandes compañías, con ventas por encima de los 1.000 millones de euros, encabezado por Inditex, Mango, Cortefiel y Desigual; y la cantidad de empresas medianas que hay -con una facturación de entre 50 y 150 millones de euros- no configura una suficiente masa crítica para darle impulso y convertirla en una compañía de 500 millones (Observatorio de la Moda Española, 2016: 16).
}

\section{Objetivos}

El objetivo principal de la presente investigación es verificar si las cuatro principales marcas de fast fashion españolas e italianas (Zara, Mango, Calzedonia y OVS) comunican su sostenibilidad corporativa, tanto en sus medios de comunicación, es decir, en sus canales online, como en el punto de venta físico a través del merchandising. Los objetivos específicos son los siguientes:

- Primero: Determinar el merchandising del punto de venta físico de Zara, Mango, Calzedonia y OVS en la capital italiana.

- Segundo: Analizar el diseño, usabilidad y comunicación de la RSC medioambiental en las tiendas online de Zara, Mango, Calzedonia y OVS

- Tercero: Comparar la comunicación de la sostenibilidad corporativa en el punto de venta online o web corporativa y el punto de venta físico de Zara, Mango, Calzedonia y OVS.

\section{Metodología}

En virtud de la posibilidad de considerar que en la comunicación de la sostenibilidad corporativa puede existir una estrategia de greenwashing, se va a analizar tanto la comunicación a través de soportes propios online (tienda online y web corporativa), como el punto de venta físico, para comprobar si lo comunicado a través de la tienda online o de la web queda reflejado del mismo modo en el punto de venta físico. Es decir, se pretende determinar si la información comunicada de aspectos medioambientales es percibida por igual en ambos escenarios de compra por parte de los consumidores.

Según Kim, Ahn y Fourney (2014: 13), «la estrategia comercial de la moda necesita involucrar al consumidor a través de una comunicación transparente, confiar en el consumidor para co-crear la estrategia comercial, y luego aprender a ser guiado por grupos de consumidores apasionados». 


\subsection{Selección de la muestra}

La muestra elegida para la investigación está formada por dos marcas de fast fashion españolas y dos italianas: Zara, Mango, Calzedonia y OVS.

La muestra española para la investigación ha sido elegida por ser sus miembros líderes de la moda española en el 2017 y años precedentes, en función de su facturación. El Mapa de la Moda 3/4 una de las principales guías del sector realizada por Modaes.es, líder en información económica del negocio de la moda³/4 muestra las posiciones de todos los líderes de la moda española en función de su facturación (Riaño y Pérez Gestal, 2017). Las posiciones son en primer lugar Inditex, en segundo Mango, en tercero Grupo Cortefiel, en cuarto Desigual y en quinto Pepe Jeans (véase Gráfico 1). Dichas posiciones siguen en el mismo orden que en el 2016. Las dos líderes son empresas consideradas como fast fashion y con sede en España: Zara en La Coruña y Mango en Barcelona.

Gráfico 1. Mapa de la Moda 2017

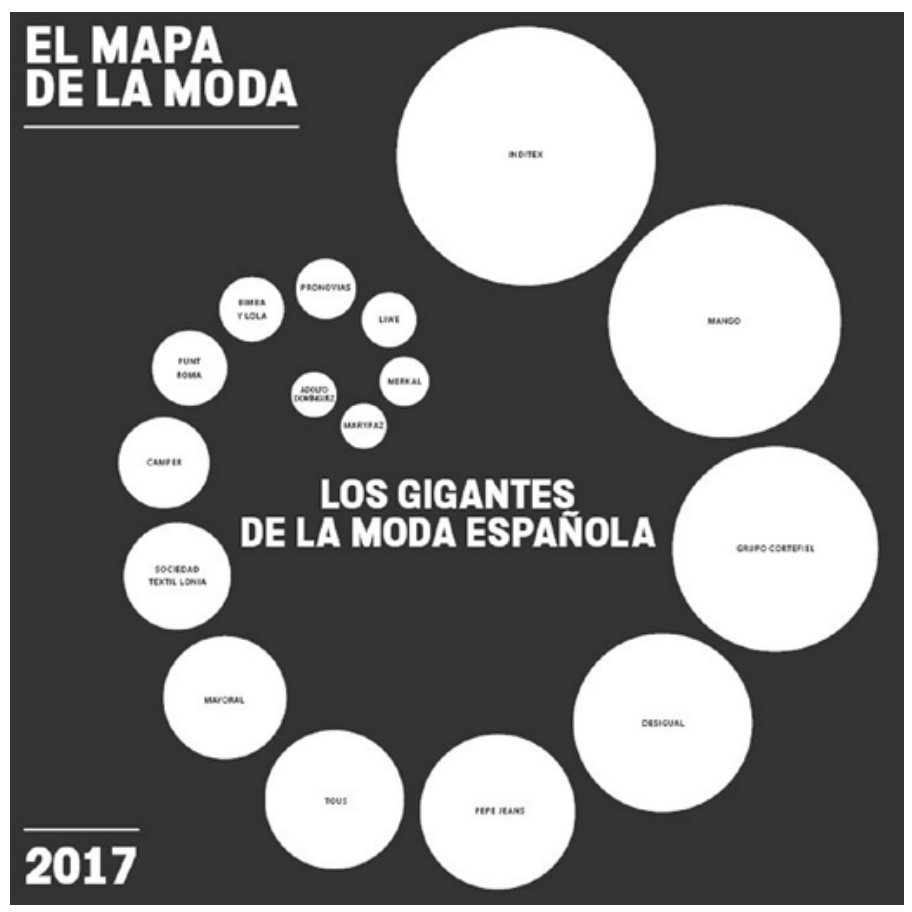

Fuente: Riaño y Pérez Gestal (2017). 
El Grupo Inditex está formado por ocho marcas: Zara, Pull\&Bear, Massimo Dutti, Bershka, Stradivarius, Oysho, Zara Home y Uterqüe. De entre las diferentes marcas del Grupo Inditex, se escogió para la investigación Zara, ya que es la que más ventas genera, según expone el grupo empresarial en los resultados del ejercicio del 2017 (Inditex, 2018) (véase Gráfico 2).

Gráfico 2. Porcentaje ventas por cadena en Inditex en el 2017

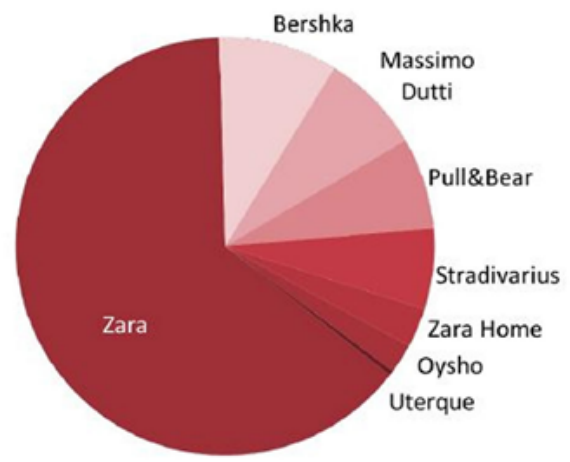

$\%$ Ventas en tienda y online

Fuente: Inditex (2018: 28).

Mango recoge diferentes líneas: Mango Woman, Mango Kids, Mango Man, Mango Baby, Mango Sport\&Intimates y Violeta by Mango. Las megastore con las que se ha expandido la marca a nivel nacional e internacional desde el 2013, ofrece todas o gran parte de las líneas del grupo, mejorando la oferta y la experiencia de compra de los clientes (Mango Pressroom, 2016). Por ello, para la investigación nos centramos en Mango como marca, donde en ella se encuentran incorporadas las diferentes líneas.

Las dos marcas italianas elegidas pertenecen a grupos empresariales que están entre las diez empresas de moda italiana más grandes, en función de su facturación con datos del 2016, según un estudio realizado por el banco de inversión Mediobanca (2018). Calzedonia Holding posee la cuarta posición, con una facturación de 2.128 millones de euros, mientras que Gruppo Coin ocupa la sexta posición con 1.558 millones de euros (véase Tabla 1). 
Tabla 1. Empresas Moda Italia: Las 10 primeras por facturación

\begin{tabular}{|c|c|c|c|c|}
\hline & Società & Sellore & $\begin{array}{l}\text { Fott. } 2016 \\
\text { (Emi.) }\end{array}$ & Marchi e insegne (Indicativo) \\
\hline 1 & LUXOTICA GROUP= & $\mathrm{OCCH}$ & 9.086 & $\begin{array}{l}\text { Amette - Killer Loop - Luxottica - Oaldey - Oliver Peoples - Persol - Ray-Ban } \\
\text { - Steroflex - Vogue Eyewear - Alain Mili + Vari in licenza - insegne: } \\
\text { LensCrafters - Pearle Vition - Sunglass Hut - OPSM - Laubman \& Pank- } \\
\text { Salmoiraghi e Vigano - GMO - Oakley "O- Stores - David Clulow - Sears } \\
\text { Optical - Target Optical - EyeMed Vision Care - Oticas Carol - ILORI - } \\
\text { Optical Shop of Aspen }\end{array}$ \\
\hline 2 & PRADA & PCA & 3.184 & Prada - Mlu Miu - Church's - Car Shoe \\
\hline 3 & GIORGIO ARMANI = & $A B B$ & 2511 & $\begin{array}{l}\text { Giorgio Armani - Giorgio Armani Privé - Emporio Armani - EAT - A|X Armani } \\
\text { Exchange - Armani Junior - Giorgio Armani beauty }\end{array}$ \\
\hline 4 & CALIEDONIA HOLOING= & $A B B$ & 2.128 & $\begin{array}{l}\text { Calzedonia - Intimissimi - Tezenis - Falconeri - Atelier Emé- Cash \& Carry by } \\
\text { Calzedonia Group (punti vendita) }\end{array}$ \\
\hline 5 & YOOX NET-A-PORTER GROUP \# & DIS & 1.871 & Vari \\
\hline 6 & GRUPPO COIN $=$ & DIS & 1.558 & $\begin{array}{l}\text { Vaí + Coin - Coincasa - OVS - OVS Kids - Upim - Excelsior Milano - Blukids - } \\
\text { lana }\end{array}$ \\
\hline 7 & $O T B=$ & $A B B$ & 1.548 & $\begin{array}{l}\text { Diesel - Diesel Black Gold - Marni - Maison Margiela - Poula Cademantori - } \\
\text { Viktor \&. Rolf - } 550 \text { SL- in licenza: John Galliano-Dsquared2 - Just Cavalli - } \\
\text { Marc Jacobs - Vivienne Westwood - Trussardi Junior }\end{array}$ \\
\hline 8 & MAX MARA FASHION GROUP= & $A B B$ & 1.427 & $\begin{array}{l}\text { Max Mara - Sportmax - Weekend by Max Mara - Max } 8 \text { Co - Marella - i Blues } \\
\text { - Pennyblack - Marina Rinaldi - persona }\end{array}$ \\
\hline 9 & SALVATORE FERRAGAMO= & PCA & 1.425 & Ferragamo - Salvatore Ferragamo - in licenza: Emanuel Ungaro \\
\hline 10 & $D S G=$ & $A B B$ & 1.259 & Dolce 3. Gabbana \\
\hline
\end{tabular}

Fuente: Mediobanca (2018: 56).

Calzedonia Holding está constituido por las marcas: Calzedonia, Intimissimi, Tezenis, Falcoreni, Atelier Emé, Cash \& Carry by Calzedonia Group. Se ha elegido Calzedonia porque está considerada como fast fashion y por ser el buque insignia del grupo, del mismo modo que Zara en el Grupo Inditex. Calzedonia Holding es un grupo en alza que está a nivel internacional, tal y como queda reflejado en la Asamblea General de Confindustria Verona e Confindustria Vicenza (Manager Verona On Line, 2014: 3) en los últimos años el presidente y creador del grupo, Sandro Veronisi, «se ha dedicado al crecimiento de Calzedonia S.p.A., creando una cadena de más de 3.500 tiendas en más de 30 países y controlando fábricas tanto en Italia como en el extranjero».

El Gruppo Coin está constituido por las marcas: Coin, Coincasa, OVS, OVS kids, Upim, Excelsior Milano, Blukids e Iana. La marca OVS es elegida para la investigación por ser de entre todas las del grupo, la que a medida que se expandió desde su creación en 1972, «desarrolló con éxito una gran confianza mutua con los clientes, alcanzando una conciencia de marca en el mercado italiano equivalente al $97 \%$ en 2013» según Doxa (cit. por OVSCorporate, 2018). Es considerado en la actualidad como el grupo líder en el mercado de ropa en Italia.

\subsection{Metodología trabajo de campo}

Para definir el encuadre medioambiental de las estrategias de comunicación y RSC de las marcas seleccionadas, se van a utilizar las siguientes técnicas de investiga- 
ción: estudio descriptivo del punto de venta físico y análisis de contenido del punto de venta online o web corporativa.

La revolución digital ha hecho que aparezcan los consumidores multicanal, los cuales, en promedio, gastan más dinero y compran con más frecuencia. Los consumidores multicanal «consideran su experiencia de compra de manera integral y buscan una experiencia integrada y coherente entre canales. No piensan en canales aislados, sino que los combinan» (Blázquez, 2014: 100).

En la situación presente del comercio se debe de hablar de estrategias omnicanal. Suponiendo este tipo de estrategias una oportunidad de mejora en la venta del minorista y, por consiguiente, también en los establecimientos físicos (Aparicio y Zorrilla, 2015).

\subsubsection{Estudio descriptivo del punto de venta físico en la capital italiana de las marcas seleccionadas para la investigación}

Realizado con el fin principal de conocer la información que llega al consumidor en el lugar donde se puede adquirir físicamente las prendas de las colecciones de cada una de las marcas. Se ha analizado el merchandising de los puntos de venta físicos en Roma de Zara, Mango, Calzedonia y OVS, en las principales zonas de comercio de la capital italiana.

Realizamos un estudio descriptivo, ya que hemos trabajado con realidades factuales y se ha realizado una interpretación de dicha realidad observada. Sandino Restrepo (2009) cita que este tipo de investigación describe un fenómeno o situación mediante el estudio de este en una circunstancia espaciotemporal determinada. Hernández Sampieri, Fernández Callado y Baptista Lucio (2010) exponen que una investigación descriptiva debe especificar las propiedades, características, perfiles de personas, grupos, comunidades, procesos, objetos y cualquier otro fenómeno que se someta a análisis.

Según Palomares Borja (2009) el merchandising ayuda a cumplir tres objetivos a la marca. El primero, transmitir la imagen de que es lo que se vende en la tienda. El segundo, generar un flujo de circulación de clientes dirigido hacia las zonas calientes de la tienda, donde el consumidor encontrará los productos que a la tienda le interesa vender más. El tercero, provocar ventas por impulso, que corresponden a las ventas de determinados productos que se encuentran en las zonas calientes, por las que el cliente va a pasar.

Las empresas deben establecerse los objetivos a alcanzar mediante la gestión del punto de venta físico, suponiendo un territorio físico donde centrar esfuerzos comunicativos. La información que se distribuya en dicho territorio permitirá dar a conocer una mayor cantidad de información sobre la promoción de ventas o las ventajas de los productos, así como lograr la fidelización del cliente (Martínez Martínez, 2005; Lobato Gómez, 2005; Navarro Bailón, 2009; Martínez Sánchez, 2015). Debido a ello, consideramos relevante un análisis centrado en conocer si se informa acerca de la sostenibilidad corporativa en el punto de venta físico de las marcas seleccionadas. 
Los componentes analizados del merchandising en cada una de las tiendas son: gestión del surtido, el diseño de la arquitectura exterior e interior del establecimiento (arquitectura comercial), exposición de los productos en el lineal desarrollado y la publicidad en el lugar de venta (gestión estratégica del lineal). En función de estos tres componentes se ha realizado el proceso de evaluación o codificación de los mensajes comunicativos en el estudio descriptivo.

La presente investigación se ha centrado en la presencia o inexistencia de productos diferenciados por su producción sostenible, y de información sobre la RSC en general, y RSC medioambiental, en particular, en el punto de venta físico de las marcas seleccionadas para el análisis.

\subsubsection{Análisis de contenido de la tienda online o web corporativa de las marcas seleccionadas para la investigación}

Un análisis centrado en conocer qué tipo de información recibe el usuario en la tienda online o web corporativa sobre la sostenibilidad corporativa de la muestra.

Según menciona Trespalacios Gutiérrez (2017: 316), un reto al que las empresas de distribución en la era de densidad digital es la transparencia en doble sentido:

\footnotetext{
Por un lado, la transparencia entendida como un proceso por el cual las empresas de distribución recogen y hacen accesible para sus grupos de interés información relevante sobre su cadena de suministro y sus productos. Por otro lado, la transparencia con que se recogen, almacenan, controlan y utilizan los datos personales de los clientes (Zamora, 2016). Las nuevas tecnologías en tienda física multiplican exponencialmente la capacidad de identificar y trazar tanto la historia y localización de los productos y sus componentes, como la de los propios clientes. La gestión socialmente responsable de esta información, contribuyendo por un lado a proteger la propiedad de los consumidores sobre sus datos personales, y por otro a la rendición de cuentas del retailer a sus grupos de interés sobre su sostenibilidad, es, sin duda, uno de los retos más sustantivos a los que se enfrentan hoy las empresas de distribución.
}

Según Mondéjar et al. (cit. por García Feijoo y Eizaguirre Zarza, 2010: 159), las principales compañías desarrollan sus propias páginas web con los objetivos de: «obtener acceso global; ofrecer información al internauta; ofrecerle servicio y apoyo; realizar acciones de marketing, marca y promociones; ofrecer un nuevo canal de venta; $y$, en menor medida, ahorrar costes».

La función de informar y de vender que tiene toda tienda online se llama merchandising virtual. «Este merchandising virtual al igual que el merchandising tradicional se ocupa de la decoración del lugar, la presentación de los productos, la rotación de los mismos y la rentabilidad del establecimiento» (Cristóbal Fransi, 2006: 140). De tal forma que, el análisis estará en paralelo con el estudio del punto de venta físico de cada una de las marcas seleccionadas para ser analizadas. Basándonos en la Tabla 2 para ese paralelismo, donde se compara los elementos del merchandising tanto en entornos físicos como virtuales. 
Tabla 2. Elementos del merchandising en aspectos físicos y virtuales.

\begin{tabular}{|c|c|c|}
\hline & $\begin{array}{l}\text { ELEMENTOS DEL } \\
\text { MERCHANDISING } \\
\text { CONVENCIONAL }\end{array}$ & $\begin{array}{l}\text { ELEMENTOS DEL } \\
\text { MERCHANDISING EN UN } \\
\text { ESTABLECIMIENTO VIRTUAL }\end{array}$ \\
\hline \multirow[b]{2}{*}{$\begin{array}{l}\text { Disposición exterior } \\
\text { del establecimiento }\end{array}$} & Rótulo & Nombrede dominio \\
\hline & Entrada del establecimiento & $\begin{array}{l}\text { Enlaces con el establecimiento desde } \\
\text { intemediarios de información y otro } \\
\text { sitios web }\end{array}$ \\
\hline \multirow{3}{*}{$\begin{array}{l}\text { Diseño interior del } \\
\text { establecimiento }\end{array}$} & Escaparate & - \\
\hline & $\begin{array}{l}\text { Trazados y disposición interna del } \\
\text { establecimiento }\end{array}$ & Est nctura del sitio web \\
\hline & $\begin{array}{l}\text { Disposición y presentación del } \\
\text { surtido }\end{array}$ & Diseño del catálogo electrónico \\
\hline \multirow{3}{*}{$\begin{array}{l}\text { Merchandising } \\
\text { de gestión }\end{array}$} & Ambientación del punto de venta & $\begin{array}{l}\text { Técnicas de animación, publicidad cn } \\
\text { el punto de venta }\end{array}$ \\
\hline & Selección y análisis del surtido & $\begin{array}{l}\text { Selección y análisis de los } \\
\text { componentes del catálogo }\end{array}$ \\
\hline & Gestión del espacio del lineal & $\begin{array}{l}\text { O rganization of the electronic } \\
\text { catalogue }\end{array}$ \\
\hline
\end{tabular}

Fuente: Rodríguez Ardura (cit. por Cristóbal Fransi, 2006: 141).

De manera similar Lohse y Spiller (1999) desarrollaron una tabla que representaba las analogías entre tiendas reales y tiendas minoristas en línea (véase Tabla 3). Según Menon y Kahn (1997), existen principalmente dos diferencias entre el comercio electrónico y el tradicional. La primera es que el establecimiento virtual se reduce a una pequeña pantalla (ordenador de escritorio, dispositivos móviles o televisión). La segunda es que la distancia y el tiempo se encuentran comprimidos. 
Tabla 3. Analogías entre tiendas físicas y minoristas en línea.

\begin{tabular}{|c|c|}
\hline "Real" Store & Online Retail Store \\
\hline Salesclerk service & Product descriptions, information pages, gift services, search function, sales clerk on the phone/email \\
\hline Store promotion & Special offers, on-line games and lotteries, links to other sites of interest, appetizer informa \\
\hline Store window displays & Home page \\
\hline Store atmosphere & Interface consistency, store organization, interface and graphics quality \\
\hline Aisle products & Featured products on hierarchical levels of the store \\
\hline Store layout & Screen depth, browse and search functions, indices, image maps \\
\hline Number of floors in the store & Hierarchical levels of the store \\
\hline Number of store entrances and store outlets/branches & Number of links to a particular online retail store \\
\hline Checkout cashier & On-line shopping basket and/or order form \\
\hline Look and touch of the merchandise & Limited to image quality and description, potential for sound and video applications \\
\hline Number of people entering the store & Number of unique visits to the online retail store \\
\hline Sales per period & Sales per period \\
\hline
\end{tabular}

Fuente: Lohse y Peter (1999).

El proceso de codificación de los mensajes comunicativos en el análisis de contenido ha sido sistemático con un procedimiento normalizado y riguroso. Se quiere conseguir una representación precisa del conjunto de mensajes de los soportes de venta online y/o webs corporativas de la muestra. Para dicho proceso, nos hemos basado en unos parámetros predefinidos utilizados en estudios precedentes tales como el trabajo de Lohse y Spiller (cit. por Cristóbal Fransi, 2002), en la investigación de Eyeglue.net (cit. por Cristóbal Fransi, 2002) y en la tesis doctoral de Cristóbal Fransi (2002).

\section{Resultados}

Los resultados obtenidos de esta investigación han sido obtenidos durante la movilidad internacional del doctorado en la Sapienza Università di Roma, en la capital italiana, en el período que va desde marzo a junio del 2018.

\subsection{Estudio descriptivo de los puntos de venta físicos de Zara, Mango, Calzedonia y OVS en Roma}

El estudio de los puntos de venta físicos se ha realizado para conocer la información que llega al consumidor en el lugar donde se adquiere físicamente las prendas de cada una de las cuatro marcas. 


\subsubsection{Gestión del surtido}

En el establecimiento de Zara se encontraron prendas de la línea sostenible Join Life entre el resto del stock expuesto, sin ser destacadas por ningún tipo de cartelería dentro del establecimiento. Solo se reconocía que una prenda pertenecía a dicha línea por las etiquetas que colgaban de la prenda. El consumidor/cliente es informado del tipo de materiales con las que se producen estas prendas sostenibles únicamente por la etiqueta interior de composición. Entre prendas del resto de las líneas de Zara (Trafaluc, Basic o Woman), sí que se encontró comunicación mediante cartelería en el punto de venta acerca del tipo de materiales con las que estaban fabricadas, como en el caso de un modelo de zapatos de hombre que estaban producidos en piel.

Mango tenía en su punto de venta físico prendas de la colección sostenible Mango Committed, al igual que en Zara, las prendas de colección sostenible no eran destacadas mediante cartelería. Se reconocía que la prenda pertenecía a la colección por las etiquetas colgadas en la prenda. En estas etiquetas se encontraba el logo de la colección en la parte inferior y en la parte superior se podía leer Made with friendly \& recycled fabrics. Committed to sustainable fashion (Hecho con telas amigables y recicladas. Comprometido con la moda sostenible) (véase Imagen 1). A parte de las etiquetas colgadas de la prenda, no se encontró ningún cartel o modo de indicar que esa prenda estaba producida de forma sostenible.

Imagen 1. Etiquetas en prenda Mango Committed

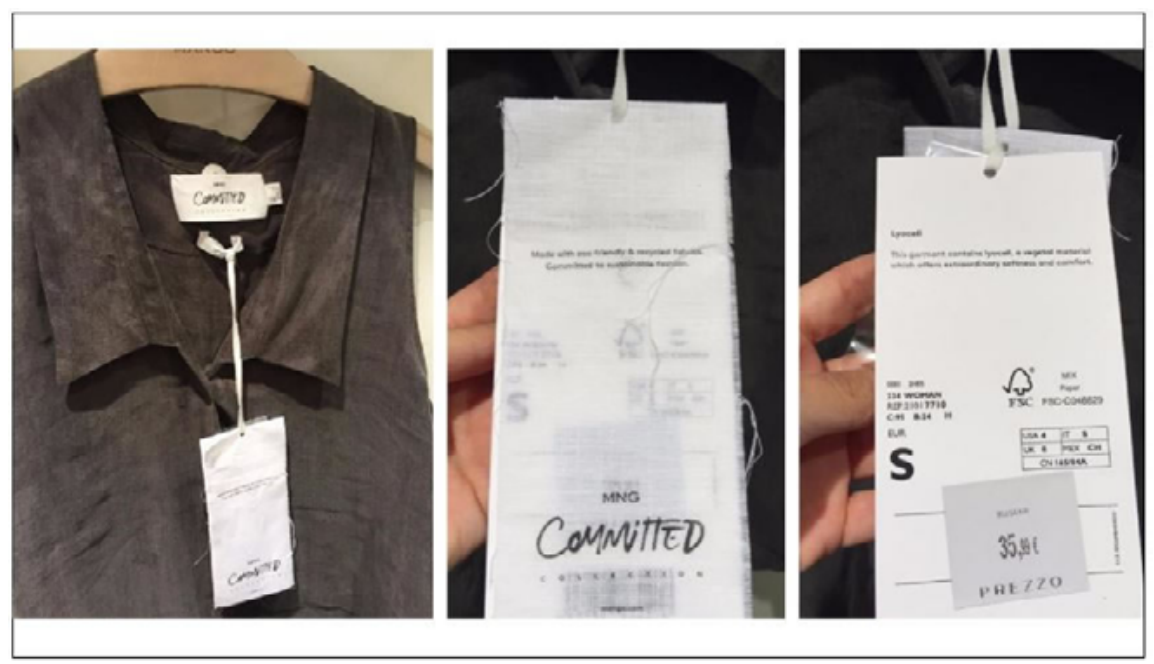

Fuente: Elaboración propia. 
Además de las prendas de la colección Mango Committed, en el punto de venta físico de Mango se encontró un grupo de prendas producidas a mano y se informaba de ello con las etiquetas colgadas, del mismo modo que en la prenda de la Imagen 1. Otro grupo del stock constaba de prendas producidas $100 \%$ en lino (el estudio se realizó en la temporada que correspondía a Primavera/Verano), dicha información aparecía nuevamente mencionada exclusivamente en la etiqueta. En dicha etiqueta se podía encontrar el siguiente texto, véase Imagen 2:

This garment containing linen has been handcrafted with love offering the very best in fit and comfort.

Linen is a fine fiber extracted from the stems of the flax plant, thanks to the natural properties of the fiber itself, linen is an eco-friendly fabric with great smoothness and silky quality. Enjoy it!

Traducción al texto previo: Esta prenda que contiene lino ha sido elaborada artesanalmente con amor, ofreciendo lo mejor en ajuste y comodidad.

El lino es una fibra fina extraída de los tallos de la planta del lino, gracias a las propiedades naturales de la misma fibra, el lino es un tejido ecológico con una gran suavidad y calidad sedosa. ¡Disfrútala!

\section{Imagen 2. Etiqueta 100\% lino de Mango}

Fuente: Elaboración propia.

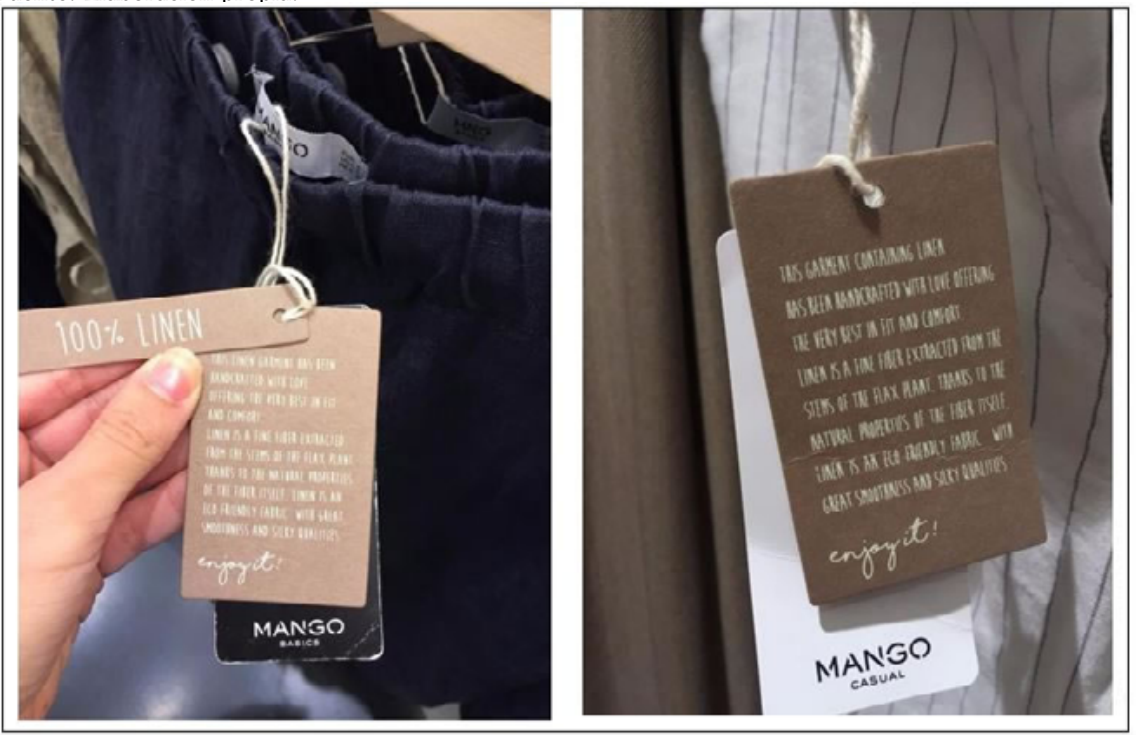


Respecto a la ubicación, la línea sostenible de Zara se encontraba en la zona fría, es decir, en ubicaciones dentro del punto de venta físico que no son de paso habitual en el proceso de la compra. En el caso de la colección sostenible de Mango se ubicaba en la zona caliente dentro de los establecimientos, en concreto, se encontraba cerca de las cajas, considerado como uno de los dos puntos calientes de los establecimientos de la marca.

En el caso de Calzedonia y OVS no se encontró en los puntos de venta cartelería que indicase que determinadas prendas estaban producidas sosteniblemente, ni el tipo de materiales con los que estaban producidas. Estas dos marcas no presentaban colecciones sostenibles a fecha del estudio.

\subsubsection{Arquitectura comercial}

En la arquitectura exterior (la identidad, la entrada y el escaparate) de los establecimientos analizados de todas las marcas no se encontró información acerca de la RSC en general, ni de la RSC medioambiental, en particular.

En la arquitectura interior (punto de acceso, zona caliente, zona fría, puntos calientes, puntos fríos, zona caliente natural disposición del mobiliario, diseño de pasillos, zona templada natural o creada) de los establecimientos de Zara, Mango y Calzedonia no se encontró mediante cartelería u otros medios información acerca de la RSC, en general, ni la RSC medioambiental, en particular; pero sí en OVS, donde se encontró un incentivo al reciclado de prendas que habían terminado el ciclo de vida. En dicho contenedor se podía leer en la parte superior OVS ricicla i tuoi abiti usati (OVS recicla tu ropa usada) (véase Imagen 3 ). 
Imagen 3. Incentivo al reciclado en establecimiento OVS

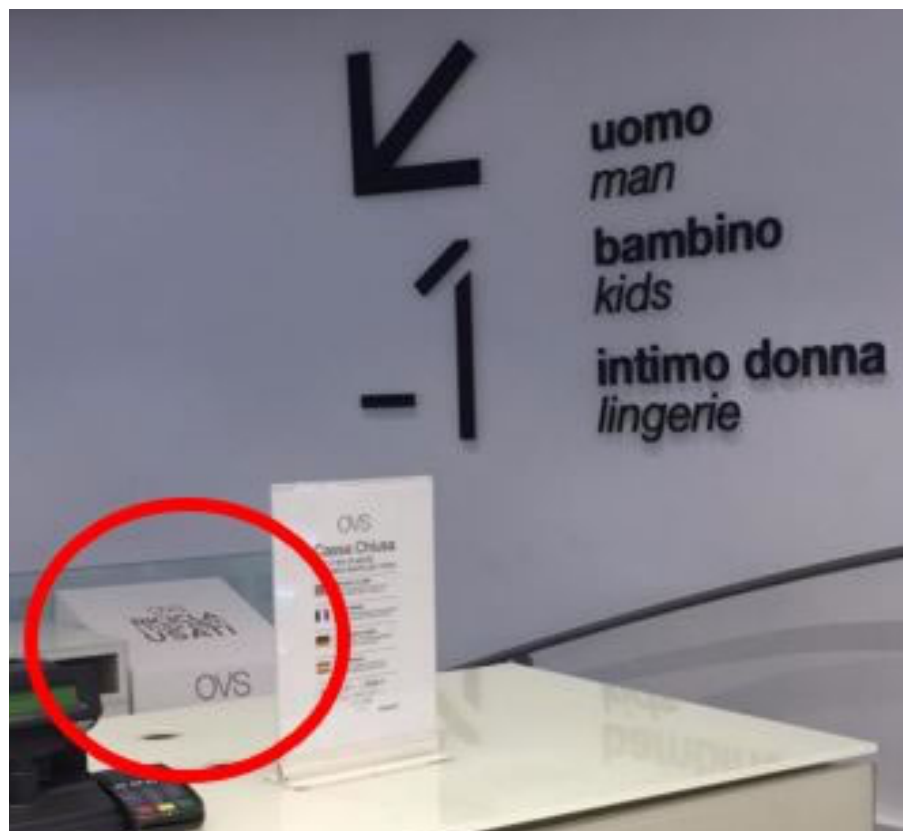

Fuente: Elaboración propia.

\subsubsection{Gestión estratégica del lineal}

Tras el estudio descriptivo del punto de venta en cada uno de los establecimientos elegidos, se analizó la gestión estratégica del lineal desde la gestión de la rotación de las categorías en cada uno de los establecimientos. Según Palomares Borja (2009) se deben colocar los productos de mayor rotación en las zonas frías, es decir, colocar los productos más vendidos en las zonas menos transitadas.

En el caso de Zara, las prendas de la línea Join Life son consideras prendas de alta rotación, alguna de ellas incorporadas dentro de la línea de Zara Basic (línea de prendas básicas). Prueba de ello es que determinadas prendas encontradas en las tiendas de la línea sostenible tenían cosido en la parte superior interior (parte superior de la espalda) la etiqueta de Zara Basic y únicamente en la etiqueta que colgaba (junto a la del precio y código de barras) ponía Join Life (véase Imagen 4).

Las prendas de Mango Committed fueron consideradas prendas de baja rotación, de hecho, en la siguiente temporada dicha colección se suprimió durante unos meses, tanto en la tienda física como en la tienda online (las primeras semanas de AW 18-19). Por ello, se encontraban en las zonas calientes tal y como se expresaba anteriormente. 
Imagen 4. Prenda Join Life y Zara Basic

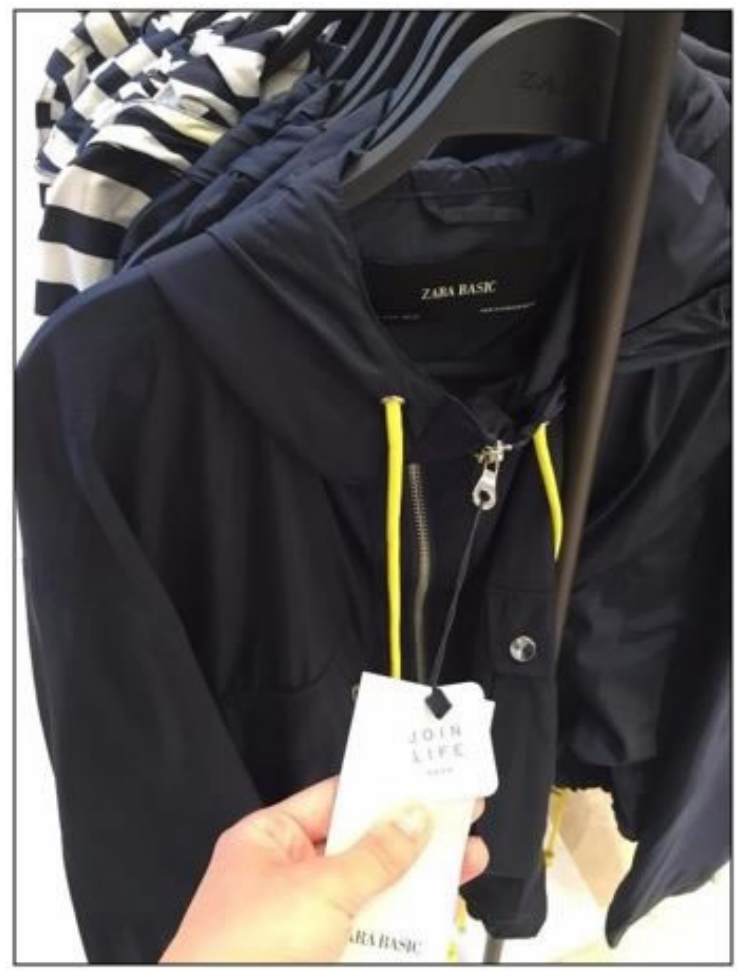

Fuente: Elaboración propia.

\subsection{Análisis de la tienda online o web de Zara, Mango, Calzedonia y OVS}

4.2.1. Análisis comparado de diseño y usabilidad de la tienda online de Zara, Mango, Calzedonia y OVS

El análisis comparado se ha llevado a cabo a través de unos parámetros predefinidos utilizados en el trabajo de Lohse y Spiller (cit. por Cristóbal Fransi, 2002), en la investigación de Eyeglue.net (cit. por Cristóbal Fransi, 2002) y en la tesis doctoral de Cristóbal Fransi (2002). Además, se añadieron puntos relevantes para el presente análisis en relación con la RSC y la RSC medioambiental.

Para el análisis realizado se ha tomado como muestra las tiendas online de las marcas correspondientes a la geolocalización italiana, ya que ha sido el lugar geográfico donde se ha desarrollado el estudio: Zara (https://www.zara.com/it/), Mango 
(https://shop.mango.com/it), Calzedonia (https://it.calzedonia.com/index.jsp) y OVS (https://www.ovs.it/it?geog=IT\&lang=it). Los resultados están expuestos de forma resumida en la Tabla 4 .

De dichos resultados, hay que destacar que tres de las cuatro empresas analizadas presentan en sus tiendas online información acerca de la empresa, dos sobre la RSC y tan solo una sobre la RSC medioambiental.

Tabla 4. Análisis comparado de diseño y usabilidad de Zara, Mango, Calzedonia y OVS

\begin{tabular}{|c|c|c|c|c|}
\hline \multirow{2}{*}{ Caracteristicas } & \multicolumn{4}{|c|}{ Marcas de fast fashion } \\
\hline & Zara & Mango & Calzedonia & OVS \\
\hline $\begin{array}{l}\text { Nombre de dominio } \\
\text { propio }\end{array}$ & $\bullet$ & $\bullet$ & $\bullet$ & $\bullet$ \\
\hline $\begin{array}{l}\text { Sección de } \\
\text { recomendaciones }\end{array}$ & $\bullet$ & $\bullet$ & $\bullet$ & $\bullet$ \\
\hline $\begin{array}{l}\text { Sección de atención al } \\
\text { cliente }\end{array}$ & $\bullet$ & $\bullet$ & $\bullet$ & $\bullet$ \\
\hline Sección de novedades & $\bullet$ & $\bullet$ & $\bullet$ & $\bullet$ \\
\hline Sección de FAQ's & $\bullet$ & $\bullet$ & $\bullet$ & $\bullet$ \\
\hline \multicolumn{5}{|l|}{$\begin{array}{l}\text { Sección de juegos y } \\
\text { concursos }\end{array}$} \\
\hline $\begin{array}{l}\text { Sección de colección } \\
\text { ética }\end{array}$ & $\bullet$ & $\bullet$ & & \\
\hline $\begin{array}{l}\text { Contacto con la } \\
\text { empresa }\end{array}$ & $\bullet$ & $\bullet$ & $\bullet$ & $\bullet$ \\
\hline $\begin{array}{l}\text { Información sobre la } \\
\text { empresa }\end{array}$ & $\bullet$ & $\bullet$ & $\bullet$ & \\
\hline $\begin{array}{l}\text { Información sobre la } \\
\text { RSC de la empresa }\end{array}$ & & $\bullet$ & $\bullet$ & \\
\hline $\begin{array}{l}\text { Información sobre la } \\
\text { RSC medioambiental } \\
\text { de la empresa }\end{array}$ & & $\bullet$ & & \\
\hline \multicolumn{5}{|l|}{$\begin{array}{l}\text { Precios con descuento } \\
\text { respecto a la tienda } \\
\text { tradicional }\end{array}$} \\
\hline $\begin{array}{l}\text { Enlaces entre } \\
\text { productos } \\
\text { relacionados }\end{array}$ & $\bullet$ & $\bullet$ & $\bullet$ & \\
\hline \multicolumn{5}{|l|}{$\begin{array}{l}\text { Diferentes criterios de } \\
\text { selección para mostrar } \\
\text { los productos }\end{array}$} \\
\hline \multicolumn{5}{|l|}{$\begin{array}{l}\text { Texto en varios } \\
\text { idiomas }\end{array}$} \\
\hline $\begin{array}{l}\text { Diferentes sistemas de } \\
\text { pago }\end{array}$ & $\bullet$ & $\bullet$ & $\bullet$ & $\bullet$ \\
\hline $\begin{array}{l}\text { Función de búsqueda } \\
\text { de productos }\end{array}$ & $\bullet$ & $\bullet$ & $\bullet$ & $\bullet$ \\
\hline Servicios gratuitos & $\bullet$ & $\bullet$ & $\bullet$ & $\bullet$ \\
\hline $\begin{array}{l}\text { Exposición de la } \\
\text { página web sin } \\
\text { desplazamiento por la } \\
\text { pantalla }\left(17,5^{\prime \prime}\right)\end{array}$ & $\bullet$ & $\bullet$ & $\bullet$ & $\bullet$ \\
\hline Situación del pedido & $\bullet$ & $\bullet$ & $\bullet$ & $\bullet$ \\
\hline Listado de favoritos & & $\bullet$ & $\bullet$ & $\bullet$ \\
\hline $\begin{array}{l}\text { "Las personas que } \\
\text { compran este } \\
\text { producto han } \\
\text { comprado..." }\end{array}$ & & & & \\
\hline
\end{tabular}

Fuente: Elaboración propia basada en el trabajo de Cristóbal Fransi, Eduardo (2002). 


\subsubsection{Estudio de la comunicación de la RSC y la RSC medioambiental en la tienda online o web corporativa de Zara, Mango, Calzedonia y OVS}

La realización de este estudio tiene como premisa, que se analiza o bien la tienda online o bien la web corporativa, en función de donde se encuentre ubicada la información acerca de la RSC y la RSC ambiental de cada una de las marcas.

En el caso de Zara y OVS, se recurre a las webs corporativas porque desde la tienda online, en los apartados correspondientes a información de la empresa, se redirige a ellas mediante links. Por lo tanto, se analiza la web corporativa de Inditex para el caso de Zara (https://www.inditex.com/), el apartado de Azienda (empresa) de la tienda online de Mango, el apartado Azienda de la tienda online de Calzedonia y las webs corporativas en el caso de la OVS (http://www.ovscorporate.it/it/ y http:// wecare.ovscorporate.it/it/).

La web corporativa destinada para dar a conocer el modelo sostenible que está presente en toda la cadena de valor de cada una de las ocho marcas del Grupo Inditex, entre ellas Zara, es una web con mucha usabilidad y un alto diseño. Haciendo que la navegación por ella sea muy agradable y sencilla. La web contiene un gran número de informes anexados en los apartados correspondientes, en función de la temática de cada uno. El consumidor interesado en conocer acerca de la RSC, y en específico la RSC medioambiental, obtendrá una amplia información actualizada en dicha web.

En los apartados destinados a la RSC de la tienda online de Mango se puede encontrar como la marca está muy concienciada con el medioambiente ya que, como ellos mismos citan en la web: «El objetivo de Mango es verificar todas las áreas en las que la compañía puede actuar en pro del medioambiente para evitar su empobrecimiento y aplicar una gestión óptima» (Mango, 2018). La información mostrada por la marca es de lectura sencilla, y con ayuda de los gráficos el consumidor puede obtener una idea general de las repercusiones que existen en el medioambiente al producir prendas de la marca. Además de proyectos llevados a cabo por la marca para cuidar no solo del medioambiente sino también del resto de stakeholders como el Acuerdo de Bangladesh sobre incendio y seguridad de edificios.

Calzedonia da pinceladas de información acerca de su RSC, en general, y de su RSC medioambiental, en particular, en el Código Ético que se encuentra anexado en el dominio de la tienda online. Se encontraron ausencias importantes como las memorias sociales e informes de sostenibilidad, que sí que se encontraron en Zara y Mango. Además, se encontró una falta de información del proceso de producción de la marca, lo que no implica que no sea ético, sino que el consumidor final no puede conocer dicho proceso a través de información publicada por la propia marca.

Se accede a la principal web corporativa de OVS (http://www.ovscorporate.it/it/) a través del menú inferior de la tienda online de la marca. En concreto, en la primera columna titulada Corporate (corporativo). Dicha web corporativa la consideramos como un site donde el consumidor puede encontrar mucha información acerca de la marca, de su funcionamiento interno y de su forma de producción. Las principales 
iniciativas llevadas a cabo por OVS se encuentran ubicadas exclusivamente en una segunda web corporativa de la marca (http://wecare.ovscorporate.it/it/). Las principales acciones de la marca que exponen son: el uso de algodón sostenible, creación de productos de valor, respeto por los animales, seguimiento de un enfoque circular, vender físicamente en tiendas sostenibles, llevar a cabo de una producción sostenible, promover proyectos que crean valor en las comunidades, utilización de recursos renovables y una preocupación medioambiental por parte del personal de la marca presente en sus acciones del día a día.

\section{Conclusiones}

La fast fashion ha hecho cambiar los calendarios de producción de los minoristas que quieren tener un espacio en el mass market, haciendo que el consumidor pueda obtener prendas que siguen las tendencias a precios reducidos y en un breve espacio temporal.

Del estudio descriptivo de los establecimientos físicos realizados en Roma de las principales marcas de fast fashion españolas e italianas, se destaca que no se hace uso de cartelería ni de ningún otro medio para comunicar acerca del modo de producción o los materiales utilizados de las prendas de las colecciones/líneas sostenibles. Mientras que, en determinadas prendas consideradas de otras colecciones/ líneas diferentes a la colección sostenibles como tal, se destaca con cartelería los materiales utilizados.

Las prendas de colecciones/líneas sostenibles, que se encontraron en Zara y Mango, se ubicaron en zonas diferentes en función de la rotación de las prendas. En el caso de Zara en las zonas frías, al ser de mayor rotación sus prendas sostenibles por ser consideradas algunas de ellas de la línea Basic. Mientras que, en el caso de Mango, se ubicaban en las calientes al ser consideradas prendas de baja rotación.

La comunicación llevada a cabo en la web corporativa de Inditex y de OVS acerca de la RSC y de su sostenibilidad corporativa queda reflejada de una forma correcta. Del mismo modo que ocurre con el apartado dedicado a ello en la tienda online de Mango, ya que el único modo de conocer su preocupación por el medioambiente y sus proyectos encaminados a ello es mediante la lectura de esta parte del dominio. La falta de información que se presencia en la tienda online de Calzedonia implica una falta de información del proceso de producción de la marca, pero no la falta de sostenibilidad en dicho proceso, sino que no se comunica aspectos de ella ni de las consecuencias ambientales que se producen en ese proceso. Zara, Mango y OVS son las marcas que se sitúan con una mayor información de su RSC, y en concreto, su RSC medioambiental hacia el consumidor a través de sus webs. Se considera que una mayor expansión de esta información ayudaría a cambiar la perspectiva que tienen muchos clientes sobre los valores de dichos grupos empresariales y de su modo de producir. 
Haciendo una comparación entre la información encontrada en el punto de venta físico y el online, se encuentra una falta de comunicación en el punto de venta físico acerca del modo de producción y materiales utilizados. En lo que se refiere a poder diferenciar la colección sostenible del resto de prendas, se encuentra una gran diferencia en el caso de Zara, ya que es más fácil de encontrar la línea sostenible en la tienda online al tener su propia categoría diferenciada que en la tienda física, siendo ubicada en zonas frías. Mientras que, en Mango, tanto en la tienda online como en la tienda física se pueden encontrar de forma rápida las prendas, por tener una sección diferenciada en la tienda online y estar en las zonas calientes en el punto de venta físico.

Se confirma, tal y como indicó Visser (2010), a nivel micro, que en términos de proyectos y prácticas específicas de RSC pueden observarse mejoras. En concreto, en nuestra muestra, se incorporan acciones de RSC en sus puntos de venta (fundamentalmente el online). A nivel global los indicadores referentes a salud social, ambiental y ética están en declive, como refleja el hecho de que las colecciones sostenibles son una pequeña parte de la colección tanto de Zara y Mango, e inexistente para Calzedonia y OVS.

Consideramos que la presente investigación refleja cómo comunican la sostenibilidad las principales marcas de fast fashion españolas e italianas a través de los puntos de venta físicos y online mostrando la necesidad de una mejora importante para hacer llegar su sostenibilidad corporativa a los consumidores.

En la actualidad, los consumidores deberían tener la mayor información posible de la sostenibilidad corporativa de las marcas de fast fashion para poder desarrollar su comportamiento de compra. Dicho lo cual, las principales marcas de fast fashion deberían centrar parte de sus esfuerzos en dar a conocer su sostenibilidad corporativa, tanto en el punto de venta online como en el punto de venta físico.

A los jóvenes les preocupa el medioambiente, están comprometidos con la disminución de la generación de residuos y tienen una herramienta de acción muy poderosa: la decisión de compra. Cada vez más, se compra con responsabilidad y anteponen a las empresas que cumplen con estándares de cuidado con el medioambiente y RSC, como señalaba la encuesta a la generación millennial de Deloitte de 2018. La muestra refleja un cambio negativo en la opinión de estos jóvenes sobre los compromisos y la ética empresarial que, a su entender, las empresas deberían tener. Para ellos, entre las acciones que una empresa debería acometer en beneficio de la sociedad está la protección del medioambiente (Deloitte, 2018).

En términos globales, a uno de cada dos jóvenes nacidos entre 1982 y 2004, el cambio climático les parece el problema más grave al que se enfrenta el mundo, según la encuesta anual Global Shapers Survey (2017), publicada por el Foro Económico Mundial. En 2019, el movimiento estudiantil 'Youth For Climate', en español Jóvenes por el Clima, se extiende por el mundo. La joven sueca Greta Thunberg inició el movimiento tras manifestarse frente al Parlamento de su país en agosto de 2018 para exigir acciones urgentes contra el cambio climático. En diciembre intervino 
en la COP24 celebrada en Polonia y miles de jóvenes comenzaron a concentrarse meses después en los 'Viernes para el Futuro'.

En un futuro sería interesante conocer la opinión del propio consumidor acerca de la información percibida sobre la RSC en general, y de la RSC medioambiental, en particular, tanto en el proceso de compra físico como en el online, y en el resto de los medios de comunicación propios de las marcas analizadas en la presente investigación.

\section{Bibliografía}

Aguilera Moyano, Joaquín de (2014). Branded Entertainment. Los contenidos de marca como herramienta de comunicación comercial en el entorno del marketing actual. Tesis doctoral. Madrid: Universidad Rey Juan Carlos.

Aguilera Moyano, Joaquín de y Baños González, Miguel (2017). Las comunicaciones en el nuevo paradigma del marketing. Experiencias, relevancia, engagement y personalización. Presentación. En: Revista ICONO14 Revista científica de Comunicación y Tecnologías emergentes, Vol. 15, no 2, 1-15. DOI: 10.7195/ri14.v14i2.1098 Aparicio, Gloria y Zorrilla, Pilar (2015). Distribución comercial en la era omnicanal. Madrid: Ediciones Pirámide.

Avendaño Castro, William R. (2011). Responsabilidad Social Corporativa (RSC) y desarrollo sostenible: una mirada desde la Declaración de Río 1992. En: Respuestas, Vol. 16, n ${ }^{\circ} 2,45-59$.

Bhardwaj, Vertica y Fairhurst, Ann (2010). Fast fashion: response to changes in the fashion industry. En: The International Review of Retail, Distribution and Consumer Research, Vol 20, no 1, 163-173. DOI: 10.1080/09593960903498300

Bigné, Enrique; Andreu, Luisa; Chumpitaz, Ruben, y Swaen, Valerie (2006). La influencia de la responsabilidad social corporativa en el comportamiento de compra de estudiantes universitarios. En: ESIC Market, Vol. 6, n ${ }^{\circ}$ 597, 163-189.

Blázquez, Marta (2014). Fashion shopping in multichannel retail: The role of technology in enhancing the costumer experience. En: International Journal of Electronic Commerce, Vol. 18, $\mathrm{n}^{\circ} 4,97-116$.

Bruce, Margaret y Daly, Lucy (2006). Buyer behaviour for fast fashion. En: Journal of Fashion Marketing and Management: An International Journal, Vol. 10, $\mathrm{n}^{\mathrm{o}} 3$, 329-344. DOI: 10.1108/13612020610679303

Byun, Sang-Eun y Sternquist, Brenda (2008). The antecedents of in-store hoarding: measurement and application in the fast fashion retail environment. En: The International Review of Retail, Distribution and Consumer Research, Vol. 8, $\mathrm{n}^{\mathrm{O}} 2$, 133-147. DOI: 10.1080/09593960701868241.

Carrera-Gallissà, Enric (2017). Los retos sostenibilistas del sector textil. En: Revista de Química e Industria Textil, Vol. 220, 20-32. 
Carroll, Archie B. (1991). The pyramid of corporate social responsibility: Towards the moral management of organizational stakeholders. En: Business Horizons, Vol. $34,39-48$.

Cristóbal Fransi, Eduardo (2002). Conceptualización de la calidad de servicio al cliente percibida en el comercio electrónico. Evaluación y aplicación en el establecimiento virtual. Tesis doctoral. Lérida: Universitat de Lleida.

Cristóbal Fransi, Eduardo (2006). El merchandising en el establecimiento virtual: una aproximación al diseño y usabilidad. En: ESIC Market, Vol. 123, 139-188.

De la Cuesta González, Marta (2004). El porqué de la responsabilidad social corporativa. En: Boletín económico de ICE, Información Comercial Española, Vol. 2813, 45-58.

Deloitte (2018). Encuesta a la generación millennial 2018. En: https://www2.deloitte.com/es/es/pages/human-capital/articles/encuesta-millennial.html (Consultado 15-07/2019).

Fletcher, Kate (2010). Slow fashion: An invitation for systems change. En: Fashion Practice, Vol. 2, no 2, 259-265. DOI: 10.2752/175693810X12774625387594

García Feijoo, María y Eizaguirre Zarza, Almudena (2010). La gestión de las variables ambientales en el entorno de compra virtual. En: Boletín de Estudios Económicos, Vol. 65, $\mathrm{n}^{\mathrm{o}}$ 199, 155-173.

Garriga, Elisabet y Melé, Domènec (2004). Corporate social responsibility theories: Mapping the territory. En: Journal of Business Ethics, Vol. 53, 51-71.

Global Shapers Survey (2017). The Annual Survey 2017 is live. En: https://www. globalshapers.org/news-updates/the-annual-survey-2017-is-live (Consultado 1507/2019).

González, José A. (2015). La sostenibilidad ecológica en el desarrollo de productos textiles: Una Revisión de Literatura. En: Realidad y Reflexión, Vol. 38, 65-97. DOI: 10.5377/ryr.v38i0.1833

Granda Revilla, Germán y Trujillo Fernández, Ricardo (2011). La gestión de los grupos de interés (stakeholders) en la estrategia de las organizaciones. En: Economía industrial, Vol. 381, 71-76.

Granero Castro, Javier y Ferrando Sánchez, Miguel (2012). Cómo elaborar el manual ambiental de la empresa según la Norma ISO 14001:2004. Madrid: FC Editorial.

Guercini, Simone (2001). Relation between branding and growth of the firm in new quick fashion formulas: analysis of an Italian case. En: Journal of Fashion Marketing and Management Vol. 5, $\mathrm{n}^{0}$ 1. 69-79. DOI: 10.1108/EUM0000000007280

Hernández Sampieri, Roberto; Fernández Callado, Carlos y Baptista Lucio, María del Pilar (2010). Metodología de la investigación. México D.F.: Editorial McGrawHill. 
ICEX (2017). Italia, primer exportador de moda de la UE. En: https://www.icex. es/icex/es/navegacion-principal/todos-nuestros-servicios/informacion-de-mercados/ paises/navegacion-principal/noticias/NEW2017724852.html?idPais=IT

ICEX (2018). Estudio de mercado. El mercado de la tecnología mercado-textil en Italia. En: https://www.icex.es/icex/es/navegacion-principal/todos-nuestros-servicios/informacion-de-mercados/paises/navegacion-principal/el-mercado/estudiosinformes/DOC2018795649.html?idPais=IT (Consultado 15-07/2019).

Inditex (2018). Resultados Ejercicio 2017. Recuperado de: https://www.inditex. com/documents/10279/341334/Resultados+ejercicio+2017.pdf/bf5a364d-c3f0-6b38c4ed-1651742ca9ad (Consultado 15-07/2019).

Kim, HaeJung; Ahn, Soo-Kyoung, y Fourney, Judith A. (2014). Shifting paradigms for fashion: From total to global to smart consumer experience. En: Fashion and Textiles, Vol. 1, no 1, 15. DOI: 10.1186/s40691-014-0015-4

Lobato Gómez, Francisco (2005). Marketing en el Punto de Venta. Madrid: Paraninfo

Lohse, Gerald L. y Spiller, Peter (1999). Internet retail store design: How the user interface influences traffic and sales. En: Journal of Computer-Mediated Communication, Vol. 5, $\mathrm{n}^{\mathrm{o}}$ 2. DOI: 10.1111/j.1083-6101.1999.tb00339.x

Lyon, Thomas P. y Maxwell, Jonh W. (2006). Greenwash: Corporate Environmental Disclosure under Threat of Audit. En: Ross School of Business, University of Michigan, 1-39.

Manager Verona On Line (2014). Assemblea Generale: Confindustria Verona e Confindustria Vicenza. En: http://www.confindustria.vr.it/confindustria/verona/ galleria.nsf/attach/B8E94B894578F93DC1257CE6006178FC/\$file/Verona\%20Manager10_Speciale\%20Assemblea\%20Generale_new.pdf?openelement (Consultado 15-07/2019).

Mango (2018). Ambiente. En: https://shop.mango.com/iframe.faces?ts=15361454 84005\&state=she_005_IT (Consultado 15-07/2019).

Mango Pressroom (2016). Las ventas de Mango crecen un 15,3\% en 2015 impulsadas por la apertura de megastores. En: https://press.mango.com/es/las-ventasde-mango-crecen-un-15-3-en-2015-impulsadas-por-la-apertura-de-megastores_2342 (Consultado 15-07/2019).

Marquis, Christopher; Toffel, Michael W. y Zhou, Yanhua (2016). Scrutiny, Norms, and Selective Disclosure: A Global Study of Greenwashing. En: Organization Science, Vol. 27, $\mathrm{n}^{\mathrm{o}} 2$, 483-504. DOI: 10.1287/orsc.2015.1039

Martínez Martínez, Inmaculada José (2005). La comunicación en el Punto de Venta: Estrategias de Comunicación en el Comercio Real y Online. Madrid: ESIC.

Martínez Sánchez, Ma Eugenia (2015). Espacios y ambientes comerciales. La influencia del contexto en la eficacia comunicativa. Tesis doctoral. Barcelona: Universitat de Barcelona. 
Mediobanca (2018). Focus sulla Moda (2012-2017). En: https://www.mbres.it/sites/default/files/resources/Presentazione_Moda_2017.pdf (Consultado 15-07/2019).

Menon, Satya y Kahn, Barbara (1997). Cross-Category Effects of stimulation on the shopping experience: An application to Internet shopping. Documento de trabajo. Philadelphia: University of Pennsylvania.

Moorhouse, Debbie y Moorhouse, Danielle (2018). Designing a sustainable brand strategy for the fashion industry. En: Clothing Cultures, Vol, 5, $\mathrm{n}^{0} 1,7-18$. DOI: 10.1386/cc.5.1.7_2

Moore, Christopher M. y Fernie, John (2004). Retailing within an international context. En: Bruce, M., Moore, C. y Birtwistle, G. (eds.) International Retailing: A Case Study Approach. Oxford: Elsevier.

Mortara, Ariela (2015). Il Made in Italy. En: Rivista Pic-Ais, Vol. 1, 19-20.

Muñoz, Emilio (2008). Dinámica y dimensiones de la ética en la investigación científica y técnica. En: Arbor, Vol. 184, n ${ }^{0}$ 730, 197-206. DOI: 10.3989/arbor.2008. i730.172

Navarro Bailón, M $\mathrm{M}^{\mathrm{a}}$ Ángeles (2009). La comunicación en el Punto de Venta bajo un Enfoque Integrador. En: Distribución y Consumo, Vol. 108, 92-102.

Observatorio de la Moda Española (2016). El Sector de la Moda en España: Retos y desafíos. En: http://xn--observatoriomodaespaola-cic.com/wp-content/ uploads/2016/06/INFORME.pdf (Consultado 15-07/2019).

OVSCorporate (2018). OVS Company Profile. En: http://www.ovscorporate.it/en/ company (Consultado 15-07/2019).

Ozdamar Ertekin, Zeynep y Atik, Deniz (2015). Sustainable markets: Motivating factors, barriers, and remedies for mobilization of slow fashion En: Journal of Macromarketing, Vol. 35, $n^{\circ}$ 1, 53-69. DOI: 10.1177/0276146714535932

Palomares Borja, Ricardo (2009). Merchandising. Teoría, práctica y estrategia. Madrid: ESIC Editorial.

Pelta, Raquel (2011). Moda sostenible, moda que cuestiona. En: http://www.monografica.org/01/Art\%C3\%ADculo/904 (Consultado 15-07/2019).

Porter, Michael E., y Kramer, Mark R. (2006). The link between competitive advantage and corporate social responsibility. En: Harvard Business Review, Vol. 84, $n^{\circ} 12,78-92$.

Quintas, Natalia y Quintas, Eva (2011). La dimensión comunicativa de la moda: apuntes del caso español. En: Zer-Revista de Estudios de Comunicación, Vol. 15, $n^{\circ} 28,197-212$.

Ramus, Catherine A. y Montiel, Ivan (2005). When are corporate environmental policies a form of greenwashing? En: Business \& Society, Vol. 44, $\mathrm{n}^{0} 4,377-414$. DOI: $10.1177 / 0007650305278120$ 
Riaño, Pilar y Pérez Gestal, Iria (2017). El Mapa de la Moda 2017 (XI): Los gigantes de la moda española. En: https://www.modaes.es/empresa/el-mapa-de-la-modaxi-los-gigantes-de-la-moda-espanola.html (Consultado 15-07/2019).

Sandino Restrepo, M. (2009). Metodología de la investigación científica: articulación de los elementos básicos del proceso de investigación. Medellín: Editorial Librería Jurídica Comlibros.

Schwartz, Mark S. y Carroll, Archie B. (2003). Corporate social responsibility: a three-domain approach. En: Business Ethics Quaterly, Vol. 13, nº 4, 503-530.

Suárez Serrano, Eugenia (2013). La Responsabilidad Social Corporativa: Un nuevo paradigma para las empresas. En: Encuentros Multidisciplinares, Vol. 15, $\mathrm{n}^{0} 45$, 22-31.

Trespalacios Gutiérrez, Juan Antonio (Coord.) (2017). Marketing insights: la respuesta del comercio a las tendencias del comportamiento social del consumidor. Oviedo: Cátedra Fundación Ramón Areces.

Trujillo, María Andrea y Vélez Bedoya, Rodrigo (2006). Responsabilidad ambiental como estrategia para la perdurabilidad empresarial. En: Universidad \& Empresa, Vol. 5, n ${ }^{0}$ 10, 291-308.

Visser, Wayne (2010). The age of Responsibility: CSR 2.0 and the New DNA of Business. En: Journal of Business Systems, Governance and Ethics, Vol. 5, n ${ }^{\circ}$ 3, 7-22. World Commission on Environment (1987). El desarrollo sostenible, una guía sobre nuestro futuro común: El informe de la Comisión Mundial sobre el Medio Ambiente y el Desarrollo. Oxford: Oxford University Press. 
OTRAS INVESTIGACIONES I 



\section{Gestión y comunicación de la cultura corporativa en empresas de las industrias creativas. Estudio de caso en el Arco mediterráneo en España Management and communication of the corporate culture in companies of the creative industries. Case study in the Mediterranean arc in Spain}

Eliseo Rodríguez Monteagudo Universidad de Alicante

Fernando Olivares Delgado Universidad de Alicante

\section{Referencia de este artículo}

Rodríguez Monteagudo, Eliseo; Olivares Delgado, Fernando (2019). Gestión y comunicación de la cultura corporativa en empresas de las industrias creativas. Estudio de caso en el Arco mediterráneo en España. adComunica. Revista Científica de Estrategias, Tendencias e Innovación en Comunicación, (18), 155-198. DOI: DOI: http://dx.doi.org/10.6035/2174-0992.2019.18.9

\section{Palabras clave}

Cultura corporativa; Industrias creativas; Territorio; Comunicación; Creatividad; Activos intangibles.

\section{Key words}

Corporate culture; Creative industries; Territory; Communication; Creativity; Intangible assets. 


\title{
Resumen
}

Este trabajo aborda el modo de gestionar y comunicar la cultura corporativa por parte de empresas de las industrias creativas presentes en el Arco Mediterráneo en España. Metodología: Se emplea el estudio de quince casos de empresas de las industrias creativas del Arco Mediterráneo en España a través de entrevistas y/o cuestionarios con CEO's, responsables de RR.HH. y/o Dircoms de dichas empresas. Hallazgos: Los datos tanto cuantitativos como cualitativos obtenidos permiten aportar una visión inédita, actual sobre la gestión y comunicación de la cultura corporativa por parte de las empresas analizadas. Limitaciones de la investigación: los datos y hallazgos hacen referencia a la muestra de estudio y, por lo tanto, no son generalizables a todas las industrias creativas. Aplicabilidad: El estudio reporta una aproximación a las industrias creativas y su gestión en la actual economía creativa. Originalidad: Ante el constante aumento de la importancia de las industrias creativas, este estudio genera datos y una visión práctica sobre la gestión de sus intangibles.

\begin{abstract}
This investigation focusses on how corporate culture is managed and communicated by companies of the creative industries which are present along the Mediterranean arc in Spain. Methodology: the study of fifteeen cases of companies in the Creative industries of the Mediterranean arc in Spain is used via interviews and/ or questionnaires to CEO's, HR responsibles and/or Communication Directors of these companies. Findings: The quantitative and qualitative data obtained provide a new and current vision on the management and communication of corporate culture by the analysed companies. Research shortcomings: The data and findings refer to the sample study and they are not therefore generalizable to all creative industries. Practical implications: The study reports an approximation to the creative industries and their management in the current Creative economy. Originality: considering the constant increase in the importance of creative industries, this study generates data and a practical vision of the management of its intangible assets.
\end{abstract}

\section{Autores}

Eliseo Rodríguez Monteagudo [eliseoromo@gmail.com] es Licenciado en Publicidad y RR.PP., Máster en Comunicación en Industrias Creativas y Doctor en Metodologías humanísticas en la era digital (línea de investigación en Comunicación en la era digital) por la Universidad de Alicante

Fernando Olivares Delgado [f.olivares@ua.es] es Doctor en Sociología, Premio Extraordinario de Doctorado y profesor de Comunicación y Marca Corporativas en la Universidad de Alicante, Director de la Cátedra de la marca corporativa y del grupo de investigación UA_Brandscience y Experto en branding estratégico y empresa familiar. 


\section{Introducción}

\subsection{Las industrias creativas y el territorio}

Para poder entender las empresas es necesario comprender en primera instancia el contexto que las rodea. Ya que, de forma directa o indirecta, las circunstancias de cada territorio repercuten no sólo en la especialización de sus actividades, sino también en la propia identidad de las empresas allí instaladas.

En este sentido, por lo que respecta especialmente a las actividades creativas, tienen un importante vínculo con la propia dinámica económica de las ciudades y su adaptación a la propia economía creativa. Así tal como demuestran Shutters, Rachata y Lobo (2015) en una investigación sobre áreas metropolitanas en Estados Unidos con más de 50.000 habitantes, la diversidad ocupacional en las mismas tiende a generar trabajos más creativos. Tal como indica también Florida (2009: 34) «la población y la actividad económica tienen un perfil muy puntiagudo, pero la innovación (el motor del crecimiento económico) se concentra todavía más».

En esta misma línea algo parecido podría extrapolarse a las principales ciudades de mediterráneo en España, en las que la diversidad ocupacional, especialmente en lo que a industrias y servicios se refiere.

De igual modo, además de la relación entre la especialización económica y el territorio, es importante también entender la relación entre la identidad empresarial y el propio lugar de origen. Así, según corroboran Brouwer y Pellenbarg (2011: 91) «es evidente que la identidad y la imagen se relacionan en gran medida también por lugar y el sentido del lugar». Asimismo, las empresas precisan generar sinergias con su entorno directo para diferenciarse y reforzar sus valores ya que

«en la situación del entorno actual [...] hace necesaria una diferenciación de los territorios (ciudad, país, región, etc.) basada en los activos intangibles que posean los territorios y que permitan un posicionamiento adecuado del lugar» (López Lita y Benlloch, 2005: 99).

A este respecto se puede observar que el territorio mediterráneo en España concentra un gran número de industrias creativas, que emplean «ciclos de creación, producción y distribución de los bienes y servicios que tienen como base fundamental la creatividad y el capital intelectual» (Naciones Unidas y UNCTAD, 2010: 36), ya que dicho territorio alberga un número considerable de tejido industrial cooperante y que el mismo espacio es favorable para impulsar actividades en el que el componente creativo es importante.

Tal concentración de industrias creativas tiende a instalarse en determinados enclaves por distintas razones estratégicas. Curiosamente la mayor parte de ellas lo hacen en un territorio o zona del Arco Mediterráneo en España. Es el denominado «Arco restringido o arco núcleo» designado por connotaciones económicas (Institut Català de la Mediterrànea, 1999). Dicho arco núcleo engloba principalmente las comunidades autónomas de Cataluña, Comunidad Valenciana e Islas Baleares. 


\subsection{Las industrias creativas y la cultura corporativa}

Además de por la creatividad asociada a la propia actividad productiva, la cultura corporativa también está condicionada por su entorno directo, incluso indirecto. Así, el made in puede trazar algunas particularidades de la propia cultura corporativa. Sobre el trasvase cultural, entre territorio y organización, Olivares (2015: 115) apunta lo siguiente:

El saber hacer territorial está en las personas físicas...y jurídicas. En forma de legado histórico, de valores compartidos, los caracteres y las señas de identidad, impregnan generación tras generación las decisiones trascendentales en materia de comercio y negocio, economía, desarrollo y cambio.

En este sentido las normas sociales, costumbres, valores predominantes, o la propia demografía del entorno de la empresa, pueden influir o verse reflejados en su cultura: El territorio organizado configura un continente de actividades y un espacio de interacción. Los valores y comportamientos forman parte de un acervo cultural, incidiendo en su estructura de organización. Como parte de este patrimonio se encuentra la cultura empresarial o la cultura económica (Institut Català de la Mediterrànea, 1999: 220).

Por lo tanto, la cultura corporativa de cualquier empresa no sólo se incuba internamente, sino que desde su implantación está en constante interacción con el entorno. Así, tal como indica Schein (1988: 11) «La cultura empresarial permite explicar muchos fenómenos de la empresa». Repercute el territorio, entre otros, en unas características identificativas de la propia cultura corporativa. En este sentido, Llopis (1992: 80) indica que: «La cultura empresarial es peculiar para cada organización...Existen varias investigaciones que han encontrado notas representativas de la manera general en que se comparten valores en las empresas pertenecientes a un mismo Estado».

El resultado es un «corredor mediterráneo creativo en España». Un territorio estratégico que, ante los nuevos modelos de negocio, la consolidación de la economía creativa y la incorporación de las nuevas generaciones (millenials, xennials, X,) merece ser estudiado con detenimiento a través de algunas industrias creativas destacadas que allí se ubican.

Por ello este estudio pretende realizar una aproximación a la gestión y comunicación de la cultura corporativa de industrias creativas del Arco Mediterráneo en España a través de empresas representativas del sector, especializadas en distintas actividades.

\section{Metodología}

\subsection{Metodología y justificación}

El presente trabajo está sustentado en base a la conceptualización y análisis de tendencias de las Industrias Creativas (Rodríguez-Monteagudo y Olivares-Delgado, 2017). 
La cultura corporativa, entre otros aspectos, requiere un análisis pormenorizado. Así como establece Stake (1998: 16) «[...] nos encontramos con una cuestión que se debe investigar, una situación paradójica, una necesidad de comprensión general, y consideramos que podemos entender la cuestión mediante el estudio de un caso particular».

Por ello optamos por llevar a cabo un estudio de casos a través de un muestreo no probabilístico, adecuado para análisis exploratorios. Y es que «[...] con frecuencia es necesario aceptar datos, diseños e inferencias sin los beneficios del muestreo probabilístico» (Kish, 1996: 31).

Aunque la selección de dichas empresas no es aleatoria, tampoco atiende a un criterio totalmente abierto, sino que la conformación de la muestra estará orientada por una serie de parámetros fijados previamente. Por tanto, no se trata de una selección discrecional. En este sentido:

Puede ser útil intentar seleccionar casos que sean típicos o representativos de otros casos, pero no es probable que la muestra de sólo un caso o de unos pocos casos sea una buena representación de otros. El objetivo primordial del estudio de un caso no es la comprensión de otros. La primera obligación es comprender este caso (Stake, 1998: 17).

En esta línea, el propio objeto de estudio requiere esa comprensión y profundidad de casos más que una aportación cuantitativa. Además, la complejidad para clasificar las industrias creativas se hace complicado poder disponer de un listado del que partir. Así como indican Boix y Lazzeretti (2011:190) «Son realmente escasos los trabajos sobre industrias creativas en España, al menos si las consideramos como un conjunto o «sector». Por tanto, los aspectos cualitativos adquieren mayor relevancia que los propiamente cuantitativos representativos.

\subsection{Objetivos}

Este análisis, estará focalizado para poder obtener información en función a través una serie de objetivos que permitan acotar e identificar las nuevas tendencias de gestionar la cultura corporativa en las industrias creativas. Los objetivos del estudio son:

- Demostrar si el territorio puede influir sobre las características de la comunicación de dichas empresas y el modo de gestión de su cultura corporativa.

- Descubrir el origen y estructura de los equipos humanos.

- Estimar la capacidad de la cultura corporativa para captar talento.

- Conocer los principales elementos constituyentes de la cultura corporativa.

- Revelar las funciones y aportaciones de la cultura corporativa a nivel funcional. 
- Detectar algunas conexiones entre cultura corporativa y gestión del cambio en las empresas

- Establecer la influencia de la multiculturalidad en la conformación de la cultura corporativa.

- Abordar la gestión de la cultura corporativa desde diversas perspectivas de la dirección empresarial.

- Analizar las acciones de comunicación de la cultura corporativa.

- Identificar los principales canales, acciones y recursos creativos para fomentar la cultura corporativa interna y externamente.

- Constatar la inferencia de la gestión y comunicación de la cultura corporativa sobre la innovación y el valor de marca.

De esta forma intentamos abordar así la hipótesis general en la que se enmarca este proceso: La ubicación, contexto sociocultural y la propia actividad de las industrias creativas mediterráneas en España favorecen una cultura corporativa propia orientada hacia el cambio, que condiciona su forma de comunicar e incide en la innovación.

\subsection{Criterios de selección de la muestra}

Los criterios de la selección de la muestra se centran en industrias creativas presentes en el Arco mediterráneo núcleo en España. Son principalmente los siguientes:

a. Según la ubicación geográfica.

Cataluña, Comunidad Valenciana e Islas Baleares, como territorios creativos en el Arco Mediterráneo en España (también AME)

Ubicación estratégica de las industrias creativas con concentración de otras Industrias Creativas especializadas en una o varias actividades.

b. Según actividades representativas de las industrias creativas.

Actividades UNCTAD 2010 a las que se suman también Gastronomía y enología

c. Según el tamaño de la empresa.

Se desarrollará una muestra atendiendo a empresas de diversos tamaños (por número de empleados ${ }^{1}$ ).

d. Según el origen y la naturaleza de la empresa.

Empresas autóctonas, por estar condicionadas e influenciada directamente por el entorno mediterráneo.

Por todo lo expuesto el universo del estudio de casos está compuesto por todas aquellas organizaciones originarias y ubicadas en Cataluña, Comunidad Valenciana

1 Según estrato de asalariados como establece la Dirección General de Industria y de la Pequeña y Mediana Empresa en España. 
e Islas Baleares, que desarrollan actividades englobadas en las industrias creativas, preferentemente localizadas en focos territoriales creativos, con diversos tamaños según el número de empleados y de diversa naturaleza.

\subsection{Procedimientos, recursos y persona de contacto}

Este estudio pretende determinar las particularidades de los sistemas y recursos para gestionar y canalizar la cultura corporativa tanto interna como externamente, siempre prestando especial atención a la capacidad creativa de las mismas antes, durante y tras este proceso.

En este sentido, es necesario pues conocer de primera mano las estrategias y toma de decisiones al respecto, así como los flujos comunicativos desde la empresa. Por ello se estima conveniente recurrir a un cargo de Dirección, responsable del Departamento de RRHH o DirCom para poder conocer de cerca las particularidades de cada uno de los casos objeto de análisis, junto a la obtención de información desde otras fuentes.

\subsection{Diseño de las variables}

Es necesario diseñar un modelo de entrevista dividido en tres partes principales, para poder obtener información desde tres perspectivas, complementarias entre sí: factores comunicativos, factores de dirección y gestión, así como los sociológicos

«La cultura se transmite a los empleados en diversas formas, siendo las más potentes las historias, rituales, símbolos materiales y lenguaje» (Robbins, 1996: 696). Por todo ello además de ahondar en estos aspectos a través de la entrevista a nivel interno como externo en la empresa, adicionalmente, también se realizará un análisis sobre la disponibilidad y determinadas particularidades de documentación corporativa e información en Webs oficiales y otros recursos 2.0 como complemento del proceso. En este sentido, como establece Villafañe (1999:162) «Existen un conjunto de instrumentos y metodologías para el análisis de la cultura corporativa. Unos están totalmente formalizados mediante cuestionarios, y las otras se basan en técnicas de análisis cualitativo».

Será necesario por tanto conocer los flujos comunicativos, pero también una serie de aspectos no observables, en relación a la cultura corporativa. En esta línea Oden (1997: 3) indica que «La cultura corporativa puede representarse en dos niveles... el nivel superior es observable externamente, pero el nivel inferior está oculto a la vista y reside en la mente de las personas»

Por lo tanto, en consonancia con la estructura de la entrevista, el estudio de la comunicación de la cultura corporativa se encargará de analizar su parte observable (historia, símbolos, ceremonias,) mientras que los aspectos de dirección y gestión atenderá a las características no observables (valores, ideologías, etc). Los aspectos sociológicos servirán por su parte para anclar y dotar de mayor sentido a los resul- 
tados. Solo, así como un todo, adquirirá significado el análisis «La cultura surge en la organización debido a la necesidad de la organización de hacer frente a aspectos externos e internos de supervivencia y éxito» (Oden, 1997: 4).

En definitiva, el esquema metodológico de análisis previsto queda establecido de la siguiente forma:

Figura 1. Esquema metodológico casos estudio

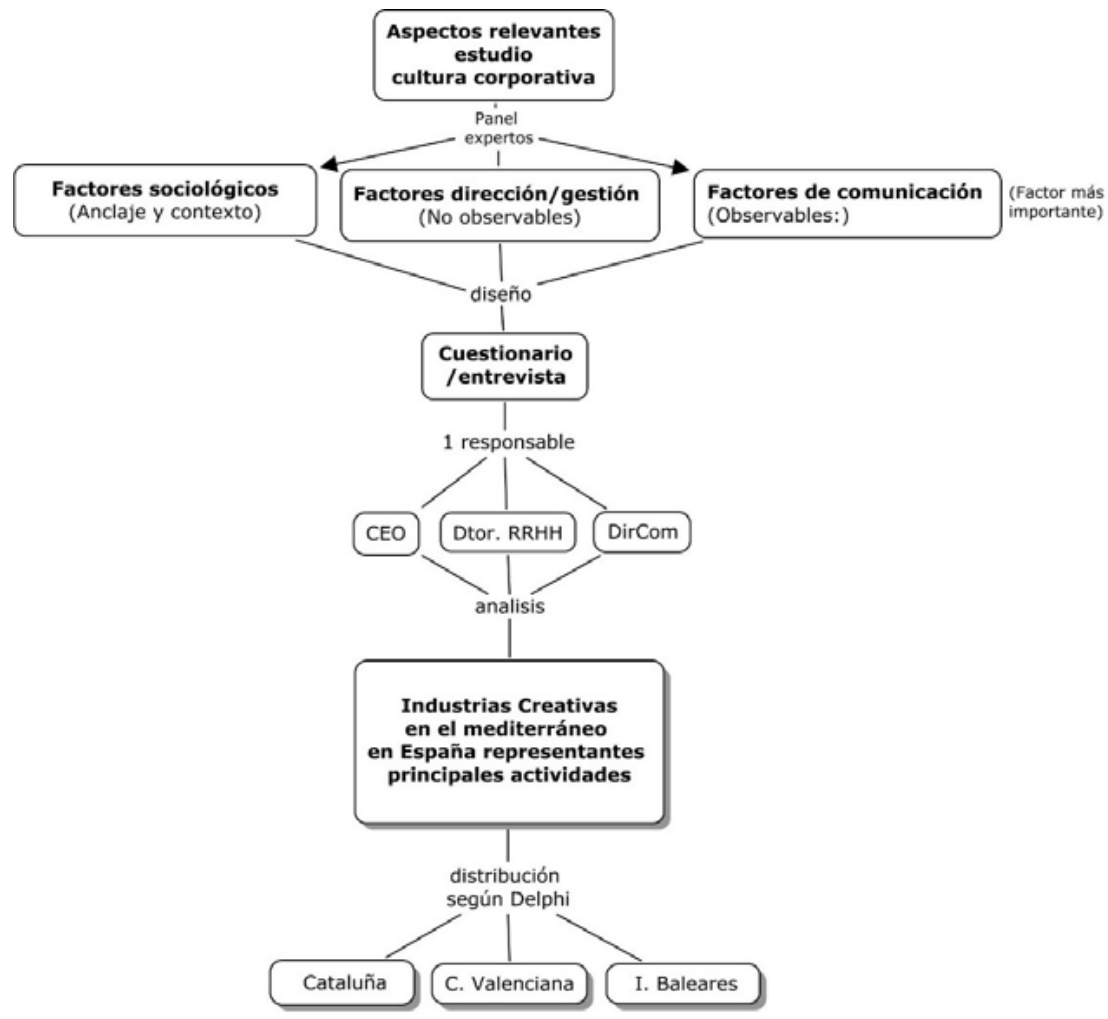

Fuente: elaboración propia

Por todo ello, el modelo de entrevista semiestructurada que servirá para recopilar toda la información, según lo establecido, se estructura en tres grandes bloques que atienden a cada uno de los aspectos citados: 
Tabla 1. Factores análisis estudio de casos

\begin{tabular}{|l|l|}
\hline Factores & Objetivo del diseño \\
\hline Sociológicos & $\begin{array}{l}\text { Variables para establecer en profundidad el origen, la evolución y principales } \\
\text { características de la organización }\end{array}$ \\
\hline De dirección y gestión & $\begin{array}{l}\text { Variables para determinar el modo de implantación, coordinación y la valora- } \\
\text { ción interna de la cultura corporativa }\end{array}$ \\
\hline De comunicación & $\begin{array}{l}\text { Variables para conocer las estrategias, acciones, recursos y resultados de la } \\
\text { comunicación de la cultura corporativa }\end{array}$ \\
\hline
\end{tabular}

Fuente: elaboración propia

En este sentido, se diseñan 45 variables tanto cerradas, con niveles de medición nominal y ordinal, como otras abiertas para obtener información tanto cuantitativa como cualitativa.

\section{Estudio de casos}

\subsection{Contacto y recursos}

Con los criterios de selección de los casos ya expuestos, se procede a contactar con un listado de posibles empresas participantes. Preferentemente se opta por la entrevista presencial, personal o telefónica semiestructurada, según ubicación de las empresas, dado que permite extraer una mayor cantidad de información y concretar otros contenidos sobre el transcurso de esta.

No obstante, también se contempla adaptar a formato cuestionario, en este caso online, sólo para aquellos casos que así lo solicitan. La adaptación a las circunstancias y disponibilidad de tiempo de cada uno de los receptores participantes, determinan en cada caso la idoneidad de la herramienta de análisis. En todos los casos se remite una carta institucional de solicitud de participación.

A continuación, tras desarrollar un protocolo de contacto y recopilación de la información entre noviembre de 2014 y febrero de 2015, se indican las actividades, ubicación, cargo de la persona de contacto de los casos que han participado, así como modo de recogida de la información. 
Tabla 2. Estudio por orden de participación

\begin{tabular}{|c|c|c|c|c|c|}
\hline Ne & $\frac{\text { Actividad creativa[1] }}{\text { (etlquctas, tags) }}$ & Ubicación[2] & Metodología & $\begin{array}{l}\text { Cargo persona } \\
\text { contacto }\end{array}$ & $\begin{array}{l}\text { Empresa } \\
\text { familiar }\end{array}$ \\
\hline 1 & $\begin{array}{c}\text { Fotografia, publicidad, cine y } \\
\text { TV }\end{array}$ & $\begin{array}{l}\text { Marratxí, } \\
\text { Mallorca } \\
\text { (Baleares) }\end{array}$ & $\begin{array}{l}\text { Entrevista } \\
\text { telefónica }\end{array}$ & $\begin{array}{c}\text { Responsable } \\
\text { RR.PP }\end{array}$ & \\
\hline 2 & Festivales y exhibiciones, cine & $\begin{array}{c}\text { Sitges, Barcelona } \\
\text { (Cataluña) }\end{array}$ & $\begin{array}{l}\text { Entrevista } \\
\text { telefónica }\end{array}$ & Dircom & \\
\hline 3 & $\begin{array}{c}\text { Software, video juegos, } \\
\text { software y contenido creativo } \\
\text { digital }\end{array}$ & $\begin{array}{l}\text { Palma de } \\
\text { Mallorca, } \\
\text { Mallorca } \\
\text { (Baleares) }\end{array}$ & $\begin{array}{l}\text { Cuestionario } \\
\text { online }\end{array}$ & $\begin{array}{l}\text { Responsable. } \\
\text { RR.HH }\end{array}$ & $\mathrm{x}$ \\
\hline 4 & $\begin{array}{c}\text { Músico en vivo, teatro, cine, } \\
\text { baile y opera }\end{array}$ & $\begin{array}{l}\text { Barcelona, } \\
\text { (Cataluña) }\end{array}$ & $\begin{array}{l}\text { Entrevista } \\
\text { telefónica }\end{array}$ & $\begin{array}{l}\text { Responsable } \\
\text { Administración }\end{array}$ & \\
\hline 5 & Juguetes, libros, software, I+D & $\begin{array}{l}\text { Onil, Alicante } \\
\text { (C. Valenciana) }\end{array}$ & $\begin{array}{l}\text { Entrevista } \\
\text { presencial }\end{array}$ & Director General & $x$ \\
\hline 6 & Gastronomia, publicaciones & $\begin{array}{l}\text { Petrer, Alicante } \\
\text { (C. Valenciana) }\end{array}$ & $\begin{array}{l}\text { Entrevista } \\
\text { presencial }\end{array}$ & Dircom & $x$ \\
\hline 7 & $\begin{array}{l}\text { Radio y otros tipos de } \\
\text { difusión, moda }\end{array}$ & Ibiza, (Baleares) & $\begin{array}{l}\text { Entrevista } \\
\text { telefónica }\end{array}$ & $\begin{array}{l}\text { Administration, } \\
\text { Marketing y } \\
\text { Communicación }\end{array}$ & \\
\hline 8 & $\begin{array}{l}\text { Diseño gráfico, diseño } \\
\text { industrial, publicidad, diseño } \\
\text { interior, arquitectura, moda }\end{array}$ & $\begin{array}{l}\text { Barcelona, } \\
\text { (Cataluña) }\end{array}$ & $\begin{array}{l}\text { Entrevista } \\
\text { telefónica }\end{array}$ & Cuentas & \\
\hline 9 & $\begin{array}{c}\text { Enologia, artesania y turismo } \\
\text { cultural }\end{array}$ & $\begin{array}{l}\text { Sant Sadurní } \\
\text { d'Anoia, } \\
\text { Barcelona } \\
\text { (Cataluña) }\end{array}$ & Cuestionario & $\begin{array}{l}\text { Director de } \\
\text { Comunicación y } \\
\text { Publicidad }\end{array}$ & $x$ \\
\hline 10 & $\begin{array}{l}1+0 \text {, Diseño interior, } \\
\text { arquitectura }\end{array}$ & $\begin{array}{l}\text { Castalla, } \\
\text { Alicante (C. } \\
\text { Valenciana) }\end{array}$ & $\begin{array}{c}\text { Vista y presencial } \\
\text { y cuestionairo }\end{array}$ & $\begin{array}{l}\text { Responsable } \\
\text { estrategia } \\
\text { corporativa y } \\
\text { comunicación }\end{array}$ & $x$ \\
\hline 11 & $\begin{array}{c}\text { Museos, Bibliotecas, Pintura y } \\
\text { escultura, fotografia, turismo } \\
\text { cultural, antigüedades, libros, } \\
\text { moda }\end{array}$ & $\begin{array}{l}\text { Barcelona, } \\
\text { (Cataluña) }\end{array}$ & Cuestionario & $\begin{array}{l}\text { Directora de } \\
\text { estrategia y } \\
\text { comunicación }\end{array}$ & \\
\hline 12 & $\begin{array}{c}\text { Escultura, artesania, joyeria, } \\
\text { diseño interior, museo, } \\
\text { antigüedades }\end{array}$ & $\begin{array}{l}\text { Tavernes } \\
\text { Blanques, } \\
\text { Valencia (C. } \\
\text { Valenciana) }\end{array}$ & $\begin{array}{l}\text { Entrevista } \\
\text { telefónica }\end{array}$ & Jefa de RR.PP. & $x$ \\
\hline 13 & Diseño gráfico, diseño interior & $\begin{array}{l}\text { Valencia, (C. } \\
\text { Valenciana) }\end{array}$ & Cuestionario & $\begin{array}{l}\text { Fundadory } \\
\text { director }\end{array}$ & \\
\hline \multirow[t]{2}{*}{14} & Moda & $\begin{array}{l}\text { Torrellano, } \\
\text { Elche, Alicante } \\
\text { (C. Valenciana) }\end{array}$ & Cuestionario & Directora RRHH & $\mathrm{x}$ \\
\hline & $\begin{array}{c}1+D \text {, diseño interior, juguetes, } \\
\text { publicaciones gastronomla, } \\
\text { moda, }\end{array}$ & $\begin{array}{l}\text { Alfafar, Valencia } \\
\text { (C. Valenciana) }\end{array}$ & $\begin{array}{c}\text { Asistencia } \\
\text { ponencia Dircom } \\
\text { y cuestionario }\end{array}$ & $\begin{array}{l}\text { Dircom y } \\
\text { Responsable } \\
\text { RRHH }\end{array}$ & \\
\hline
\end{tabular}

Fuente: elaboración propia 
Aunque el estudio no es generalizable, la muestra abarca todas las actividades que engloban las II. Creativas según el listado establecido. Asimismo, las empresas se distribuyen entre las tres comunidades autónomas del Arco núcleo Mediterráneo en España, con especial presencia en Cataluña y la Comunidad Valenciana. La mitad de ellas son además empresas familiares (EF, en adelante). De igual modo existen empresas de todos los tamaños atendiendo al número de empleados. Se incorpora además un caso complementario fuera de muestra.

Figura 2. Distribución territorio creativos mediterráneos muestra

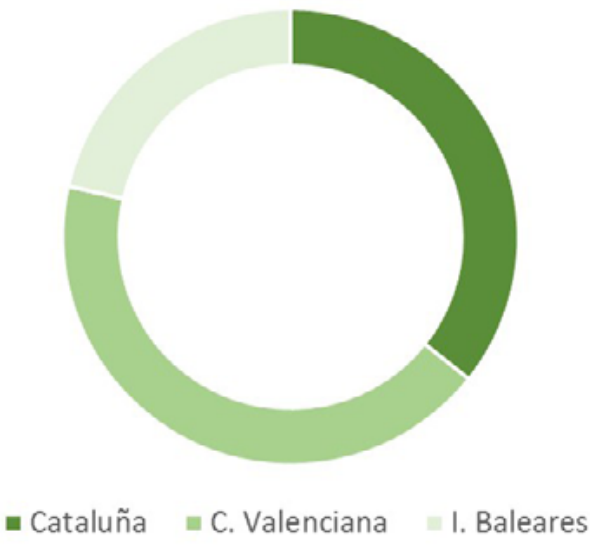

Fuente: elaboración propia

\subsection{Participación casos}

Además de todos los casos expuestos, hemos optado también por incorporar otro adicional que se desmarca de uno de los criterios de selección establecidos, el origen mediterráneo de la empresa. De esta forma se amplía el alcance de la investigación y permite comparar resultados según origen de las empresas, a la vez que plantea otros futuribles estudios en esta línea.

\subsection{Proceso de recopilación de datos}

Además de profundizar en estos aspectos a través de las entrevistas personales presenciales y telefónicas, así como los cuestionarios, se ha reforzado este estudio con análisis de contenido de información corporativa, sólo en aquellos casos en los que se ha precisado ampliar o complementar la información. En este sentido, se ha 
recurrido a la revisión de documentos aportados voluntariamente por las empresas participantes, así como otra información oficial publicada en las respectivas Webs, recursos 2.0 y documentos corporativos, entre otros.

\section{Resultados estudio de casos}

\subsection{Resultados análisis muestra}

A continuación, se exponen los resultados obtenidos de los 14 casos (la empresa no originaria del Arco Mediterráneo se analizará de forma aislada) tras el análisis de la información. Los datos son tratados de forma acumulada y presentados estadísticamente en el estudio. De esta forma conseguimos mantener la confidencialidad, asegurando el anonimato de la autoría y la privacidad interna desde una perspectiva cualitativa la de información aportada por cada una de las empresas.

\subsubsection{Factores sociológicos}

\section{Variable 1: Origen la idea de negocio}

Los datos desvelan que la formación previa de los fundadores ha sido el factor más determinante a la hora de impulsar los modelos de negocio analizados. De esta forma los conocimientos adquiridos previamente influyen no sólo en el modo de emprendimiento sino también sobre el tipo de actividad desarrollada. En menor medida, la tradición del territorio favorece también la puesta en marcha de determinados proyectos.

Figura 3. Origen idea del negocio

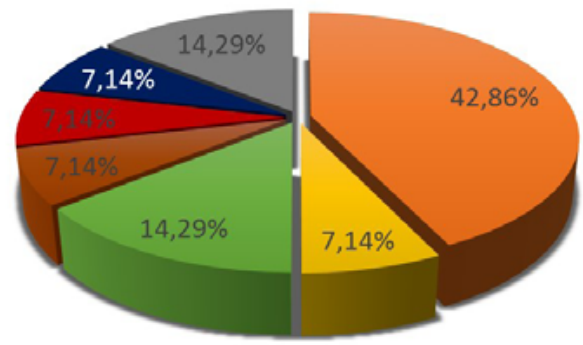

$$
\begin{aligned}
& \text { = Formación previa } \quad \text { Oportunidad de mercado } \\
& \text { = Tradición del territorio_ } \quad \text { Tradición familiar } \\
& \text { - Cambio orientación negocio familiar Entidad pública } \\
& \text { - NC }
\end{aligned}
$$

Fuente: elaboración propia 


\section{V2. Motivos ubicación sede central localidad mediterránea}

Al identificar las motivaciones que han establecido la localización geográfica de las empresas participantes, sobresale como razón principal la localidad de origen de los fundadores de dichas empresas.

Figura 4. Factores ubicación sede central
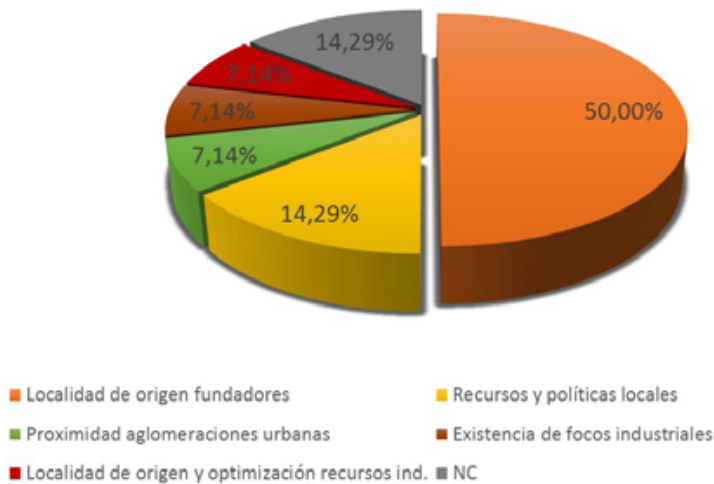

Fuente: elaboración propia

\section{V3. Capital humano}

\section{V3.1. $\mathrm{N}^{\mathrm{o}}$ trabajadores directos}

Entre la muestra de este estudio existen microempresas, pequeñas y medianas empresas, así como grandes empresas. Esta diversidad, además de permitir establecer interesantes comparaciones atendiendo a distintos tamaños de las organizaciones, determina que las industrias creativas los son por naturaleza, si interferir, al menos en lo que la actividad se refiere, el número de trabajadores de la organización.

\section{V3.2. Tipo de organigrama}

Aunque aquéllas que disponen de una estructura vertical superan ligeramente a las que cuentan con una organización horizontal, se detecta una tendencia que apunta hacia la horizontalidad, como así lo establece uno de los casos que está modificando su organigrama estructural en este sentido. 


\section{V3.3. Extensión empresa}

Existe una importante ramificación de los casos analizados en forma de red distribuida por diferentes puntos geográficos. Suele ser común desplegar empresas filiales, delegaciones, puntos de distribución de productos y/o tiendas propias para poder comercializar los productos y servicios resultantes por dichas empresas creativas en múltiples lugares estratégicos, tanto en España como a nivel internacional.

\section{V4. Multiculturalidad.}

\section{V4.1. $\mathrm{N}^{\mathrm{O}}$ de trabajadores procedentes de otros países sede central}

Los equipos conformados por trabajadores de distintos países en la sede central es una constante a la hora de dotar los recursos humanos. En este sentido, la mayoría de los casos que han aportado la información al respecto, cuentan en su plantilla entre 1 y 10 personas procedentes de otros países.

\section{V4.2. Continentes de precedencia empleados otros países}

En las empresas participantes que cuentan con trabajadores procedentes de otros países, en su mayoría provienen de Europa. También se aprecia cierta dinámica en la contratación de recursos humanos desde América (hace referencia tanto a América del Norte como del Sur). Tras esta tendencia, el continente africano aparece en tercer lugar. Aunque en menor medida, Asia y Oceanía también nutren de empleados a las Industrias Creativas estudiadas.

\section{V4.3. Ubicación departamental empleados otros países}

En relación con la ubicación departamental de dichos empleados procedentes de otros países y continentes, según las empresas que han aportado esta información, suelen ocupar puestos de muy diversa índole, sin resaltar un puesto en particular. Nos obstante, entre los datos obtenidos, si parece predominar perfiles orientados a departamentos principalmente comerciales, de marketing y comunicación.

\section{V5. Valores y el espíritu mediterráneo de los fundadores en la cultura corporativa}

Se confirma la inferencia de los valores de la familia y del entorno mediterráneo sobre las respectivas culturas corporativas. 
Figura 5. Influencia valores mediterráneos y familiares

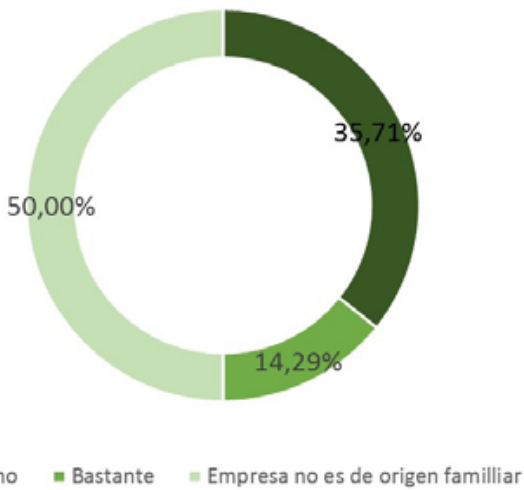

- Mucho $=$ Bastante = Empresa no es de origen familliar

Fuente: elaboración propia

En este sentido, aunque han sido muy pocas las empresas que han concretado dichas aportaciones hacen referencia a un ambiente familiar en el seno de las organizaciones, un estilo de dirección y gestión muy particular, así como una excelente relación con el entorno y una cultura de relación.

Figura 6. Ejemplos influencia valores mediterráneos y familiares
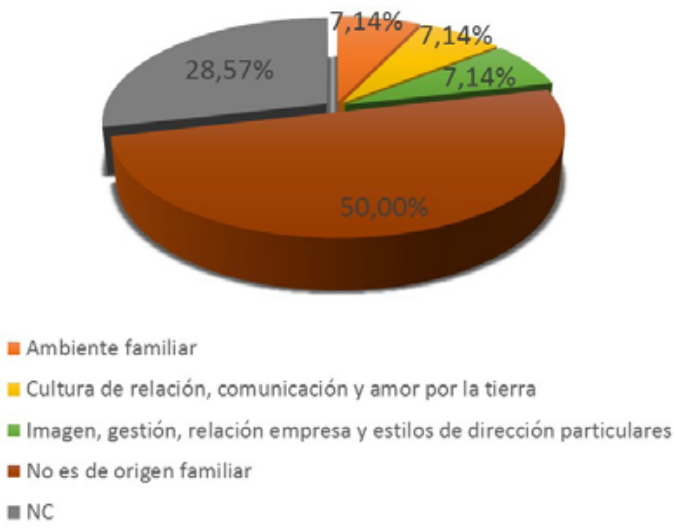

Fuente: elaboración propia 


\section{V6. Evolución empresa}

\section{V6.1. Año de inicio de la actividad principal}

Entre la muestra, existen tanto empresas con una amplia historia y trayectoria como otras de reciente creación. Sí parece significativo que éstas últimas están más vinculadas con nuevos sectores emergentes mientras que las más longevas se vinculan sobre todo con sectores más tradicionales pero que paulatinamente han evolucionado y diversificado su actividad.

\section{V6.2. Otras actividades creativas adicionales procedentes de la principal que generan negocio}

Es habitual en las Industrias Creativas participantes desarrollen otra serie de actividades creativas complementarias a la principal, con un carácter eminentemente multidisciplinar y transversal en el modelo de negocio.

\subsubsection{Factores de gestión y dirección}

V7. Importancia estratégica de la cultura corporativa

La mayoría de las empresas han destacado la importancia estratégica de la cultura corporativa de forma muy significativa. Este aspecto denota el carácter vital de este intangible a la hora de establecer los distintos propósitos corporativos y comerciales.

Tabla 3. Valoración importancia cultura corporativa

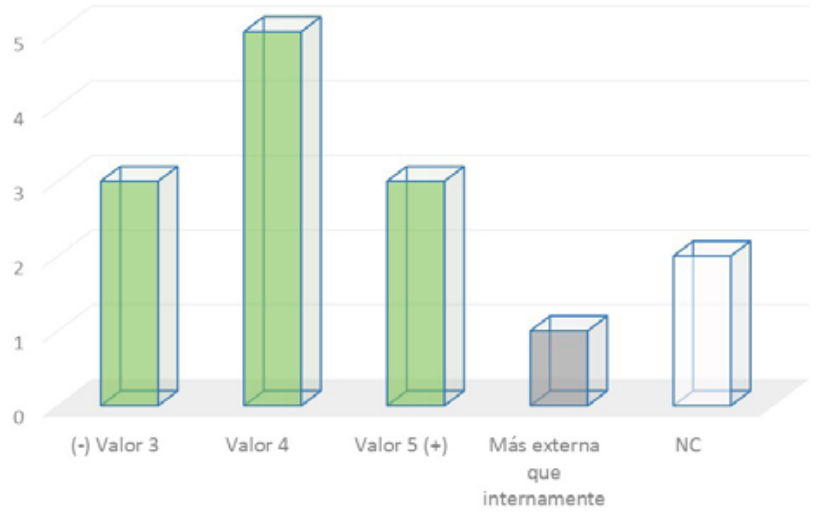

Fuente: elaboración propia 


\section{V8. Recursos destinados a la gestión de la cultura en la empresa}

Los resultados revelan que en la mayoría de los casos se dedican recursos, tanto humanos como económicos directos, a la gestión de la propia cultura corporativa, certificando la necesidad de dotar a la empresa de la infraestructura pertinente para poder implantar y desarrollar los procesos vinculados con la cultura corporativa.

Figura 7. Recursos directos gestión cultura corporativa

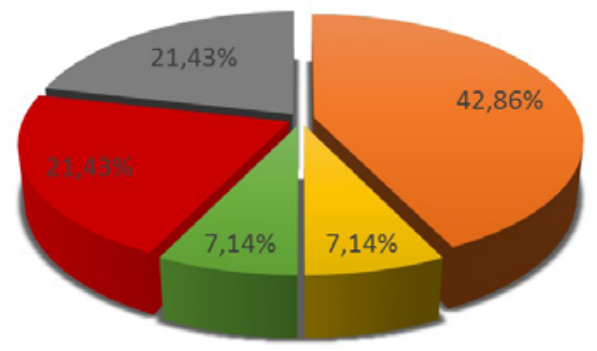

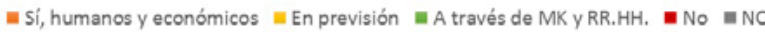

Fuente: elaboración propia

\section{V9. Partida presupuestaria anual asignada a la cultura corporativa}

Por la complejidad de su concreción, por la confidencialidad de este aspecto o simplemente por no disponer de la asignación de dicha partida han existido mayoritariamente abstenciones a la hora de aportar dicha información.

\section{V10. Implantación cultura corporativa}

Los resultados constatan que la cultura corporativa se implanta desde la Dirección en la mayoría de los casos analizados. Los órganos de poder de las respectivas empresas son las que determinan e instauran las características de la cultura corporativa de sus respectivas organizaciones. No obstante, en la mitad de los casos que representan esta tendencia, dicha cultura corporativa también se nutre con aportaciones de los propios empleados. 
Figura 8. Implantación cultura corporativa

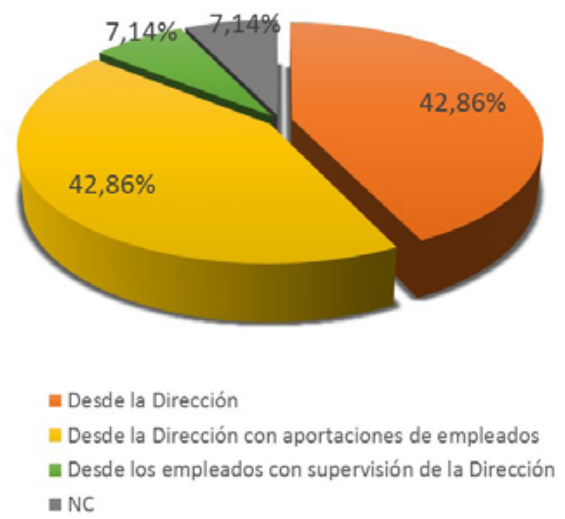

Fuente: elaboración propia

\section{V11. Tipología valores que constituyen la cultura corporativa}

Existe una amplia diversidad y combinaciones de valores que constituyen las respectivas culturas corporativas. Sin embargo, la conjugación de valores profesionales y personales se confirma como la fórmula predominante. En este sentido la creatividad se ha citado con bastante regularidad.

Tabla 4. Tipología valores cultura corporativa

\begin{tabular}{|l|r|r|}
\hline & Frecuencia & Porcentaje \\
\hline Valores profesionales y de producto & 1 & 7,14 \\
Valores profesionales y personales & 4 & 28,57 \\
Valores profesionales, de producto y geográficos & 1 & 7,14 \\
Valores éticos, profesionales y hacia el cliente & 1 & 7,14 \\
Valores éticos, profesionales y personales & 2 & 14,29 \\
Valores éticos, profesionales, hacia el cliente y personales & 3 & 21,43 \\
Valores hacia el cliente y producto & 1 & 7,14 \\
Valores hacia el cliente, profesionales y personales & 1 & 7,14 \\
Total & 14 & 100,00 \\
\hline
\end{tabular}

Fuente: elaboración propia 
V12. Influencia territorio mediterráneo sobre empresa y su cultura corporativa

Además de las propias aportaciones internas de los equipos de Dirección y los propios empleados, son muchas las aportaciones con las que el entorno mediterráneo nutre también o impregna las culturas corporativas, al menos de los casos de estudio. Se puede pues establecer la importancia del entorno como elemento generador de ventajas competitivas, tales como culturas más abiertas, la propia creatividad o la influencia sobre los propios valores corporativos entre otros aspectos.

Tabla 5. Influencia del territorio mediterráneo

\begin{tabular}{|c|c|c|}
\hline & Frecuencia & Porcentaje \\
\hline Influye mucho (sin concretar) & 1 & 7,1 \\
\hline Mejora la relación con lo local & 1 & 7,1 \\
\hline Mejora la forma de vivir y entender la empresa & 1 & 7,1 \\
\hline Influye en los valores corporativos & 2 & 14,3 \\
\hline Estimula una mayor creatividad & 1 & 7,1 \\
\hline Influyen en los trabajos realizados & 1 & 7,1 \\
\hline Influye y promueve acciones & 1 & 7,1 \\
\hline $\begin{array}{l}\text { Promueve una cultura más abierta y estimula } \\
\text { una mayor creatividad }\end{array}$ & 1 & 7,1 \\
\hline $\begin{array}{l}\text { Aporta ventajas competivivas, promueve } \\
\text { cultura abierta, influye en los valores y estimula } \\
\text { mayor creatividad }\end{array}$ & 2 & 14,3 \\
\hline $\begin{array}{l}\text { Aporta ventajas competitivas, promueve un } \\
\text { cultura más abierta y estimula una mayor } \\
\text { creatividad }\end{array}$ & 1 & 7,1 \\
\hline No influye & 2 & 14,3 \\
\hline Total & 14 & 100,0 \\
\hline
\end{tabular}

Fuente: elaboración propia

V13. Origen valores de su cultura corporativa.

Los valores, como ejes de la propia cultura corporativa, son propuestos por la propia Dirección y se nutren también de aquellos valores propuestos por los empleados teniendo siempre presente las inquietudes de la sociedad y los valores sociales resultantes. 
Figura 9. Origen valores cultura corporativa
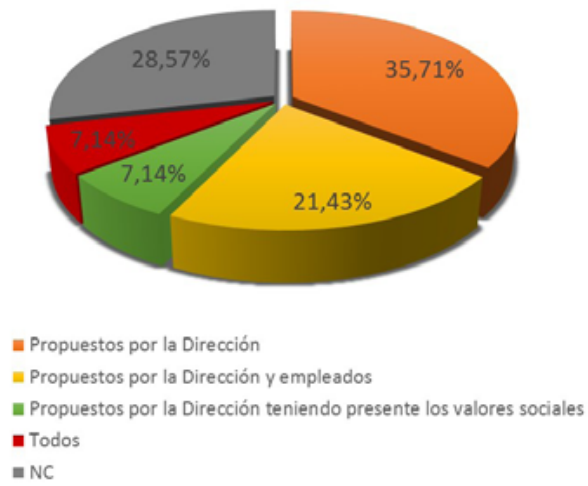

Fuente: elaboración propia

\section{V14. Valores corporativos compartidos por los empleados directos}

Se constata que los valores de la mayoría de empresas participantes son compartidos por todos sus empleados. Aspecto que evidentemente refuerza la cultura corporativa y evita posibles grietas internas entre los recursos humanos, respaldando además un proyecto común compartido.

Sin embargo, aunque de forma minoritaria, encontramos también situaciones en las que la cultura corporativa sí parece variar, dependiendo de distintas circunstancias, especialmente atendiendo a los departamentos y/o jerarquía en el seno de la organización.

Figura 10. Asimilación valores corporativos

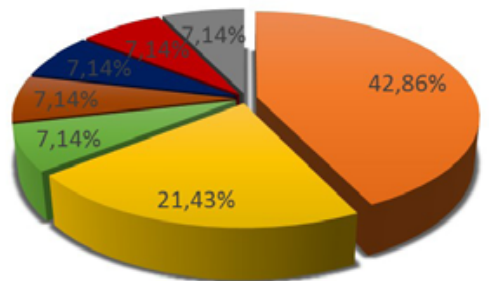

WSi, por igual por todos los empleados

= Sí, por igual por todos los empleados e incluso se hacen partícipes a los colaboradores

= Si, pero el nivel de aceptación varía en función de la jerarquía

= Si, pero el nivel de aceptación varía en función de dept.

- Si, pero el nivel de aceptación varía en función de la jerarquía y dept.

- Varían según sean empleados fijos o temporales

a NC

Fuente: elaboración propia 


\section{V15. Otros elementos significativos que conforman su cultura corporativa}

Además de los valores, existen otra serie de elementos que definen y constituyen las culturas corporativas de los casos analizados. Así, los propios comportamientos de las empresas, su identidad corporativa y las presunciones básicas, de forma conjunta, es la combinación mayoritariamente aportada por dichas empresas para exponer los componentes de sus culturas.

Figura 11. Otros elementos de la cultura corporativa
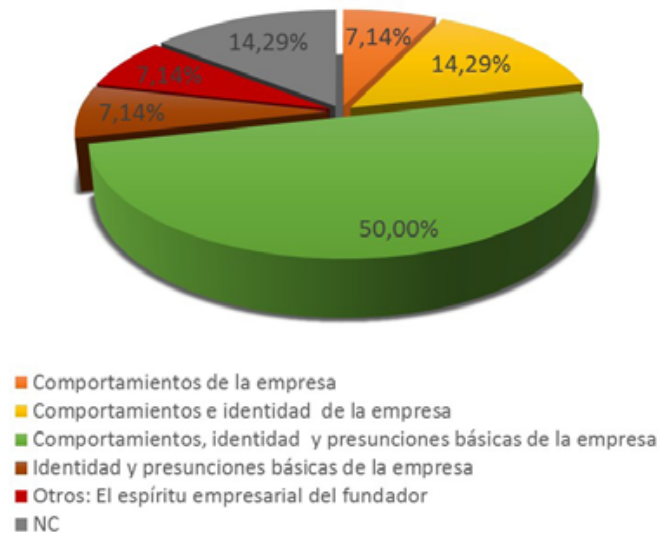

Fuente: elaboración propia

\section{V16. Orientación estratégica de su cultura corporativa}

La combinación de la orientación de la cultura corporativa hacia el cambio y por otra parte hacia el cliente conjuntamente es una constante en la mayoría de casos, reafirmando la necesidad de orientar la cultura de empresa no sólo hacia el cliente sino también para desarrollar procesos internos que repercutan en la innovación. 
Figura 12. Orientación estratégica cultura corporativa

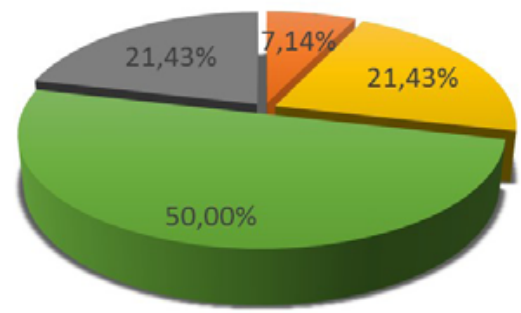

\section{- Orientación hacia el cliente Orientación hacia el cambio \\ a Orientación hacia el cliente y el cambio $\mathbf{n}$ NC}

Fuente: elaboración propia

\section{V17. Funciones cultura corporativa}

Respecto a las principales funciones de la cultura corporativa, la mayoría de casos coinciden en señalar una serie de aportaciones ventajosas de carácter interno. La implicación y motivación de los trabajadores, la construcción de la identidad corporativa, la unión y cohesión de grupo así como la orientación de la conducta se establecen como prioritarias.

Tabla 6. Funciones cultura corporativa

\begin{tabular}{|l|r|r|}
\hline & Frecuencia & Porcentaje \\
\hline Implicación y motivación & 1 & 7,14 \\
\hline Unión y cohesión & 1 & 7,14 \\
\hline Guiar conducta & 1 & 7,14 \\
\hline Construcción de la identidad / guiar conducta & 1 & 7,14 \\
\hline Implicación y motivación / construcción identidad & 1 & 7,14 \\
\hline Implicación y motivación / unión y cohesión & 2 & 14,29 \\
Implicación y motivación / unión y cohesión / empoderamiento & 7,14 \\
\hline Implicación y motivación / construcción de identidad / unión y cohesión & 2 & 14,29 \\
\hline Implicación y motivación / construcción identidad / unión y cohesión / & 4 & 28,57 \\
guiar conducta & 14 & 100,0 \\
\hline Total & 2 \\
\hline
\end{tabular}

Fuente: elaboración propia 


\section{V18. Inferencia cultura corporativa en la creatividad}

La cultura corporativa presenta unas particularidades que genera creatividad en los trabajadores. Así se determina tras analizar los datos aportados, pudiendo establecer que la cultura corporativa repercute en resultados tangibles de un número elevado de las empresas participantes en el estudio. Incluso dos de los casos establecen que dichos resultados son tanto de carácter tangible como intangible.

Figura 13. Inferencia cultura corporativa en la creatividad
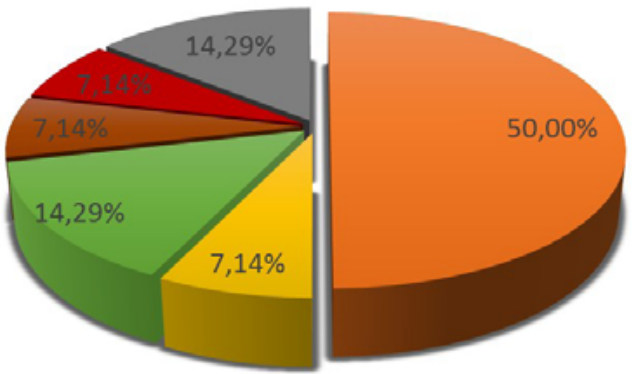

$$
\begin{aligned}
& \text { - Sí, con resultados tangibles } \quad \text { Sí, con resultados intangibles } \\
& \text { =Si, con resultados tangibles e intangibles Es un elemento favorable } \\
& \text { - No de forma directa } \quad \text { NC }
\end{aligned}
$$

Fuente: elaboración propia

\section{V19. Integración de empleados a través de la cultura corporativa}

Atendiendo al carácter integrador de los empleados directos como consecuencia de la gestión y comunicación de la cultura corporativa, todas las empresas que aportan dicha información valoran muy positivamente este aspecto. 
Figura 14. Capacidad integradora cultura corporativa

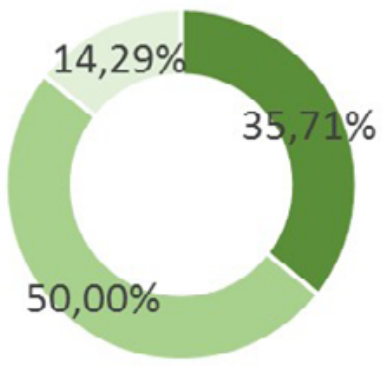

\section{- Mucho $=$ Bastante $\quad \mathrm{NC}$}

Fuente: elaboración propia

\section{V20. Ventajas multiculturalidad corporativa}

Existe un alto consenso al respecto de las ventajas que les aporta la multiculturalidad de su plantilla. En este sentido, se extrae también que dichas ventajas son mucho mayores que otras posibles desventajas que pudieran surgir a raíz del mestizaje corporativo. Incluso uno de los casos destaca los beneficios más allá de la empresa, en la sociedad en general.

Figura 15. Ventajas multiculturalidad

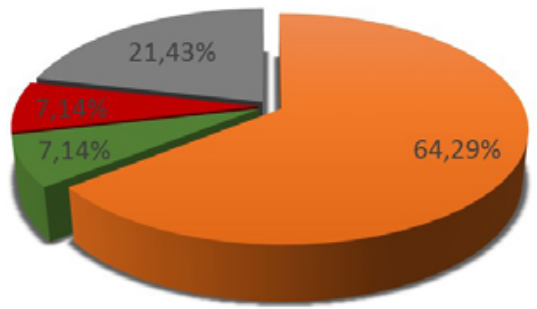

" Más beneficios que desventajas

- No existe multiculturalidad

Fuente: elaboración propia 


\section{V21. Captación talento mediante la cultura corporativa}

Se constata que la cultura corporativa de las empresas mediterráneas analizadas facilita la captación del talento de España y a nivel internacional. Los resultados obtenidos demuestran que grupos sociales prefieren trabajar en determinadas empresas por las particularidades que presentan sus respectivas culturas corporativas.

Figura 16. Influjo de la cultura en la captación de talento

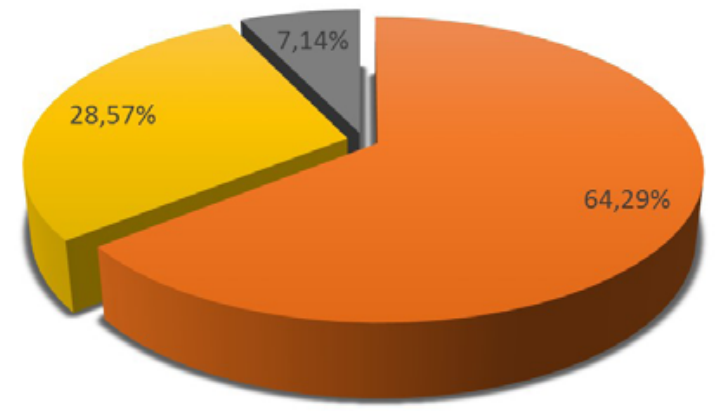

=Si, atrae el talento de España y otros países $\mathbf{m} \mathrm{Si}$, atrae el talento de España $\mathbf{n} \mathrm{NC}$

Fuente: elaboración propia

\section{V22. Criterios para contratar un trabajador creativo}

De los resultados se extrae que el conocimiento ya adquirido por los empleados a través de la formación y la experiencia se contempla como un requisito importante. De igual forma la capacidad y ambición personal de los trabajadores se establece como otro de los parámetros que se tienen muy presentes. La multidisciplinareidad, también influye en los procesos de selección. Así, aunque de forma más puntual, otros condicionantes serían aspectos a considerar, tales como la organización y la meticulosidad a la hora de desenvolverse en el puesto laboral. 
Tabla 7. Perfil contratación trabajador creativo

\begin{tabular}{|c|c|c|}
\hline & Frecuencia & Porcentaje \\
\hline Conocimiento ya adquirido mediante formación & 1 & 7,14 \\
\hline Conocimiento ya adquirido por experiencia & 1 & 7,14 \\
\hline La multidisciplinareidad & 1 & 7,14 \\
\hline Evaluación experiencia mediante casting & 1 & 7,14 \\
\hline Varía según el puesto & 2 & 14,29 \\
\hline Organización, limpieza y meticulosidad & 1 & 7,14 \\
\hline $\begin{array}{l}\text { Conocimiento ya adquirido mediante formación } \\
\text { y experiencia }\end{array}$ & 1 & 7,14 \\
\hline $\begin{array}{l}\text { Conocimiento ya adquirido mediante formación } \\
\text { / capacidad y ambición personal }\end{array}$ & 2 & 14,29 \\
\hline $\begin{array}{l}\text { Conocimiento ya adquirido mediante formación } \\
\text { y experiencia / capacidad personal }\end{array}$ & 1 & 7,14 \\
\hline $\begin{array}{l}\text { Conocimiento por formación y experiencia / } \\
\text { multidisciplinareidad /capacidad y ambición / } \\
\text { trabajo en equipo }\end{array}$ & 1 & 7,14 \\
\hline $\begin{array}{l}\text { Conocimiento ya adquirido mediante formación } \\
\text { y experiencia / multidisciplinareidad / } \\
\text { capacidad y ambición }\end{array}$ & 2 & 14,29 \\
\hline Total & 14 & 100,00 \\
\hline
\end{tabular}

Fuente: elaboración propia

\section{V23. Particularidades cultura corporativa}

Los casos analizados intentan particularizar las propias características de su cultura de empresa. No obstante, establecen de forma mayoritaria que éstas pueden compartir ciertos aspectos, principalmente entre empresas con actividades y/o ubicaciones semejantes. Por tal motivo no serían propiamente singulares. Contrariamente, 3 de los 14 casos estudiados sí afirman que su cultura corporativa es única y por tanto no comparable con cualquier otra, aun compartiendo sector o localización con otras entidades. En este mismo sentido otro caso determina que al menos los elementos básicos también son únicos. 
Figura 17. Particularidad cultura corporativa
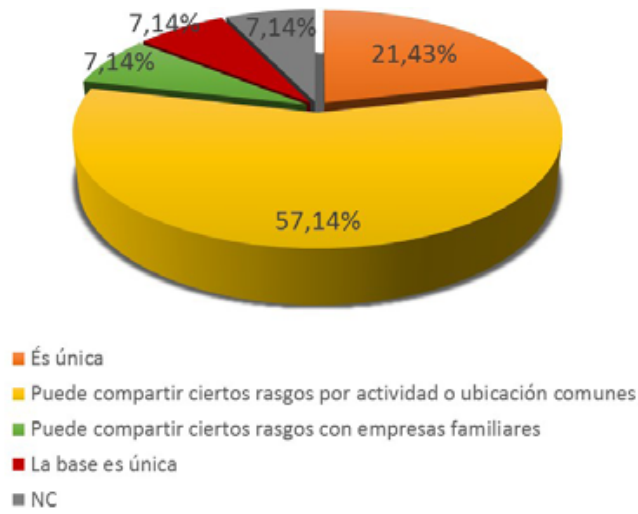

Fuente: elaboración propia

\section{V24. Liderazgo en la empresa}

El análisis confirma que el liderazgo es significativo, especialmente en empresas vinculadas con actividades creativas. De forma amplia lo corroboran así los resultados, siendo el fundador o los fundadores y el equipo directivo de las organizaciones, todos en su conjunto, las figuras referentes y orientativas para el resto de los empleados. Aunque en menor medida, junto con la propia dirección también suele ser habitual la existencia de líderes por departamentos.

Figura 18. Existencia del liderazgo
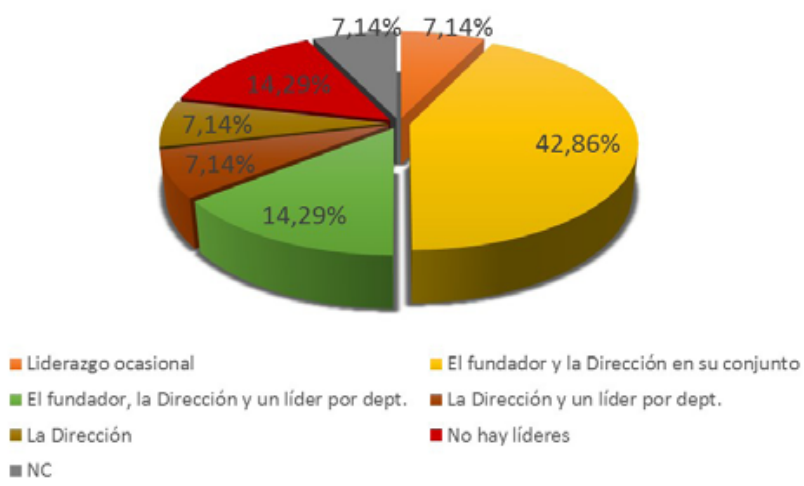

Fuente: elaboración propia 


\section{V25. Existencia subculturas corporativas}

Por lo que respecta a las subculturas, entendidas como áreas o espacios en los que el grado de aceptación de ciertos elementos de la cultura corporativa pueden variar, detectamos dos tendencias. En este sentido algunas empresas determinan que existen subculturas en sus respectivas empresas constituyéndose éstas especialmente por departamentos, relación entre empleados y subsedes de la empresa.

No obstante, otro número significativo afirma la inexistencia de subculturas en su organización, como ha quedado también constatado anteriormente en la variable del nivel de aceptación de los valores por todos los empleados, reafirmando la solidez de su cultura desde todas las perspectivas.

Figura 19. Generación de subculturas

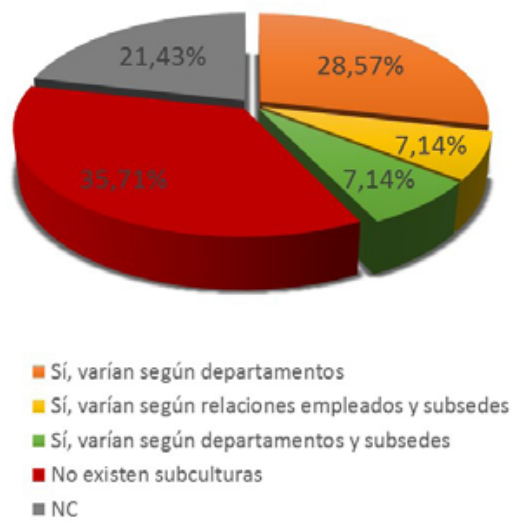

Fuente: elaboración propia

\section{V26. Solidaridad vs competitividad}

La solidaridad y el respaldo entre los trabajadores es una constante en la mayoría de casos. Por otra parte 4 de los casos establecen que dicha solidaridad puede ser variable, dependiendo de las diversas áreas de las empresas. Sólo en uno de los casos se ha resaltado la ausencia de solidaridad por motivos asociados a la competencia interna. 
Figura 20. Solidaridad vs competitividad corporativa
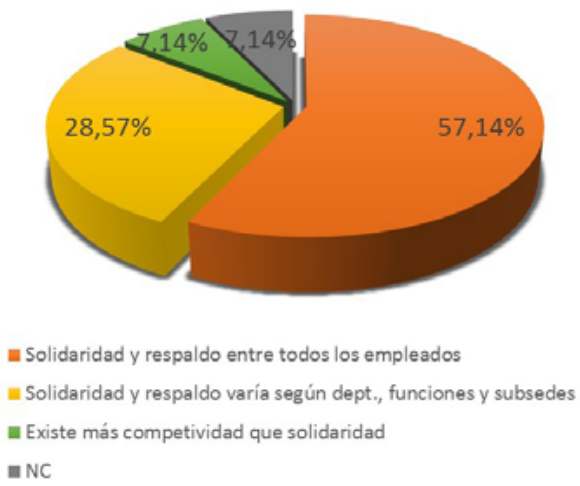

Fuente: elaboración propia

V27. Elementos indicativos de innovación empresarial

La mayoría de entrevistados y encuestados estiman que sus respectivas empresas son innovadoras. En consecuencia, son diversos los elementos con los que argumentan dicha afirmación y demuestran dicha capacidad innovadora. Entre ellas destacan el lanzamiento de nuevos productos de forma continuada y también la implantación de procesos pioneros de producción y/o logística. Otros como la consecución de premios y reconocimientos o incluso la alta inversión en $I+D$ también justifican dichas afirmaciones.

Figura 21. Indicadores innovación
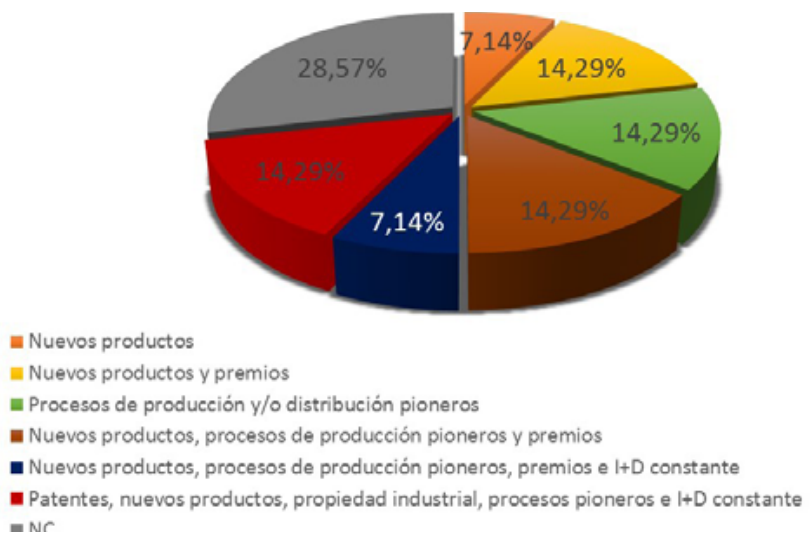

Fuente: elaboración propia 


\section{V28. Influencia de la cultura corporativa en la rentabilidad del negocio}

La cultura corporativa influye en la rentabilidad del negocio. Así se desprende de los resultados, a través de los cuales los casos de estudio inciden en resaltar que la cultura corporativa repercute en un retorno económico posterior.

Figura 22. Rentabilidad económica cultura corporativa

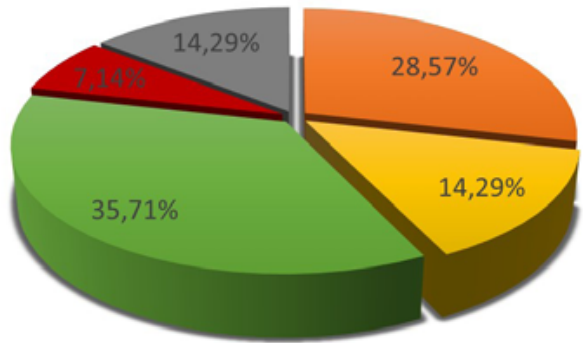

= Si, con un retorno económico elevado

wis con un retorno económico reducido

= Si, con un retorno económico (sin especificar)

no

nC

Fuente: elaboración propia

\subsubsection{Factores comunicativos}

\section{V29. Importancia de la comunicación de la cultura corporativa}

En relación con la comunicación de la cultura corporativa, las empresas que aportan esta información le otorgan importancia y se posicionan desde los valores medios hasta los más altos. En este sentido, podemos corroborar el papel estratégico que adquiere la comunicación de la cultura corporativa en empresas vinculadas con actividades comerciales orientadas hacia la creatividad. 
Tabla 3. Valoración importancia comunicación cultura corporativa

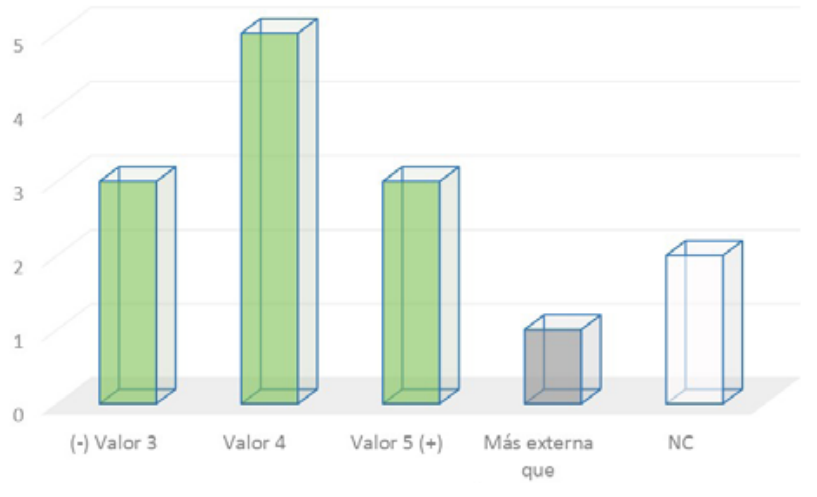

Fuente: elaboración propia

\section{V30. Creatividad en la gestión y comunicación de la cultura corporativa}

Los resultados obtenidos confirman que las industrias creativas participantes en el estudio dotan de creatividad tanto la gestión como la comunicación de su cultura corporativa. Así lo han corroborado la mayoría de casos, decretando de este modo la necesidad de aportar nuevas formas de organizar y canalizar todo lo que rodea la cultura de empresa.

Figura 23. Creatividad gestión y comunicación cultura corporativa

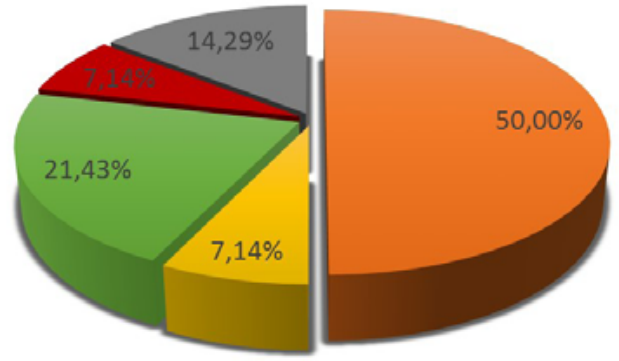

= Sí, la gestión y la comunicación $=$ Sí, la gestión $=$ Sí, la comunicación $\mathbf{m}$ No $=$ NC

Fuente: elaboración propia 


\section{V31. Estrategias de comunicación fruto de la diversidad cultural}

Se constata que aquellas empresas que cuentan con una diversidad cultural en su plantilla, este aspecto les reporta una línea de comunicación más global como consecuencia de dicha diversidad. Por lo tanto, dicho mestizaje corporativo aporta nuevas visiones que permiten implantar amplias estrategias capaces de adaptarse a múltiples mercados y/o públicos.

Figura 24. Aportaciones multiculturalidad comunicación corporativa

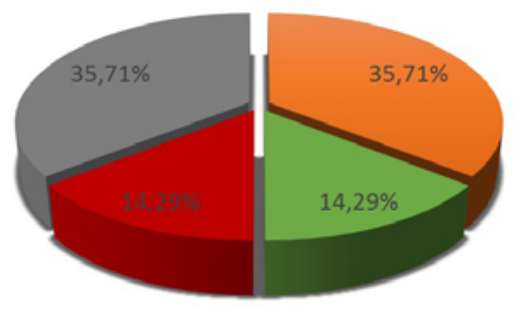

= Si, una línea de comunicación global

- No existe multiculturalidad

Fuente: elaboración propia m Sí, distintas líneas de comunicación adaptadas $=\mathrm{NC}$

\section{V32,33. Elementos del espacio de trabajo para potenciar la cultura de empresa}

El espacio de trabajo se convierte en un elemento canalizador también de la cultura de empresa. Así los elementos del entorno directo del espacio de trabajo constituyen importantes vías para canalizar la cultura corporativa de los casos de estudios analizados. En este sentido, la conjugación de arquitectura, interiorismo y el propio equipamiento de trabajo son elementos recurrentes a la hora de potenciar la cultura corporativa en la mayoría de casos analizados. 
Figura 25. Elementos entorno comunicación cultura corporativa
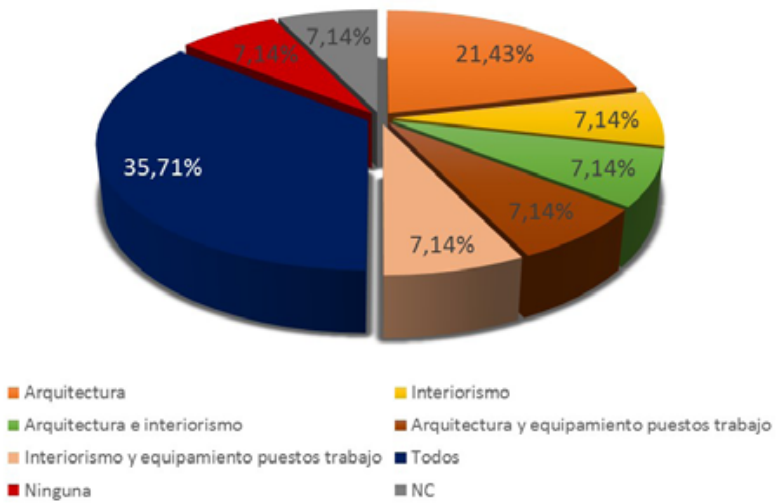

Fuente: elaboración propia

\section{V34,35. Tipología de comunicación interna cultura corporativa}

La comunicación personal, cara a cara; la comunicación offline, basada en canales tradicionales directos; así como la comunicación online, a través de Internet, combinadas de forma conjunta suele ser una constante para canalizar la cultura corporativa de forma interna, atendiendo a las aportaciones de la mayoría de casos analizados.

Figura 26. Tipología comunicación interna cultura corporativa

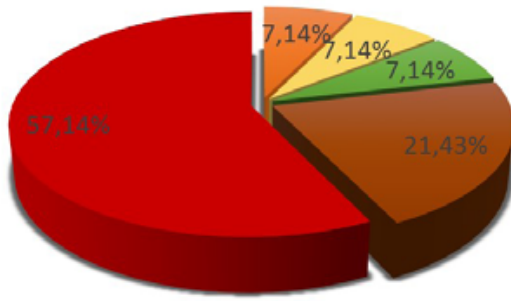

E Comunicación personal

E Comunicación online

a Comunicación personal y offline combinadas

- Comunicación personal y online combinadas

- Todas

Fuente: elaboración propia 


\section{V36,37. Tipología de Comunicación externa cultura corporativa}

A la hora de comunicar y promocionar la cultura corporativa entre los públicos externos, al igual que internamente, la combinación de comunicación personal, offline y online se convierte en la principal fórmula seleccionada por las empresas. No obstante, atendiendo al resto de respuestas, la comunicación online, tanto de forma aislada como combinada con los otros tipos de comunicación, se presenta como la principal de las posibles opciones de comunicación empleada.

Figura 27. Tipología comunicación externa cultura corporativa

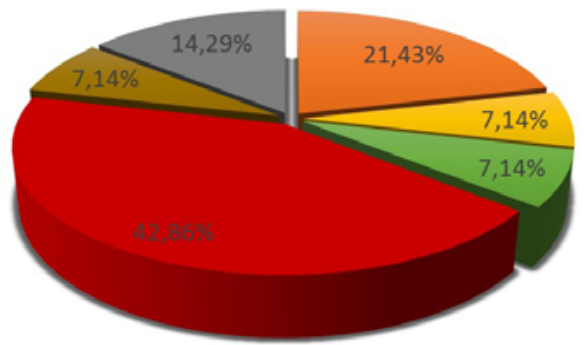

- Comunicación online

= Comunicación offline y online combinadas

= Ninguna
= Comunicación personal y online combinadas

- Todas

inC

Fuente: elaboración propia

\section{V38. Comunicación valores corporativos}

Los valores están publicados en distintos soportes tanto interna como externamente. Se recogen principalmente a nivel interno en documentos corporativos que puede encontrarse en muchos casos en las respectivas Webs. Asimismo, otras herramientas como Intranet, redes sociales, videos corporativos, aplicaciones o blogs también suele recopilar de alguna forma los valores que constituyen parte importante de las culturas corporativas de dichas empresas. 
Tabla 8. Publicación valores corporativos.

\begin{tabular}{|l|r|r|}
\hline & Frecuencia & Porcentaje \\
\hline Documentos corporativos internos & 3 & 21,43 \\
\hline Web corporativa & 3 & 21,43 \\
Vídeo corporativo interno & 1 & 7,14 \\
Web / RRSS & 1 & 7,14 \\
\hline Documentos corporativos públicos / Web & 1 & 7,14 \\
\hline $\begin{array}{l}\text { Documentos corporativos internos / Web / Intranet / RRSS } \\
\text { internas / vídeo corporativo público }\end{array}$ & 1 & 7,14 \\
\hline $\begin{array}{l}\text { Documentos corporativos públicos e internos / Web / Intranet } \\
\text { / RRSS/ Video corporativo público / app pública e interna }\end{array}$ & 1 & 7,14 \\
\hline $\begin{array}{l}\text { Documentos corporativos públicos e internos / Web / Intranet } \\
\text { / blog / RRSS públicas }\end{array}$ & 1 & 7,14 \\
\hline $\begin{array}{l}\text { Documentos públicos e internos / Web / Intranet / RRSS } \\
\text { públicas e internas / vídeo público e interno / app pública }\end{array}$ & 1 & 7,14 \\
\hline NC & 1 & 7,14 \\
\hline Total & 14 & 100,00 \\
\hline
\end{tabular}

Fuente: elaboración propia

\section{V39. Estilo comunicación componentes de la cultura de empresa}

Por lo que respecta a los modos de presentar dichos valores, bien sea interna o externamente, la mayoría de las empresas apuestan por diversos modos de hacerlo. Así, suele ser común no solamente exponerlos, sino además argumentar el porqué de ellos y no otros, demostrarlos con hechos o datos, incluso ilustrarlos y redactarlos complementándolos con un lenguaje atractivo. Algunos de los casos simplemente los enumeran o explican. 
Tabla 9. Modos comunicación elementos cultura corporativa

\begin{tabular}{|c|c|c|}
\hline & Frecuencia & Porcentaje \\
\hline Simplemente se enumeran & 2 & 14,29 \\
\hline Se explican y argumentan & 2 & 14,29 \\
\hline Se enumeran / se narran / se exponen con un leguaje cuidado y positivo & 1 & 7,14 \\
\hline $\begin{array}{l}\text { Se enumeran / se explican y argumentan / se demuestran con hechos / se } \\
\text { ilustran / se narran }\end{array}$ & 1 & 7,14 \\
\hline $\begin{array}{l}\text { Se enumeran / se explican y argumentan / se demuestran con hechos / } \\
\text { se ilustran /se exponen con un lenguaje cuidado y positivo }\end{array}$ & 1 & 7,14 \\
\hline Se explican y argumentan / se narran / se ilustran & 1 & 7,14 \\
\hline Se explican y argumentan / se exponen con un lenguaje cuidado & 1 & 7,14 \\
\hline Se explican y argumentan / se demuestran con hechos & 1 & 7,14 \\
\hline $\begin{array}{l}\text { Se explican y argumentan / se demuestran con hechos / se ilustran / se } \\
\text { exponen con un lenguaje cuidado y positivo }\end{array}$ & 3 & 21,40 \\
\hline NC & 1 & 7,14 \\
\hline Total & 14 & 100,0 \\
\hline
\end{tabular}

Fuente: elaboración propia

V40. Influencia territorio mediterráneo en la selección de herramientas/ acciones de comunicación de la cultura corporativa

Queda constatado también que el territorio mediterráneo incide a la hora de recurrir a determinadas acciones y herramientas para comunicar la cultura corporativa. Así lo afirman la mayoría de las empresas participantes, estableciendo así el condicionamiento del entorno a la hora de diseñar y determinar el modo de canalizar la cultura de empresa hacia los diferentes stakeholders de la misma. Es por ello que el entorno incide también en el diseño de la comunicación. 
Figura 28. Influencia mediterráneo comunicación cultura corporativa

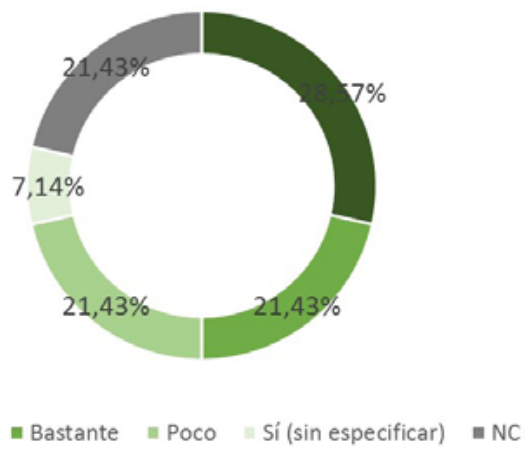

Fuente: elaboración propia

\section{V41. Estilo mediterráneo contenidos comunicativos internos y/o externos vinculados con la cultura de empresa}

El estilo mediterráneo condiciona elementos y contenidos comunicativos relacionados con la cultura corporativa. De este modo lo reflejan los resultados, que establecen que los casos de estudio analizados suelen recurrir directa o indirectamente a contenidos relacionados con el entorno mediterráneo como refuerzo o inspiración para acciones comunicativas principalmente corporativas.

Tabla 10. Estilo mediterráneo contenidos comunicación

\begin{tabular}{|l|r|r|}
\hline & Frecuencia & Porcentaje \\
\hline Sí, con referencia en los textos & 1 & 7,14 \\
Si, en el estilo de trabajo & 1 & 7,14 \\
Sí, con el uso de colores mediterráneos & 1 & 7,14 \\
Sí, a través fotografías / naming & 1 & 7,14 \\
Sí, a través fotografías / estilo de trabajo & 1 & 7,14 \\
Si, a través fotografías / textos / naming e IVC & 3 & 21,43 \\
Si, a través de fotografías / textos / vídeos & 2 & 14,29 \\
Si, a través fotografías / textos / uso colores / slogan / & 1 & 7,14 \\
naming / inconografías / vinilos y decoración & 1 & 7,14 \\
Si, a través fotografías / textos / uso colores / slogan / & & \\
naming, /Ivc / inconografías / decoración / himno & 2 & 14,29 \\
\hline No se emplean & 14 & 100,00 \\
\hline Total & & \\
\hline
\end{tabular}


Por tanto, podemos corroborar que el estilo mediterráneo impregna elementos y contenidos comunicativos vinculados directa o indirectamente con la cultura corporativa. En este sentido, en función de los resultados al respecto, obtenemos un mapa en red que vincula la cultura mediterránea con la comunicación y la cultura corporativa.

Figura 29. Estilo mediterráneo en la comunicación y la cultura corporativa

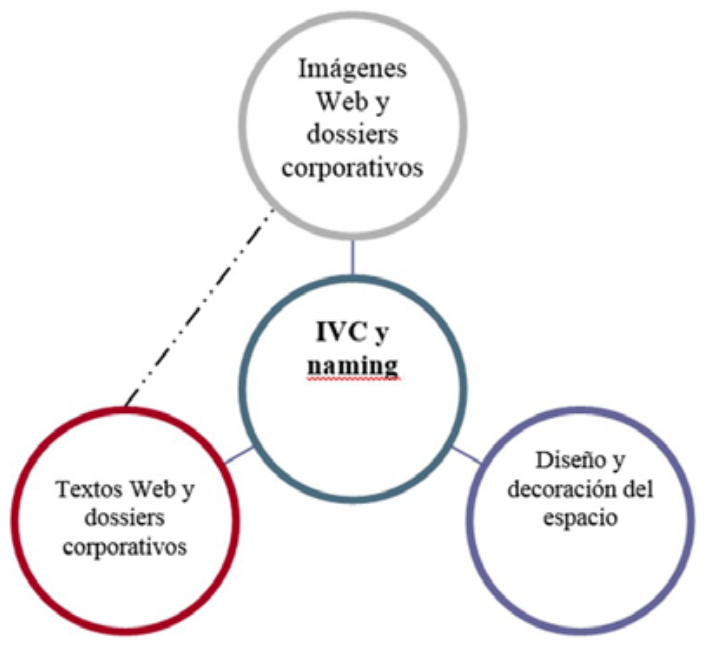

Fuente: elaboración propia

\section{V42. Existencia de plan de comunicación escrito}

Existe un equilibro entre aquellas empresas que cuentan con un plan de comunicación escrito y aquellas que no suelen plasmarlo habitualmente en un documento anualmente. Por lo tanto, es un aspecto que aún no está totalmente consolidado en la mayoría de empresas. 
Figura 30. Existencia plan de comunicación

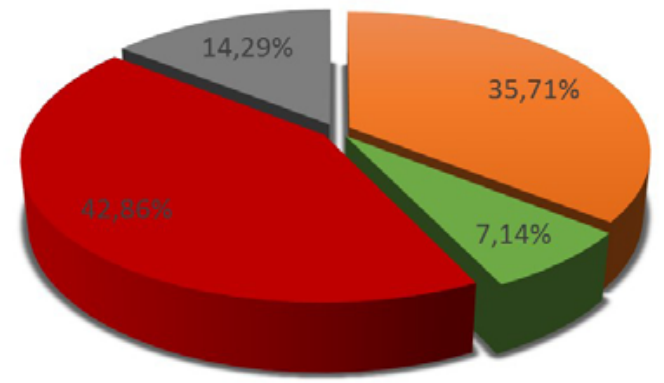

ESi, con referencias a la cultura corp. $\mathbf{E}$ Si, sin referencias a la cultura corp.

- No $\quad$ NC

Fuente: elaboración propia

\section{V43. Nuevas tecnologías y comunicación en la era digital sobre la cultura corporativa}

Se verifica que tanto el empleo de las nuevas tecnologías como los propios procesos de comunicación han fortalecido el papel de la cultura corporativa en la era digital en general entre la muestra que conforma esta investigación. En consecuencia, la cultura corporativa ha ido posicionándose en un lugar preferente y estratégico, especialmente en la actual economía creativa.

Figura 31. Importancia era digital difusión y valoración cultura corporativa

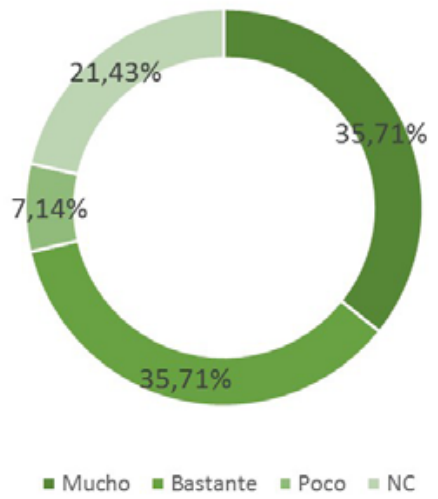

Fuente: elaboración propia 


\section{V44. Considera pues que su cultura corporativa a través de su comunicación}

La cultura corporativa a través de la comunicación que llevan a cabo la mayoría de casos genera una imagen interna que repercute tanto en la imagen externa como en los propios resultados comerciales. Sin embargo, algunos casos, apuntan únicamente a la imagen interna y externa. Sea como sea parece innegable que la cultura perfectamente gestionada y comunicada reporta múltiples beneficios.

Figura 32. Influencia comunicación cultura corporativa

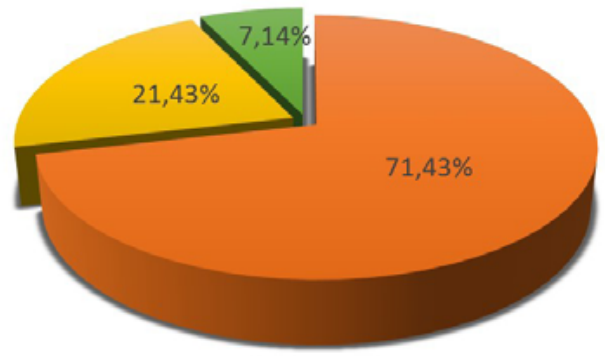

\footnotetext{
E Genera una imagen interna que favorece la externa y los resultados comerciales

= Genera una imagen interna que favorece la externa

Eenera sólo imagen externa
}

Fuente: elaboración propia

V45. Aportaciones cultura corporativa innovación y valor de marca

Existe también un altísimo consenso a la hora de determinar que la gestión y comunicación de las culturas de empresas analizadas posibilitan el aumento de la innovación, así como el valor económico de las respectivas marcas. Se establece así pues la cultura como un intangible fundamental para empresa desde múltiples áreas estratégicas, especialmente afines con actividades creativas. 
Figura 33. Aportaciones cultura corporativa innovación y valor de marca

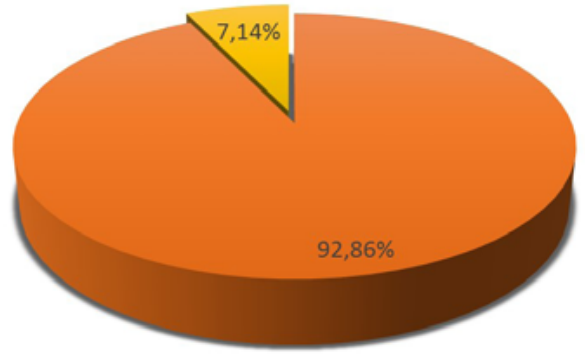

= Aumentan tanto la innovación como el valor de marca

= Aumentan sólo el valor económico de marca

Fuente: elaboración propia

\subsection{Resultados caso complementario: empresa no originaria pero ubicada en el mediterráneo en España}

Del caso adicional, se pueden extraer diversos y significativos resultados que amplían y complementan los propósitos del estudio, tales como la incorporación de la multiculturalidad; el desarrollo de actividades creativas adicionales; la propia gestión jerarquizada de la cultura corporativa con aportaciones de los empleados y alta presencia de valores personales y profesionales; la integración de trabajadores, captación del talento y generación de creatividad como resultado de la misma así como la comunicación creativa de la cultura y relacionada al territorio.

\subsection{Resultados globales y valoración}

Se constata que la ubicación y la actividad de las industrias creativas mediterráneas en España favorecen de distintas formas y en mayor o menor grado una cultura corporativa muy particular, vinculada con el territorio, propensa al cambio y creativa en sus modos de gestionarla y comunicarla a través de distintos canales y formatos, confirmando así la hipótesis de partida.

\section{Conclusiones}

Presentamos a continuación las conclusiones en relación a los tres factores principales en los que se ha basado este estudio y a la muestra obtenida, ya que «el cometido real del estudio de casos es la particularización, no la generalización» (Stake, 1998: 20). 
1. Factores sociológicos. Las empresas de corte creativo originadas en el Arco Mediterráneo en España analizadas se caracterizan por una amplia diversidad tanto en lo que a la propia actividad creativa desarrollada se refiere, el tamaño, la trayectoria, la naturaleza constitutiva como el propio organigrama de estas. En cambio, se identifican por ubicarse en la localidad de origen de los fundadores dada la formación previa de los mismos, incorporando a su vez empleados de otros países y desarrollando otras actividades complementarias constatando así que "las Industrias Creativas, aunque no descartan la publicidad convencional, recurren a la amplificación y ramificación de actividades para promocionar su marca a través de otros productos y servicios” (Rodríguez-Monteagudo, Hidalgo-Marí y Segarra-Saavedra, 2014: 147).

2. Factores de dirección y gestión. La cultura corporativa de las industrias creativas en el AME analizadas adquiere una alta importancia estratégica para las mismas, destinando cada vez más recursos humanos y económicos para ello, implantándose principalmente desde la Dirección con aportaciones puntuales de empleados y siendo los valores asociados a aspectos profesionales y personales los predominantes. De igual modo los comportamientos, la identidad y las presunciones básicas de las empresas también configuran la propia cultura con una clara orientación de la misma hacia el cliente y el cambio. En este sentido existe un constatable liderazgo directivo y una alta integración de los empleados, así como solidaridad y respaldo entre ellos, fruto entre otros aspectos de la motivación, la cohesión, la construcción de la identidad, así como la guía de conducta generada por la propia cultura corporativa, favorecida también por la multiculturalidad.

La generación de creatividad con resultados principalmente tangibles, así como la captación del talento y un reporte económico son algunos de las consecuencias resultantes de la gestión de la cultura corporativa de las empresas analizadas. Por su parte, aunque algunas empresas determinan la exclusividad de su cultura corporativa, otras en cambio establecen rasgos comunes con distintas empresas por motivos de ubicación y/o actividad similar.

Factores de comunicación. La importancia de la comunicación de la cultura corporativa de las industrias creativas en el AME estudiadas es elevada, siendo permanente la creatividad a lo largo de dicho proceso. En este sentido se emplean recursos internos y externos tanto de forma personal directa como offline y online en su conjunto y en los que el espacio de trabajo además contribuye a dicha canalización, condicionando el propio entorno mediterráneo la selección de acciones y recursos, así como los propios contenidos. La publicación de los valores a modo de credo corporativo al que se refieren Mayo y Lank (1994), como eje de la cultura corporativa, es habitual a través de múltiples formas, formatos y canales. En consecuencia, dicha forma de comunicar, con presencia considerable de las nuevas tecnologías, favorecen el carácter estratégico de una cultura corporativa que repercute favora- 
blemente en la reputación corporativa actual, en los resultados comerciales, en la innovación y, en definitiva, en el valor de marca.

Por último, en relación con el estudio del caso adicional fuera de muestra, constatamos que, aunque no sea originaria de dicho lugar, también está influenciada por el territorio ya que comparte altos niveles de los parámetros de gestión y comunicación identificados con el entorno.

\section{Bibliografía}

Boix, Rafael y Lazzeretti, Luciana (2012). Las industrias creativas en España: una panorámica. En: Investigaciones regionales, $\mathrm{n}^{0}$ 22. Alcalá de Henares: Asociación Española de Ciencias Regional, 181-206.

Brouwer, Aleid y Pellenbarg, Pieter (2011). The Importance of Place in Corporate Identity an Investigation on the Presence of Old Dutch Firms on the Internet. En: European Spatial Research and Policy, Vol. 18, nº 2. Berlin: De Gruyter, 79-94. http://doi.org/10.2478/v10105-011-0014-z

Florida, Richard L. (2009). Las ciudades creativas: por qué donde vives puede ser la decisión más importante de tu vida. Barcelona: Paidós.

Institut Català de la Mediterrànea (Ed.). (1999). El espacio mediterráneo latino: cultura, empresa, paisaje, población y cooperación. Barcelona: Icaria.

Kish, Leslie (1995). Diseño estadístico para la investigación. Madrid: CIS Siglo XXI. Llopis, Juan (1992). La cultura de empresa: análisis y enfoque cualitativo para la toma de decisiones. Alicante: Caja de Ahorros del Mediterráneo Universidad.

López Lita, Rafael y Benlloch, María Teresa (2005). De la marca comercial a la marca territorio. En: Recerca. Revista de Pensament y Anàlisi, $\mathrm{n}^{\mathrm{o}}$ 5. Castellón de la Plana: Universitat Jaume I, 87-100.

Mayo, Andrew y Lank, Elizabeth (2000). Las organizaciones que aprenden: the power of learning: una guía para ganar ventaja competitiva. Barcelona: Gestión 2000 .

Naciones Unidas y UNCTAD (2010). Informe sobre la economía creativa. En: http:// unctad.org/es/Docs/ditctab20103_sp.pdf (Consultado el 18-07-2019).

Oden, Howard W. (1997). Managing corporate, innovation, and intrapreneurship. Westport: Quorum Books.

Olivares, Fernando (2015). Empresas y marcas made in Alicante. En: Canelobre: Imagen, diseño y comunicación en Alicante (1975-2015), $\mathrm{n}^{\circ}$ 65. Alicante: Instituto Alicantino de Cultura Juan Gil-Albert, 102-115.

Robbins, Stephen P. (1996). Organizational behavior: concepts, controversies, applications. Englewood Cliffs: Prentice Hall. 
Rodríguez-Monteagudo, Eliseo; Hidalgo-Marí, Tatiana y Segarra-Saavedra, Jesús (2014). La gastronomía como producto de entretenimiento. Análisis de restaurantes y programas culinarios de éxito en España desde una perspectiva creativa. En: Pangea, vol. 5, $\mathrm{n}^{0}$ 1. La Laguna: Sociedad Latina de Comunicación Social, 145-157. Rodríguez-Monteagudo, Eliseo (2015). La cultura corporativa en las industrias creativas. Análisis de la gestión y comunicación de la cultura corporativa desde la perspectiva de los intangibles en empresas creativas del Arco Mediterráneo en España. Tesis doctoral. Alicante: Universidad de Alicante.

Rodríguez-Monteagudo, Eliseo; Olivares-Delgado, Fernando (2017). La cultura corporativa en las industrias creativas del Arco Mediterráneo en España a través de un análisis Delphi. En: Revista Mediterránea de Comunicación/Mediterranean Journal of Communication, Vol. $8 \mathrm{n}^{\circ}$ 2. Alicante: Universidad de Alicante 189-223. https:// www.doi.org/10.14198/MEDCOM2017.8.2.13

Shutters, Shade T.; Muneepeerakul, Rachata y Lobo, José (2015). Constrained pathways to a creative urban economy. En: Urban Studies, Vol. 53, n ${ }^{\circ} 16$. Thousand Oaks: SAGE Publishing, 3439-3454.

Schein, Edgar H. (1988). La Cultura empresarial y el liderazgo: una visión dinámica. Esplugues de Llobregat: Plaza \& Janés.

Stake, Robert E. (1998). Investigación con estudio de casos. Madrid: Morata.

Villafañe, Justo (1999). La gestión profesional de la imagen corporativa. Madrid: Pirámide.

\section{Agradecimientos}

Todas las empresas han colaborado y participado voluntariamente, informadas en todo momento sobre la finalidad de la presente investigación. Otorgamos un altísimo valor a la participación e información aportada por las empresas participantes. Es un honor además para esta investigación poder contar con estos casos de estudio que pueden consultarse detalladamente en https://goo.gl/ScKr9a 


\title{
Actitud del menor ante la publicidad que recibe a través de los dispositivos móviles Children attitude faced with the advertising they receive through their mobile devices
}

\author{
Beatriz Feijoo \\ Universidad de los Andes, Chile
}

Aurora García González

Universidad de Vigo

\section{Referencia de este artículo}

Feijoo, Beatriz y García González, Autora (2019). Actitud del menor ante la publicidad que recibe a través de los dispositivos móviles. adComunica. Revista Científica de Estrategias, Tendencias e Innovación en Comunicación, (18), 199-218. DOI: http://dx.doi.org/10.6035/2174-0992.2019.18.10

\section{Palabras clave}

Niños; Publicidad digital; Dispositivos móviles, Redes sociales; Interacción.

\section{Key words}

Children; Online advertising; Mobile devices; Social networks; Interaction.

\section{Resumen}

Este trabajo parte de la consideración del niño como usuario activo de dispositivos móviles, así como consumidor y como receptor de mensajes publicitarios, con capacidad de adquisición y de consumo de bienes. 
Las marcas y anunciantes son conscientes del poder de influencia del niño en las decisiones de compra del hogar, de ahí el interés por conocer qué tipo de mensajes publicitarios están recibiendo a través de las pantallas con las que marcas y anunciantes se aseguran llegar a este perfil de audiencia.

La relevancia de esta investigación radica en su propósito de establecer un punto de partida sólido que posibilite investigaciones posteriores relativas al cuidado del menor, la supervisión de contenido y la mediación parental y o social.

Los resultados ofrecen datos sobre la actitud que los niños (diez a catorce años) desarrollan ante los mensajes publicitarios que reciben a través de los dispositivos móviles que emplean, medida en términos de detección, nivel de atención, confianza e interactividad, conseguidos a partir de una encuesta autoaplicada mediante una tablet en 500 hogares de la Región Metropolitana de Santiago de Chile. Entre las principales conclusiones, destaca que los menores confían más en la publicidad lanzada por los canales que más usan en sus dispositivos móviles (YouTube, WhatsApp, juegos online), plataformas en las que contenido de entretenimiento y publicitario aparece cada vez más entremezclado.

\begin{abstract}
This research starts from the consideration of the children as an active user of mobile devices, as well as their profile of consumer and receptor of advertising messages, with the ability of acquisition and consumption of products.

The marketing strategies are conscious of the children influence power in the home purchase decisions, hence it would be interesting knowing which type of advertising messages they receive through these screens in which brands include ads to guarantee reaching this audience profile.

The importance of this research roots in the purpose of stablishing a strong starting point that makes possible future studies focused in the childcare, the supervision of content and the parental and social mediation.

The results offer data on the attitude that children (ten to fourteen years) keep in front of the advertising messages they receive through their mobile devices, measured in terms of detection, level of attention, confidence and interactivity, statistics extracted from a survey supplied in 500 homes of the Metropolitan Region of Santiago of Chile. Among the main conclusions, it is important to highlight that minors trust more in the advertising launched by channels they most used in their mobile devices (Youtube, WhatsApp, on-line games), platforms in which entertainment and advertising appears increasingly mixed.
\end{abstract}

\title{
Autoras
}

Beatriz Feijoo [bfeijoo@uandes.cl] es Doctora en Comunicación y licenciada en Publicidad y Relaciones Públicas y Comunicación Audiovisual por la Universidad 
de Vigo. Profesora Contratada Doctora de Publicidad y Comunicación Audiovisual, ejerce de docente e investigadora en la Facultad de Comunicación de la Universidad de los Andes (Chile). Autora de diversas publicaciones y artículos científicos sobre comunicación y niños e IP de proyecto de investigación financiado con fondos concursables (Fondecyt $N^{\circ} 11170336$ ) sobre esta misma temática.

Aurora García González [auroragg@uvigo.es] es Doctora en Comunicación Pública y, en la actualidad, Profesora Titular de Periodismo con acreditación para el Cuerpo de Catedráticos, en la Facultad de Ciencias Sociales y de la Comunicación de la Universidad de Vigo. Es Directora de la Sección Departamental de Comunicación e IP del grupo de Investigación CS1 (ICOM) de la misma Universidad. Autora de numerosos publicaciones y artículos científicos. Imparte la materia «Opinión Pública», en el Grado de Publicidad y el curso «Metodología de la investigación en Comunicación» en el Programa de Doctorado en Comunicación.

\section{Créditos}

Este trabajo de investigación se circunscribe al proyecto Fondecyt $\mathrm{N}^{\circ} 11170336$ con el título «El menor de edad como consumidor. Análisis de la publicidad que recibe el usuario de 10 a 14 años a través de los dispositivos móviles», financiado por la Comisión Nacional de Investigación Científica y Tecnológica (CONICYT) del Gobierno de Chile 


\section{Introducción}

Las estadísticas evidencian, por un lado, que los dispositivos móviles juegan un papel preponderante en la vida de los niños (Cabello y Claro, 2017; Kabali, et al., 2015; Feijoo, 2015) y, por otro, la relevancia que van adquiriendo estas pantallas como soporte publicitario. De ahí que resulte pertinente abordar qué tipo de mensajes publicitarios reciben los menores a través de sus dispositivos móviles. El hecho de que una corriente importante de la investigación sobre infancia y nuevas tecnologías esté orientada a los usos que el usuario infantil hace de las mismas, pero sin atender al tipo de publicidad que recibe durante esos usos, pone más en relevancia la necesidad de un estudio de estas características.

Es en este contexto donde se sitúa el presente estudio. Dada la relevancia social del tema, existen muchas investigaciones centradas en el análisis del uso de dispositivos móviles por los niños y jóvenes, sin embargo, se cree pertinente dar un paso más en el planteamiento temático y abordar la investigación desde un campo de la comunicación más específico como es el de la publicidad. Aunque también es extensa la bibliografía sobre marketing y niños (Roedder, 1999; McNeal, 1992; Tur-Viñes y Ramos-Soler, 2008; Brée, 1995) en este caso, esta investigación se centra en los mensajes publicitarios difundidos a través de los dispositivos móviles, plataformas que cada vez tienen mayor representatividad en el pastel de la inversión publicitaria.

Se aborda la figura del niño desde su rol de consumidor y público objetivo de marcas y productos para poner el foco sobre su predisposición hacia la publicidad que recibe a través de sus dispositivos móviles. El objetivo es conocer y analizar el nivel de atención y de interacción que mantiene con ella.

\section{La publicidad en los dispositivos móviles}

Los dispositivos móviles van adquiriendo cada vez mayor representatividad en el total de la inversión publicitaria. Aunque el gasto en este tipo de modalidad publicitaria es modesto en comparación con la invertida en medios más convencionales como la televisión -31 millones de US\$ frente a los 330 millones de US\$ de televisión en abierto en Chile (IAB Chile, 2016) — , las consultorías digitales pronosticaron para 2018 un crecimiento interanual del $60 \%$ de la inversión en publicidad móvil, alcanzando los 85 millones de US\$. Se trata de cifras que se estiman que sigan creciendo a un ritmo exponencial hasta 2020, cuando se prevé que el marketing móvil represente el $67 \%$ del gasto en publicidad digital y un 13\% del total de la inversión publicitaria en Chile.

Uno de los factores que ralentizan el crecimiento del marketing móvil es la falta de información y experiencia con las estrategias de pull advertising: gracias a una encuesta realizada a medio centenar de líderes empresariales se corroboró que, a pesar de conocer las potencialidades de la publicidad móvil, solamente un $45 \%$ confirmó haberla aprovechado. Un 37\% argumentó falta de estrategia como la principal razón de no disponer de un plan comunicativo a través de móviles (Wang, Kim y Malthouse, 2016). 
La publicidad móvil debe adaptarse al dinamismo del dispositivo, contrariamente a lo que sucede en los medios tradicionales, más estáticos. Partiendo del enfoque defendido por la Teoría de los Usos y Gratificaciones, Atkinson (2013) destacó tres pilares básicos que los anunciantes deben tener en cuanta cuando recurren a estas nuevas formas de comunicarse: la confianza institucional, la participación y market mavenism (genios del mercado/líderes de opinión/influencers).

Las marcas ya consolidadas deben recurrir a estrategias de pull advertising aunque sea más cara, del mismo modo que aquellas que aún son poco conocidas, renunciando al empleo de push advertising pues incrementa la percepción negativa en el consumidor (Valvi y West, 2015). No obstante, marcas emergentes optan por la push advertising en móviles por ser más económica ya que sus presupuestos no suelen ser muy elevados.

Olarte-Pascual, Pelegrín-Borondo, Reinares-Lara y Sierra-Murillo (2014) establecieron una clasificación de los usuarios según su grado de afinidad con la publicidad en móviles. Diferenciaron tres grupos: el rojo, usuarios que rechazan totalmente la publicidad en el teléfono móvil; el amarillo, con actitud indiferente hacia este tipo de publicidad y el verde, aquellos que la aprecian.

Los nativos digitales pasan más de la mitad de su tiempo de consumo digital empleando aplicaciones (Wang et al., 2016) y es un hecho el crecimiento exponencial del número de descargas de apps, tanto gratuitas como de pago. Estadísticas extraídas de Apple Store o de Google Play muestran que en 2015 el número total de descargas de apps superó los 135 mil millones y alcanzó los 200 mil millones en 2017. Wu (2015) estableció que el éxito o fracaso de este tipo de formatos dependerá de su uso continuo por parte de los consumidores. Por ello, definió aquellos factores que impulsan al usuario a emplear frecuentemente las aplicaciones, confirmando el papel central de la interacción, la que finalmente determinará el grado de conexión, de unión (stickiness) entre marca y usuario (Wang et al., 2016). Los investigadores indicaron tres variables que afectan directamente a este proceso de unión: el nivel de confianza en la marca, el intento de generar opiniones positivas y la realización de transacciones comerciales. Las apps deben reforzar entre los consumidores hábitos ya establecidos, no como plataformas para nuevas informaciones.

También existen investigaciones que profundizaron en la potencialidad de las apps como soporte publicitario (Valvi y West, 2015). Las clasificaron en cuatro categorías según los criterios de frecuencia y permanencia de uso. Diferenciaron entre game apps, entertainment apps (social media), utility apps y failure apps. La mejor opción para albergar publicidad serían las entertainment apps por su uso regular con alta frecuencia. Cuando se consultan este tipo de apps, el consumidor suele atender al mismo tiempo múltiples inputs, por lo que puede estar más receptivo a la publicidad. En esta línea de investigación también trabajó Logan (2015) para analizar cómo la experiencia del usuario con una aplicación afecta directamente a su actitud hacia los anuncios insertados en dicha app. La investigación sugiere que los consumidores son más tolerantes a la publicidad en apps asistenciales (como 
Google Maps) e informativas (Google o Wikipedia). Cuando un consumidor busca y descarga una aplicación que no le aporta ningún valor, el efecto negativo de la insatisfacción que genera la app puede trasladarse a la imagen de la propia marca (Wang et al., 2016).

Los dispositivos móviles se han vuelto imprescindibles para un sector publicitario cuya eficacia depende ya más de la calidad que de la cantidad de impactos conseguidos, sobre todo en un público tan exigente a nivel comunicacional y mediático como son los menores de edad, de gran relevancia para el mercado de bienes tecnológicos y de ocio especialmente.

\section{Los menores como receptores de publicidad a través de los dispositivos móviles}

Según datos del último estudio sobre usos, oportunidades y riesgos en el uso de las TIC en Chile del proyecto Kids Online (Cabello y Claro, 2017), un 92\% de niños y adolescentes usuarios de internet disponen de smartphone, un $79 \%$ de notebook y un $51 \%$ de ordenador fijo. Aunque el informe destaca diferencias significativas en el equipamiento tecnológico en función del estrato socioeconómico (C1-C2, C3, D-E), la penetración del smartphone es la más uniforme socialmente de todos los dispositivos analizados.

Estas estadísticas de equipamiento tecnológico y de acceso a la red siguen poniendo de relieve la firme penetración de las diferentes pantallas, especialmente de los dispositivos móviles, y cada vez a edades más tempranas: según Emarketer (2015), un $60 \%$ de los adolescentes latinoamericanos reciben su primer teléfono móvil a los 12 años, comenzando a navegar, interactuar con las redes sociales, jugar y chatear a través de esta pantalla unipersonal. Estos dispositivos se han convertido en el principal acceso a internet, frente a la cual los niños pasan gran parte de su tiempo conectados bien en juegos online (a través de apps), bien en redes sociales, plataformas en las que resulta cada vez menos evidente la diferenciación entre lo que es entretenimiento y lo que es publicidad.

Son varios los autores (An y Kang, 2014; Chen, Zhu, Xu y Zhey, 2013; Terlutter y Capella, 2013) que destacan una confusión entre lo que es contenido y lo que son mensajes netamente publicitarios, motivado en parte por su todavía reciente implementación como soportes publicitarios (apps, advergaming) y por la consecuente falta de bases regulatorias al respecto.

De este modo, Chen, Zhu, Xu y Zhey (2013) demostraron que las categorías de edad (PEGI, ESRB) empleadas para clasificar el contenido de videojuegos y de otro software de entretenimiento como las aplicaciones móviles, no contemplan la supervisión de los mensajes publicitarios que se insertan en ellas. Es decir, la publicidad que llega al menor a través de una app no pasó ningún tipo de filtro, aunque la app sea idónea para su edad. Algo semejante ocurre con otro formato publicitario de uso recurrente en los dispositivos móviles para llegar a los jóvenes: el adverga- 
ming. Es común entre la comunidad científica el cuestionamiento de si la audiencia infantil es capaz de distinguir las intenciones comerciales de determinados juegos disponibles para las múltiples plataformas. Es más, los proveedores de contenidos parecen no facilitar la diferenciación entre videojuegos patrocinados y aquellos sin intención comercial (An y Kong, 2014: 526).

Este escenario comunicacional adquiere relevancia social por el papel asumido por los menores de edad y su nivel de exposición a las pantallas, que según datos de la revista Pediatrics (Kabali et al., 2015) acceden a un teléfono móvil de forma regular a edad de 4 años. Esto es, empiezan a participar tempranamente de una realidad mediática en la que las normas publicitarias todavía no están muy definidas.

Existe abundante bibliografía que analiza y describe los patrones de acceso y uso de los dispositivos móviles entre los menores de edad, pero sin atender específicamente al estudio de los mensajes publicitarios que se mezclan con el contenido consumido.

\footnotetext{
«As the amount of time children spend on the internet increases, it is critical to continually monitor their online environment in order to deter or minimise any unfair commercial influences on their values, lifestyle and diets. The results of this study have prompted us to pay more close attention to popular gaming sites» (An y Kang, 2014: 528).
}

Esta investigación busca llenar ese vacío al profundizar en la relación existente entre los menores y los mensajes publicitarios que reciben cuando emplean algún dispositivo móvil con conexión a internet.

\section{Actitud del menor ante la publicidad que recibe en sus dispositivos móviles}

El menor, especialmente desde los ocho años, edad a partir de la cual es consciente de la intención persuasiva de la publicidad (visto en Chu, Blades y Herbert, 2014), interesa al mercado publicitario por su perfil de consumidor integrado socialmente, por su aprecio por las marcas y por su estilo imitativo (Salgado Carrión, 2006: 32). Se caracteriza por practicar «un consumo instantáneo», con poca paciencia y tolerancia a los tiempos de espera por lo que el deseo y su respectiva satisfacción deben cubrirlos de forma casi inmediata. La relación entre marcas comerciales y niños suele ser más fiel cuanto mayor es la edad del niño ya que cuando son pequeños suelen fijarse más en el producto en sí que en la marca que lo dispensa. El menor labra su rol de consumidor al asimilar y copar los hábitos de los que le rodean y al apropiarse de conductas de sus mayores. «De ahí que la influencia tanto de los padres como de los amigos del colegio y de lo que perciben por los medios [...] sea fundamental en su comportamiento» (Salgado Carrión, 2006: 33).

Algunos estudios (Chu et al., 2014) desarrollados con niños comprendidos entre seis y diez años han detectado la presencia de una actitud escéptica hacia los anuncios. En todos los grupos de edad analizados, al menos algunos de los niños dijeron creer y confiar en los anuncios, pero también se advirtió que la proporción de niños que confiaban en la publicidad se reducía a medida en que iban creciendo. 
Los resultados de estas investigaciones indujeron a pensar que incluso a los 10 años de edad, hay niños dispuestos a aceptar anuncios de manera acrítica. Pero, de ordinario, conforme crecen van desarrollando también más escepticismo hacia los anuncios. Esto se había ya contrastado en investigaciones anteriores (Robertson y Rossiter, 1974; Ward, Reale y Levinson, 1972).

Siguiendo a Koslow (2000) cabe afirmar que son muy pocos los niños de seis años con una actitud de escepticismo hacia la publicidad; algunos con ocho años de edad la demuestran ocasionalmente, no siempre, y, sin embargo, más de la mitad de los niños de 10 años sí la expresan; por lo tanto, los niños adoptan una actitud crítica hacia la publicidad entre ocho y 10 años de edad.

Un hallazgo importante del estudio fue que muchos niños que habían comprendido la intención persuasiva del anuncio, mantenían su confianza en la publicidad. Esta comprensión de la intención persuasiva de la publicidad parece alcanzarse alrededor de los ocho años, y de hecho la mayoría de los niños de ocho y 10 años de ese estudio la identificaron.

Aunque muchos niños pueden tener conocimiento de la intención persuasiva (Ali y Blades, 2014) no se puede garantizar que tengan una visión particularmente profunda de los motivos de los anunciantes. Los niños pueden haberse dado cuenta de que el propósito principal de la publicidad es persuadir, pero siguen siendo bastante confiados sobre la naturaleza de la publicidad. El público infantil puede creer que los anunciantes solo usan persuasión para alentar a los clientes a comprar lo que querían comprar de todos modos. Esto sugiere que los niños pueden ser vulnerables a los reclamos y técnicas de publicidad durante algún tiempo incluso después de haber advertido la intención persuasiva de un anuncio.

Algunos autores (Kunkel, et al. 2004) han usado la edad en que se comprende la intención persuasiva como base para sugerir el establecimiento de normas reguladoras, y parece recomendado aplicar una regulación más estricta de la publicidad cuando se dirige a niños menores de ocho años. No obstante, como parece demostrarse, los niños creen y confían en los anuncios durante algunos años después de esa edad, por lo que cualquier esfuerzo regulador para proteger a los niños debe orientarse también hacia la población mayor de ocho años de edad. Por la misma razón, las intervenciones y la alfabetización mediática a través de programas que están diseñados para ayudar a los niños pequeños a entender mejor la publicidad deben tener en cuenta que algunos niños pueden mantener una actitud ingenua acerca de la publicidad y no desarrollar una actitud de escepticismo hasta después de los 10 años de edad.

En relación a la actitud con la que la audiencia más joven recibe publicidad en sus dispositivos móviles, otros estudios destacan, como ya ocurría con la promoción online (Andersen, Tufte, Rasmussen y Chan 2008; Sandberg, 2011), cómo el usuario se irrita al verla en sus dispositivos (Martínez, Jarlbro y Sandberg, 2013), un comportamiento que se suaviza al percibir un mayor índice de utilidad y entretenimiento en los contenidos publicitarios. Para reducir dicha predisposición negativa, 
los investigadores aconsejan el diseño de mensajes promocionales con información relevante y beneficios adicionales por abrir y leer los mensajes: ofertas únicas, promociones, descuentos-muy valorados por el usuario- envío gratuito, acceso a productos exclusivos... (2013: 744). Una investigación centrada en analizar el nivel de impacto de la publicidad de Facebook en la generación Y Duffette (2015) resalta los puntos fuertes de emplear plataformas móviles como soportes publicitarios frente a otras pantallas estáticas como el PC.

\section{Material y métodos}

El objetivo de esta investigación pretende conocer la actitud que los menores de diez a catorce años mantienen con la publicidad que reciben a través de los dispositivos móviles, pantallas a través de las cuales las marcas y anunciantes se aseguran llegar a este perfil de audiencia. Se busca profundizar en el nivel de ligazón que los niños establecen con un contenido promocional que cada vez más se presenta entremezclado con contenido de entretenimiento. Por ello, se definieron para este estudio las siguientes variables de análisis:

- Acceso, uso y consumo del dispositivo móvil como información previa que contextualice la relación que los niños mantienen con dichos dispositivos: tipo de móvil empleado y de conexión a internet; principales acciones realizadas, horario de uso y aplicaciones instaladas.

- Aquellas directamente establecidas para conocer cómo se comporta el niño ante los inputs publicitarios recibidos: detección, actitud, nivel de confianza que le despiertan e interacción con la publicidad recibida a través del móvil. También se insertó una serie de variables centradas específicamente en la publicidad en redes sociales.

Se recurrió a la metodología cuantitativa de la encuesta autoaplicada mediante dispositivo electrónico (cuestionario en tablet). El universo seleccionado para este estudio en concreto fueron los menores entre diez y catorce años de la Región Metropolitana de Santiago de Chile y se definió como tamaño de muestra 500 hogares en dónde en cada uno se pasó un cuestionario al niño residente que cumpliese el perfil buscado.

Según el Censo chileno de 2017, la Región Metropolitana cuenta con 373.129 niños de entre diez y catorce años diferenciados por sector/macrozona (distribución geográfica clásica utilizada para dividir la región) según muestra la siguiente tabla: 
Tabla 1.

\begin{tabular}{|l|l|}
\hline Macrozona & Niños de 10 a 14 años \\
\hline Centro & 47.148 \\
\hline Norte & 50.553 \\
\hline Oriente & 69.954 \\
\hline Poniente & 73.877 \\
\hline Sur & 131.597 \\
\hline
\end{tabular}

Fuente: Censo chileno, 2017

A posteriori, se calculó el \% de niños entre diez y catorce años por comuna ${ }^{1}$ que integra cada macrozona a la cual se le asignó a cada una, una muestra de cien casos. Estos cien casos se distribuyeron en función del peso de este grupo de edad en cada comuna.

Por tanto, el resultado fue un diseño probabilístico por áreas (macrozonas) con distribución no proporcional de los casos a nivel de sectores de la comuna y contemplando un error del $\pm 4,4 \%$ bajo los supuestos de muestreo aleatorio simple y un $95 \%$ de confianza. El trabajo de campo tuvo lugar entre los meses de mayo y julio de 2018.

Según Sierra Bravo (2001: 305), el instrumento básico de la observación por encuesta es el cuestionario, recurriendo en este caso al cuestionario simple que consistió en un listado de preguntas estandarizadas lo que permite aunar y comparar las respuestas. Igualmente, su capacidad para abarcar un amplio abanico de cuestiones en un mismo estudio y su adecuación para obtener información diversa de un conjunto amplio de personas, lo convirtieron en el método más idóneo para esta investigación.

Los datos estadísticos que se exponen en este análisis pertenecen a la primera fase de una investigación más amplia recogida en el proyecto Fondecyt Iniciación $\mathrm{N}^{\circ}$ 11170336 con el título «El menor de edad como consumidor. Análisis de la publicidad que recibe el usuario de 10 a 14 años a través de los dispositivos móviles», financiado por la Comisión Nacional de Investigación Científica y Tecnológica (CONICYT) del Gobierno de Chile.

\section{Resultados}

En este apartado de resultados se presentan los principales datos estadísticos extraídos de aquellas preguntas de un cuestionario más extenso destinadas a conocer la actitud que los niños desarrollan ante los mensajes publicitarios que reciben a

1 División administrativa básica en dicho país. 
través de los dispositivos móviles que comúnmente emplean, medida en términos de detección, nivel de atención, confianza y de interacción preferentemente. Dada la penetración de las redes sociales entre las edades objeto de estudio (diez-catorce años), también se muestran resultados sobre la publicidad emplazada en estas plataformas.

En relación al perfil de usuario de dispositivo móvil estudiado, casi la totalidad de la muestra utiliza smartphone $(99 \%)$, siendo mayoritariamente ellos los dueños del mismo (82\%). Respecto a las marcas de los dispositivos, en primer lugar, se encuentra Samsung (47\%), seguida de Huawei (14\%) y LG (11\%). Asimismo, los teléfonos móviles de los menores son en su mayor parte regalados por algún familiar o amigo cercano (68\%), los que cambian mayoritariamente cada uno (33\%) o dos años (29\%). En cuanto a la forma de conectarse a la red, un $94 \%$ se conecta con datos móviles propios de los cuales un 53\% mediante prepago y un $44 \%$ a partir de un contrato mensual con alguna teleoperadora.

En cuanto a los principales usos dados al dispositivo, las tres acciones que mayoritariamente realiza el menor en los dispositivos móviles corresponden a «entretenimiento y ocio» $(83 \%)$, «comunicarse» $(77 \%)$ y «revisar o tener actividad en redes sociales» $(43 \%)$. El horario en donde se registra el mayor uso del teléfono móvil declarado por los menores es entre 15:00 a 17:59 (43\%), principalmente en momentos en que están con sus amigos (53\%) o viendo TV (42\%).

Casi la totalidad de menores ha descargado aplicaciones en los dispositivos móviles que utiliza $(93 \%)$, siendo las más descargadas reproductores de música o video $(66 \%)$, redes sociales (56\%) y juegos (54\%). Más específicamente, YouTube (92\%) y WhatsApp (83\%) se corresponden a las aplicaciones más descargadas por los menores de forma transversal en los distintos segmentos analizados (edad y sexo); Instagram se posiciona como la tercera aplicación más descargada (52\%) y a una distancia considerable se sitúan Facebook (39\%), Netflix (32\%), Spotify (17\%), Twitter (6\%) y Uber (1\%).

Pasando ya a la relación que el niño mantiene con la publicidad que recibe en los dispositivos móviles que usa, sobre la pregunta directa si el menor ha detectado publicidad en ciertos canales, más de la mitad de la muestra identificó algún mensaje promocional por YouTube (86\%), Facebook (77\%), dentro de juegos (74\%), Instagram (73\%) o Twitter (66\%). En un segundo nivel se encuentra WhatsApp $(30 \%)$ y otros canales menos empleados por este rango de edad: llamada telefónica $(25 \%)$, SMS $(22 \%)$ y email $(18 \%)$. Coincide que las apps en las que un mayor porcentaje de niños diferencia publicidad son también las que se posicionaron como más descargadas.

Tomando como referencia los niños que sí detectaron publicidad, más de la mitad de los menores ignora completamente la publicidad que ve (52\%), un $24 \%$ la cierra o la bloquea, un $21 \%$ sólo le presta atención, mientras que una minoría (3\%) le presta atención y hace click sobre ella. 
En lo referido a la confianza que los distintos canales despiertan en los niños para recibir publicidad, YouTube (33\%), WhatsApp (32\%), los videojuegos (25\%) e Instagram (20\%) se posicionan como los más confiables para los menores; por el contrario, Twitter es el canal que entrega menos confianza (84\%) como medio publicitario, así como la llamada telefónica $(70 \%)$, la mensajería $(79 \%)$ o el mailing (78\%), tal como se observa en la Figura 1.

Figura 1. Nivel de confianza que despierta en los niños la publicidad por distintos canales.

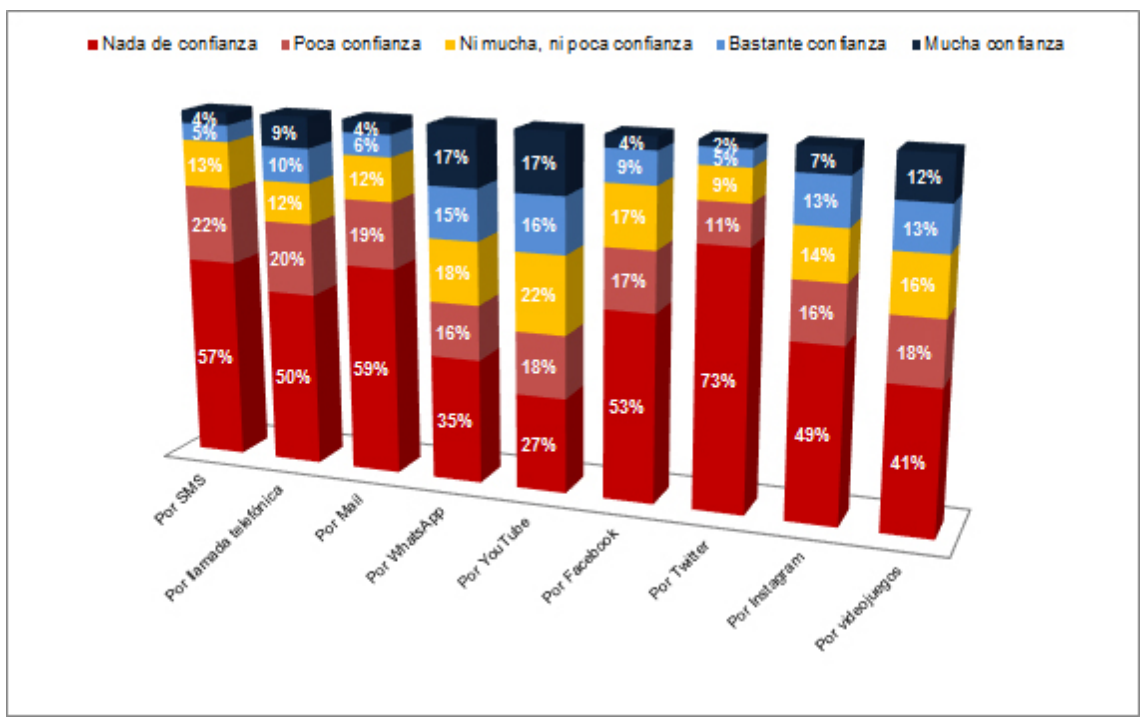

Fuente: elaboración propia.

Uno de cada tres niños recuerda alguna marca de la que ha recibido publicidad a través de su dispositivo móvil, sin embargo, declaran muy poca interactividad con la misma. Como se muestra en la Figura 2, interaccionan con alguna frecuencia con la publicidad preferentemente para que el acceso a contenidos sea gratuito (21\%) o para disfrutar de promociones (13\%). Un $84 \%$ afirma nunca haber comprado el producto anunciado y $81 \%$ nunca haber compartido la experiencia sobre una compra o uso de algún producto. 
Figura 2. Nivel de interacción con la publicidad recibida en el dispositivo móvil.

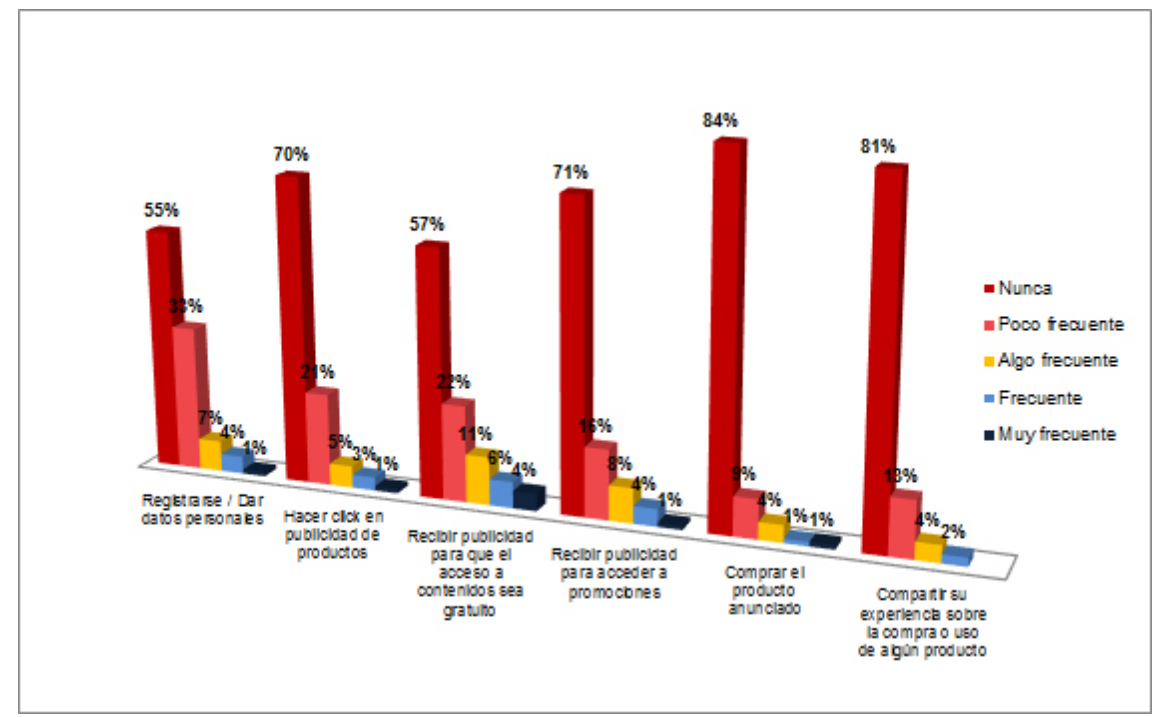

Fuente: elaboración propia.

Poniendo el foco en las redes sociales como uno de los principales soportes publicitarios en los dispositivos móviles, un 35\% de la muestra cree que el uso de estas plataformas lo acerca a distintas marcas, mientras que un $40 \%$ afirma que gracias a las redes sociales pudo conocer nuevas marcas. Ahora bien, al preguntar de nuevo por la frecuencia con la que el menor interacciona en redes sociales, los índices de participación suelen ser más bajos, especialmente cuando se trata de vincularse con productos o marcas. 
Figura 3. Nivel de frecuencia con la que los niños realizan ciertas acciones en redes sociales.

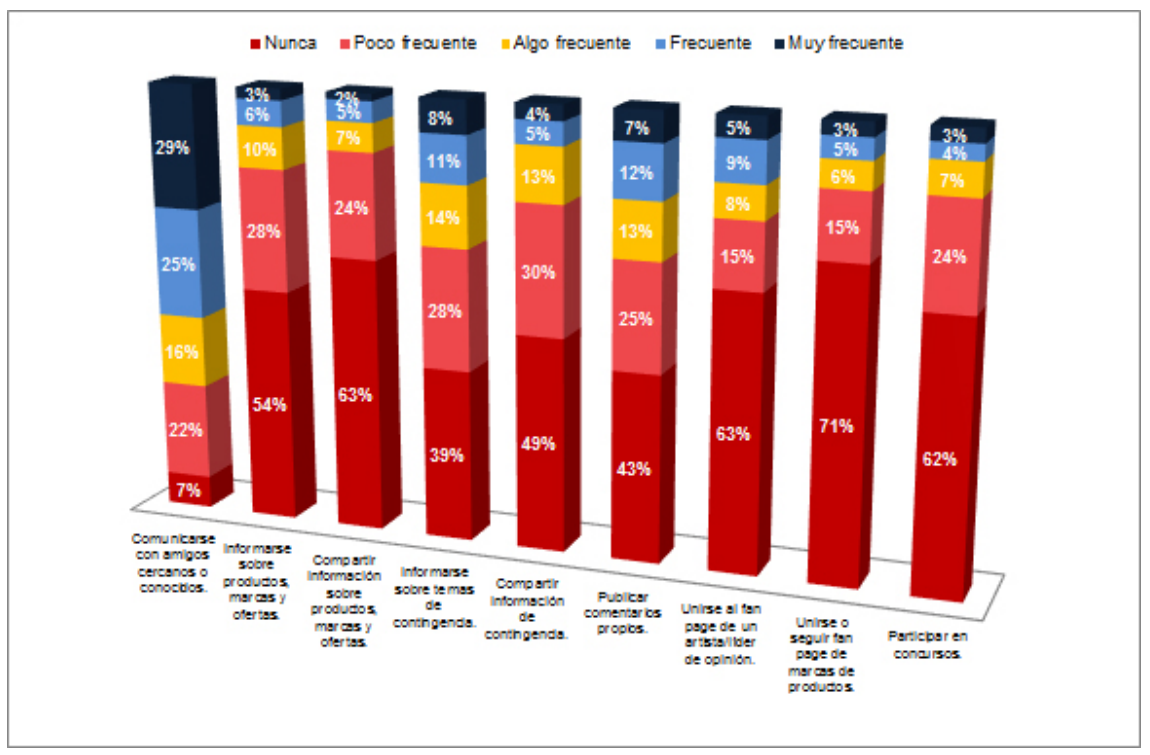

Fuente: elaboración propia.

Según la Figura 3, «comunicarse con amigos cercanos o conocidos» (70\%), «informarse sobre temas de contingencia» (33\%) y «publicar comentarios propios» (32\%) son las acciones más recurrentes en redes sociales, mientras que aquellas más relacionadas con la interacción publicitaria como «unirse al fan page de un artista/ líder de opinión» (22\%), «informarse sobre productos, marcas y ofertas» $(19 \%)$, «compartir información sobre productos, marcas y ofertas» (14\%), «unirse o seguir fan page de marcas» (14\%) o "participar en concursos» (14\%) son menos asiduas entre la muestra. Entre las marcas seguidas en redes sociales, destacan especialmente las deportivas (46\%) y las de ropa/moda $(22 \%)$. 
Figura 4. Categorización de las marcas seguidas en redes sociales.

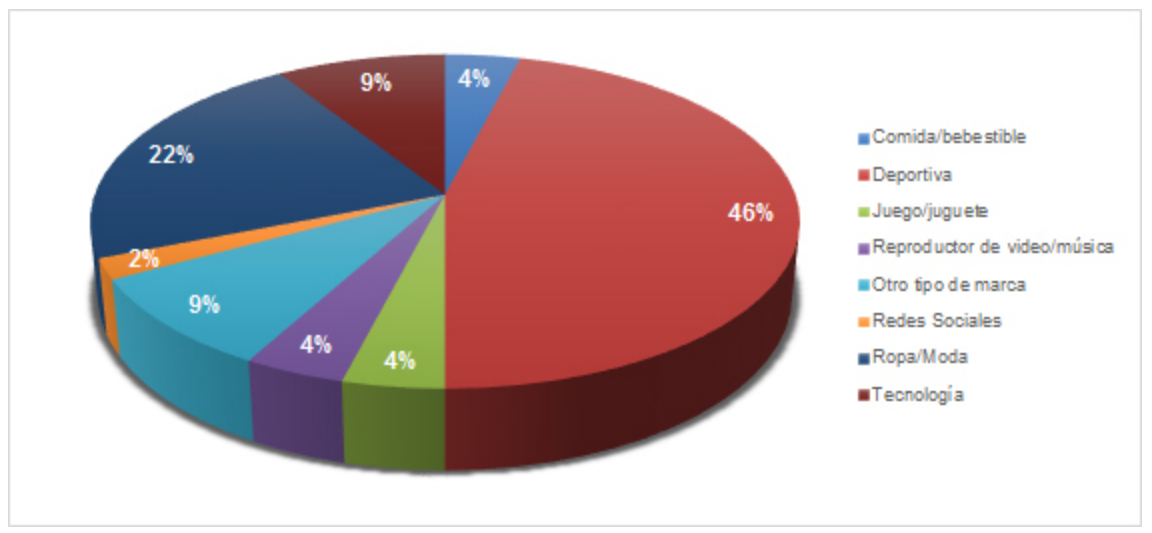

Fuente: elaboración propia.

Es destacable comprobar que la edad del niño no resultó ser un factor determinante con respecto a la publicidad recibida en sus dispositivos. El análisis estadístico no arrojó inferencias significativas en relación a la edad de la muestra y su nivel de interacción con los mensajes publicitarios. No obstante, sí que se observó un mayor índice de detección de publicidad a través de canales que tienden a ser más empleados por el segmento de edad trece-catorce años (Twitter, Facebook, email o sms), los que consecuentemente también general una menor desconfianza como soportes publicitarios en comparación con los más pequeños (diez a doce años).

\section{Discusión y conclusiones}

Los datos estadísticos presentados revelan que el teléfono móvil, un medio que nació para comunicarse, se fue transformando paulatinamente en otra pantalla para el consumo de ocio y entretenimiento. Como se mostró en los resultados, hay una mayor proporción de niños que usan el dispositivo para una finalidad lúdica que para comunicarse. Este es un dato importante para los anunciantes y marcas ya que a través del entretenimiento (youtubers, emplazamiento de productos en los contenidos) se puede llegar de una forma efectiva a los públicos más jóvenes. YouTube resultó ser la aplicación más descargada, aunque sí es cierto que, tras el buscador de vídeos, las apps más populares fueron redes sociales. Ahora bien, cabría profundizar en mayor medida cuáles son las rutinas de los niños en redes sociales como Instagram o Facebook, cada vez más encaminadas al entretenimiento que al fin comunicativo, por su carga visual, especialmente la primera.

Se pudo comprobar además que, para los niños, los canales que generan más confianza para recibir publicidad en los dispositivos móviles coinciden con las apps que 
más descargan, principalmente YouTube y WhatsApp, lo que lleva a concluir que tienden a fiarse más de aquellos inputs publicitarios que reciben a través de las plataformas en las que mejor se manejan y a las que, previsiblemente, más tiempo dedican. Por el contrario, las formas más convencionales de marketing móvil, como son la mensajería, la llamada telefónica o el envío de emails, son las que generan más desconfianza entre las nuevas generaciones además de Twitter, con poca penetración entre este público joven.

Los datos obtenidos siguen la línea argumental de la actitud prudente y escéptica de los niños ante la publicidad que remarcaron algunos autores como Chu, Blades y Herbert (2014): los menores identifican los mensajes comerciales, son conscientes de que las plataformas que frecuentemente usan contienen publicidad, es más, uno de cada tres niños recuerda haber recibido publicidad en su dispositivo, sin embargo, interactúan muy poco con ella. Solo un $3 \%$ hace click en la publicidad que le llega frente a un $76 \%$ que declara ignorarla totalmente o bien cerrarla y bloquearla. Aunque se trata de una generación interactiva (Bringué y Sádaba, 2009), caracterizada por su rol de prosumidor, en este estudio se extrae un nivel de interacción relativamente bajo con la publicidad, un papel pasivo que otros autores (Gallardo y Jorge, 2012, visto en Sáez y Gallardo, 2017) ya habían destacado al analizar su perfil de espectador de vídeos en internet. En relación a la edad cabe subrayar que en líneas generales la actitud escéptica ante la publicidad se mantiene, aunque se reduce en canales que los niños de más edad (trece-catorce años) empiezan a utilizar con más frecuencia como es el email, Twitter o Instagram.

No obstante, el interés del menor parece incrementar cuando percibe cierta utilidad en los mensajes publicitarios (Martí et al., 2013). Se confirma en este estudio que su predisposición es más favorable si el consumo de publicidad permite acceso gratuito a ciertos contenidos o para acceder a promociones. Bien la postura general suele ser escéptica, cuatro de cada diez niños reconocen la función informativa de la publicidad en el sentido de que los acerca a nuevos productos y marcas, especialmente deportivas y de moda.

Como se comentó en un principio, los menores cada vez emplean más sus dispositivos con una finalidad lúdica y de entretenimiento, de ahí que pasen gran parte de su tiempo conectados bien en canales como YouTube, bien en juegos online (a través de apps). Coincide que la publicidad lanzada por estos canales es la que les genera más confianza, pero al mismo tiempo son plataformas en las que el contenido y la publicidad aparecen cada vez más entremezclados, evidenciando una cierta «anarquía» con respecto a la diferenciación y categorización de los mensajes publicitarios (An y Kang, 2014; Chen et al., 2013; Terlutter y Capella, 2013). Por ello, recuperando la reflexión de Ali y Blades (2014), ante esta publicidad no se puede garantizar que los niños tengan una consciencia real de los motivos de los anunciantes, por lo que sería interesante profundizar en investigaciones futuras sobre la capacidad del menor para identificar estas nuevas estrategias que tienden a diluir las fronteras entre lo que es propiamente contenido de entretenimiento y lo que es publicidad. 
Por último, conviene aclarar que los resultados que se presentan en este artículo pertenecen a la primera fase de un proyecto de mayor envergadura que se inició bajo un enfoque cuantitativo, lo que implica una serie de limitaciones (conclusiones basadas en la percepción de la muestra, información estadística, respuestas cerradas...) que se intentan compensar en las siguientes fases de ejecución al emplear metodología cualitativa, como etnografía digital y entrevistas.

\section{Bibliografía}

Ali, Moondore y Blades, Mark (2014). Do Very Young Children Understand Persuasive Intent in Advertisements? En: Blades, M.; Oates, C.; Blumberg, F.; Gunter y B.. (Eds.). Advertising to children: New directions, new media. Nueva York: Springer. An, Soontae y Kang, Hannah (2014). Advertising or games? Advergames on the internet gaming sites targeting children. En: International Journal of Advertising, Vol. 33, $\mathrm{n}^{\circ}$ 3. Eastboune: Taylor \& Francis Online, 509-532. https://doi.org/10.2501/ IJA-33-3-509-532

Andersen, Lars P.; Tufte, Birgitte; Rasmussen, Jeanette y Chan, Kara (2008). The Tweens Market and Responses to Advertising in Denmark and Hong Kong. En: Young Consumers, Vol. 9, $\mathrm{n}^{\circ}$ 3. Bradford: Emerald Group Publishing, 189-200. https://doi.org/10.1108/17473610810901624

Atkinson, Lucy (2013). Smart shoppers? Using QR codes and 'green 'smartphone apps to mobilize sustainable consumption in the retail environment. En: International Journal of Consumer Studies, Vol. 37, $\mathrm{n}^{0}$ 4. Oxford: Blackwell Science, 387393. http://dx.doi.org/10.1111/ijcs.12025

Brée, Joël (1995). Los niños, el consumo y el marketing. Barcelona: Paidós.

Bringué, Xavier y Sádaba, Charo (2009). La generación interactiva en España. Niños y adolescentes ante las pantallas. Madrid: Ariel y Fundación Telefónica.

Cabello, Patricio y Claro, Magdalena (2017). Presentación de datos preliminares. Encuesta Kids Online Chile. Santiago: Kids Online Chile / PUCV.

Chen, Ying; Zhu, Sencun; Xu, Heng y Zhou, Yilu (2013). Children's Exposure to Mobile In-App Advertising: An Analysis of Content Appropriateness. En: (SocialCom), 2013 International Conference on Social Computing, Alexandria. http:// dx.doi.org/10.1109/SocialCom.2013.36

Chu, Maria T.; Blades, Mark y Herbert, Jane (2014). The Development of Children's Scepticism About Advertising En: Blades, M.; Oates, C.; Blumberg, F. y Gunter, B. (Eds.). Advertising to children: New directions, new media. New York: Springer.

Duffette, Rodney-Graeme (2015). The influence of Facebook advertising on cognitive attitudes amid Generation Y. En: Electronic Commerce Research, Vol. 15, $\mathrm{n}^{\mathrm{o}}$ 2. Long Beach: California State University, 243-267. https://doi.org/10.1007/ s10660-015-9177-4 
Emarketer (2015). Key Digital Trends for 2016. En: https://www.emarketer.com/ Webinar/Key-Digital-Trends-2016/4000125 (Consultado el 18-07-2019)

Feijoo, Beatriz. (2015). La infancia ante las pantallas: Análisis del consumo de medios audiovisuales (Tv, videojuegos e internet) entre los niños gallegos de último curso de primaria en 2010. Tesis doctoral. Pontevedra: Universidade de Vigo.

IAB Chile (2016). Resumen Informe anual inversión publicitaria. En: https://www. iab.cl/2016/05/02/inversion-publicidad-online-chile-2015-crece-respecto-2014/ (Consultado el 18-07-2019)

Kabali, Hilda K.; Irigoyen, Matilde M.; Nunez-Davis, Rosemary; Budacki, Jennifer G.; Mohanty, Sweta H.; Leister, Kristin P. y Bonner, Robert L. (2015). Exposure and use of mobile media devices by young children. En: Pediatrics, Vol. 136, n ${ }^{\circ} 6$. Evanston: American Academy of Pediatrics, 1-9. https://doi.org/10.1542/peds.2015-2151

Kunkel, Dale; Wilcox, Brian L.; Cantor, Joanne; Palmer, Edward; Linn, Susan y Dowrick, Peter (2004). Psychological issues in the increasing commercialization of childhood. En: Wilcox, B. L.; Kunkel, D.; Cantor, J.; Dowrick, P.; Linn, S. y Palmer, E. (Eds.). Report of the APA task force on advertising and children. Washington DC: American Psychological Association.

Koslow, Scott (2000). Can the truth hurt? How honest and persuasive advertising can unintentionally lead to increased consumer skepticism. En: Journal of Consumer Affairs, Vol. 34. Oxford, Wiley-Blackwell, 245-267. https://doi. org/10.1111/j.1745-6606.2000.tb00093.x

Logan, Kelty (2015). How uses and gratifications of smartphone apps affect attitudes toward in-app advertising. En: American Academy of Advertising. Conference. Proceedings (Online). Lubbock: American Academy of Advertising.

Martí-Parreño, José; Sanz-Blas, Silvia; Ruiz-Mafé, Carla y Aldás-Manzano, Joaquín (2013). Key factors of teenagers' mobile advertising acceptance. En: Industrial Management \& Data Systems, Vol. 113, no 5. Wembley: Embankment Press, 732-749. https://doi.org/10.1108/02635571311324179

Martínez, Carolina; Jarlbro, Gunilla y Sandberg, Helena (2013). Children’s views and practices regarding online advertising. En: Nordicom Review, Vol. 34, n ${ }^{\circ} 2$. Goteborg: Nordicom, 107-122. https://doi.org/10.2478/nor-2013-0057

McNeal, James (1992). Kids as Customers: A Handbook of Marketing to Children. Nueva York: Lexington Books.

Olarte-Pascual, María Cristina; Reinares-Lara, Eva María; Pelegrín-Borondo, Jorge; y Sierra-Murillo, María Yolanda (2014). La publicidad en el teléfono móvil: tres grupos de clientes, veintisiete recomendaciones de actuación. En: Universia Business Review, $\mathrm{n}^{\mathrm{o}}$ 41. Madrid: Recoletos, 126-144.

Robertson, Thomas S., y Rossiter, John R. (1974). Children and commercial persuasion: An attribution theory analysis. En: Journal of Consumer Research, Vol. 1 Chicago: University of Chicago Press, 13-20. https://doi.org/10.1086/208577 
Roedder, Deborah (1999). Consumer socialization of children: a retrospective look at twentyfive years of research. En: Journal of Consumer Research, Vol. 26, n ${ }^{\circ} 3$. Chicago: University of Chicago Press, 183- 220. https://doi.org/10.1086/209559

Sáez-Barneto, Gloria y Gallardo, Jorge (2017). La relación de los youtubers con la publicidad y sus espectadores. El caso de YouTube España. En: Telos: Cuadernos de comunicación e innovación, $\mathrm{n}^{0}$ 107. Madrid: Fundación Telefónica España, 47-57.

Salgado Carrión, José Antonio (2006). La presencia de la televisión en los hábitos de ocio de los niños. Madrid: Fundación Autor.

Sandberg, Helena (2011). Tiger Talk and Candy King: Marketing of Unhealthy Food and Beverages to Swedish Children. En: Communications - European Journal of Communication Research, Vol. 36, no 2. Berlin: De Gruyter, 217-244. https:// doi.org/10.1515/comm.2011.011

Sierra Bravo, Restituto (2001). Técnicas de Investigación Social. Teorías y ejercicios. Madrid: Ediciones Paraninfo.

Terlutter, Ralf y Capella, Michael L. (2013). The gamification of advertising: analysis and research directions of in-game advertising, advergames, and advertising in social network games. En: Journal of Advertising, Vol. 42, $\mathrm{n}^{\mathrm{o}} 2$ 2-3. Eastboune: Taylor \& Francis Online, 95-112. https://doi.org/10.1080/00913367.2013.774610

Tur-Viñes, Victoria y Ramos-Soler, Irene (2008). Marketing y niños. Madrid: ESIC Editorial.

Valvi, Aikaterini C. y West, Douglas C. (2015) Mobile Applications (Apps) in Advertising: A Grounded Theory of Effective Uses and Practices. En: Kubacki, K. (Ed.), Ideas in Marketing: Finding the New and Polishing the Old. Developments in Marketing Science: Proceedings of the Academy of Marketing Science. Cham: Springer.

Wang, Becky; Kim, Su y Malthouse, Edward C. (2016). Branded Apps and Mobile Platforms as New Tools for Advertising. En: Brown, R.; Jones, V. y Ming-Wang, B. (Eds.). The New Advertising: Branding, Content, and Consumer Relationships in the Data-driven Social Media Era. Santa Barbara: ABC-CLIO.

Ward, Scott; Reale, Greg y Levinson, David (1972). Children’s perceptions, explanations, and judgements of television advertising: A further exploration. En Rubenstein, A.; Comstock, G. A. y Murray, J. P. (Eds.). Television and social behavior (Vol. 4), Television in day-to-day life: Patterns of use. Washington DC: US Government Printing Office.

Wu, Linwan (2015). Factors of continually using branded mobile apps: the central role of app engagement. En: International Journal of Internet Marketing and Advertising, Vol. 9, n ${ }^{\circ}$ 4. Ginebra: Suiza, 303-320. http://dx.doi.org/10.1504/IJIMA.2015.072884 



\title{
Netflix, estrategia y gestión de marca en torno a la relevancia de los contenidos
}

\author{
Netflix, strategy and brand management \\ around the relevance of the content
}

Santiago Mayorga Escalada Universidad Europea Miguel de Cervantes

\section{Referencia de este artículo:}

Mayorga Escalada, Santiago (2019). Netflix, estrategia y gestión de marca en torno a la relevancia de los contenidos. adComunica. Revista Científica de Estrategias, Tendencias e Innovación en Comunicación, (18), 219-244. DOI: http://dx.doi. org/10.6035/2174-0992.2019.18.11

\section{Palabras clave}

Netflix; Branding; Gestión de marca; Engagement; Streaming; Contenido de marca

\section{Keywords}

Netflix; Branding; Brand management; Engagement; Streaming; Branded content

\section{Resumen}

Las marcas han sabido adaptarse a cada realidad determinada a lo largo de su evolución histórica. Su identidad, simbólica e intangible, ha ganado protagonismo frente a los productos y sus beneficios puramente funcionales. La llegada del siglo XXI trae consigo una serie de cambios disruptivos muy profundos: democratización tecnológica, realidad global hiperconectada, sociedad líquida, microsegmentación, etc. Este hecho deviene en un evidente cambio paradigmático que empodera tanto a los usuarios como a las marcas, situándolas en una relación de iguales donde el 
ámbito digital condiciona las principales relaciones de comunicación. Las marcas avanzan en la profesionalización de su proceso estratégico e integral de gestión, ofreciendo contenidos relevantes que les ayudan a crear experiencias únicas a través de un engagement potente con el usuario.

Netflix es una de las marcas que mayor notoriedad global ha adquirido en los últimos años a raíz de su política estratégica, volumen de negocio, política de comunicación, y oferta de contenidos. Esta cuestión valida la pertinencia de la presente investigación centrada en analizar, a través de un desarrollo teórico previo de la disciplina y su posterior adaptación a un estudio de caso, los principales elementos que dan forma a la política de gestión estratégica de marca llevada a cabo por esta plataforma de entretenimiento en streaming.

Teniendo en cuenta la naturaleza del estudio y, una vez analizados los principales resultados extraídos, observamos cómo los contenidos juegan un papel absolutamente esencial en toda la política de gestión integral y estratégica de la marca Netflix. El protagonismo de los contenidos en la construcción de la marca es transversal y va desde el propio concepto de negocio hasta la implementación de la estrategia a través de sus principales acciones de comunicación publicitaria y promocional.

\begin{abstract}
Brands have been able to adapt to each specific reality throughout their historical evolution. Its identity, symbolic and intangible, has taken prominence in the face of products and their purely functional benefits. The arrival of the XXIst century carries a series of very profound disruptive changes: technological democratization, hyperconnected global reality, liquid society, microsegmentation, etc. This fact becomes a clear paradigm shift that empowers both users and brands, placing them in a peer relationship where the digital environment conditions the main communication relationships. Brands advance in the professionalization of their strategic and integral management process, offering relevant content that helps them create unique experiences through a powerful engagement with the user.

Netflix is one of the brands that has gained the most global notoriety in recent years as a result of its strategic policy, business volume, communication policy and content offer. This question validates the pertinence of this research focused on analyzing, through a prior theoretical development of the discipline and its subsequent adaptation to a case study, the main elements that shape the policy of strategic brand management carried out for this platform of entertainment in streaming. Considering the nature of the study and, once analyzed the main results extracted, we observe how the contents play an absolutely essential role in the overall and strategic management policy of the Netflix brand. The protagonism of the contents in the construction of the brand is transversal and goes from the very concept of business to the implementation of the strategy through its main advertising and promotional communication actions.
\end{abstract}




\section{Autor}

Santiago Mayorga Escalada [smayorga@uemc.es] es Doctor en Comunicación por la Universidad Pontificia de Salamanca. Docente en la Universidad Europea Miguel de Cervantes. Miembro de la Asociación de Investigadores de la Comunicación y de la Red Iberoamericana de Investigadores en Publicidad. Sus líneas de investigación giran en torno a la gestión de marcas, el branding, las comunicaciones integradas de marca, las nuevas tendencias en comunicación y publicidad y la gestión de marcas en el deporte profesional. 


\section{Introducción}

Las marcas han sabido adaptarse a cada realidad determinada a lo largo de su evolución histórica (Eguizábal, 1998). Su identidad, simbólica e intangible, ha ganado protagonismo frente a los productos, y sus argumentos funcionales. La llegada del siglo XXI trae consigo una serie de cambios disruptivos muy profundos. Internet, junto con la democratización tecnológica, provoca que las sociedades desarrolladas evolucionen hacia una nueva realidad híper-conectada, transmedia, líquida, globalizada y micro-segmentada donde impera la inmediatez. Este hecho devine en un evidente cambio paradigmático (comunicación, comportamientos, consumo, etc.) que empodera a los usuarios, convirtiéndolos en el centro indiscutible de la acción de las marcas (Ballester y Sabiote, 2011).

Se avanza hacia una mayor profesionalización del proceso de gestión de marca, buscando mayor valor añadido y una capacidad eficiente de adaptación a la nueva realidad paradigmática. Las marcas intentan crear un engagement potente a través del establecimiento de conexiones relevantes que ayudan a crear experiencias de usuario únicas (Alloza, 2010). Se convierten el activo más valioso con que cuentan las corporaciones en la actualidad (Clifton, 2009).

$\mathrm{Al}$ calor de estas circunstancias se produce una expansión constante de la industria del entretenimiento o showbusiness. Nos encontramos ante un sector que crece exponencialmente a lo largo de las últimas décadas del siglo XX hasta llegar a ser enormemente potente en pleno siglo XXI (Bustamante, 2009). El sector audiovisual, entendido en toda su magnitud, es uno de los tentáculos más reconocibles que forman parte de la industria del entretenimiento. También lo hacen las nuevas ideas de negocio que aparecen en torno a la oferta transmedia de múltiples contenidos audiovisuales. De entre todo este espectro de nuevas ofertas destaca el caso paradigmático de Netflix.

\section{Hipótesis y Metodología}

Teniendo en cuenta lo expuesto previamente vamos a acotar de forma teórica la disciplina de la gestión de marca teniendo en cuenta los cambios disruptivos acaecidos en los últimos tiempos, así como la necesaria adaptación del proceso a la nueva realidad paradigmática. A partir de aquí podremos acercarnos a la cuestión de forma aplicada a través del estudio de caso de la marca Netflix, atendiendo especialmente al papel que juegan los contenidos dentro del proceso de gestión de la marca. La finalidad principal de cualquier estudio de caso, como técnica empírica de naturaleza cualitativa, es investigar la particularidad, la unicidad, del caso singular. En síntesis, con esta definición, pasamos a plantear la hipótesis de trabajo para la presente investigación afirmando que: «dentro del proceso de gestión de la marca Netflix los contenidos se configuran como un elemento estratégico relevante».

En el transcurso de la investigación se persigue obtener un volumen de certezas suficientes como para poder validar o refutar finalmente la hipótesis. Para ello es 
necesario establecer una serie de objetivos que, teniendo en cuenta el caso concreto, se plantean dos que dan continuidad estructural y coherencia a la investigación: acotar la disciplina que da forma al proceso de gestión de marca y estudiar los elementos estratégicos más relevantes dentro del proceso de gestión de la marca Netflix. A partir de este momento queda definida la estructura interna de la investigación en torno a dos etapas perfectamente diferenciadas y, a su vez, absolutamente complementarias: cuerpo teórico y estudio de caso.

\section{Investigación}

La técnica metodológica empleada para desarrollar la fase asociada al primer objetivo de la investigación es la revisión bibliográfica y documental de expertos en gestiones de marca, nacionales e internacionales, procedentes tanto del sector profesional como del ámbito académico.

\subsection{Cuerpo teórico: gestión de marca}

Nos acercamos al estudio del proceso de gestión de marca a través de las Ciencias de la Comunicación. La disciplina se conforma a lo largo del tiempo en torno a la integración de tres grandes corrientes: el management (Kapferer, 2012), el marketing (Keller, 2008) y la comunicación estratégica/comercial (De Chernatony y Lynch, 2004).

\subsubsection{Historia y evolución de las marcas}

El papel de la marca ha pasado por diferentes momentos a lo largo de la historia, adaptándose a las necesidades de las personas en cada una de las diferentes civilizaciones existentes. Su evolución más relevante se produce a finales del siglo XIX y a lo largo de todo el siglo XX (Eguizábal, 2007). En la actualidad las marcas gozan de un papel protagonista constituyéndose como el activo más relevante y valioso con el que cuentan las corporaciones.

La naturaleza histórica de las marcas ha sido siempre motivo de estudio. Nos encontramos ante un fenómeno que por su naturaleza resulta difícil de acotar (Benavides, 2013). Esta situación provoca que se realicen numerosos acercamientos a la materia a través de diferentes corrientes y disciplinas lo que genera múltiples interpretaciones. Los expertos, en vez de avanzar hacia un marco teórico claro, conciso y pedagógico tienden a construir perspectivas personalistas donde prima el afán comercial o el posicionamiento profesional (Fernández Gómez, 2013).

El papel protagonista que adopta la marca en nuestros días conlleva un enorme ejercicio de dinamismo y capacidad de innovación que facilite la adaptación constante a la coyuntura del momento (Keller, 2008). Teniendo en cuenta esta perspectiva vamos a entender la marca como la experiencia de una promesa cumplida (Mayorga, 2018). 


\subsubsection{El proceso de gestión de marcas}

La disciplina que da lugar al desarrollo de todo este proceso estratégico de gestión de una marca es enormemente compleja. Al igual que ocurre con el fenómeno de la marca, existe una confusión atávica a la hora de acercarse a esta disciplina tanto desde el punto de vista profesional como desde el ámbito académico (Fernández Gómez, 2013; Benavides, 2017). Esta problemática se reproduce de forma escalonada a la hora de identificar elementos que son inherentes al proceso. Esta cuestión conduce a que no exista un marco teórico de consenso entre especialistas.

Conforme a lo expuesto construimos una amalgama teórica de expertos para lograr acotar la disciplina de la gestión de marcas. Para ello tomamos los principales ítems que nos llevan a la construcción de un marco teórico básico. De acuerdo con esta lógica afirmamos que la gestión de marca se conforma como un proceso estratégico integral, de naturaleza multidisciplinar, que logra alinear de forma coherente todas las acciones y elementos que van a dar forma a la marca frente a la percepción de sus públicos (Keller, 2011; Ayestarán, 2016; Rosenbaum-Elliot, Percy y Pervan, 2015). La administración de un proceso tan complejo sólo puede desarrollarse con éxito si se realiza de una forma profesional y planificada (Velilla, 2010). Acotamos la naturaleza del proceso de gestión de marcas a través de las principales características que le dan forma:

Sistema holístico de naturaleza multidisciplinar

La realidad del sector nos indica que cualquier intento por comprender la disciplina tiene que escapar de la atomización y de los planteamientos reduccionistas, buscando la integración de todos los elementos que conforman el proceso (Baena y Cerviño, 2014).

Nos encontramos ante un sistema complejo, de naturaleza eminentemente multidisciplinar. Joan Costa acota la disciplina a través de su naturaleza holística donde «[...] no se puede conocer las partes sin conocer el todo, y a la inversa... el todo es más que la suma de sus partes...el todo no es posible reducirlo a partes porque todas ellas son interdependientes y es así como toman sentido al formar el todo» (Costa, 2013: 14).

Proceso estratégico de gestión integral

Si hay una característica fundamental que recorre de forma transversal el proceso holístico de gestión de marca es su carácter estratégico (Aaker y Joachimsthaler, 2005). Nos encontramos ante un sistema complejo que, a través de la estrategia, alinea de forma integral todos los elementos, acciones, agentes y disciplinas que lo componen, alineándolos en torno a un objetivo común a largo plazo (Munuera Alemán y Rodríguez Escudero, 2006). 
Adaptarse al presente, predecir el futuro

Cualquier proceso de gestión de marca ha de saber adaptarse al presente, estando prevenido para anticiparse a las condiciones futuras (Fernández Gómez, 2013). Los paradigmas clásicos han caído con la llegada del siglo XXI gracias, en gran medida, al desarrollo y la democratización tecnológica (Stalman, 2014). En este sentido la marca es el único agente poderoso desde el que las corporaciones pueden establecer conexiones potentes con los usuarios a largo plazo, ofreciéndoles experiencias únicas y conversaciones pertinentes de tú a tú.

Propuesta de valor, única y diferente

El proceso de gestión de marca busca, de forma estratégica e integral, posicionarse de una forma determinada tanto dentro del mercado en el que opera como en la mente de sus públicos objetivo (Aaker, 2012).

El fin último de la marca, a través de su proceso estratégico de gestión, es dotarse de valor añadido. La creación de una experiencia única y relevante, cumpliendo la promesa realizada, hace que los usuarios fidelicen su relación con la marca y estén dispuestos a pagar más por ella. Este es el momento ideal donde el proceso de gestión de marca alcanza su plenitud (Keller, Parameswaran y Jacob, 2011).

Coherencia, constancia y consistencia

Cualquier proceso de gestión de marca exitoso, desarrollado a través de un plan estratégico integral, reúne tres características comunes que se antojan indispensables: coherencia, constancia y consistencia (Stalman, 2014: 43).

\subsubsection{Etapas estructurales del proceso}

Recogiendo tanto la naturaleza esencial como las características básicas de la disciplina se conforma una suerte de artefacto teórico que logra acotar el fenómeno. Para finalizar este trabajo identificamos dos grandes partes que dan sentido estructural al proceso (Cerviño y Baena, 2014; De Chernatony, 2010; Healey, 2009; Ollé y Riu, 2009).

Construcción/estrategia de marca. Se refiere a la parte interna en que se da forma a la estrategia y se alinean a todos los elementos de construcción de la marca en torno a ella. Esta parte se divide a su vez en una serie de etapas de descubrimiento hasta llegar a la conformación de la idea de negocio, la identidad, el concepto y el posicionamiento de la marca a través de un concepto único y diferenciador en forma de promesa a sus públicos (Benavides, 2017).

Comunicación de marca. Esta parte hace referencia a la implementación de la estrategia de marca a través de todos los elementos y acciones de comunicación necesarios para hacer eficiente la conexión con el target (Fill y Turnbull, 2016). 
Esta parte tiene que ver tanto con elementos internos como con acciones externas de comunicación, estando coordinadas en todo momento por un programa de comunicaciones integradas de marca.

Hay otras dos etapas reconocibles dentro de todo proceso de gestión de marca. Teniendo entidad propia, son subsidiarias de la parte de construcción y comunicación de marca, activándose en función de las necesidades estratégicas del momento. Hablamos de la tarea de medición (Aaker, 2012) y de arquitectura de marca (Martín García, 2005).

\subsection{Estudio de caso: gestión de marca Netflix y relevancia de los contenidos como elemento estratégico dentro del proceso}

Para desarrollar de forma procedente esta etapa se va a utilizar una integración de tres técnicas metodológicas: revisión documental, observación de elementos y cotejo de información para identificar aspectos relevantes (Marshall y Rossman, 1989).

De forma lógica y coherente con los objetivos planteados utilizamos, como anclaje estructural, el marco teórico construido en el punto anterior. Toda vez que tenemos acotada la disciplina y, conocemos las partes fundamentales que dan forma al proceso, podemos establecer un guion lógico que aplicaremos en el análisis del proceso de gestión estratégica de la marca Netflix. Teniendo en cuenta la hipótesis y los objetivos marcados en la investigación se analiza de forma específica y transversal el papel que juegan los contenidos dentro de las dos partes fundamentales en que se divide el proceso:

\subsubsection{Construcción/estrategia de marca}

Como ya se ha desgranado en el marco teórico, la parte de construcción de marca hace referencia a la conformación interna de una determinada estrategia para la marca, estableciendo una serie de líneas maestras que seguir en el medio y largo plazo (Ávalos, 2010). A través de esta fase se conforma la personalidad, los valores, los atributos y el concepto clave que va asociado al posicionamiento, la diferenciación y la propuesta de valor de la marca (Keller, 2008). Con el objeto de ser precisos con la investigación y lograr entender la coherencia interna del proceso vamos a analizar los elementos más significativos que dan forma a esta primera parte:

\section{a. Historia}

'Netflix, Inc.' nace en el año 1997. Todo comienza cuando Reed Hastings es penalizdo económicamente por 'Blockbuster' al retrasarse en la devolución de una película. A raíz de esta circunstancia pone en marcha un modelo de negocio innovador: alquiler de películas desde tu casa sin recargos (Tucker, 2015). En 1999, Netflix lanza una oferta de suscripción mensual con posibilidad de alquiler ilimitado de películas (Thompson, 2003). Todas las ventajas competitivas quedan integradas ese mismo 
año en torno a una web. En el año 2000 la marca amplía notablemente los servicios online, introduciendo un programa informático que ofrece recomendaciones a los usuarios de forma individualizada. En 2002, Netflix cuenta con más de 600.000 usuarios. En 2003 implementan una patente informática que facilita los trámites online y ofrece un nuevo modelo de sugerencias a través de la valoración de sus propios usuarios. A lo largo del año 2006 llevan a cabo un concurso tecnológico para seguir desarrollando patentes.

El negocio de Netflix crece exponencialmente apostando por una ofertad de calidad en sus contenidos a través de un servicio online cada vez más eficiente (Tucker, 2015). En 2007 la marca revoluciona el sector introduciendo la reproducción de sus contenidos vía streaming. En 2008 y 2009 amplían su mercado, introduciéndose en plataformas televisivas y dispositivos móviles. El número de suscriptores asciende a los 10 millones en el año 2009 (Netflix Media Center, 2018).

Netflix cierra en el año 2010 su primera expansión de mercado dentro de un nicho estratégico, implantando su presencia en todos los dispositivos móviles de Apple. A partir de este momento se pone en marcha el gran objetivo: globalizar la marca. Ese mismo año se introduce en el mercado canadiense. En 2011 expande su oferta a Latinoamérica y el Caribe. A partir del año 2012 aterriza de forma escalonada en Europa, Reino Unido y países nórdicos. La expansión global continúa con éxito en el año 2013, convirtiéndose en la primera plataforma online que recibe un Primetime Emmy por una serie de producción propia, House of Cards.

En 2014 la marca cuenta con 50 millones de suscriptores. En 2015, Netflix se introduce en Australia, Nueva Zelanda y Japón. Ese mismo año cierra su desembarco en Europa con la entrada en el mercado español, italiano y portugués. En 2016 alcanza su objetivo estratégico de expansión comercial internacional y, en 2017, cuenta con más de 100 millones de suscriptores (EuropaPress, 2017).

A partir del año 2018 la marca se fija nuevos retos estratégicos: aumentar paulatinamente su inversión en contenido propio hasta llegar al 50\% de su oferta (Statt, 2017), uso integral del big data y adaptación a las diferentes realidades locales. Netflix cierra 2018 con 139 millones de suscriptores lo que supone un incremento del 35\% con respecto a los datos del año anterior. Los ingresos de la compañía subieron este pasado año un 27\%, situándose en los 4.190 millones de dólares (Netflix Investors, 2019).

Para 2019 Netflix se plantea aumentar de forma significativa sus ingresos a pesar de las inversiones en contenido propio y la amenaza de la competencia (Disney creará su propia plataforma). En este sentido los datos del primer cuatrimestre del año indican que la marca sigue creciendo aunque por debajo de los ambiciosos resultados que tenía previstos: 7,86 millones de nuevos suscriptores y un aumento de los ingresos totales que pasan a 4.520 millones de dólares frente a los 3.700 millones de dólares en el mismo cuatrimestre del pasado año (Netflix Investors, 2019). 


\section{b. Idea de negocio}

Conocer la historia de la empresa junto con sus principales ítems corporativos facilita comprender cuál es la idea central del negocio. Esta cuestión pone de manifiesto el concepto estratégico de la marca y cómo se adapta a las circunstancias a lo largo del tiempo a través de la toma de decisiones.

La marca Netflix se posiciona, según la agencia neoyorkina encargada de realizar su último gran programa de branding, como «el servicio de streaming de medios líder en el mundo [...] Uno de los innovadores originales del contenido en streaming. [...] Con una amplia gama de series originales, adquisiciones de alto perfil y una base de usuarios en explosión. [...] Netflix es una marca viva, en constante evolución» (Gretel, 2013).

De acuerdo con el posicionamiento de la marca y, teniendo en cuenta la información extraída a través del trabajo de revisión bibliográfica realizado, vamos a resumir la idea de negocio de Netflix en cinco conceptos estratégicos clave:

- Marca global. Netflix pone en marcha diferentes planes de crecimiento internacional de su marca a partir del año 2010, dando por concluida la fase de expansión global en el año 2018. Este trabajo se desarrolla de forma planificada, a través de diferentes etapas, y entendido por la compañía como una de las principales líneas maestras de su estrategia de negocio (IzquierdoCastillo, 2015). Los contenidos son contratados o producidos teniendo en cuenta el mercado global en el que opera, abriendo el abanico de ofertas a los contenidos de tipo local una vez que la marca se ha asentado a lo largo de muy diferentes países.

- Desarrollo tecnológico. Netflix ha logrado adaptarse a la nueva realidad paradigmática, entendiendo los cambios disruptivos que se producen y ofreciendo soluciones tecnológicas relevantes al servicio de las demandas de consumo y comunicación que exigen los usuarios. La marca hace suya la filosofía de aprender para adaptarse (Chahal, 2017). Todos los desarrollos tecnológicos que logran implantar vienen precedidos de un proceso de investigación, desarrollo, innovación y soluciones concretas a cuestiones determinadas que han sido perfectamente identificadas previamente. La innovación tecnológica de Netflix se convierte en una parte imprescindible de su propuesta de negocio, siempre al servicio del usuario, siendo especialmente relevante a través de tres soluciones estratégicas:

- Streaming. Netflix entiende que el usuario se sitúa en el centro de las acciones de la marca con el fin de satisfacer sus principales necesidades. En este sentido revoluciona la industria audiovisual y del entretenimiento dándole la posibilidad al usuario de consumir cualquier contenido que se oferta dentro de la plataforma en el momento que quiera, desde el lugar que quiera y a través de la pantalla/dispositivo que más le apetezca (Summers, Brecht, Eager y Gutarin, 2016). Todo ello es posible a través de la reproduc- 
ción de contenidos por streaming. Esta decisión estratégica sitúa a Netflix como una marca líder, puntera en el ámbito de la innovación tecnológica, que logra reinventar el sector. En este sentido algunos académicos sitúan a Netflix como una marca pionera dentro de la denominada nueva «industria del saber», directamente ligada con la innovación tecnológica en el ámbito digital (Burroughs, 2019).

- Convergencia y mutación. Netflix logra hacer realidad su principal promesa de marca a través de una plataforma online donde el consumidor tiene la posibilidad de acceder vía streaming a los mejores contenidos del mercado. Se conforma un sistema de consumo audiovisual online de naturaleza convergente que enlaza con los modelos teóricos descritos a comienzos de la década de los años noventa (Scolari, et al, 2012). El desafío que lanza Netflix al sector audiovisual del entretenimiento va más allá y, en este aspecto, logra conformar una oferta integral que aúna, siempre en beneficio del consumidor, la fórmula de: internet + cine + televisión (Heredia, 2017). Netflix genera un engagement muy potente al conectar de forma relevante la marca con su público a través de un sistema de convergencia audiovisual que cuenta con la mejor oferta de contenidos. En definitiva, nos encontramos ante un nuevo modelo que logra mutar la oferta de contenidos audiovisual de entretenimiento vía streaming (Ahumada, 2013).

- Gestión de información y datos de usuario. La apuesta por el desarrollo tecnológico con el fin de ofrecer un servicio totalmente adaptado a las necesidades de sus usuarios ha llevado a Netflix a buscar, a lo largo de su existencia, la mejor forma de manejar datos y recoger el feedback de usuario. La demanda del usuario al servicio del diseño de la oferta como pata estratégica de la marca (Fernández-Manzano, Neira y Clares-Gavilán, 2016). Este hecho ha sido determinante para disponer de una oferta absolutamente microsegmentada e individualizada gracias a las inversiones en big data, hasta llegar al actual algoritmo con el que trabaja la marca en el que se incluye el uso de inteligencia artificial (Carrillo, 2019). Tod Yellin, vicepresidente de producto de Netflix afirma que: «No hay nada complicado en el algoritmo de Netflix. Es realmente una colaboración entre las personas que ven Netflix, nuestros usuarios, y nosotros, tratando de hacer más fácil el camino para que alguien encuentre el contenido correcto en el momento indicado» (Schulkin, 2019). La toma de decisiones a través del uso de big data en Netflix garantiza la eficiencia de resultados en todos sus ámbitos: inversión en contenido externo, tipología temática de los contenidos, producción propia de contenidos, marketing, etc.

- Calidad y contenidos propios. La marca canaliza su éxito a través de una apuesta estratégica por invertir en la compra y/o la producción de contenidos de calidad que resulten de interés para sus usuarios. Netflix nace como un mero distribuidor para pasar a convertirse en productor de sus propios 
contenidos (2017). En el año 2013 se estrena en la plataforma su primera serie de producción propia, House of cards, y dos años después hace lo propio en formato película con Beast of no Nation, estrenada en este caso de forma simultánea en la plataforma y en el circuito habitual de cines. A partir de estos hitos la marca establece de forma estratégica en 2016 una serie de objetivos centrados en aumentar los contenidos de producción propia por encima del $50 \%$ de la oferta total, llegando en una segunda etapa que comienza a finales del año 2017 a apostar por la producción propia adaptada al ámbito local/nacional (Fernández, 2019).

\subsubsection{Comunicación de marca}

En coherencia con lo expuesto en el marco teórico y, una vez analizados los elementos principales que dan forma a la parte de construcción, vamos a describir los principales elementos que cimentan la parte de comunicación de la marca Netflix, y cuál es el papel que juegan los contenidos dentro de la misma.

La agencia global de branding y comunicación estratégica 'Gretel' se encarga de implementar el posicionamiento estratégico para conectarlo con los públicos de interés a través de diferentes técnicas de comunicación en múltiples puntos de contacto. De esta manera vamos a analizar los elementos clave que van a guiar la estrategia de comunicación de la marca:

\section{Unificación de la marca}

Netflix logra experimentar en los últimos años un crecimiento sobresaliente gracias al desarrollo de nuevos objetivos de negocio, manteniendo en todo momento la coherencia de su concepto estratégico. Naz Arandi, planner de la agencia 'Gretel', expone que la estrategia de unificación realizada para Netflix se desarrolla a través de un consumer insight. La promesa de la marca se revela de la siguiente forma: 'conectamos a la gente con historias para amar' (Arandi, 2015). Este insight es el epicentro sobre el que se cimenta toda la estrategia de comunicación de la marca. Es evidente el papel absolutamente relevante que se le da desde Netflix a los contenidos (historias para amar), siendo la principal razón de comunicación (promesa de marca/propuesta de valor) para lograr conectar con su target.

\section{Programa de identidad visual}

De forma coherente con la estrategia se desarrolla todo un sistema visual encargado de visibilizar la identidad de la marca. Esta comunicación gráfica va a servir además de plataforma para incluir y promocionar de forma protagonista los contenidos más destacados que ofrece la marca. La agencia 'Gretel' señalada que: 
«nuestro reto era crear algo lo suficientemente amplio para una marca global pero que a la vez fuese único e identificable. Crear algo flexible pero a la vez esquemático y fuerte. Tenía que ser visualmente llamativo, adaptable a cada formato e interpretable por las agencias y distribuidores de todo el mundo» (Diligent Team, 2015).

El programa de identidad visual va a girar en torno a «The Stack» (Vargas, 2015): una metáfora visual y un sistema gráfico de identidad en uno; es un catálogo de exposición de contenidos dinámico e infinito. El look y feel de la marca va a girar en torno a esta construcción gráfica donde los contenidos, como vemos, son un elemento estratégico fundamental de comunicación.

Figura 1. Uso implementado de la construcción de identidad visual «The Stack»

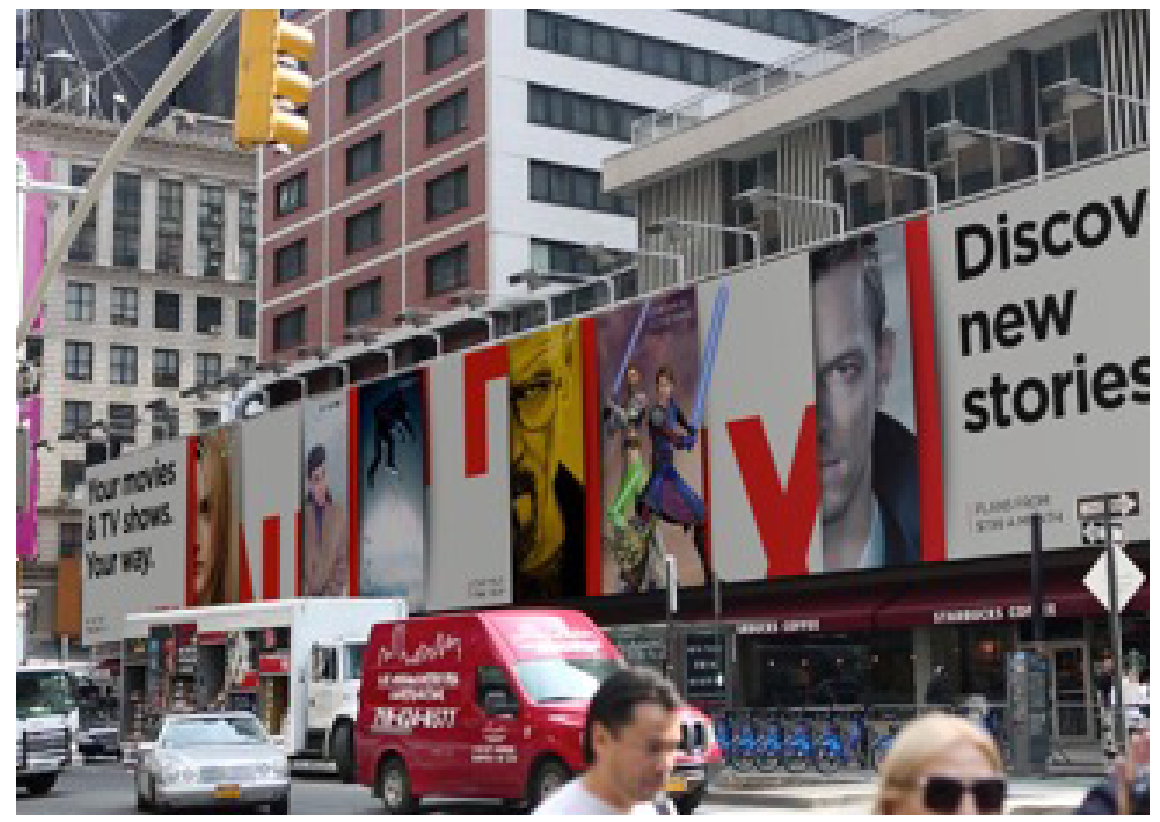

Fuente: Netflix.

Junto al programa de identidad visual que comunica de forma gráfica el concepto de la marca se produce un restyling del logo para que también quede alineado con la estrategia. Nos encontramos ante una construcción visual, compacta y minimalista, que se lee con mayor facilidad lo que permite que sea usado con fondos que hagan alusión a la oferta de contenidos de la plataforma. Netflix presenta en 2016 una versión reducida del logo con el fin de adaptarse y facilitar su implementación en diferentes situaciones del entorno digital, representando un significado simbólico 
de la continuidad en la oferta de contenidos de calidad (García, 2016). Este último logo también puede entenderse como un guiño a los contenidos en lo temporal: pasado (cinta de las películas) y presente (binge-watching).

Figura 2. Logo y logo reducido para el entorno digital

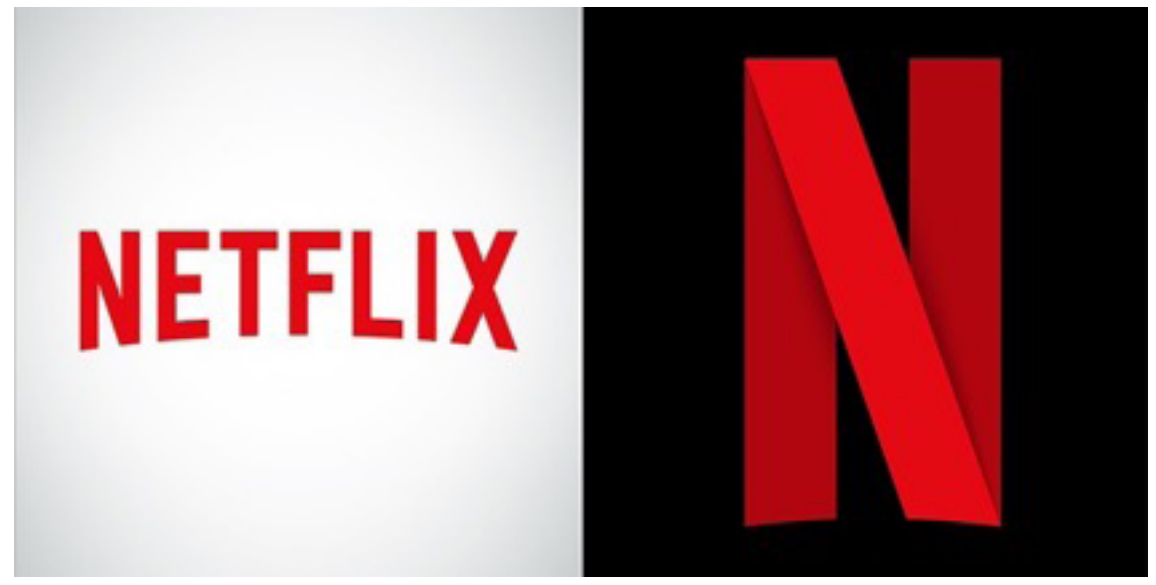

Fuente: Netflix.

Nos encontramos ante otro elemento estratégico de comunicación protagonista, encargado de dar sentido global al concepto de la marca en todos sus puntos de contacto con los usuarios. Con base nuevamente en el insight consumer, la agencia Gretel establece como global brand claim el: «See what's next». En torno a esta frase se filtra de forma implícita la oportunidad que se le ofrece al usuario de descubrir constantemente nuevas historias a través de la enorme oferta de contenidos de calidad de que dispone la marca, creando engagement gracias a una experiencia única. Es una construcción que además potencia la política de marca tanto en el ámbito de la innovación tecnológica como en su dimensión global.

El brand claim es desmenuzado por la agencia Gretel de forma estratégica, aludiendo a las siguientes asociaciones de conceptos donde queda manifiestamente claro el protagonismo que se le da a los contenidos (Whipps, 2016): «See: Connecting people with stories, Looking fordward, Exploring, Viewing the content. Next: What will Netfilx do next?, Innovation, Anticipation, Curiosity, The next show/episode». 
Figura 3. Brand claim de Netflix y desarrollo estratégico de conceptos asociados a la marca
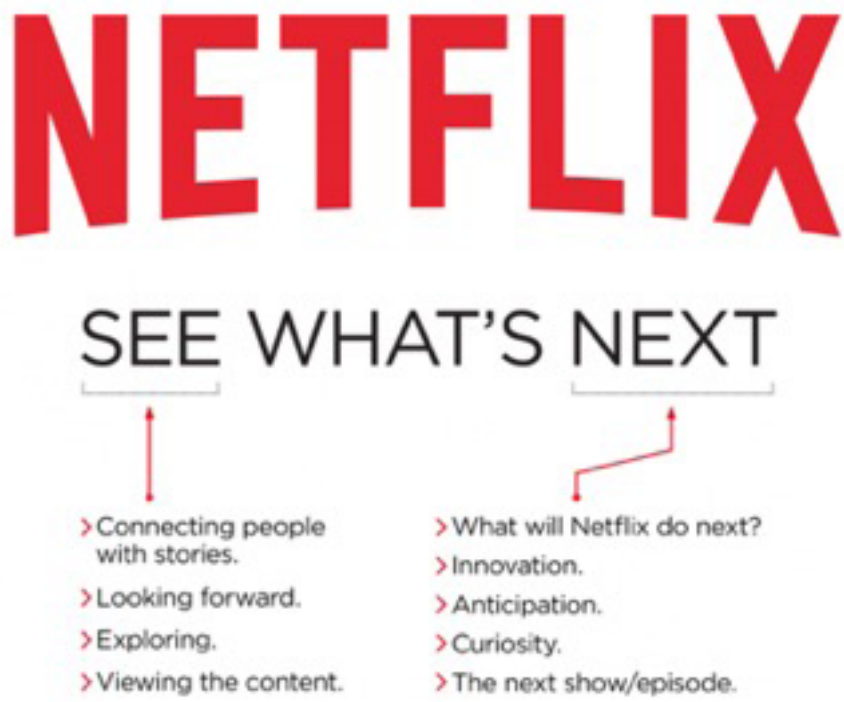

Fuente: Whipps (2016).

Netflix ha ido construyendo y utilizando toda una serie de claims alternativos que, de forma coherente con el brand claim principal, mantienen la comunicación del concepto y de los atributos sobre los que se ancla la marca. Algunos de estos claims han sido: «Anytime. Anywhere. Instantly»; «All episodes, all seasons, now streaming»; «Your movies y TV shows. You way». Es evidente cómo los contenidos (propios y de calidad) juegan un papel protagonista y transversal en los claims junto con las otras dos patas estratégicas de la marca: desarrollo tecnológico y marca global. Las fortalezas estratégicas de la marca puestas al servicio de los usuarios.

Comunicaciones integradas de marca

La gestión del resto de elementos que intervienen en la parte de comunicación se implementa a través de la elaboración de un programa de comunicaciones integradas de marca donde destaca el trabajo eficiente de marketing basado en el uso de big data, el feedback de usuario a través de redes sociales, el relato uniforma y coherente a través del trabajo de storytelling, y el branded content donde los contenidos propios de la plataforma retroalimentan las promociones de la marca. Netflix 
logra comunicar con éxito, y de forma integral-transmedia, su concepto de marca a través de potenciar sus fortalezas estratégicas.

De forma general, la marca desarrolla una inversión en marketing centrada en fijar tanto su posición global como los atributos principales que dan sentido a la promesa de negocio, adaptándose a los mercados locales con campañas publicitarias y acciones de comunicación concretas que buscan el impacto y la viralización, donde los contenidos de la plataforma son los principales protagonistas (Miguel, 2017).

Figura 4. Promo publicitaria de la serie Narcos en la Puerta del Sol de Madrid

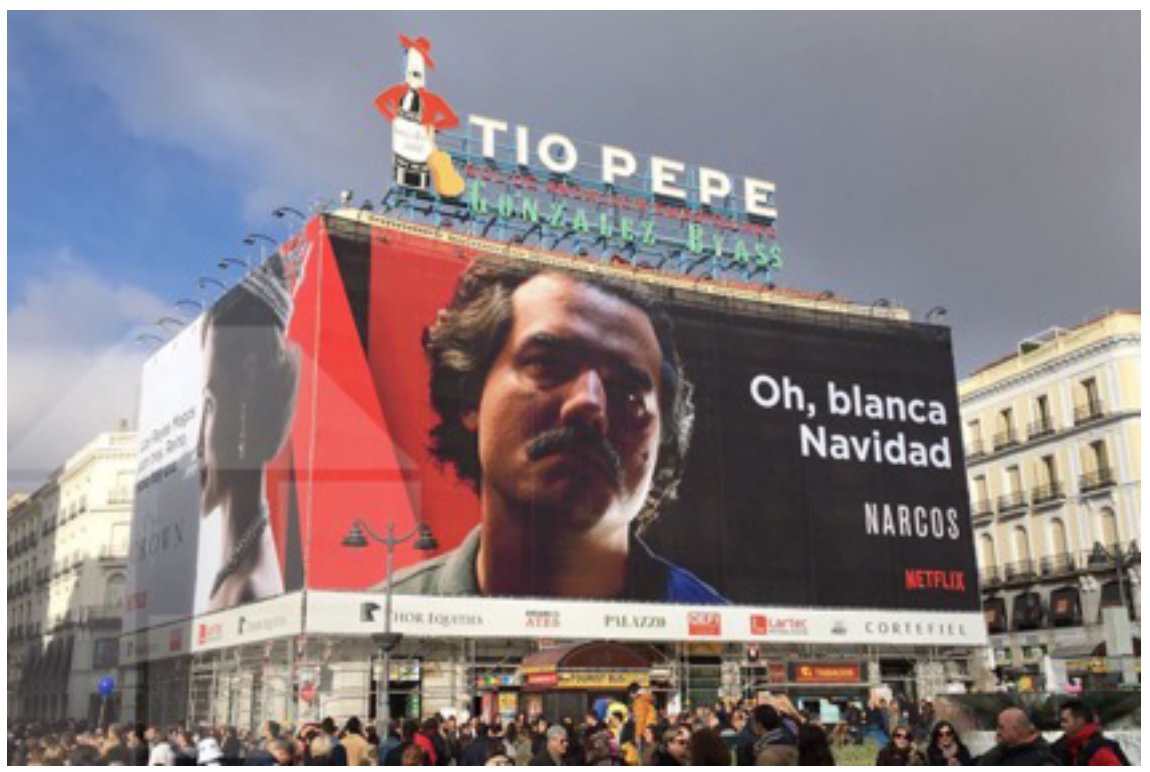

Fuente: Netflix.

El uso que hace Netflix de las redes sociales es muy activo y dinámico, cercano con el usuario, utilizando un tono desenfadado donde el humor conecta de forma potente con su target a través de la activación de conversaciones de tú a tú. Las autopromociones de contenido son las que más tráfico registran en redes y las que más actividad de usuarios generan. En todas las acciones de comunicación comercial de la marca, reconocidas por ser originales e impactantes, aparece de forma protagonista el contenido que ofrece Netflix a modo de un gran catálogo de experiencias. Resulta realmente llamativo el juego de comunicación que hace la marca en redes sociales con sus usuarios a través del uso de múltiples gifs (todos ellos extraídos de series propias que se ofertan en la plataforma). 
Figura 5. Comunicado en redes sociales de Netflix España a sus usuarios el día 1 de enero

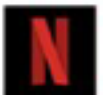

\section{Netflix}

1 de enero a las 12:07 - Madrid, Comunidad de Madrid - $\Theta$

\section{Atención: Hoy estamos con ibuprofeno, mucha agua y las luces bajitas. Ponte alguna serie mientras volvemos.}

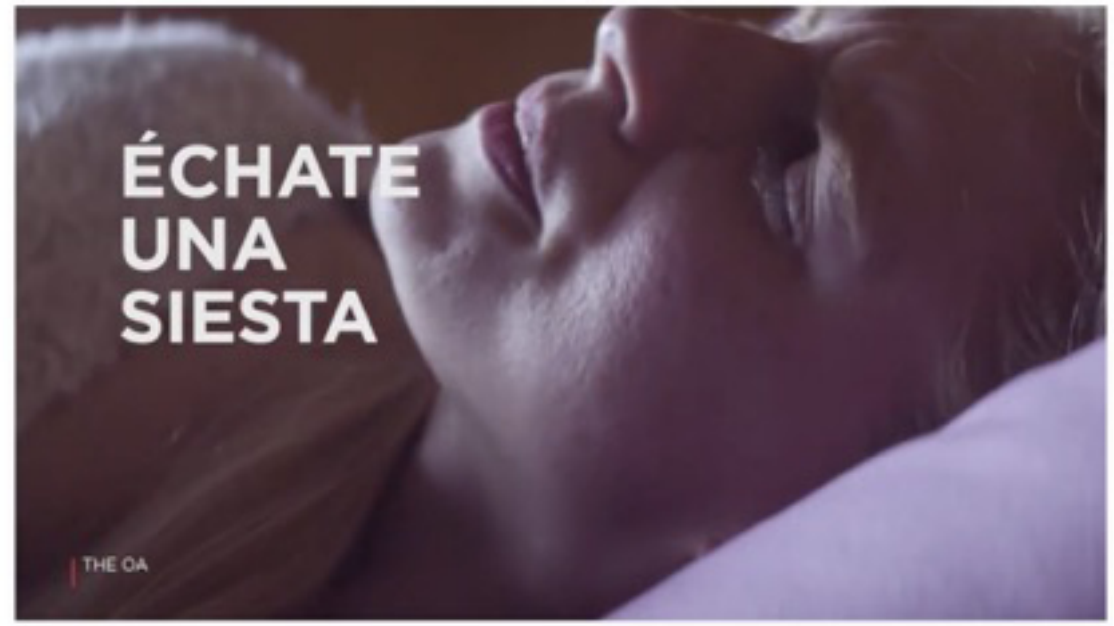

\section{6 reproducciones}

Fuente: elaboración propia.

El principal baluarte en las comunicaciones integradas de marca dentro del caso de Netflix es el marketing de contenidos, o branded content. Se utilizan los contenidos que ofrece la plataforma en todo tipo de acciones de comunicación no intrusivas con el objetivo de conectar de forma relevante con el target. De esta forma se logra afianzar el awareness y la imagen de la marca, además de activar la promesa de una experiencia única. Artículos en prensa, movimientos sociales virales, notoriedad a historias y personajes reales, apps, cameos, autoparodias, eventos o promociones cargadas de polémica son algunos de los principales ejemplos que ilustran el abanico de acciones de marketing de contenido exitoso desarrollado por Netflix. 
Figura 6. Campaña de promoción en Alemania de la serie Santa Clarita Diet

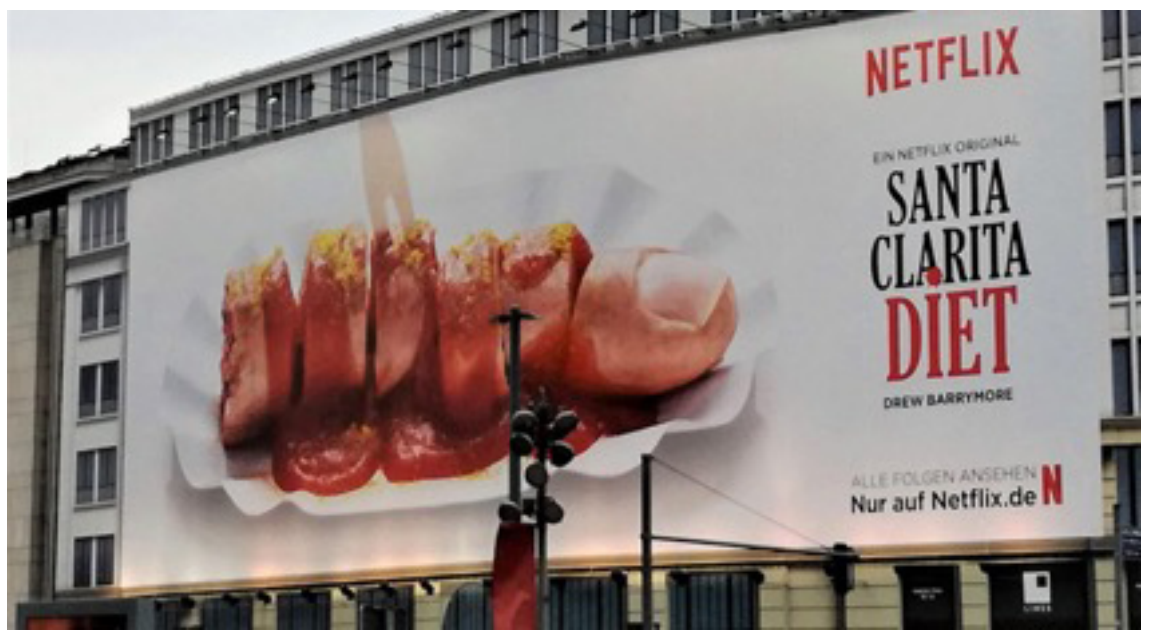

Fuente: Netflix.

Tener el concepto de la marca perfectamente definido y utilizarlo como elemento estratégico a la hora de comunicar permite que Netflix maneje con total naturalidad todos los campos de batalla de la comunicación estratégica, integrando perfectamente tanto la dimensión publicitaria/promocional online como la offline. La estrategia y la creatividad en la comunicación dan valor a las acciones que posteriormente pueden ser desplegadas a través de diferentes soportes. Pasamos de las campañas publicitarias gráficas o audiovisuales más tradicionales a los gifs y el lenguaje de redes sociales, manteniendo en cualquier caso el mensaje sobre el protagonismo de un contenido determinado que se oferta en la plataforma. Pero Netflix va mucho más allá y ha desarrollado campañas de marketing y comunicación innovadoras en el ámbito de la realidad virtual $360^{\circ}$ (Stranger Things), la cocreación junto con otra marca como Google (máquina expendedora que se controla con la mente. Stranger Things), la tecnología face swap (House of cards), las apps (entrenador personal con personajes de series, gifs de sus series, de servicios en temas relacionados con los contenidos que oferta, etc.), inventos para potenciar la experiencia de usuario (los calcetines que pausan tu serie si te duermes, construir el botón de Netflix para automatiza algunas de las tareas necesarias para un agradable visionado de series, etc.) y la producción propia de promociones basadas en la utilización de elementos genuinos de la marca (contar una historia a través del concepto binge watching para la campaña Binge for love de San Valentín). 
Figura 7. Justificante laboral de Netflix para usuarios que han estado practicando binge la noche anterior
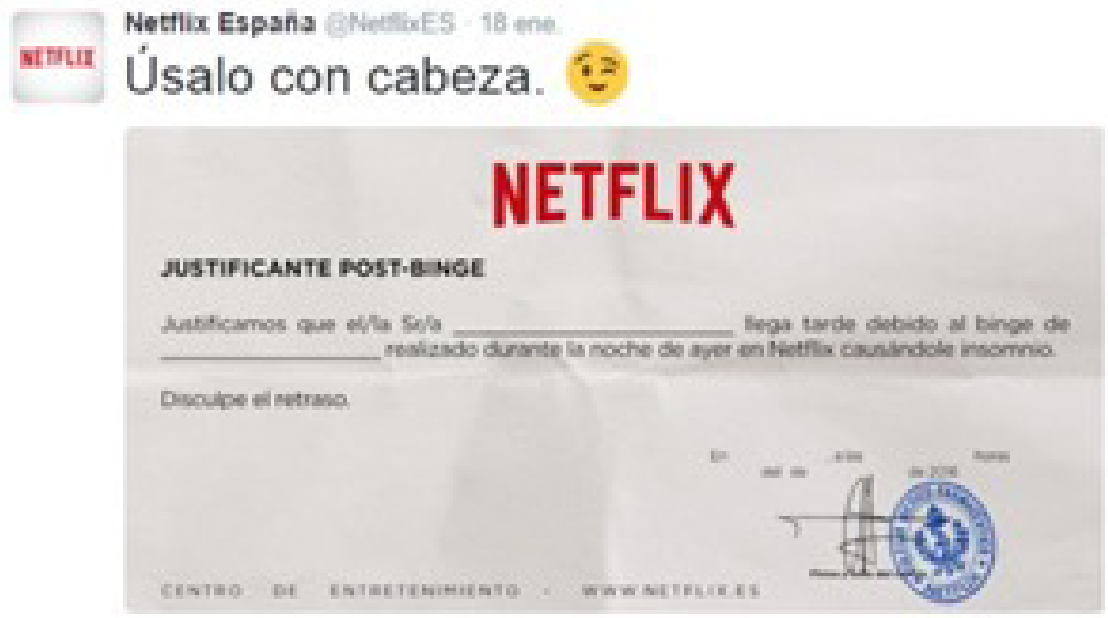

Fuente: elaboración propia.

Los planes de marketing y comunicaciones integradas de marketing son otro punto estratégico de la marca para la toma de decisiones eficaces a través del uso de avances tecnológicos: big data y data management. En este caso el algoritmo de Netflix recoge una serie de información y variables de usuario que ayudan a establecer una tipología determinada a la hora de segmentar para plantear posteriormente acciones concretas de marketing en torno a al protagonismo de los contenidos.

\section{Conclusiones}

Después de realizar el proceso de investigación se han extraído una serie de datos que, tras ser analizados, vamos a presentar de forma ordenada como conclusiones que nos llevarán a dar una respuesta escalonada tanto a los objetivos como a la hipótesis planteada.

Objetivo 1. Acotar la disciplina que da forma al proceso de gestión de marca.

Teniendo en cuenta la problemática atávica existente en torno a la gestión de marcas para lograr un consenso entre expertos que acote la disciplina se crea un cuerpo teórico ad hoc a través de la revisión bibliográfica donde: 
- Se define la gestión de marcas como un proceso estratégico integral, de naturaleza multidisciplinar, que logra alinear de forma coherente todas las acciones y elementos que van a dar forma a la marca frente a la percepción de sus públicos.

- Las características principales que dan forma al proceso de gestión de una marca son: sistema holístico de naturaleza multidisciplinar, proceso estratégico de gestión integral, adaptación al presente y predicción del futuro, propuesta de valor única y diferente de forma coherente, constante y consistente.

- El proceso de gestión estratégica de marca se divide en dos grandes partes: construcción (descubrimiento interno y planteamiento de la estrategia) y comunicación (implementación de la estrategia para contactar la marca con los públicos). Existen otras dos etapas que funcionan de forma subsidiaria a las principales: medición y arquitectura.

Objetivo 2. Estudiar los elementos estratégicos más relevantes dentro del proceso de gestión de la marca Netflix.

En este sentido es imprescindible remarcar la importancia de estudiar los contenidos, y cuál es su papel, dentro de las partes y elementos de constitución en que se divide el proceso.

\section{Construcción de marca}

- La historia de Netflix nos presenta una marca proactiva, dinámica y revolucionaria que pasa de retadora a ser líder global reinventando prácticamente el sector.

- El posicionamiento estratégico de la marca (los mejores contenidos al servicio de los usuarios) y su propuesta de valor pivotan en torno a tres líneas fundamentales: marca global, desarrollo tecnológico (streaming, convergencia de medios en torno a una plataforma de marca online, y gestión de información a través del big data y la conformación de un algoritmo propio) y protagonismo absoluto de los contenidos (de calidad y aumento notable de la producción propia).

\section{Comunicación de marca}

- La estrategia y el concepto conectan con los usuarios a través de una experiencia única en torno a la comunicación de un insight de consumidor que coloca a los contenidos como la pieza fundamental de la promesa de marca. Se utilizan claims complementarios que están perfectamente alineados con la estrategia de comunicación descrita. 
- El trabajo de identidad y comunicación visual gira en torno al protagonismo de los contenidos (ya sea como elementos complementarios o como principales protagonistas dentro de la construcción gráfica).

- El programa de marketing y comunicaciones integradas de marca se adapta perfectamente a la nueva realidad paradigmática, conectando de forma potente con los usuarios a través de nuevas tendencias en comunicación publicitaria online y offline. En todos los casos, los contenidos de la marca son los principales protagonistas en sus comunicaciones.

- La tecnología y el uso del big data se ponen también al servicio de la toma de decisiones en marketing y comunicación. Avala la eficacia en el protagonismo indiscutible de los contenidos.

Hipótesis. Dentro del proceso de gestión de la marca Netflix los contenidos se configuran como un elemento estratégico relevante.

Cumplir con los objetivos de la investigación nos proporciona una serie de argumentos que, tras ser pertinentemente analizados, van a llevarnos hasta la resolución de la hipótesis.

Afirmamos que los contenidos se conforman como un elemento completamente transversal dentro de la estrategia de la marca Netflix. Están presentes a lo largo de toda la historia de la compañía, jugando siempre un papel esencial tanto en la propuesta de valor como en la promesa de la marca.

Dentro del proceso de gestión de la marca los contenidos desempeñan un rol protagonista, siendo absolutamente omnipresentes. Aparecen de forma nuclear a lo largo de todos los elementos que dan forma a la parte de construcción de la marca. En la parte de comunicación se configuran como el elemento primordial que pone en contacto a la marca con los usuarios a través de la promesa de una experiencia única, generando un engagement muy potente. Tanto es así que Netflix es la marca más valorada por los millenials (Merca2.es, 2017).

Concluimos, por tanto, que la hipótesis de trabajo plateada queda totalmente validada ya que los contenidos se configuran como un elemento estratégico absolutamente relevante dentro del proceso de gestión de la marca Netflix.

\section{Referencias}

Aaker, David (2012). Building strong brands. Nueva York: Simon and Schuster.

Aaker, David y Joachimsthaler, Erich (2005). Liderazgo de marca. Bilbao: Deusto. Ahumada, Rafael (2013). La televisión por Internet: de la convergencia a la mutación. En: Quórum Académico, Vol. 10, nº 2. Valencia: Universitat de València, 277-288. 
Munuera Alemán, José Luis y Rodríguez Escudero, Ana Isabel (2007). Estrategias de marketing: un enfoque basado en el proceso de dirección. Madrid: Esic.

Alloza, Ángel (2010). Brand engagement: Marca, experiencia. En: Capriotti, P. y Schulze, F. (eds.), Responsabilidad Social Empresarial,. Barcelona: Colección Libros de la Empresa.

Arandi, Naz (2015). Netflix brand strategy + website. En: http://www.itsnaz.com/ brandstrategy/ (Consultado el 18-07-2019).

Ávalos, Carlos (2010). La marca: identidad y estrategia. Buenos Aires: La Crujía.

Ayestarán, Raquel (2016). Planificación estratégica y gestión de la publicidad. Conectando con el consumidor. Madrid: ESIC.

Ballester, Elena y Sabiote, Estela (2011). Las experiencias de marca: estudio exploratorio de sus consecuencias en la relación consumidor-marca. En: European Journal of Management and Business Economics, Vol. 20, n ${ }^{0}$ 3. Ámsterdam: Elsevier, 121-139.

Benavides, Juan (2017). Los nuevos caminos en la evolución de las marcas. Madrid: Fragua.

Benavides, Juan (2013). A propósito del Brand Management. En: Fernández Gómez, J. (ed.). Estrategia publicitaria y gestión de marcas. Madrid: McGraw-Hill.

Burroughs, Benjamín (2019). House of Netflix: Streaming media and digital lore. En: Popular Communication, Vol. 17, $\mathrm{n}^{0}$ 1. Mahwah: Lawrence Erlbaum Associates, 1-17.

Bustamante, Enrique (2009). De las industrias culturales al entretenimiento. La creatividad, la innovación... Viejos y nuevos señuelos para la investigación de la cultura. En: Diálogos de la Comunicación, Vol. 78. Lima: FELAFACS, 1-25.

Carrillo, Javier (2019). Paradigma Netflix. El entretenimiento de algoritmo. Barcelona: UOC.

Cerviño, Julio y Baena, Verónica (2014). Nuevas dimensiones y problemáticas en el ámbito de la creación y gestión de marcas. En: Cuadernos de Estudios Empresariales, $\mathrm{n}^{\mathrm{o}}$ 24. Madrid: Universidad Complutense de Madrid, 11-50.

Chahal, Mindi (2017). Netflix CEO: Focus more on stories and less on screen size. En: https://www.marketingweek.com/2017/02/28/netflix-mobile-world-congress/ (Consultado el 18-07-2019).

Fernández-Manzano, Eva-Patricia; Neira, Elena y Clares-Gavilán, Judith (2016). Gestión de datos en el negocio audiovisual: Netflix como estudio de caso. En: El profesional de la información, Vol. 4, no 25. Barcelona: El Profesional de la Información, 568-577.

Clifton, Rita (2009). Brands and branding. New York: John Wiley \& Sons. 
Costa, Joan (2013). Los 5 pilares del branding. Anatomía de la marca. Barcelona: CPC Editor.

De Chernatony, Leslie y Lynch, Joanne (2004). The power of emotion: Brand communication in business-to-business markets. En: The Journal of Brand Management, Vol. 11, no 5. Londres: Henry Stewart, 403-419.

De Chernatony, Leslie (2010). Creating powerful brands. Oxford: Routledge.

Diligent Team (2015). Unificación de marca para Netflix global. En: https://www. diligent.es/unificacion-de-marca-netflix/ (Consultado el 18-07-2019).

Eguizábal, Raúl (1998). Historia de la publicidad. Madrid: Eresma y Celeste.

Eguizábal, Raúl (2007). Teoría de la publicidad. Madrid: Cátedra.

EuropaPress (2017). Netflix supera los 100 millones de usuarios. En: http://www. europapress.es/tv/noticia-netflix-supera-100-millones-usuarios-20170718151127.html (Consultado el 18-07-2019).

Fernández, Javier G. (2019). ¿Por qué Netflix necesita más contenido original? En: http://www.expansion.com/economiadigital/companias/2019/05/05/5cc8040d2260 1de1188b45e7.html (Consultado el 18-07-2019).

Fernández Gómez, Jorge (2013). Estrategia publicitaria y gestión de marcas. Madrid: McGraw-Hill.

Fill, Chris y Turnbull, Sara Louise (2016). Marketing communications: brands, experiences and participation. Londres: Pearson.

García, Modesto (2016). Netflix presenta una nueva versión de su logo. En: http:// www.brandemia.org/netflix-presenta-una-nueva-version-de-su-logo (Consultado el 18-07-2019).

Martín García, Manuel (2005). Arquitectura de marcas: modelo general de construcción de marcas y gestión de sus activos. Madrid: ESIC Editorial.

Gretel (2013). Netflix branding. En: http://v4.gretelny.com/project/56/netflix-branding (Consultado el 18-07-2019).

Healey, Matthew (2009). ¿Qué es el branding?. Barcelona: Gustavo Gili.

Heredia, Verónica (2017). Revolución Netflix: desafíos para la industria audiovisual. En: Chasqui, Revista Latinoamericana de Comunicación, $\mathrm{n}^{\circ}$ 135. Quito: Ciespal, 275-295.

Izquierdo-Castillo, Jessica (2015). El nuevo negocio mediático liderado por Netflix: estudio del modelo y proyección en el mercado español. En: El profesional de la información, Vol. 6, n ${ }^{\circ}$ 24. Barcelona: El Profesional de la Información, 819-826.

Kapferer, Jean-Noël (2012). The new strategic brand management: Advanced insights and strategic thinking. London: Kogan page publishers. 
Keller, Kevin Lane; Parameswaran, M. G. y Jacob, Isaac (2011). Strategic brand management: Building, measuring, and managing brand equity. Londres: Pearson Education.

Keller, Kevin Lane (2008). Administración estratégica de marca. Branding. Madrid: Pearson Educación.

Marshall, Catherine y Rossman, Gretchen (1989). Designing qualitative research. Newbury: Sage.

Mayorga, Santiago (2018). La gestión de marca en el contexto universitario español: análisis de los grados de publicidad y relaciones públicas. Tesis doctoral. Salamanca: Universidad Pontificia de Salamanca.

Miguel, Esther (2017). El día en que Netflix decidió traspasar el último límite español en publicidad: ETA. En: https://magnet.xataka.com/en-diez-minutos/el-dia-enque-netflix-decidio-traspasar-el-ultimo-limite-espanol-en-publicidad-eta (Consultado el 18-07-2019).

Netflix Investors (2019). Letter to stakeholders. 2018 Quarterly Earnings. En: https://www.netflixinvestor.com/financials/quarterly-earnings/default.aspx (Consultado el 18-07-2019).

Netflix Media Center (2018). Netflix Timeline. A brief history of the company that revolutionized watching of movies and TV shows. En: https://media.netflix.com/en/ about-netflix (Consultado el 18-07-2019).

Ollé, Ramón y Riu, David (2009). El nuevo brand management: cómo plantar marcas para hacer crecer negocios. Barcelona: Gestión 2000.

Merca2.es (2017). Aviso a navegantes: Netflix, la marca del mundo más valorada por los jóvenes. En: https://www.merca2.es/netflix-marca-valor/ (Consultado el 18-07-2019).

Rosenbaum-Elliott, Richard; Percy, Larry y Pervan, Simon (2015). Strategic brand management. Oxford: Oxford University Press.

Schulkin, Julieta (2019). Claves para comenzar a entender el algoritmo secreto de Netflix. Infobae. En: https://www.infobae.com/america/tecno/2019/03/24/claves-para-comenzar-a-entender-el-algoritmo-secreto-de-netflix (Consultado el 18-07-2019).

Scolari, Carlos Alberto; Fernández de Azcárate, Sara; Garín, Manuel; Guerrero, Mar; Jiménez, Manel; Martos, Aitor; Obradors, Matilde; Oliva, Mercè; Pérez, Óliver y Pujada, Eva (2012). Narrativas transmediáticas, convergencia audiovisual y nuevas estrategias de comunicación. En: Quaderns del CAC 38, Vol. 15, $\mathrm{n}^{\mathrm{O}} 1$. Barcelona: CAC, 79-89.

Stalman, Andy (2014). Brandoffon: el branding del futuro. Barcelona: Grupo Planeta. Statt, Nick (2017). Netflix plans to spend $\$ 8$ billion to make its library 50 percent original by 2018. En: https://www.theverge.com/2017/10/16/16486436/netflix-original-content-8-billion-dollars-anime-films (Consultado el 18-07-2019). 
Summers, Jim; Brecht, Tim; Eager, Derek y Gutarin, Alex (2016). Characterizing the workload of a Netflix streaming video server. En: IEEE International Symposium on Workload Characterization. Piscataway: IEEE Computer Society, 1-12.

Thompson, Nicholas (2003). Netflix's Patent May Reshape DVD-Rental Market. En: http://www.nytimes.com/2003/06/26/business/technology-netflix-s-patent-mayreshape-dvd-rental-market.html (Consultado el 18-07-2019).

Tucker, Matt (2015). La historia de Netflix y el futuro de la televisión. En: http:// www.elrincondemarketing.es/la-historia-de-netflix-y-el-futuro-de-la-television. (Consultado el 18-07-2019).

Vargas, Paulina (2015). Netflix refines responsive design with "The Stack". En: https://webdesignledger.com/netflix-refines-responsive-design-with-the-stack/ (Consultado el 18-07-2019).

Velilla, Javier (2010). Branding. Tendencias y retos en la comunicación de marca. Barcelona: UOC.

Whipps, Kevin (2016). Netflix's new Brand Identity might be the best we've seen all year. En: https://creativemarket.com/blog/netflixs-new-brand-identity-might-bethe-best-weve-seen-all-year (Consultado el 18-07-2019). 



\section{Diez años de investigación en las principales revistas científicas de comunicación. Tendencias y temáticas en las publicaciones de mayor impacto en JCR y SJR. Ten years of research in the highest ranked communication journals. Trends and subjects in JCR and SJR's highest impact publications}

Ángel Vizoso Universidad de Santiago de Compostela

Sara Pérez-Seijo Universidad de Santiago de Compostela

Xosé López-García Universidad de Santiago de Compostela

\section{Referencia de este artículo}

Vizoso, Ángel; Pérez-Seijo, Sara y López-García, Xosé (2019). Diez años de investigación en las principales revistas científicas de comunicación. Tendencias y temáticas en las publicaciones de mayor impacto en JCR y SJR. adComunica. Revista Científica de Estrategias, Tendencias e Innovación en Comunicación, (18), 245-270. DOI: http://dx.doi.org/10.6035/2174-0992.2019.18.12

\section{Palabras clave}

Estudios sobre comunicación; Revistas de la comunicación; Metodologías de investigación; Tendencias en la investigación; Producción científica; Análisis bibliométrico

\section{Keywords}

Communication studies; Communication journals; Research methods; Research trends; Scientific production; Bibliometrics 


\title{
Resumen
}

La comunicación, entendida como campo de estudio y como disciplina, aunque es relativamente joven, ha conseguido una importante madurez en la primera década del siglo XXI como muestra la producción científica y la centralidad que ha conseguido en las sociedades actuales. Este artículo es el resultado de la realización de una Revisión Sistemática de la Literatura científica en las trece revistas académicas del área de la comunicación que ocupan los dos principales rankings de indexación: Journal Citation Reports (JCR) y Scimago Journal \& Country Rank (SJR). Tras el análisis de 5.291 textos, ha sido posible encontrar algunos de los patrones y tendencias que se siguen en la publicación de investigaciones académicas en el campo de la comunicación. De este modo, este artículo muestra cómo algunas de las publicaciones privilegian algunos temas frente a otros. $\mathrm{Al}$ mismo tiempo, se ha identificado un notable crecimiento de la producción académica gracias, en parte, a la facilidad de difusión a través de la incorporación de plataformas de publicación en línea por parte de las revistas científicas. Además, se ha identificado la presencia y evolución de determinadas temáticas a lo largo de los últimos diez años para entender su desarrollo e importancia. Este texto contribuye a la literatura científica centrada en la comprensión de los patrones de publicación y cita entre investigadores mostrando las principales tendencias en la investigación de la comunicación a lo largo de la última década.

\begin{abstract}
Communication, understood as a field of study, is an area with a relatively short history, especially if compared with disciplines like Medicine or Physics. This research article is the result of a Systematic Literature Review of the thirteen-top ranked peer-reviewed journals in the area of communication: Journal Citation Reports (JCR) and Scimago Journal \& Country Rank (SJR). After reviewing 5,291 articles, publishing patterns and thematic tendencies were identified. Thus, this article evidences that some journals privilege some topics over others as well as the rise of the academic research in communication due to the ease of publishing, thanks to online publishing platforms adopted by peer-reviewed journals. Likewise, the presence of many topics across the period of analysis was identified in order to set a general idea about their temporal development through the last ten years. This contributes to the literature corpus related to publication and citation patterns among journals and scholars by highlighting the main trends in communication research in the last decade.
\end{abstract}

\begin{abstract}
Autores
Ángel Vizoso [angel.vizoso@usc.es] es Investigador en Formación en el grupo de investigación Novos Medios de la Universidade de Santiago de Compostela. Sus trabajos se centran fundamentalmente en el área de la visualización de la información,
\end{abstract}


el fact-checking y la producción periodística en los cibermedios. Es, además, beneficiario del Programa de Formación del Profesorado Universitario del Ministerio de Ciencia, Innovación y Universidades (Gobierno de España).

Sara Pérez-Seijo [s.perez.seijo@usc.es] es Investigadora en Formación del grupo Novos Medios de la Universidade de Santiago de Compostela. Sus trabajos se centran en el estudio del Periodismo Inmersivo y las nuevas formas de producción multimedia e interactiva en los cibermedios. Además, es beneficiaria del Programa de Formación del Profesorado Universitario del Ministerio de Ciencia, Innovación y Universidades (Gobierno de España).

Xosé López-García [xose.lopez.garcia@usc.es] es Catedrático de Periodismo en el Departamento de Ciencias de la Comunicación de la Universidade de Santiago de Compostela. Desde el año 1994 ejerce como coordinador del grupo de investigación Novos Medios, cuyas líneas de investigación se centran en el estudio de los medios digitales e impresos y el análisis del impacto de la tecnología en la comunicación mediada entre otras.

\section{Créditos}

Este artículo se ha elaborado en el marco del proyecto «Cibermedios nativos digitales en España: formatos narrativos y estrategia móvil» (Referencia RTI2018093346-B-C33), del Ministerio de Ciencia, Innovación y Universidades, y cofinanciado por el Fondo Europeo de Desarrollo Regional (FEDER). Forma parte también de las actividades del grupo de investigación Novos Medios (GI-1641) de la Universidade de Santiago de Compostela, apoyado por el Programa de Consolidación e Estruturación de Unidades de Investigación Competitivas de la Xunta de Galicia (Referencia: ED431B 2017/48). Los autores Ángel Vizoso y Sara Pérez-Seijo son, además, beneficiarios del Programa de Ayudas para la Formación del Profesorado Universitario (FPU), financiado por el Ministerio de Educación, Cultura y Deporte (Gobierno de España). 


\section{Introduction}

Communication is both a research field and a discipline (de Moragas, 2011) with a short history, especially if compared with disciplines such as Medicine or Physics. On this basis, many authors set communication research as a subject of the 20th century (Carlson, Robinson, Lewis y Berkowitz, 2018). However, in the last few years, we have witnessed a significant growth in communication journals and communication research. The expansion of communication studies and faculties among international Universities and the need of researchers and professors for those formation centres have been crucial in the development of this field.

Likewise, the current panorama is influenced by the birth of new publications and the increase in production of those still running. It constitutes a dual response both for the increasing number of authors and the ease for publishing through the Internet. Thanks to the web publishing, it is possible to reach new audiences globally, as print issues are not needed. At the same time, publishing in the highest ranked journals - frequently set in countries such as the United States or United Kingdom - is now a more realistic possibility than twenty or thirty years ago, when logistics were more complex.

Our study aims at establishing patterns around the most studied subjects in communication research in the period 2008-2018. Through a systematic analysis of the production in the thirteen journals that take up the first ten publications of the Journal of Citation Reports (JCR) and Scimago Journal \& Country Rank (SJR), a classification of the articles in different categories was established.

Findings of the study could be useful for understanding current trends in the study of communication, as well as its recent development. In the same way, results provide an overview of emergent topics and fields of study, as well as of those areas of less interest for both researchers and journals. Thus, the research addresses some of the key areas in communication research fields and discusses future directions for them.

\section{Literature Review}

\subsection{Overview on communication research field}

Communication as an object of study is, unlike other disciplines, a very recent field of research. Barnett, Huh, Kim, and Park (2011) showed, following Berger, Roloff, and Roskos-Ewoldsen (2009), that communication joined social sciences later, in contrast with other branches of knowledge. This idea is supported by Bruhn Jensen (2018) when he sets how:

«The field of communication research was a product of the twentieth century, as social-scientific and humanistic traditions joined forces to account for the technologically mediated condition in which humans learn from the past, asses the present and imagine the future, so as to make their own history". 
Michael Meyen (2015) supports the idea of this delay in the integration of communication in social sciences. The author turns to Abbott's Chaos of Disciplines (2002) to establish that research in areas like sociology, economics, psychology and political science is considerably older than research in communication. Likewise, the author sets that the birth of the field is the product of both political and economic interests (Meyen, 2015).

Juha Koivisto et al. (2008) conducted a large study to identify the main trends, institutions and challenges that shape the fields of communication and media research. In order to have a complete overview of this domain, the authors established the beginning in the emergence of communication university courses and faculties, specifically in the academic training started in the United States by the decade of 1870s. In Europe, «the first European university courses in journalism were held in Paris as early as $1899 »$ (Koivisto et al., 2008). However, it was not until the second decade of the twentieth century when this kind of studies proliferated. Therefore, there is almost a thirty years lag in the beginning of regular academic formation between the United States and Europe. The difference foresees one of the present characteristics of the communication research field nowadays: the prevalence of the United States in universities and journals, as we will mention below.

Besides the fact that the study and research in communication was considered part of social sciences later than other disciplines like political science, psychology and economics, the area presents, since its very beginning, a remarkable dichotomy. From the first steps of research in communication, scholars have discussed about the division between mass and interpersonal communication (Rogers \& Chaffee, 1983; Delia, 1987; Park \& Leydesdorff, 2009). It was considered that both fields had different natures. However, there are studies that defend integration instead of division of mass and interpersonal communication (Berger \& Chaffee, 1988; Wiemann, Pingree \& Hawkins, 1988). The cited authors were aware of the complexity of the field, and tried to bring together both mass and interpersonal communication to better understand the of communication processes.

In addition to the enormous complexity of communication as a field integrated in the area of social sciences, there are also many objects of study. As Vidales notes, there are a «diversity of looks, objects and agendas» (Vidales, 2015) which make communication a particular and diverse field of study where many different approaches of many different problems and situations are possible (Martín-Algarra, 2009). We therefore attend to the constant development of new approaches and frameworks that are highly connected to the different contexts where communication processes take place. Thus, it is very influenced by circumstances like «national traditions, methodological loyalties, long-running skills-or-scholarship disputes, mixed disciplinary roots, subfield chauvinisms, and North-South disparities» (Pooley \& Park, 2012).

Because of the noted dichotomy and the fragmentation of the field, in the first steps of the research in communication, there was a discussion about the direction of in- 
vestigations. Different research organizations were born in order to connect researchers from different parts of the world. Thus, international and national collectives such as the International Communication Association (ICA) or the International Association for Media and Communication Research (IAMCR) emerged. However, although these initiatives began with the objective of put together researchers from different countries, in the years after the World War II a deep ideological debate was conducted inside one of the biggest associations: the cited IAMCR. Meyen (2015) shows how, in the years of the Cold War, IAMCR conferences were spaces for ideological battlefields between members of the association who wanted to apply their ideological tendency to the study of communication by privileging some topics over others. Thus, as we can see, the development of a research field is highly related to the context and the ideological predominance of those who are studying it. Therefore, changes are frequent and common, because they enrich the advance of investigations by adopting different paradigms.

With the objective of communicate and spread the findings of researchers all around the world, academic journals were born many years after the development of communication as a research field. Thus, we can find the first samples of academic journals in the second half of the seventeenth century. They represented a significant improvement in the communication of researchers' results. Before the emergence of regular academic publications, researchers used to interchange letters with their colleges in order to know more about their investigations. However, the expansion of the movable type printing modified the communication of science with the introduction of academic journals, easier to print and disseminate due to the new printing system. Examples of publications in this period are Le Journal des Scavans (France, 1665), Philosophical Transactions of the Royal Society (United Kingdom, 1665), or Acta Eruditorum (Germany, 1682) (Castillo-Esparcia, RubioMoraga \& Almansa-Martínez, 2012).

If we pay attention to the specific field of communication research, we can see how it is deeply linked to the invention of the printed press (Meyen, 2015). Thereby, Michael Meyen (2015) highlight the fact that in the first steps in the development of newspapers, communication studies were dominated by outsiders like novelists, theologians or others who wrote about the topic. It was not until 1690 when Tobias Peucer defended the first dissertation addressing communication at the University of Leipzig.

Nowadays, researchers work in the era of the digitalisation of contents. Contributions from colleagues all around the world are available through the Internet. Accessing contents from investigations of every research fields - even works in progress - is easier than ever thanks to the development of academic social networks as well as the indexation in databases. As a result, researchers have a lot of contents located in the same platform, which opens a new amount of possibilities when they are trying to make progresses in their findings (Vilches, 2011: 21). 


\subsection{Different approaches in the study of communication}

We look now into the meta-research in communication. We will try to set an overview of the recent published literature focused on the analysis of the published research in academic communication journals. Thus, as we will see, there are many different approaches for study this area, each one valid but also with its particularities.

One of the possibilities for the analysis of a particular research field is the scrutiny of different topics and subjects addressed (Montero-Díaz et al., 2018). Thus, in the particular case of communication, it is possible to find articles that try to delve into the literature of many different themes. Examples of this could be those centred in investigations on the Internet (Tomasello, Lee \& Baer, 2010; Borah, 2017), advertising (Benavides Delgado, 2012; Baladrón-Pazos, Correyero-Ruiz \& Manchado Pérez, 2014; Avant, Kim \& Hayes, 2017), communication ethics (Díaz-Campo \& Segado-Boj, 2017), social media (Ha et al., 2015), communication theories like framing (Borah, 2011), and mobile communication (Kim et al., 2017). These are just a few samples of investigations conducted with the objective of identifying the state of research of the issue in question.

Another possible approach is the bibliometric study of the academic production in one particular area. In the case of communication as a research field, we can see different types of investigations. Examples of this could be those focused in the cocitation patterns among authors (Piedra-Salomón, 2010; 2015), the existence of citation networks among the main authors of the field (Barnett, Huh, Kim, \& Park, 2011), number of authors per text and affiliation (Fernández-Quijada \& Masip, 2013) and the existence of differences in publishing between scholars from leading countries in research and those situated in the periphery (Demeter, 2017). In the same way, we can easily find studies on the use of particular methodologies during investigation processes (Castillo-Esparcia Rubio-Moraga, and Almansa-Martínez, 2012). Lastly, there are a lot of contributions which try to show trends in different academic journals in a certain period of time (Bryant \& Miron, 2004; Roca-Correa \& Pueyo-Ayhan, 2012; Bermejo-Berros, 2014) and country (de-Filippo, 2013; Martínez-Nicolás \& Saperas-Lapiedra, 2016). This kind of studies are very useful to understand the recent development of a field such as, in this case, communication. Contributions like these are a good basis for the implementation of new research lines, as they can access previous works in the matter of study.

\subsection{Communication research nowadays}

We turn now to the present to look into the current trends in the study of communication. In this point, we follow Peter Simonson and David W. Park when they point out how:

«Communication and media studies are at a key historical moment, occasioned by the everwidening recognition of the social significance of their subject matters, the continued structural transformation of higher education, and the rapid growth of the field around the world» (Simonson \& Park, 2016: 2). 
Therefore, according to Simonson and Park, communication and its study are now more important than ever. It occurs due to the rapid growth of the field as well as the birth of new spaces and platforms where communication processes take place. Although communication is a very diverse and fragmented field (Vidales, 2015; Montero-Díaz et al., 2018), there is a growing interest in its study (Díaz-Campo \& Segado-Boj, 2017). Thus, in the last two decades we have seen the rise of meta-research in this area with handbooks and papers focused on the analysis of previous works related with communication processes, tools, theories, and spaces (RodrigoAlsina, 2001; Tomasello, 2001; Bryant \& Miron, 2004; Cappella, 2017).

As noted before, the growth and spread in communication research is closely linked to the foundation of communication schools and university courses. Since the last two decades of the past century, the spread of communication schools provoked the rise of research in this area as well as the foundation of new journals and conferences where researchers could show their findings (de-Filippo, 2013). Communication, like other research field, is nowadays a very dynamic field where «researchers retire, but more new researchers emerge. Journals fold, but a higher number are launched» (Jinha, 2010).

However, if we pay attention to the geographical and linguistic development of this particular research field, we can see how there are two zones and speeds in the study of communication. First of all, we are in front of a very US-centred discipline (Meyen, 2015) with certain - but lower - presence of some European countries like United Kingdom, Germany, France and Spain. In terms of language, English is the main language of the field, and there are fewer journals in other languages in the top positions of the main indexation ranks. For instance, Comunicar, which is issued both in Spanish and English, is in the 12th position of the Journal Citation Reports - in the communication category - , but there are not more examples like this in the first 25 places of the index. Likewise, this journal is ranked in the 25th position of the Scimago Journal and Country Rank, being the very first journal not just issued in English.

Finally, in order to meet the objective of this section, which is drawing a general panorama about the current characteristics of communication studies, we have to emphasise that, in the last few years, communication studies have changed their scope a little bit. In the first years of the new millennium, communication research was dominated by studies focused on traditional broadcast and print media (Kamhawi \& Weaver, 2003). The introduction and development of a new medium, the Internet, has changed this paradigm (Borah, 2017). Nowadays, research in communication highlights the expansion and maturing of the Internet, describes the characteristics and potentialities of Social Networks Sites and tries to find the relation between the use of new devices and human communicative processes. 


\subsection{The particular case of Spain}

In the last section of the literature review, we put our scope in the particular case of the Spanish academic production (Martínez-Nicolás \& Carrasco-Campos, 2018). It constitutes a remarkable reality because in the last few years it has experimented a rapidly growth due to the requirements for the accreditation of the six-year terms of academic experience. Hence, researchers have to prove their best achievements so they try to publish in the highest ranked journals in order to have bigger merits.

This situation resulted in a rise in the production of academic literature from Spanish researchers in every single area of knowledge, and communication is not an exception. For example, Fernández-Quijada and Masip (2013) found that in 2010 the academic production of research in communication was the tenth part of the total registered in the previous thirty years. It is an important measure, because it is necessary to note that communication faculties in Spain were not regularly established until the decade of 1970 (Fernández-Quijada, Masip \& Bergillos, 2013).

Therefore, Spanish scholars have to combine their research with the constant objective of publishing in the highest ranked journals to achieve better marks in the accreditation process. Thus, since 1970, communication as a research field has experimented the birth of many journals as well as the publishing of monographs and guidebooks. It is a consequence of both the necessity of results of Spanish researchers and the rise and development of communication studies in Spain.

In terms of the thematic division of communication studies, Spanish researchers in communication opt for the study of media content, following a «traditional or conservative pattern» (Martínez-Nicolás \& Saperas-Lapiedra, 2016) focused on the analysis of practices and products. The explanation of this phenomenon could be the fast-paced production process of the academic research due to the noted necessities for the recognition of the scholars' achievements.

\section{Method}

The methodology used in this article was the methodological triangulation, through the combination of qualitative and quantitative methods. The first step was the performance of a Systematic Literature Review (SLR), according to the disposed by Lluís Codina (2017). This technique lets «identifying, evaluating, and interpreting available data on a particular research field within a period of time» (RamírezMontoya \& García-Peñalvo, 2018). This particular analysis was focused on the journals ranked in the first ten positions of the Journal Citation Reports (JCR) and the Scimago Journal \& Country Rank (SJR). Although there are many different ranks, both JCR and SJR are the most renowned and used to establish the impact factor within academic journals of any subject. As part of this review, content analysis was conducted in order to find out the main trends in publishing of the analysed journals. 
As told before, the analysis was centred in the first ten positions of each rank in their communication categories. Here, Journal Citation Reports offers 79 results and Scimago Journal \& Country Rank, 294 (on May 2nd, 2018). After selecting the category, it was observed that the number of journals of the sample would be 13 because New Media \& Society, Journal of Communication, Communication Research, Journal of Advertising, Communication Theory, Information, Communication \& Society and Political Communication are part of both indexes. Likewise, Journal of Computer-Mediated Communication, Media Psychology and Public Understanding of Science are ranked in the first ten positions of the Journal of Citation Reports while Research on Language and Social Interaction, International Journal of Press/Politics and Public Opinion Quarterly are ranked in the first ten places of the Scimago Journal \& Country Rank.

After the establishment of the sample, the period of analysis was set between January 2008 and April 2018. This period constitutes a good example of development in many fields of communication research like the expansion of social network sites and the technical improvements in mobile communications and the Internet. At the same time, authors wanted to know how the interest on some topics and areas was decreasing and increasing with the changes and whether there were room for studies in growing areas such as information visualization, fact-checking and mobile journalism. 
Table 1. Analysed categories

\begin{tabular}{|c|c|}
\hline Category name & Built-in items \\
\hline 1. Use of the Internet & Privacy, functionalities, safety, user rights, anonymity \\
\hline 2. Social Media & $\begin{array}{l}\text { Uses, effects of the use, social media platforms } \\
\text { characteristics }\end{array}$ \\
\hline 3. Mobile Communication & $\begin{array}{l}\text { Smartphone and cell phone use, mobile applications, effects } \\
\text { of using smartphones }\end{array}$ \\
\hline $\begin{array}{l}\text { 4. Interpersonal } \\
\text { communication }\end{array}$ & $\begin{array}{l}\text { Interpersonal communication and, construction of } \\
\text { community }\end{array}$ \\
\hline $\begin{array}{l}5 . \text { Discourse, content and case } \\
\text { analysis }\end{array}$ & $\begin{array}{l}\text { Research articles based on discourse, content, and case } \\
\text { analysis. }\end{array}$ \\
\hline 6. Fact-checking & Fact-checking, misinformation, and information verification. \\
\hline 7. Information visualization & Information visualization and design \\
\hline 8. Audience studies & Studies related with audience measures \\
\hline $\begin{array}{l}\text { 9. Use, effects, and media } \\
\text { reception and public opinion }\end{array}$ & $\begin{array}{l}\text { Studies related with the use of the media, its effects and its } \\
\text { reception and analysis about public opinion }\end{array}$ \\
\hline $\begin{array}{l}\text { 10. Information and } \\
\text { Communication Technologies }\end{array}$ & $\begin{array}{l}\text { Studies related with the influence of Information and } \\
\text { Communication Technologies in communicative processes: } \\
\text { search engines, software, digital divide, digital literacy, or } \\
\text { video games }\end{array}$ \\
\hline $\begin{array}{l}\text { 11. Communication } \\
\text { management }\end{array}$ & Organizational, crisis, and corporative communication \\
\hline $\begin{array}{l}\text { 12. Big Data and data } \\
\text { journalism }\end{array}$ & $\begin{array}{l}\text { Studies related with the development of Big Data techniques } \\
\text { in communicative processes }\end{array}$ \\
\hline 13. Transparency & Organizational and governmental transparency \\
\hline 14. Communication theories & $\begin{array}{l}\text { Communication theories, research methodologies, and } \\
\text { literature reviews }\end{array}$ \\
\hline 15. Production processes & $\begin{array}{l}\text { Work with journalistic sources, gatekeeping processes, and } \\
\text { news diffusion }\end{array}$ \\
\hline 16. Traditional media & Print newspapers and traditional broadcasting \\
\hline 17. Online media & Characteristics and production processes in online media \\
\hline 18. User-Generated Content & $\begin{array}{l}\text { Crowdsourcing, user comments, blogosphere, and co- } \\
\text { creation sites }\end{array}$ \\
\hline $\begin{array}{l}\text { 19. Funding and informative } \\
\text { enterprise management }\end{array}$ & $\begin{array}{l}\text { Entrepreneurial management of informative business, new } \\
\text { concepts and strategies for informative enterprises }\end{array}$ \\
\hline 20. New narratives & Transmedia, crossmedia, virtual reality, augmented reality \\
\hline $\begin{array}{l}\text { 21. Citizen's participation and } \\
\text { mobilization }\end{array}$ & Activism, protests, and social movements \\
\hline 22. Advertising & Advertising, marketing, e-commerce, and public relations \\
\hline 23. Legislation and regulations & Censoring, copyright, piracy, press freedom \\
\hline $\begin{array}{l}\text { 24. New content distribution } \\
\text { platforms }\end{array}$ & $\begin{array}{l}\text { Studies related with the development of new platforms for } \\
\text { content distribution like Netflix or Amazon }\end{array}$ \\
\hline
\end{tabular}

Source: created by authors 
The following step in the construction of the analysis method was the identification of those articles that would be present in the sample. In order to solve this question, only original research articles were analysed, not book reviews, editorials, introductions, summaries and other type of contents. The number of articles analysed was 5.291, divided among 735 issues between January 2008 and April 2018. In order to classify the obtained articles as accurate as possible, 24 categories were set, as showed in Table 1.

The authors were aware that many articles could fix in more than one category. However, each article was assigned to the category in which it fit best after reading its title, abstract and keywords. After that, the obtained data were processed using Microsoft Excel, in order to obtain thematic tendencies among the analysed journals as well as the representation of each research field into the sample during the selected period.

In the qualitative side of the used methods, a micro-discussion group among Journalism academics was conducted after the data collection. For executing this method, four researchers discussed the configuration of the analysis card as well as the categorization of each article. After the review, they were asked about the possibilities and the development of communication as a research field. The use of this tool to discuss the findings of our research will help us in our objective to establish the growing potential of some research subjects. At the same time, it constitutes a good technique for understanding the path of the decreasing themes as well as the current trends in communication research.

With the available data from these two steps of the investigation, an interpretative analysis was conducted. The identification of the key elements from the obtained data was followed by a reasoning aimed at setting conclusions around the present and future of communication research. Hence, an analytical study based on empirical data as well as a bibliographical review of academic text related with the investigation on communication, citations analysis, and bibliometric studies was conducted in order to understand the recent development of this area to foresee the future of communication research.

After establishing the methodology for the study, three research questions were set:

- RQ1: Which are the publishing patterns of academic communication journals?

- RQ2: Which are the main issues addressed in recent research in communication?

- RQ3: What is the development of the addressed issues during the period of analysis?

- RQ4: Is there any particular thematic specialisation across the different journals?

These questions conducted our analysis in order to discover the main characteristics of recent research in communication. In the next section, results of this work will be shown for its subsequent discussion and the establishing of conclusions related with the matter of study. 


\section{Results}

As told before, this study is the result of a Systematic Literature Review of 735 issues of thirteen high ranked in the top-ten positions of the two main citation indexes: Journal Citation Reports (JCR) and Scimago Journal \& Country Rank (SJR). In this section, thanks to the obtained data, we will answer our three research questions in order to be able to demarcate the main tendencies of communication research during the past ten years.

\subsection{Publishing patterns of academic communication journals}

In the first stage of our results, we pay attention to the publishing patterns of the thirteen analysed journals. Thus, we can see how every publication has, at least, four issues per year. The following chart contains the number of issues per year published by the thirteen main communication journals:

Table 2. Number of issues per year

\begin{tabular}{|l|c|c|c|c|c|c|c|c|c|c|c|}
\hline & 2008 & 2009 & 2010 & 2011 & 2012 & 2013 & 2014 & 2015 & 2016 & 2017 & 2018 \\
\hline $\begin{array}{l}\text { New Media \& } \\
\text { Society }\end{array}$ & 6 & 8 & 8 & 8 & 8 & 8 & 8 & 11 & 11 & 12 & 3 \\
\hline $\begin{array}{l}\text { Journal of } \\
\text { Computer- } \\
\begin{array}{l}\text { Mediated } \\
\text { Communication }\end{array}\end{array}$ & 4 & 4 & 4 & 4 & 4 & 4 & 3 & 6 & 6 & 6 & 0 \\
\hline $\begin{array}{l}\text { Journal of } \\
\text { Communication }\end{array}$ & 4 & 4 & 4 & 6 & 6 & 6 & 6 & 6 & 6 & 6 & 0 \\
\hline Media Psychology & 4 & 4 & 4 & 4 & 4 & 4 & 4 & 4 & 4 & 4 & 2 \\
\hline $\begin{array}{l}\text { Communication } \\
\text { Research }\end{array}$ & 6 & 6 & 6 & 6 & 6 & 6 & 8 & 8 & 8 & 8 & 3 \\
\hline $\begin{array}{l}\text { Journal of } \\
\text { Advertising }\end{array}$ & 4 & 4 & 4 & 4 & 4 & 4 & 4 & 4 & 4 & 4 & 1 \\
\hline $\begin{array}{l}\text { Communication } \\
\text { Theory }\end{array}$ & 4 & 4 & 4 & 4 & 4 & 4 & 4 & 4 & 4 & 4 & 0 \\
\hline $\begin{array}{l}\text { Information, } \\
\text { Communication } \\
\text { and Society }\end{array}$ & 8 & 8 & 8 & 8 & 9 & 10 & 10 & 12 & 12 & 12 & 7 \\
\hline $\begin{array}{l}\text { Public } \\
\text { Understanding of } \\
\text { Science }\end{array}$ & 4 & 6 & 6 & 6 & 8 & 8 & 8 & 8 & 8 & 8 & 3 \\
\hline $\begin{array}{l}\text { Political } \\
\text { Communication }\end{array}$ & 4 & 4 & 4 & 4 & 4 & 4 & 4 & 4 & 4 & 4 & 2 \\
\hline $\begin{array}{l}\text { Rescarch on } \\
\text { Language and } \\
\text { Social Interaction }\end{array}$ & 4 & 4 & 4 & 4 & 4 & 4 & 4 & 4 & 4 & 4 & 1 \\
\hline $\begin{array}{l}\text { International } \\
\text { Journal of } \\
\text { Press/Politics }\end{array}$ & 4 & 4 & 4 & 4 & 4 & 4 & 4 & 4 & 4 & 4 & 1 \\
\hline $\begin{array}{l}\text { Public Opinion } \\
\text { Quarterly }\end{array}$ & 5 & 5 & 5 & 5 & 4 & 5 & 5 & 5 & 5 & 5 & 1 \\
\hline *2018's results were collected until April only. & 4 & 4 & 4 & & & & & & & \\
\hline
\end{tabular}

*2018's results were collected until April only.

Source: created by authors 
As Table 2 shows, seven journals maintained their publishing patterns during the period of analysis. They were Media Psychology, Journal of Advertising, Communication Theory, Political Communication, Research on Language and Social Interaction, International Journal of Press/Politics, and Public Opinion Quarterly. Journals which maintained their tendency during these ten years published mainly four issues per year, with the exception of Public Opinion Quarterly with five issues per year.

On the other side, we can see that six journals increased their production to a greater or lesser extent. They are New Media \& Society, Journal of ComputerMediated Communication, Journal of Communication, Communication Research, Information, Communication \& Society, and Public Understanding of Science. Thus, journals such as New Media \& Society and Information, Communication \& Society increased their production from 6 and 8 numbers per year respectively in 2008 to 12 in 2017, being the more productive outlets among the thirteen ranked in the top ten positions of Journal Citation Reports and Scimago Journal \& Country Rank, as Figure 1 shows:

Figure 1. Issue production between January 2008 and April 2018

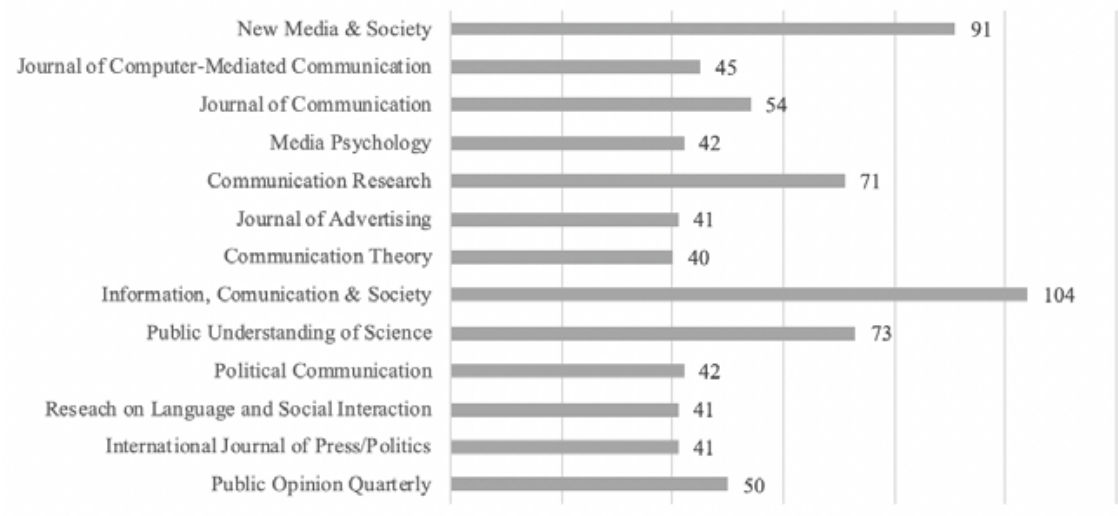

Source: created by authors

As far as the number of articles published by each journal in the period of analysis is concerned, we obtained very similar results. New Media \& Society and Information, Communication \& Society were the most prolific journals with 851 and 737 research articles published between January 2008 and April 2018, as shown in Figure 2: 
Figure 2. Article production per journal between January 2008 and April 2018

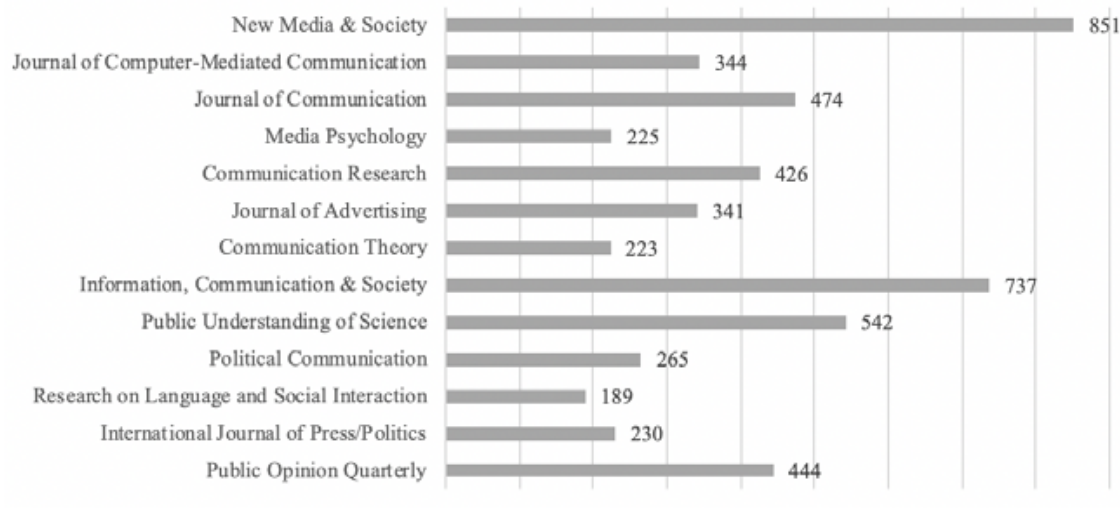

Source: created by authors

As Figure 1 and Figure 2 show, there is a correlation between the number of issues published by a journal and the final number of articles of the outlet. It is important to start this analysis displaying data around the publishing patterns of academic journals. Recently, we have attended to the explosion of new technologies, which affected publishing industry too. Nowadays, academic journals can spread their message through the Internet, without the logistic limitations provoked by the print processes a few years ago. Thus, we can see how the tendency among communication journals is to increase the number of issues and, as a consequence, the number of articles available for their audiences.

\subsection{Main issues addressed in recent research in communication}

The objective of this second Research Question to understand the main trends in communication research. Therefore, we pay attention to the presence of the twenty-four categories highlighted in the method section along our sample. As told before, the authors are aware that many articles could fit perfectly in more than one category and, of course, that a deeper thematic division could be displayed. However, the introduction of more topics could harm the understanding of the study by making difficult dealing with it. Figure 3 contains the results from the analysis of the thematic division of the 5,291 reviewed articles: 
Figure 3. Thematic division of published articles

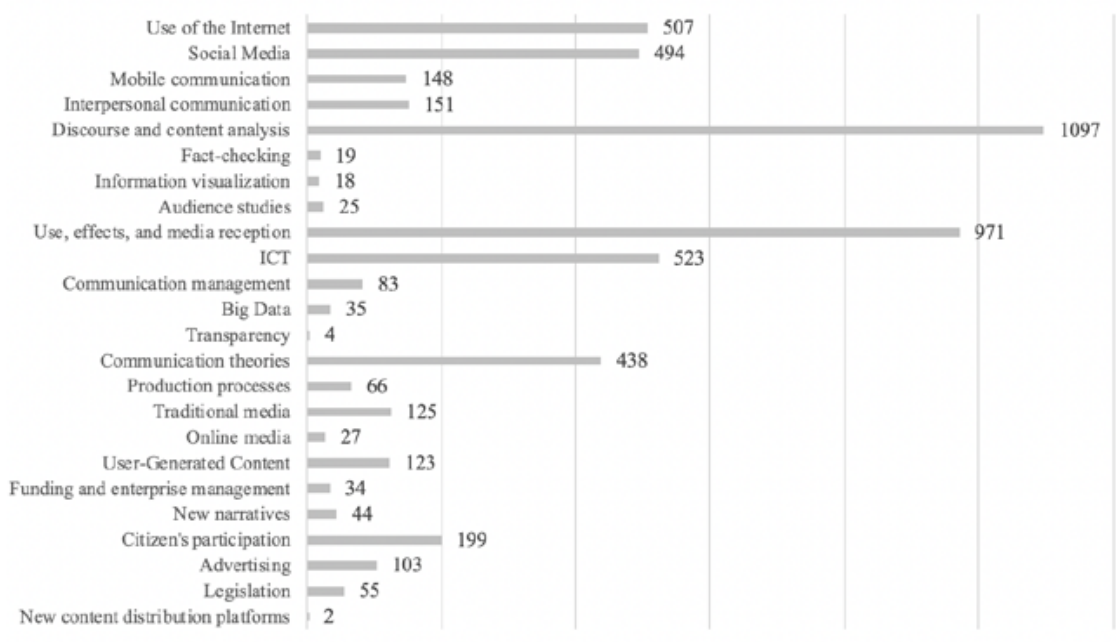

Source: created by authors

As Figure 3 shows, discourse, content and case analysis are the main types of articles among the reviewed ones -1,097-. It is followed by the analysis of the use, effects, media reception, and public opinion, with 971 matches in the sample. Articles focused on the development of new technologies such as the use of the Internet -507 examples—, Social Media -494 articles — and the influence and use of Information and Communication Technologies in communicative processes - 523 examples - are part of the second step in terms of presence. Communication theories and methodologies with 438 examples in the sample is another important subject of study for communication researchers.

In contrast, we found that if we look into the thirteen high-ranked communication journals, there are issues with lower - and even residual- presence. This could be the case of studies related to growing disciplines and fields of study like Big Data, fact checking or information visualization which, in the following years, are supposed to grow exponentially in practically and theoretically. However, our study shows how these topics, as well as others with low presence, have not been deeply studied by scholars. Some explanations for this phenomenon could be the novelty of the fields of study, the specialization of the journals in some particular fields and the publication of the research related with these issues in specialized journals ranked out of the top-ten positions of the main indexes. In the next section, we will try to explain the development of some of the analysed themes by explaining its presence in academic journals in the last ten years. 


\subsection{Development of the addressed issues during the period of analysis}

We review in this section the development of the most present topics in articles published. As noted before, the six main issues treated by the analysed journals were: discourse, content, and case analysis; use of the Internet; Information and Communication Technologies; use, effects, reception of the media and public opinion; Social Media; and communication theories. Figure 4 displays its progress during the last ten years.

Figure 4. Development of the most studied subjects

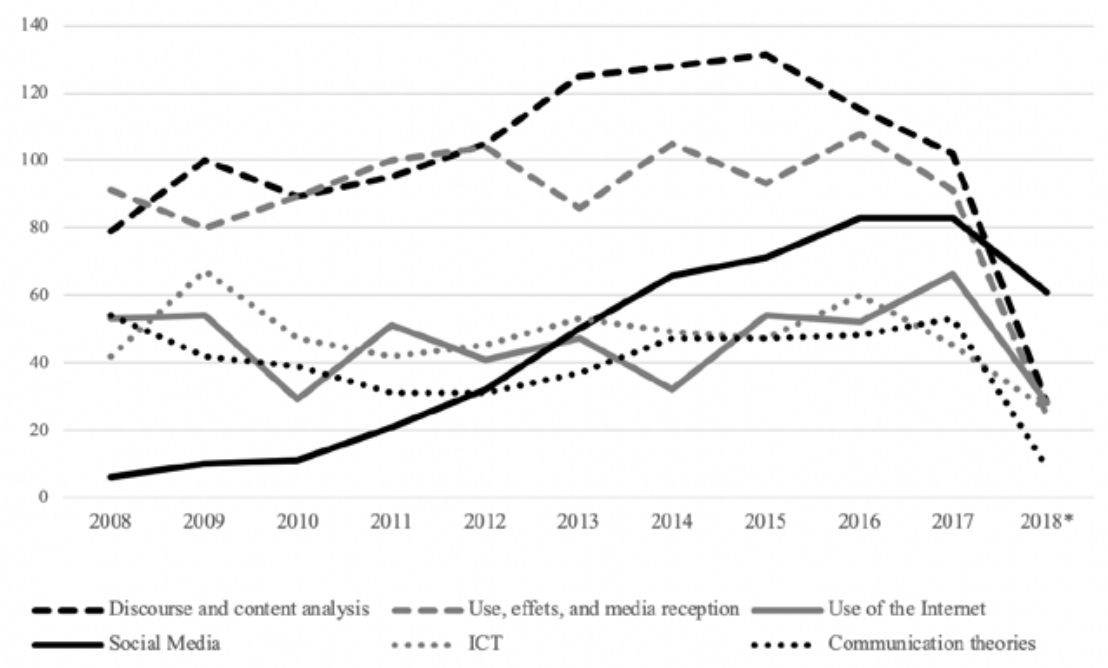

*2018's results were collected until April only.

Source: created by authors

Figure 4 shows many interesting patterns and tendencies in the last few years. Especially attractive is the case of Social Media studies. As we can see, the black line starts in a very low position, due to the publication of only six articles related with this matter in 2008. However, during the years the growth was consistent and, in 2017 - the last complete year of the analysis-, the highest ranked communication journals published 83 articles related with Social Media platforms and its characteristics and applications into communicative processes. If we look into the current year, between January and April 63 articles have been published yet. Thus, research on Social Media is supposed to increase in number at the end of 2018. 
Discourse, content and case analysis studies have experimented a growth between 2012 and 2015. However, this category shows more homogeneous values than Social Media studies. Something similar occurs with texts focused on the use of the Internet; Information and Communication Technologies; communication theories; and use, effects, media reception and public opinion. Those fields of study show very homogeneous tendencies and, although it exists variation through the years, they have been highly studied consistently.

\subsection{Thematic specialisation across the different journals}

As noted by Borah (2017), the merge of different spaces and platforms where communication is possible turns out in the growth of academic journals related with many particular topics. This could be the case of the development and spread of the Internet, which provoked the appearance of publications like New Media \& Society, Journal of Computer-Mediated Communication as well as many special issues of existing journals (Borah, 2017). Following this idea, in this section we will try to present the most paradigmatic publishing trends. In order to reach this objective, we will show data around the most addressed topics by paying attention to the publishing patterns of the analysed outlets.

The editors of New Media \& Society displayed the main ideas of its foundation in the first number of the publication by saying that the journal was the result of the «remarkable growth in scholarship addressing the social implications of emerging communication and information technologies» (Jankowski et al., 1999). Thus, this journal was created to group together research around topics such as the development of the Internet and new information and communication technologies and how they influence communicative processes.

The idea coincides with the presence of these topics into the analysed sample of articles. As noted before, New Media \& Society published 851 research articles between January 2008 and April 2018. Within this sample, we identified 163 articles involving the Internet - use, effects and characteristics-. Social Media, as well as its use and development have presence in 164 articles whereas there were 137 related with information and communication technologies and their implications for communicative processes. Finally, the fourth most addressed topic was mobile communication, with 76 research articles. Therefore, the four main themes have technological roots and they constitute the $63.45 \%$ of the published articles in the last ten-year period with 540 examples.

Journal of Computer-Mediated Communication shows a very similar pattern. Thus, out of its 344 research articles published during the past ten years, 70 are focused on the study of Social Media, 53 on the analysis of the Internet and 51 address the implications of Information and Communication Technologies. It constitutes more than a half of the published research - a $50.58 \%$ out of the total number of arti- 
cles- concentred in three topics. The fourth main issues are the discourse, case and content studies with 38 examples.

Journal of Communication's main topics are discourse, case and content analysis —with 117 examples out of the 474 published articles-; media use and its effects and public opinion - with 87 articles-; and communication theory -in 69 times-. Those three issues constitute the $57.59 \%$ of the published research in this journal in the last ten years. More technological subjects like Social Media and Information and Communication Technologies have 39 and 34 examples respectively, being together the $15.40 \%$ out of the total.

Media Psychology published 225 research articles between January 2008 and April 2018. Out of those, 122 were focused on the use, effects and reception of the media and public opinion - more than a half with the $54.22 \%$ out of the total- In second, third and fourth place in terms of presence we can find research related with Information and Communication Technologies -38 examples-; Social Media and the Internet - 10 examples of each category - which constitutes the $25.77 \%$ of the published research in the period of analysis.

Communication Research's most addressed topic was use, effects and media reception and public opinion with 131 examples out of the 426 published articles. It constitutes a $30.75 \%$ out of the total. The second most addressed topic was interpersonal communication with 70 examples $-16.43 \%$ of the published research in this journal-. Another two important subjects tackled by Communication Research were discourse, content and case analysis - with 46 examples, the $10.79 \%$ of the times - and communication theories and methodologies - 40 times, the $9.38 \%$ out of the total research published by this journal-.

Journal of Advertising follows a very similar pattern where use, effects and media reception and public opinion is the main subject with 130 examples out of the 341 published articles. Thus, in this particular case it is necessary to note that most of the articles are focused on the reception and effects of advertisements, not on the reception of the media in general. Discourse, content and case analysis, with 55 examples, are the second most addressed thematic with 55 examples, and advertising - in this case generalities about advertising - is the third subject with major amount of publisher research in this journal -52 articles, $15.24 \%$ out of the total-.

Communication Theory, just as its name shows, is mainly coped by research about communication theories. Thus, we have found 122 articles related with this subject out of the 223 published by this journal $-54.70 \%-$. The second most addressed issues are discourse, content and case analysis, with a presence of 33 articles $-14.79 \%$ out of the total-.

Information Communication \& Society follows the same pattern as New Media \& Society and Journal of Computer-Mediated Communication, where studies on new technologies are the most important concerns. Thus, 171 examples of research articles related with Information and Communication Technologies were found 
$-23.20 \%$ out of the 737 articles published by this journal during the period of analysis-. Social Media is the second most addressed category with 167 examples $-22.65 \%$ - and there were 59 articles related with the Internet, its uses and its effects $-8 \%$ of the whole research of Information, Communication \& Society-.

In Public Understanding of Science, 213 out of the 542 published research articles are focused on discourse, content and case analysis - 39.29\%-, whereas 172 tackle the use, effects and reception of the media $-31.73 \%$ out of the total-. The third most addressed subject is citizen's participation and mobilization with 47 examples, an $8.67 \%$ of the research published by this journal between 2008 and 2018.

Political Communication follows a very similar pattern. The main subject is discourse, content and case analysis - with 77 examples out of the 265 articles published by the journal, a percentage of the $29.05 \%-$. The second most addressed category is use, effects and reception of the media and public opinion with 58 examples -a $21.88 \%$ out of the total-. In third place, we can find 29 studies related with communication theories, a $10.94 \%$. In this case, we have to highlight the low presence of articles related with new technologies and the influence of technology in communicative processes. Thus, Political Communication opts for a more analytic and theoretical research in contrast with some of the reviewed journals.

Something similar occurs with Research on Language and Social Interaction, where discourse, content and case analysis are the main issues of this particular outlet with 151 examples out of the 189 published by the journal during the period of analysis. It constitutes the $79.89 \%$ of the total of articles of this publication and it is the highest presence of a single category in the conducted analysis. In second term, interpersonal communication appears in the $8.46 \%$ of the published research, with 16 examples of articles related with this area. The rest of the subjects have a residual role, with a very low presence.

International Journal of Press/Politics follows the main tendency observed in this section, the high presence of studies based on discourse, content and case analysis. It happens in 49 times, the $21.30 \%$ out of the 230 articles published by this journal in the last ten years period. Use, effects and reception of the media and public opinion is the second most addressed category with 42 examples - the $18.26 \%$ Studies related with the analysis of traditional media - traditional radio and television broadcast or print newspapers - are the third option, with 34 examples the $14.78 \%$ out of the total research published by International Journal of Press/ Politics.

Lastly, Public Opinion Quarterly follows the same tendency noted before with journals like International Journal of Press/Politics, Political Communication or Public Understanding of Science. It predominates the presence of research based on discourse, content and case analysis with a presence of 204 articles out of the $444 \mathrm{pu}$ blished by the journal between 2008 and 2018, a 45.94\%. The second most addressed thematic is the use, effects and reception of the media and public opinion with 139 
examples, a $31.30 \%$ out of the total. Thus, these two categories gather more than three quarters of the whole research of this journal with the $77.25 \%$ of the total.

\section{Discussion and conclusions}

Gathered data from the 5,291 reviewed articles shows some interesting patterns in the development of the high-ranked communication journals in the last ten years. Thus, if we look into their publishing frequency, we can see how six of the thirteen analysed journals augmented the number of published issues per year. As a result, more research articles are now available and this number is even bigger and more accessible due to the ease of online publishing. Because of this rise in the productivity of the main communication journals, many of them have increased the number of published articles.

When it comes to topics in publication patterns, results evidence a high presence of studies based on discourse, content and case analysis, being more than a fifth of the total amount of analysed research. Investigations around the use, effects and reception of the media and public opinion is the second most addressed category with 971 articles out of the 5,291 of the sample. Information and Communication Technologies is the third most studied subject with 523 articles, with similar numbers than research related with the Internet - 507 articles - and Social Media -494 examples-.

If we pay attention to the development cycle of the most studied subjects, we can see how many of them have a constant presence in academic journals during the last ten years. This could be the case of research related with the Internet, communication theories and the use, effects and reception of the media. In contrast, research related with Social Media platforms and its implications for communicative processes has experimented a significant growth since 2008. Thus, as shown in Figure 4, research related with this topic has experimented a constant growth year after year since the appearance of Social Networking Sites.

Finally, three tendencies have been identified relating the presence of topics in the analysed journals. As noted before, there are emergent journals where the most addressed subjects are related with new technologies. This is the case of New Media \& Society, Journal of Computer-Mediated Communication, and Information, Communication and Society. The second trend is the particular case of Communication Theory, with a theoretical approach, which publishes articles focused on communication theories and discourse analysis. Finally, the most common thematic approach is the main presence of research based on discourse, case and content analysis, as well as the analysis of the use, effects and reception of the media. Nine of the thirteen analysed journals to a greater or lesser extent shares this tendency: Journal of Communication, Media Psychology, Communication Research, Journal of Advertising, Public Understanding of Science, Political Communication, Research on Language and Social Interaction, International Journal of Press/Politics, and Public Opinion Quarterly. 
Regarding to the limitations of the conducted study, as noted in the method section, the authors were aware that many of the reviewed articles could fit in more than one single category. However, they were assigned to the category in which they fitted better. This study is based only in thirteen journals, those located in the top-ten of the two main citation indexes Journal of Citation Reports (JCR) and Scimago Journal \& Country Rank (SJR). It is a little sample among all the academic publications in the field of communication, but it is a good example of the current trends in the study of this field.

Finally, there is room for further research related with publication patterns in communication journals as well as the presence and development of different subjects over the years. It could be interesting to assess research related with topics such as information verification, Information and Communication Technologies, and mobile communication. Those fields, as well as others like Social Media and the Internet, have an interesting future within the context of academic research.

\section{References}

Abbott, Andrew (2002). Chaos of Disciplines. Chicago: University of Chicago Press.

Avant, J. Adam; Kim, Kyongseok \& Hayes, Jameson L. (2017). Thirty Years of Advertising Research in Leading Communication and Marketing Journals: Learning From the Parent Disciplines. In: Journal of Current Issues \& Research in Advertising, vol. 38, $\mathrm{n}^{\mathrm{o}}$ 1. Clemson: CtC Press, 44-64. DOI: https://doi.org/10.1080/106 41734.2016.1233154

Baladrón-Pazos, Antonio J.; Correyero-Ruiz, Beatriz \& Manchado Pérez, Benjamín (2014). Three decades of advertising research in Spain: analysis of scientific communication journals (1980-2013). In: Communication \& Society, vol. 27, no 4. Pamplona: Universidad de Navarra, 49-71. DOI: https://doi.org/10.15581/003.27.4.49-71

Barnett, George A.; Huh, Catherine; Kim, Youngju \& Park, Han Woo (2011). Citations among communication journals and other disciplines: a network analysis. In: Scientometrics, Vol. 88, $\mathrm{n}^{\mathrm{o}}$ 2. Amsterdam, Elsevier, 449-469. DOI: https://doi. org/10.1007/s11192-011-0381-2

Benavides Delgado, Juan (2012). La investigación en comunicación y publicidad: nuevos temas y problemas. In: Questiones Publicitarias vol. 17. Sevilla: Universidad de Sevilla, 71-93. DOI: https://doi.org/10.5565/rev/qp.55

Berger, Charles R. \& Chaffee, Steven H. (1988). On Bridging the Communication Gap. In: Human Communication Research, vol. 15, $\mathrm{n}^{0} 2$ 2. Oxford: Oxford University Press, 311-318. DOI: https://doi.org/10.1111/j.1468-2958.1988.tb00187.x

Berger, Charles R.; Roloff, Michael E. \& Roskos-Ewoldsen, David R. (2009). What is communication science. In: Berger, C. R.; Roloff, M. E. \& Roskos-Ewoldsen, D. R. (eds.), The handbook of communication science. Thousand Oaks: Sage. 
Bermejo Berros, Jesús (2014). Evolución de los paradigmas, metodologías y campos de la comunicación en Revista Latina de Comunicación Social durante la década 2004-2013. In: Revista Latina de Comunicación Social, vol. 69. La Laguna: Sociedad Latina de Comunicación Social, 5-24. Retrieved from https://dialnet.unirioja. es/servlet/articulo? codigo $=4733324$

Borah, Porismita (2011). Conceptual Issues in Framing Theory: A Systematic Examination of a Decade’s Literature. In: Journal of Communication, vol. 61, i. 2. Oxford: International Communication Association, 246-263. DOI: https://doi. org/10.1111/j.1460-2466.2011.01539.x

Borah, Porismita (2017). Emerging communication technology research: Theoretical and methodological variables in the last 16 years and future directions. In: New Media \& Society, vol. 19, n ${ }^{\circ}$ 4. London: SAGE Publishing, 616-636. DOI: https:// doi.org/10.1177/1461444815621512

Bruhn Jensen, Klaus (2018). The Double Hermeneutics of Communication Research. In: Javnost - The Public, vol. 5, $\mathrm{n}^{\mathrm{o}}$ 1-2. Ljubljana: Euricom and Cankarjeva zalozba, 177-183. DOI: https://doi.org/10.1080/13183222.2018.1418968

Bryant, Jennings \& Miron, Dorina (2004). Theory and Research in Mass Communication. In: Journal of Communication, vol. 54, $\mathrm{n}^{0} 4$. Oxford: International Communication Association, 662-704. DOI: https://doi.org/10.1111/j.1460-2466.2004. tb02650.x

Cappella, Joseph N. (2017). Vectors into the Future of Mass and Interpersonal Communication Research: Big Data, Social Media, and Computational Social Science. In: Human Communication Research, vol. 43, ${ }^{\circ}$ 4. Oxford: Oxford University Press, 545-558. DOI: https://doi.org/10.1111/hcre.12114

Carlson, Matt; Robinson, Sue; Lewis, Seth C. \& Berkowitz, Daniel A. (2018). Journalism Studies and its Core Commitments: The Making of a Communication Field. In: Journal of Communication, Vol. 68, $\mathrm{n}^{\mathrm{o}}$ 1. Oxford: International Communication Association, 6-25. DOI: https://doi.org/10.1093/joc/jqx006

Castillo-Esparcia, Antonio; Rubio-Moraga, Ángel \& Almansa-Martínez, Ana (2012). La investigación en Comunicación. Análisis bibliométrico de las revistas de mayor impacto del ISI. In: Revista Latina de Comunicación Social, vol. 67. La Laguna: Sociedad Latina de Comunicación Social, 248-270. DOI: https://doi.org/10.4185/ RLCS-067-955-248-270

Codina, Lluís (2017). Bases de datos académicas para investigar en Comunicación Social: revisiones sistematizadas, grupo óptimo y protocolo de búsqueda. En: http://portalcomunicacion.com/lecciones_det.asp?lng=esp\&id=96 (Viewed 17-072019).

de-Filippo, Daniela (2013). Spanish Scientific Output in Communication Sciences in WOS. The Scientific Journals in SSCI (2007-12). In: Comunicar, vol. 21, n 41. Huelva: Grupo Comunicar, 25-34. DOI: https://doi.org/10.3916/C41-2013-02 
de Moragas, Miquel (2011). La comunicación, disciplina y campo de estudio. La experiencia latina. In: Eu-Topías, vol. 1-2, Valencia: Universitat de València e Institut Européen de l’Université de Genève, 1-12.

Delia, Jesse G. (1987). Communication research: A history. In: Berger, C.R. \& Chaffee, S. H. (eds.). The handbook of communication science. Beverly Hills: Sage.

Demeter, Marton (2017). The Core-Periphery Problem in Communication Research: A Network Analysis of Leading Publication. In: Publishing Research Quarterly, vol. 33, $n^{\circ}$ 4. New Brunswick: Springer, 402-420. DOI: https://doi.org/10.1007/s12109017-9535-2

Díaz-Campo, Jesús \& Segado-Boj, Francisco (2017). Análisis de la investigación sobre ética de la comunicación en España (1980-2015). In: Estudios Sobre El Mensaje Periodístic, vol. 23, $\mathrm{n}^{\circ}$ 2. Madrid: Universidad Complutense de Madrid, 759-772. DOI: https://doi.org/10.5209/ESMP.58014

Fernández-Quijada, David \& Masip, Pere (2013). Three Decades of Spanish Communication Research: Towards Legal Age. In: Comunicar, vol. 21, $\mathrm{n}^{\mathrm{o}}$ 41. Huelva: Grupo Comunicar, 15-24. DOI: https://doi.org/10.3916/C41-2013-01

Fernández-Quijada, David; Masip, Pere \& Bergillos, Ignacio (2013). El precio de la internacionalidad: la dualidad en los patrones de publicación de los investigadores españoles en comunicación. In: Revista Española de Documentación Científica, vol. 3, $\mathrm{n}^{\circ}$ 2. Madrid: CINDOC. DOI: https://doi.org/10.3989/redc.2013.2.936

Ha, Louisa; Hu, Xiao; Fang, Ling; Henize, Sarah; Park, Sanghee; Stana, Alex \& Zhang, Xiaoqun (2015). Use of Survey Research in Top Mass Communication Journals 2001-2010 And the Total Survey Error Paradigm. In: Review of Communication, vol. 15, $\mathrm{n}^{\mathrm{o}}$ 1. London: Taylor \& Francis Online, 39-59. DOI: https://doi.org/ 10.1080/15358593.2015.1014401

Jankowski, Nicholas; Jones, Steve; Samarajiva, Rohan \& Silverstone, Roger (1999). Editorial. In: New Media \& Society 1(1). London: SAGE Publishing, 5-9. DOI: https://doi.org/10.1177/14614449922225483

Jinha, Arif E. (2010). Article 50 million: an estimate of the number of scholarly articles in existence. In: Learned Publishing, vol. 23, $\mathrm{n}^{\circ} 3$. Worting: Association of Learned and Professional Society Publishers, 258-263. DOI: https://doi. org/10.1087/20100308

Kamhawi, Rasha \& Weaver, David (2003). Mass Communication Research Trends from 1980 to 1999. In: Journalism \& Mass Communication Quarterly, vol. 80, $\mathrm{n}^{\mathrm{0}}$ 1. Columbia: University of South Carolina, 7-27. DOI: https://doi. org/10.1177/107769900308000102

Kim, Yonghwan; Kim, Bumsoo; Kim, Youngju \& Wang, Yuan (2017). Mobile communication research in communication journals from 1999 to 2014. In: New Media \& Society, vol. 19, $\mathrm{n}^{\mathrm{o}}$ 10. London: SAGE Publishing, 1668-1691. DOI: https://doi. org/10.1177/1461444817718162 
Koivisto, Juha; Thomas, Peter; Aslama, Minna; Sïra, Kalle; Rice, Ronald \& Aula, Pekka (2008). Mapping Communication and Media Research: Paradigms, Institutions, Challenges. In: http://www.helsinki.fi/crc/Julkaisut/Koivisto-ThomasPDF.pdf (Viewed 17-07-2019).

Martín-Algarra, Manuel (2009). La comunicación como objeto de estudio de la teoría de la comunicación. In: Análisi, vol. 38. Barcelona: Revista Anàlisi, 151-172.

Martínez-Nicolás, Manuel \& Carrasco-Campos, Ángel (2018). La transformación de una comunidad científica. Evolución del patrón de autoría de la investigación española sobre comunicación publicada en revistas especializadas (1990-2014). In: Revista Latina de Comunicación Social, vol. 73. La Laguna: Sociedad Latina de Comunicación Social, 1368-1383. DOI: https://doi.org/10.4185/RLCS-2018-1311

Martínez-Nicolás, Manuel \& Saperas-Lapiedra, Enric (2016). Objetos de estudio y orientación metodológica de la reciente investigación sobre comunicación en España (2008-2014). In: Revista Latina de Comunicación Social, vol. 71. La Laguna: Sociedad Latina de Comunicación Social, 1365-1384. DOI: https://doi.org/10.4185/ RLCS-2016-1150es

Meyen, Michael (2015). Communication Research and Media Studies, History of. In: International Encyclopedia of the Social \& Behavioral Sciences. Amsterdam: Elsevier. 278-283. DOI: https://doi.org/10.1016/B978-0-08-097086-8.03054-3

Montero-Díaz, Julio; Cobo, Manuel-Jesús; Gutiérrez-Salcedo, María; Segado-Boj, Francisco \& Herrera-Viedma, Henrique (2018). A science mapping analysis of 'Communication' WoS subject category (1980-2013). In: Comunicar, vol. 26, n ${ }^{\circ}$ 55. Huelva: Grupo Comunicar, 81-91. DOI: https://doi.org/10.3916/C55-2018-08

Park, Han Woo \& Leydesdorff, Loet (2009). Knowledge linkage structures in communication studies using citation analysis among communication journals. In: Scientometrics, vol. 81, $\mathrm{n}^{0} 1$. Amsterdam, Elsevier, 157-175. DOI: https://doi. org/10.1007/s11192-009-2119-y

Piedra-Salomón, Yelina (2010). Campo científico de la Comunicación: examinando su estructura intelectual a través del análisis de cocitación. In: Revista Latina de Comunicación Social, vol. 65. La Laguna: Sociedad Latina de Comunicación Social, 204-2013. DOI: https://doi.org/10.4185/RLCS-65-2010-893-204-213

Piedra-Salomón, Yelina (2015). Campo científico de la comunicación: Análisis del dominio. Doctoral dissertation. Granada: Universidad de Granada.

Pooley, Jefferson D. \& Park, David W. (2012). Communication research. In: Simonson, P.; Peck, J.; Craig, R. T. \& Jackson, J. P. (eds.), The Handbook of Communication History. New York: Routledge.

Ramírez-Montoya, María Soledad \& García-Peñalvo, Francisco-José (2018). Cocreación e innovación abierta: Revisión sistemática de literatura, Co-creation and open innovation: Systematic literature review. In: Comunicar, vol. 26, $\mathrm{n}^{\circ} 54$. Huelva: Grupo Comunicar, 9-18. DOI: https://doi.org/10.3916/C54-2018-01 
Roca-Correa, David \& Pueyo-Ayhan, Natalia (2012). The scientific productivity in Communication across the journal Zer. In: Revista Latina de Comunicación Social, vol. 67. La Laguna: Sociedad Latina de Comunicación Social, 287-316. DOI: https:// doi.org/10.4185/RLCS-067-957-287-316-EN

Rodrigo Alsina, Miquel (2001). Teorías de la comunicación. Bellaterra: Universitat Autònoma de Barcelona.

Rogers, Everett M. \& H. Chaffee, Steven (1983). Communication as an Academic Discipline: A Dialogue. In: Journal of Communication, vol. 33, $\mathrm{n}^{\mathrm{o}} 3$. Oxford: International Communication Association, 18-30. DOI: https://doi. org/10.1111/j.1460-2466.1983.tb02402.x

Simonson, Peter \& W. Park, David (2016). The International History of Communication Study Title. New York: Routledge.

Tomasello, Tami K. (2001). The status of Internet-based research in five leading communication journals, 1994-1999. In: Journalism \& Mass Communication Quarterly, vol. 78, no 4. Columbia: University of South Carolina, 659-674.

Tomasello, Tami K.; Lee, Youngwon \& Baer, April P. (2010). 'New media’ research publication trends and outlets in communication, 1990-2006. In: New Media \& Society, vol. 12, $\mathrm{n}^{\circ}$ 4. London: SAGE Publishing, 531-548. DOI: https://doi. org/10.1177/1461444809342762

Vidales, Carlos (2015). Historia, teoría e investigación de la comunicación. In: Comunicación y Sociedad, vol. 23. Pamplona: Universidad de Navarra, 11-43.

Vilches, Lorenzo (2011). La investigación en comunicación. Métodos y técnicas en la era digital. Barcelona: Gedisa.

Wiemann, John M.; Pingree, Suzanne \& Hawkins, Robert P. (1988). Fragmentation in the Field-and the Movement Toward Integration in Communication Science. In: Human Communication Research, vol. 15, $\mathrm{n}^{\mathrm{0}}$ 2. Oxford: Oxford University Press, 304-310. DOI: https://doi.org/10.1111/j.1468-2958.1988.tb00186.x 


\section{El vínculo entre la marca España y la cultura en la prensa diaria The link between marca España and the culture in the daily press}

Fernando Carcavilla Puey

Universidad San Jorge

Ricardo Zugasti Azagra

Universidad de Zaragoza

\section{Referencia de este artículo}

Carcavilla Puey, Fernando y Zugasti Azagra, Ricardo (2019). El vínculo entre la marca España y la cultura en la prensa diaria adComunica. Revista Científica de Estrategias, Tendencias e Innovación en Comunicación, (18), 271-294. DOI: http:// dx.doi.org/10.6035/2174-0992.2019.18.13

\section{Palabras clave}

Prensa; Diplomacia cultural; Identidad nacional; Marca España; Marca país; Análisis de contenido

\section{Keywords}

Press; Cultural diplomacy; National identity; Marca España; Nation brand; Content analysis

\section{Resumen}

La institución Marca España fue creada por el Gobierno de la nación en junio de 2012 con el objetivo de mejorar la imagen del país tanto en el exterior como en el interior (Ministerio de Asuntos Exteriores y Cooperación, 2016). Según diversos autores, la diplomacia cultural es una actividad eficaz para construir una imagen-país positiva a largo plazo en el exterior. Asimismo, es destacable el papel de la cultura 
en la construcción de la identidad nacional. El principal objetivo de este artículo es describir las características de la cobertura periodística del término «marca España» vinculado a la cultura entre los años 2012 y 2015. Este periodo, que abarca la mayor parte de la primera legislatura de Mariano Rajoy, se caracteriza por un contexto de crisis económica, social e institucional (Manfredi y Cachinero, 2013). Se toman como muestra los tres diarios españoles con mayor difusión, El País, El Mundo y La Vanguardia, y se analizan todas las piezas que incluyan la expresión «marca España» mediante un análisis de contenido. Los resultados ponen de manifiesto la importancia de la cultura, y fundamentalmente del deporte, en la construcción mediática del concepto «marca España». Asimismo, se muestra la amplia vinculación de la cultura con aspectos positivos de la realidad, hecho que permite moldear una opinión pública favorable.

\begin{abstract}
Marca España institution was created by the Spanish Government in June 2012 in order to improve the country image both abroad and within the national territory (Ministerio de Asuntos Exteriores y Cooperación, 2016). According to various authors, cultural diplomacy is an effective activity to build a positive long-term country image abroad. Likewise, the role of culture in the construction of national identity also stands out. The main objective of this article is to describe the features of the journalistic coverage of the term «marca España» linked to culture between 2012 and 2015. This period, which covers most of Mariano Rajoy's first legislature, is defined by a context of economic, social and institutional crisis (Manfredi and Cachinero, 2013). We take as a sample the three Spanish newspapers with the widest distribution, El País, El Mundo and La Vanguardia, and all the pieces that include the expression «marca España» are analyzed through a content analysis. The results show the importance of culture, basically of sport, in the media construct of the notion of «marca España». In addition, we show the broad link between culture and positive aspects of reality, which can shape a favorable public opinion.
\end{abstract}

\title{
Autores
}

Fernando Carcavilla Puey [fcarcavilla@usj.es] es Doctor en Comunicación por la Universidad San Jorge de Zaragoza. Pertenece al grupo de investigación Comunicación, Periodismo, Política y Ciudadanía, reconocido por el Gobierno de Aragón. Profesor de Publicidad y Relaciones Públicas, Universidad San Jorge.

Ricardo Zugasti Azagra [rzugasti@unizar.es] es Doctor en Comunicación por la Universidad de Navarra y forma parte del Departamento de Lingüística General e Hispánica (área de Periodismo) de la Universidad de Zaragoza. Pertenece al grupo de investigación Comunicación, Periodismo, Política y Ciudadanía, reconocido por el Gobierno de Aragón. 


\section{Créditos}

Este artículo es producto del grupo de investigación «Comunicación, Periodismo, Política y Ciudadanía», referencia S-101, reconocido como grupo de investigación consolidado y financiado por el Gobierno de Aragón (Departamento de Investigación, Innovación y Universidad) y con fondos FEDER de la Unión Europea. 


\section{Introducción}

El Alto Comisionado para la Marca España fue creado por el Gobierno de la nación en el año 2012 en un contexto caracterizado por la crisis económica, social e institucional, la corrupción política y las reivindicaciones secesionistas en Cataluña. Según el Ministerio de Asuntos Exteriores y Cooperación (2016),

«Marca España es una estrategia de gestión consciente de la imagen y reputación de España. Es una política de Estado cuya eficacia reside en el largo plazo. Su objetivo es mejorar la imagen de nuestro país, tanto en el interior como más allá de nuestras fronteras».

Uno de los canales básicos para construir la imagen exterior de un país lo constituyen sus exportaciones culturales (Anholt, 2009a). Varios autores consideran estas actividades como diplomacia cultural (Lynch, 2005; La Porte, 2006; Manfredi, 2011; Azpíroz, 2012). No obstante, los productos culturales también pueden ejercer influencia en la autoimagen de la ciudadanía y en el sentimiento colectivo de identidad nacional.

La información periodística contribuye en buena medida a la construcción de la realidad, priorizando la relevancia de los acontecimientos y atribuyéndoles un significado (Casero-Ripollés, 2009). En consecuencia, los vínculos establecidos por la prensa diaria entre el ámbito de la cultura y la marca España ayudan a moldear el significado social de dicho concepto.

El propósito general de este trabajo es detectar las asociaciones entre el concepto «marca España» y las distintas áreas de la cultura en la prensa española y describir algunas de las características del relato periodístico en un momento concreto de la reciente historia de España caracterizado por un contexto de crisis económica, social e institucional (Manfredi y Cachinero, 2013) que le otorga especificidad e interés como objeto de estudio. No obstante, más allá del estudio de un caso concreto, pero a través de él, pretendemos acercarnos a la comprensión de un concepto amplio y difuso como es la marca país.

El artículo se divide en las siguientes partes. En primer lugar, se desarrolla un breve marco teórico que fundamenta la investigación. Seguidamente, se plantean los objetivos e hipótesis y se justifica la metodología de análisis empleada. A continuación, se exponen los resultados de la investigación sobre la cobertura periodística del concepto «marca España» en relación con el ámbito de la cultura, tanto a nivel general como por cada diario analizado. Finalmente, se muestran las conclusiones y se esbozan futuras vías de investigación. 


\section{Estado de la cuestión}

\subsection{Marca país y diplomacia pública}

La marca país o nation brand es un concepto relativamente novedoso acuñado por Simon Anholt en 1998. Dicho término hace referencia a la importancia estratégica de la gestión de la reputación de los países (Olins, 2005; Anholt, 2009a).

La diplomacia pública, por su parte, engloba una serie de actividades cuyo objetivo es influir en la opinión pública de otros países para favorecer la política exterior (Mannheim, 1994; Batora, 2005). Esta capacidad de influencia mediante la atracción de la cultura y los valores de un país se denomina soft power (Nye, 2004).

Noya y Prado (2012) establecen una diferencia conceptual entre las estrategias de marca país y las de diplomacia pública. Las primeras tienen objetivos económicos y persiguen la atracción de turistas e inversores y el estímulo del comercio exterior. El principal objetivo de las segundas es fortalecer la influencia política en otros países.

Sin embargo, no todos los autores comparten esta perspectiva. Fan (2010) considera que el nation branding está integrado por cuatro ámbitos principales. En concreto, la autora vincula el country of origin con las exportaciones; el branding de lugar con el turismo; la diplomacia pública con el branding político; y, por último, la identidad nacional con el branding cultural.

Por el contrario, Azpíroz (2012) concede preeminencia a la diplomacia pública y considera la marca país como una de sus variantes, aunque indica la posibilidad de que las estrategias de marca país sean únicamente acciones de marketing y queden excluidas de la diplomacia pública.

En la práctica, el mayor problema que presentan las estrategias de marca país es la elevada dificultad para implementarlas. Por una parte, hay muchas variables que escapan al control de sus gestores y no pueden ser corregidas a corto plazo (Anholt 2009a; Fan, 2010). La segunda razón es la imposibilidad de reducir la complejidad de un país a un mensaje o concepto unitario, distintivo y coherente que abarque a todos los grupos de interés. En ese sentido, Fan considera que deben aplicarse estrategias independientes en las distintas áreas clave (promoción turística, atracción de inversiones, exportación de productos, etc.).

Además, Anholt reconoce que la imagen de los países se basa en estereotipos profundamente arraigados y difíciles de cambiar mediante el branding. En consecuencia, el autor rechaza el concepto nation branding al considerarlo confuso e inadecuado y propone reemplazarlo por «identidad competitiva» (2009b).

Este nuevo concepto implica un cambio de perspectiva en el que se tiene más en cuenta los mensajes que emiten los distintos grupos de interés o stakeholders. Anholt propone trazar una estrategia conjunta que implique a los principales agentes públicos y privados, en la que se coordinen sus acciones para mejorar la reputación del país (2009b). 
Estos agentes se agrupan en seis áreas de actividad que representan los principales canales de interacción de los países con el exterior y, en consecuencia, de configuración de su imagen (Anholt 2009a). En la figura 1 se representa el modelo de «identidad competitiva» de Anholt, cuyas áreas se describen a continuación:

1. La exportación de productos: las marcas líderes con prestigio internacional aportan valor a la imagen del país y facilitan la internacionalización de otras marcas de su sector siempre que su origen sea comunicado explícitamente (Peralba, 2010; Foro de Marcas Renombradas Españolas, 2016).

2. Intercambios culturales: hace referencia a las exportaciones culturales y presencia deportiva internacional del país. Como se ha comentado anteriormente, este ámbito se relaciona con la diplomacia cultural y el desarrollo de la identidad nacional.

3. Turismo: el branding de lugar o de destino se vincula a las acciones de promoción turística. Aunque su propósito principal es aumentar las visitas, a un nivel secundario, la preferencia de los visitantes hacia el país de destino suele aumentar, convirtiéndose en prescriptores en su país de origen (Anholt, 2009b).

4. Gobierno y política: este ámbito hace referencia al atractivo e influencia política del país en el exterior y se vincula con la diplomacia pública.

5. Inversiones y talento: se refiere a las medidas adoptadas y a la capacidad de un país para atraer inversores, empresas, trabajadores, eventos, investigadores y estudiantes.

6. Personas: las personalidades con prestigio internacional en distintas áreas como cultura y deportes pueden ejercer una influencia positiva en el exterior al ser identificados con su país de origen (Peralba, 2010; Sánchez Guitián, 2012). También se incluye la población local en su conjunto, pues su comportamiento, tanto en el extranjero como al tratar a los visitantes, ejerce influencia en las percepciones. 
Figura 1. Canales básicos de la «identidad competitiva»

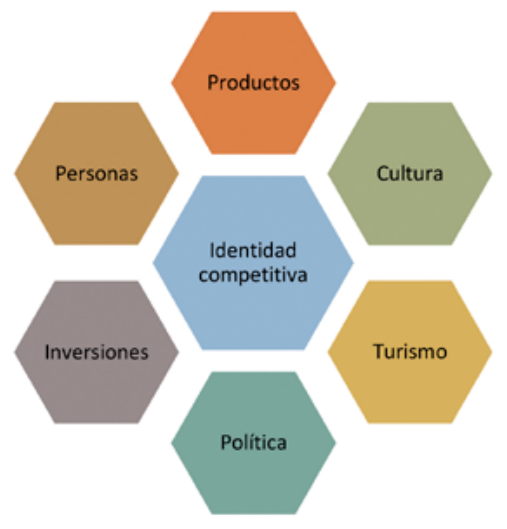

Fuente: elaboración propia. Adaptado de Anholt (2009a: 209).

\subsection{Diplomacia cultural e identidad nacional}

La Porte define la diplomacia cultural como «el intercambio de ideas, información, arte y otros aspectos de la cultura entre las naciones y sus ciudadanos para fomentar una comprensión mutua» (2006: 3). La autora afirma que la diplomacia cultural se basa en el convencimiento de que las manifestaciones culturales son las que mejor representan a una nación, e indica que se trata de acciones diplomáticas a largo plazo. Además, señala la importancia del carácter bidireccional, facilitando la comunicación equitativa por ambas partes, construyendo relaciones estables y duraderas (La Porte, 2006).

La diplomacia cultural se ha centrado tradicionalmente en intercambios educativos y culturales, así como en la difusión de contenidos de esta naturaleza a través de los medios de comunicación (Azpíroz, 2012). La autora señala que estas actividades se articulan en ámbitos específicos como la literatura, el cine, la música o la organización de eventos. Anholt (2009a) también incluye los equipos deportivos nacionales.

Manfredi incluye el cine en las acciones de diplomacia cultural, junto a la literatura, la música, los programas formativos y la formación de profesionales (2011). Morillas (2014) no menciona explícitamente el concepto «diplomacia cultural», pero vincula la diplomacia pública con la industria cultural, la enseñanza y la promoción de la lengua. Además, el autor sostiene que la difusión cultural supone un estímulo para la economía al fomentar la demanda de productos autóctonos en el exterior.

La difusión de la cultura puede ser una poderosa herramienta para ejercer influencia internacional. Determinados productos culturales podrían considerarse propa- 
gandísticos en la medida que ofrezcan una visión sesgada o parcial sobre un hecho con la intención de generar simpatía hacia determinadas ideas o valores. Rius y Martín (2015) sostienen que la política cultural ha sido instrumentalizada y simplificada por élites públicas y privadas para alcanzar objetivos ajenos a la promoción cultural. Según los autores, la cultura deja de ser un sector independiente y se convierte en una herramienta al servicio de intereses económicos y políticos.

Sin embargo, la subordinación de la cultura al poder con el objetivo de lograr influencia no es un fenómeno novedoso, sino una constante a lo largo de la historia. Desde siempre, las naciones han tratado de moldear su reputación para lograr lealtades domésticas y promover su poder e influencia en países vecinos (Olins, 2005). Según Nye (2004), el poder blando o soft power se contrapone al concepto tradicional de poder coercitivo o hard power, basado en la fuerza militar y económica de un país. El soft power permite ejercer influencia exterior mediante el atractivo de la cultura y los ideales políticos de un país.

Aunque el principal objetivo de una marca país es aumentar la influencia y mejorar la reputación exterior, varios autores consideran a la población local como un público (Oviamionayi, 2004; Olins, 2005; Morillas, 2014). En el informe realizado por De San Eugenio et al. (2013) los expertos consultados consideran de gran importancia que las comunidades locales se sientan identificadas con la marca de territorio y se cree un sentimiento de pertenencia. En la misma línea, Olins (2005) considera esencial que los habitantes del país comprendan y apoyen el proyecto, y para ello es necesaria la colaboración mediática.

Morillas (2014) hace referencia al carácter pedagógico de la diplomacia pública, tanto en el interior como en el exterior y Rius y Martín (2015) señalan que las estrategias de construcción de imagen-país combinan acciones de política cultural en ambos sentidos.

Guibernau señala la importancia del sistema educativo y de los medios de comunicación como instrumentos clave para diseminar una particular imagen de la nación basada en símbolos y rituales; valores y principios; tradiciones y modos de vida; enemigos comunes y «una clara definición de cómo ser un buen ciudadano» (2009: 46).

Por otra parte, Batora apunta que «el prerrequisito para una diplomacia pública con éxito es el atractivo de las ideas y valores que representa el Estado dentro del propio Estado» (2005: 5). En ese sentido, Rius y Martín (2015) afirman que el proyecto Marca España es una iniciativa excluyente y centralista cuyo discurso enfatiza algunos símbolos de identidad nacional tradicionales y estereotipados con los que parte de la población no se identifica. Los autores sostienen que se trata de una simplificación excesiva de la diversidad cultural de la nación que provoca un resentimiento creciente en amplios sectores de la ciudadanía.

La identidad nacional es «un sentimiento colectivo asentado en la creencia de pertenecer a la misma nación y de compartir muchos de los atributos que la hacen distinta de otras naciones» (Guibernau, 2009: 26). Sus principales características 
son la continuidad en el tiempo y la diferenciación respecto de los otros. Según Guibernau (2009), la identidad nacional parte de un concepto de nación como entidad con raíces históricas y proyección de futuro cuya diferenciación proviene del sentimiento de pertenencia a una comunidad que comparte una cultura, un pasado, unas tradiciones y unos símbolos vinculados a un territorio.

Manfredi (2011) sostiene que el refuerzo de la identidad nacional es uno de los principales objetivos de la diplomacia pública. Xifra (2010) utiliza el concepto «construcción nacional» para referirse al proceso estratégico que llevan a cabo las naciones para alcanzar sus objetivos en etapas de desarrollo económico, social y político. En dicho proceso, las relaciones públicas son una vía para construir, mantener y restablecer el sentimiento de comunidad (Kruckeberg y Starck, 1998).

En entidades territoriales no estatales como Cataluña, Flandes y Québec, el refuerzo de la identidad nacional es un objetivo común para construir una imagen alternativa a la del estado-nación en el que se inscriben (Manfredi, 2011). El autor señala la importancia estratégica de la comunicación en estos procesos de descentralización.

\section{Objetivos e hipótesis}

Todo lo expuesto en el apartado anterior pone de relieve la importancia de la cultura como instrumento de influencia en el exterior y de refuerzo de la identidad nacional, especialmente en el contexto de crisis y reivindicaciones independentistas en el que se crea la institución Marca España. La investigación se centra en este último aspecto, es decir, en la dimensión interna o identitaria de la marca España y su proyección interior a través de la prensa española. Por estas razones, el objetivo general de este trabajo es analizar las características de la cobertura periodística del término «marca España» vinculado a la cultura.

Hemos incluido el deporte en el ámbito de la cultura dado que Anholt (2009a) lo considera una actividad de diplomacia cultural. De manera más concreta, planteamos los siguientes objetivos específicos:

- O1. Conocer en qué medida se vincula el concepto «marca España» con el ámbito de la cultura en la prensa diaria española. Para ello, consideramos la dualidad del término, tanto en su referencia a la institución Marca España como en su sentido de identidad, imagen o reputación de España.

- O2. Detectar si el hecho noticioso es valorado de forma positiva o negativa con relación a la marca España.

- O3. Concretar con qué ámbitos concretos de la cultura se relaciona el concepto marca España.

- O4. Definir los rasgos de la cobertura informativa realizada por cada uno de los diarios analizados, detectando diferencias y aspectos comunes. 
Teniendo en cuenta los anteriores objetivos, planteamos las siguientes hipótesis en nuestra investigación:

- H1. El ámbito de la cultura tiene una amplia presencia en el discurso generado por la prensa diaria española en torno al concepto «marca España» debido a su destacado papel en la construcción de la identidad nacional (Guibernau, 2009) y a que las manifestaciones culturales son las que mejor representan a una nación (La Porte, 2006).

- H2. A pesar del contexto sociopolítico adverso, los hechos noticiosos vinculados a la marca España son predominantemente positivos debido al atractivo de la cultura como herramienta de influencia y soft power (Nye, 2004; Rius y Martín, 2015).

- H3. El fútbol será el ámbito de la cultura con mayor protagonismo en la cobertura por su carácter popular y su amplia difusión internacional.

- H4. El discurso de cada diario presentará particularidades al conceder diferente importancia a determinados aspectos de la cultura asociados a la marca España.

\section{Metodología}

\subsection{Técnica}

Para analizar la información se ha optado por realizar un análisis de contenido cuantitativo, una técnica habitual en la investigación en Ciencias Sociales indicada para el estudio de la cobertura periodística que hemos planteado anteriormente. Según Sierra Bravo, el análisis de contenido cuantitativo es «la técnica sin duda más elaborada y que goza de mayor prestigio científico en el campo de la observación documental» (1997: 287). Esta técnica, cuyo fin es medir unas variables concretas (Kerlinger, 1986), permite describir el contenido manifiesto de la comunicación de forma sistemática, objetiva y cuantitativa (Berelson, 1952).

Que el análisis de contenido sea sistemático significa establecer previamente unas reglas explícitas para seleccionar los contenidos sometidos a análisis y aplicarlas en la selección de la muestra. Además, los procesos de codificación, análisis y evaluación también deben estar uniformados (Wimmer y Dominick, 1996).

La objetividad en el análisis de contenido hace referencia a que los sesgos del investigador no pueden influir en los resultados, los cuales deberían ser invariables independientemente de la persona que realice el proceso. En este sentido, es necesario el establecimiento de reglas inequívocas para categorizar los contenidos. Sin embargo, como indican Wimmer y Dominick (1996), en la práctica es muy difícil alcanzar la objetividad perfecta.

Por último, el análisis de contenido tiene que ser cuantitativo dado que persigue una representación precisa de un conjunto de unidades de análisis. Además, la cuanti- 
ficación permite realizar una síntesis de los resultados obtenidos, simplificando el proceso de evaluación y permite al investigador el uso de herramientas estadísticas (Wimmer y Dominick, 1996).

Como señala Zurutuza (2012), el análisis de contenido cuantitativo implica medir la frecuencia de la aparición de una serie de rasgos en un contenido. Para ello, el investigador tiene que delimitar previamente su objeto de estudio, la muestra, la franja temporal y la unidad de análisis con la que trabajará.

El código de análisis diseñado para la investigación comprende cuatro variables con sus respectivos valores asociados que se muestran en la tabla 1. El diseño del código es original y se fundamenta en la dimensión cultural del modelo de identidad competitiva de Anholt (2009a). Las categorías de contenido abarcan las principales disciplinas de la cultura y el deporte. Una vez finalizado el proceso de codificación, los datos recogidos se han tratado estadísticamente con el programa SPSS y se presentan como gráficos y tablas de frecuencias en el apartado de Resultados. 
Tabla 1. Código de análisis de contenido

\begin{tabular}{|c|c|c|}
\hline \multicolumn{2}{|c|}{ Variable } & Valores asociados \\
\hline 1 & $\begin{array}{l}\text { Diario al que pertenece la } \\
\text { unidad de análisis. }\end{array}$ & $\begin{array}{l}\text { 1. El País } \\
\text { 2. El Mundo } \\
\text { 3. La Vanguardia }\end{array}$ \\
\hline 2 & $\begin{array}{l}\text { ¿Se vincula la marca España } \\
\text { con la cultura? }\end{array}$ & $\begin{array}{l}\text { 1. Sí } \\
\text { 2. No }\end{array}$ \\
\hline 3 & $\begin{array}{l}\text { En caso de respuesta afirma- } \\
\text { tiva en la variable } 2 \text {, ¿cómo } \\
\text { valora la unidad de análisis la } \\
\text { influencia del hecho noticioso } \\
\text { sobre la marca España? }\end{array}$ & $\begin{array}{l}\text { 1. Positiva } \\
\text { 2. Negativa }\end{array}$ \\
\hline 4 & $\begin{array}{l}\text { En caso de respuesta afirma- } \\
\text { tiva en la variable } 2 \text {, ¿a qué } \\
\text { campo hace referencia? }\end{array}$ & $\begin{array}{l}\text { 1. Arquitectura } \\
\text { 2. Artes plásticas } \\
\text { 3. Cine } \\
\text { 4. Deportes I: Atletismo } \\
\text { 5. Deportes II: Baloncesto - Selección } \\
\text { 6. Deportes III: Baloncesto - Otros equipos } \\
\text { 7. Deportes IV: Balonmano - Selección } \\
\text { 8. Deportes V: Balonmano - Otros equipos } \\
\text { 9. Deportes VI: Ciclismo } \\
\text { 10. Deportes VII: Fútbol - Selección } \\
\text { 11. Deportes VIII: Fútbol - Real Madrid } \\
\text { 12. Deportes IX: Fútbol - F. C. Barcelona } \\
\text { 13. Deportes X: Fútbol - Otros equipos } \\
\text { 14. Deportes XI: Motor } \\
\text { 15. Deportes XII: Natación } \\
\text { 16. Deportes XIII: Tenis } \\
\text { 17. Deportes XIV: Otros deportes } \\
\text { 18. Deportes XV: Deporte en general } \\
\text { 19. Folklore y tradiciones } \\
\text { 20. Gastronomía } \\
\text { 21. Historia de España (en sentido general o local/autonómicol } \\
\text { 22. Idioma español } \\
\text { 23. Literatura y teatro } \\
\text { 24. Medios de comunicación } \\
\text { 25. Moda y alta costura } \\
\text { 26. Música } \\
\text { 27. Toros } \\
\text { 28. Varios de los anteriores / cultura en general } \\
\text { 29. Otros }\end{array}$ \\
\hline
\end{tabular}

Fuente: elaboración propia.

1 En la variable número 3 se entenderá por valoración positiva aquella en la que se destaque una visión positiva o el enfoque sea neutro. Se entenderá por valoración negativa aquella en la que se destaque una visión negativa. 


\subsection{Diseño de la muestra}

El elemento central de la investigación lo constituyen las fuentes hemerográficas pues el objetivo principal de la investigación es analizar el tratamiento periodístico del concepto «marca España» vinculado a la cultura. Para el diseño de la muestra se han tenido en cuenta tres criterios: temporal, de difusión y de pluralidad.

El criterio temporal establece el periodo delimitado entre junio de 2012, mes en el que se creó la figura del Alto Comisionado del Gobierno para la Marca España, y diciembre de 2015, que coincide con el cierre de la legislatura del Gobierno responsable del proyecto Marca España. Como apuntan Manfredi y Cachinero, este periodo se caracteriza por «la crisis de credibilidad de los ciudadanos hacia las instituciones, las empresas y las entidades financieras y, por otra parte, la crisis de liderazgo dentro de todas estas» (2013: 3). Además, estas condiciones adversas propiciaron el auge del independentismo en Cataluña (Molina, 2012).

Respecto al criterio de difusión, se han escogido las ediciones impresas de dos diarios de ámbito nacional editados en Madrid (El País y El Mundo) y uno editado en Barcelona (La Vanguardia) cuyos promedios de difusión diaria fueron los más elevados en el año 2013 entre la prensa diaria generalista (OJD, 2017). En cuanto al criterio de pluralidad política y periodística, el enfoque de El País y El Mundo sobre diversas cuestiones de actualidad ha sido tradicionalmente divergente. Por otra parte, La Vanguardia es el diario más leído en Cataluña y su tratamiento periodístico del concepto «marca España» reviste un especial interés por la coyuntura secesionista que anteriormente hemos señalado.

Se consideran unidades codificables todas aquellas piezas pertenecientes a cualquier género periodístico que incluyan literalmente el término «marca España» ubicadas en la edición básica de los diarios. Tras consultar las hemerotecas en línea de los tres diarios, se han obtenido 936 unidades codificables: 359 de El País, 386 de El Mundo y 191 de La Vanguardia.

\section{Resultados}

\subsection{Descripción general de la cobertura}

El 41,3\% de las unidades de análisis vinculan la marca España con la cultura, según observamos en el gráfico 1. Es destacable que el $64,3 \%$ de esas unidades destaca una visión positiva o neutra de la influencia del hecho noticioso sobre la marca España. Este resultado supera en más de diez puntos porcentuales las valoraciones positivas registradas en el ámbito de las empresas españolas (Carcavilla y Zugasti, 2019). 
Gráfico 1. Vinculación del concepto «marca España» con la cultura y valoración de la influencia del hecho noticioso sobre la marca España (en porcentaje).

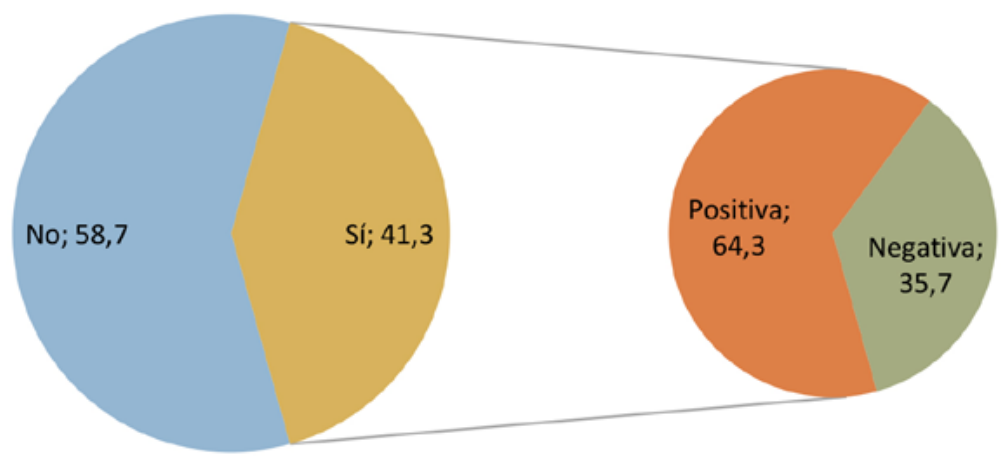

Fuente: elaboración propia.

Dado que el concepto de cultura considerado en este trabajo es muy amplio y abarca diversidad de campos, vamos a concretar cuáles de ellos adquieren mayor protagonismo en la cobertura periodística. El gráfico 2 muestra una síntesis de los distintos ámbitos culturales que se relacionan con la marca España.

El ámbito más destacable es el deportivo, pues sumando todas sus categorías representa un $33,7 \%$ de las informaciones que relacionan el concepto «marca España» con el área de cultura. Haciendo un análisis más detallado, comprobamos que el fútbol registra el 19,2\% de la cobertura y en esta categoría, el mayor protagonismo lo ostenta la Selección Española de Fútbol con un 7,5\%. Este dato no es sorprendente, dado que el fútbol es el deporte más seguido en España y la Selección es el equipo que representa al conjunto de la nación. Además, la Selección había ganado la Eurocopa en 2008, el Mundial en 2010 y, de nuevo, la Eurocopa en 2012. Esta sucesión de éxitos propició la construcción de un relato que presenta a la Selección como un símbolo de valores y atributos positivos y un ejemplo para los españoles. Sirva como ejemplo un editorial del diario El Mundo en el que se afirma que «ellos han logrado triunfos deportivos con unidad, esfuerzo, superación, juego limpio y disciplina, los valores que tanto se echan en falta en otros ámbitos de la vida española». El entonces seleccionador nacional, Vicente Del Bosque, aseguró, en esta línea, que los seleccionadores nacionales «son los únicos que pueden hablar con propiedad de la Marca España como símbolo de un éxito colectivo» (Suárez, 25 de marzo de 2013: 3). 
Tras la Selección Española, el Fútbol Club Barcelona es el segundo equipo más relevante, con una cobertura del 5,7\%. El Real Madrid alcanza menos de la mitad de resultados que su eterno rival con un 2,6\% de cobertura. En un artículo de La Vanguardia sobre el clásico que enfrenta a ambos equipos se afirma que «si España exporta algo, es fútbol, es la marca España de verdad» (Amela, 23 de marzo de 2015: 53). Además, las referencias a otros equipos de fútbol españoles equivalen al 3,4\% de los resultados.

La Selección de baloncesto de España con una cobertura del 2,3\% también registra una presencia destacable teniendo en cuenta que se trata de un deporte más minoritario que el fútbol. Sin embargo, gracias a sus logros en los últimos años, ha recibido el favor del público y en torno a ella se ha construido una narrativa similar a la descrita anteriormente para la Selección Española de Fútbol.

La hegemonía del fútbol relega a otros deportes a un segundo plano. No obstante, encontramos coberturas destacables en algunas disciplinas como el tenis $(1,8 \%)$ y la natación $(1,6 \%)$ debido a su vinculación con figuras prominentes en la competición internacional como son Rafael Nadal y Mireia Belmonte. Las categorías que completan la cobertura deportiva son los deportes de motor (1\%), el atletismo $(0,8 \%)$, y el ciclismo $(0,5 \%)$. Por último, el deporte como categoría genérica obtiene una cobertura del 5,7\%.

Podemos afirmar que el deporte es un vehículo que permite transmitir una serie de valores a la población. Además, cuando se trata de competiciones internacionales en las que un equipo o deportista individual representan con éxito a su país, resulta fácil establecer un vínculo emocional entre la población y los deportistas al identificarse con ellos y con los valores positivos que representan, reforzando el sentimiento colectivo de pertenencia y la identidad nacional que describe Guibernau (2009).

Es importante recordar que autores como Costa (2004) y De Toro (2009) afirman que las marcas permiten desarrollar emociones positivas y sentimientos de pertenencia a un grupo social y eso es algo que también genera el deporte, como ilustra el titular mostrado en la figura 2. Recordemos que, en el ámbito de las marcas de territorio, De San Eugenio et al. (2013) señalan la importancia de la identificación con la marca y el sentimiento de pertenencia de la población local.

Figura 2. Titular relativo al deporte como herramienta de cohesión social.

\section{«El deporte pone de acuerdo a España»}

Fuente: Suárez (25 de marzo de 2013: 1. El Mundo, suplemento DXT). 
De cara al exterior, el deporte se convierte en un instrumento de influencia internacional y símbolo del poder blando de una nación. El medallero olímpico no deja de ser un ranking para medir la capacidad y el prestigio de las grandes potencias, como pone de manifiesto el significado que adquirió para la URSS y los Estados Unidos el dominio deportivo en competiciones internacionales durante la Guerra Fría (Taylor, 1990).

Además del deporte, hay una variedad de ámbitos culturales vinculados a la marca España entre los que se reparte la cobertura. Destaca la historia de España, tanto en sentido general como local o autonómico, con un 9,6\% de la cobertura. Este dato no resulta sorprendente, teniendo en cuenta que la identidad de un territorio es configurada por su recorrido histórico. En ese sentido, cabe recordar que Guibernau (2009) considera la continuidad en el tiempo basada en unas raíces históricas como uno de los rasgos principales de la identidad nacional. Por su parte, Capriotti (2009) señala la evolución histórica de una organización como uno de los factores que influyen en la identidad corporativa.

La categoría artística recibe en su conjunto un 19,6\% de la cobertura. En este apartado se recogen las principales disciplinas artísticas, entre las que destacan la literatura y el teatro $(6,7 \%)$, seguidas por la música $(4,1 \%)$, el cine $(3,9 \%)$, las artes plásticas $(3,1 \%)$, y la arquitectura $(1,8 \%)$.

En relación con la literatura, destacamos las informaciones publicadas a raíz de la concesión del Premio Cervantes al escritor Juan Goytisolo en el año 2014, si bien el vínculo con la marca España se debe a la actitud crítica del escritor hacia dicho concepto. No obstante, el premio Cervantes pone en valor la lengua y la literatura castellanas, las cuales son un medio de difusión cultural y, por extensión, una herramienta de soft power. Del mismo modo, creemos que las demás disciplinas artísticas pueden ejercer una función similar en la medida en que tengan una proyección internacional, especialmente aquellas en lengua castellana. En el campo de la música, detectamos la tendencia a relacionar el flamenco con la marca España, por ejemplo, en diversas informaciones publicadas tras la muerte del guitarrista Paco de Lucía en el año 2014. Este género vinculado al folclore andaluz es una de las manifestaciones culturales españolas más reconocidas en el exterior. Consideramos que, pese a tratarse de un estereotipo cultural, el flamenco es un rasgo de identidad español muy arraigado en el imaginario colectivo.

Otros ámbitos destacables por orden de cobertura son medios de comunicación $(6,7 \%)$, moda y alta costura $(5,9 \%)$, folclore y tradiciones $(5,9 \%)$, gastronomía $(5,4 \%)$, idioma español $(3,4 \%)$ y toros $(2,3 \%)$.

Con relación a la gastronomía, destacan algunas informaciones relativas a los esfuerzos por difundir la gastronomía española en el exterior y al fenómeno de los concursos de cocina en televisión. El periodista Fernando Ónega, en un ejemplo de visión negativa hacia esta vinculación, se muestra escéptico ante esta tendencia al afirmar que «si la marca España basa el concepto y el producto del país en imágenes de deportistas y cocineros, sólo conseguirá que España sea un país de deportistas y cocineros» (Ónega, 8 de marzo de 2014: 17). 
La combinación de varias disciplinas de las anteriormente citadas y la cultura, entendida de forma genérica, obtienen una cobertura del $6,5 \%$.

Gráfico 2. Campo de la cultura al que se hace referencia (en porcentaje).

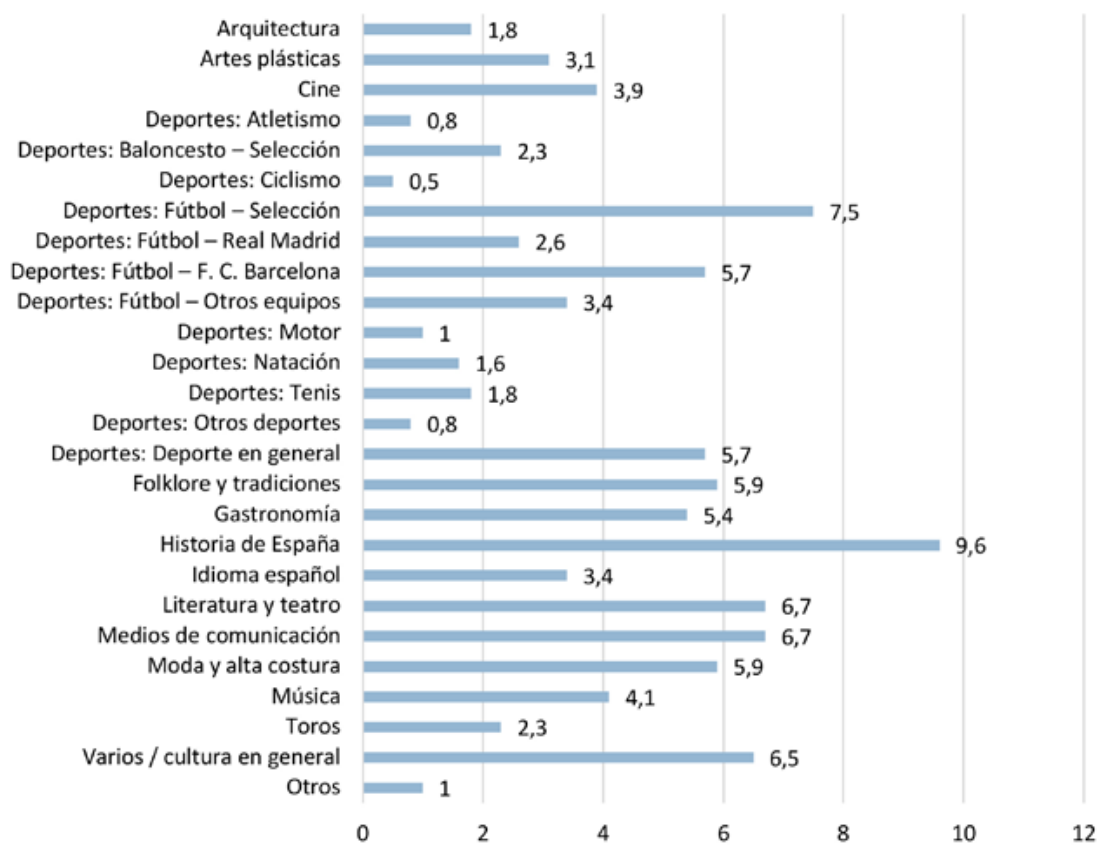

Fuente: elaboración propia.

\subsection{Vinculación de la marca España con la cultura según periódico}

En cuanto a la vinculación del concepto «marca España» con el área de cultura, El País es el diario que registra un porcentaje más elevado (44,3\%), seguido por $\mathrm{La}$ Vanguardia (42,4\%) y El Mundo (38,1\%), según se muestra en la tabla 2. El inferior porcentaje registrado por El Mundo puede guardar relación con la escasez de unidades de análisis publicadas por dicho diario en la sección de «Cultura» $(10,6 \%)$ frente a El País $(24,2 \%)$ y La Vanguardia $(27,2 \%)$. 
Tabla 2. Vinculación del concepto «marca España» con el área de cultura según periódico (en porcentaje).

\begin{tabular}{|l|l|l|l|}
\hline Vinculación con el área de cultura & El País & 38,1 & 42,4 \\
\hline Sí & 44,3 & 61,9 & 57,6 \\
\hline No & 55,7 & 100 & 100 \\
\hline Total & 100 & El Mundo & Languardia \\
\hline
\end{tabular}

Fuente: elaboración propia.

Sin embargo, El Mundo es el periódico que valora más positivamente la influencia de los hechos noticiosos sobre la marca España en esta área. En concreto, sus valoraciones positivas alcanzan el 74,1\% frente al 61,6\% obtenido por El País y el $51,9 \%$ de La Vanguardia.

En relación con el campo de la cultura al que se hace referencia, vamos a destacar a continuación los resultados más significativos en la cobertura de los tres diarios. Como ya hemos comentado en el apartado anterior, el ámbito deportivo es el más destacado dentro de la categoría de «cultura». Recordemos que el porcentaje obtenido sumando todas sus categorías representa el 33,7\% de las informaciones que relacionan el concepto «marca España» con dicha área. Sumando los porcentajes de todas las categorías deportivas por periódico, las cifras obtenidas muestran que La Vanguardia $(38,2 \%)$ es el diario que, en proporción, mayor relación establece entre deporte y marca España, seguido por El Mundo (33,9\%), y El País (30,7\%). Este resultado llama la atención, dado que La Vanguardia es el periódico que menos unidades de análisis publica en la sección «Deportes» $(3,1 \%)$ frente a El País $(5,6 \%)$ y El Mundo (6\%). De este hecho inferimos que La Vanguardia presenta una mayor tendencia a vincular el deporte con la marca España en cuestiones que trascienden lo deportivo, por ejemplo, la candidatura olímpica de Madrid 2020.

Analizando las categorías deportivas concretas, vamos a destacar las principales diferencias que hemos encontrado. La Selección Española de Fútbol obtiene un lugar destacado en la cobertura de los tres diarios, especialmente en El Mundo $(8,8 \%)$, seguido por El País (6,9\%) y La Vanguardia (6,2\%). Los dos principales clubes de fútbol españoles, Real Madrid y Fútbol Club Barcelona, obtienen un protagonismo desigual según la cabecera analizada. Concretamente, el Real Madrid alcanza un 4,4\% en El País, un 2,5\% en La Vanguardia y tan solo un 0,7\% en El Mundo. Por su parte, el Fútbol Club Barcelona destaca en La Vanguardia $(8,6 \%)$ y en El Mundo $(6,8 \%)$, mientras que su presencia es inferior en El País $(3,1 \%)$.

En otros deportes, destaca la presencia obtenida por la natación en La Vanguardia $(6,2 \%)$ respecto a El País $(0,6 \%)$ y El Mundo (0\%). Sin embargo, la explicación de este resultado reside en el protagonismo concedido por el diario catalán a un polémico tuit escrito por el director adjunto de la Marca España a raíz de la pitada al himno nacional en el Mundial de natación celebrado en Barcelona. Este hecho 
ejemplifica la vinculación con la marca España de un acontecimiento relacionado con el deporte cuya relevancia es política.

Para cerrar el apartado deportivo, aquellas informaciones que vinculan el deporte en general con la marca España alcanzan un mayor protagonismo en La Vanguardia (9,9\%), seguido por El Mundo (5,4\%) y El País $(3,8 \%)$.

En el campo artístico, cuya frecuencia en la cobertura general es del 19,6\%, detectamos algunas diferencias entre los diarios. Así, El País $(25,8 \%)$ es el que más protagonismo concede a las artes, mientras que La Vanguardia $(18,5 \%)$ y El Mundo $(13,6 \%)$ se sitúan por debajo de la cifra general. No obstante, La Vanguardia es el diario que mayor porcentaje de informaciones registra en la sección de "Cultura» $(27,2 \%)$, seguido por El País (24,2\%) y, a una mayor distancia, El Mundo (10,6\%). Sin embargo, ni todas las informaciones publicadas en la sección de "Cultura» tienen un contenido artístico ni todas las informaciones referentes al arte se encuentran en dicha sección. La conclusión más evidente al observar estas cifras es que El Mundo concede a las artes una importancia inferior que El País y La Vanguardia en relación con la marca España. De todas las disciplinas integradas en esta categoría, destacamos el protagonismo alcanzado por la literatura y el teatro en El País $(10,1 \%)$ frente a La Vanguardia $(6,2 \%)$ y El Mundo $(3,4 \%)$. Algo similar sucede con el cine, cuya presencia en El País (5,7\%) es superior a la registrada en La Vanguardia (3,7\%) y El Mundo (2\%).

La historia de España, tanto en sentido general como local o autonómico, es uno de los ámbitos más destacados en la cobertura, especialmente en La Vanguardia $(12,3 \%)$ y El País (10,7\%) respecto a El Mundo (6,8\%). En este caso, observamos una tendencia en El País a abordar los temas de la Guerra Civil Española y las víctimas del franquismo, algo que no sucede ni en El Mundo ni en La Vanguardia, en cuyas coberturas no detectamos ningún tema histórico recurrente.

En referencia a otras áreas, la gastronomía tiene un notable protagonismo en $E l$ Mundo $(8,8 \%)$ respecto a La Vanguardia $(4,9 \%)$ y El País $(2,5 \%)$. La moda y alta costura destacan en El Mundo (7,5\%), seguido por El País (5\%) y La Vanguardia $(4,9 \%)$. El idioma español obtiene mejores cifras en El Mundo $(4,1 \%)$ y El País $(3,8 \%)$ que en La Vanguardia $(1,2 \%)$, comprensible por el hecho de que Cataluña sea una comunidad autónoma con lengua propia. Por último, los toros obtienen un protagonismo similar en El País (3,1\%) y El Mundo (2,7\%), mientras que en La Vanguardia no reciben ninguna mención. Este hecho puede explicarse por la prohibición de las corridas de toros en Cataluña mediante la Ley 28/2010.

\section{Conclusiones}

El ámbito de la cultura se vincula a la marca España en algo más de cuatro de cada diez publicaciones. Este resultado indica que la asociación establecida por la prensa entre la marca España y la cultura es suficientemente amplia para validar la primera hipótesis de la investigación: el ámbito de la cultura tiene una presencia destacada en el discurso generado por la prensa diaria española en torno al concepto «marca España». 
Además, más de dos de cada tres publicaciones vinculadas a la cultura muestran valoraciones positivas o neutras acerca de la influencia del hecho noticioso sobre la marca España. Consideramos que se trata de un resultado muy favorable que demuestra nuestra segunda hipótesis: a pesar del contexto sociopolítico adverso, los hechos noticiosos vinculados a la marca España son predominantemente positivos debido al atractivo de la cultura como herramienta de influencia y soft power.

El deporte es el ámbito cultural que más asociaciones registra con la marca España, al aparecer en una de cada tres publicaciones vinculadas a la cultura. Además, casi dos terceras partes de las publicaciones vinculadas al deporte hacen referencia al fútbol. Destaca la presencia de la Selección Española de Fútbol, en torno a la cual se genera un discurso que la vincula a una serie de valores positivos y ejemplarizantes para la sociedad. En este sentido, se convierte en un instrumento para trasladar a la población la importancia del esfuerzo colectivo y la cohesión para superar las dificultades frente al pesimismo derivado de la crisis económica, y en un símbolo que refuerza el sentimiento de identidad nacional compartida. Así, queda demostrada la tercera hipótesis: el fútbol será el ámbito de la cultura con mayor protagonismo en la cobertura por su carácter popular y su amplia difusión internacional.

La vinculación del concepto «marca España» con el área de cultura es muy similar en la cobertura de los tres diarios analizados, siendo El Mundo el diario que registra mayor volumen de valoraciones positivas. Observamos que, en el ámbito deportivo, El Mundo y El País suelen identificar la marca España con los éxitos alcanzados por determinados deportistas o equipos españoles. Sin embargo, La Vanguardia muestra una mayor inclinación a vincular el deporte con la marca España en asuntos extradeportivos de trasfondo político. Tal es el caso de la atención prestada por el diario catalán a la candidatura olímpica de Madrid 2020. El País muestra una mayor tendencia a asociar la marca España con el ámbito cultural y artístico. Es el diario que más vincula sus publicaciones al área de cultura, principalmente en disciplinas como la literatura, el teatro y el cine. Estas conclusiones demuestran parcialmente la cuarta hipótesis: si bien hay diferencias visibles entre las cabeceras analizadas, existe una notable homogeneidad que refuta parte de la hipótesis.

El presente trabajo demuestra que la importancia de la cultura en la construcción de la marca-país queda reflejada en la cobertura periodística del concepto «marca España». Además, la amplia asociación de la cultura con aspectos positivos de la realidad pone de manifiesto su relevancia para moldear una opinión pública favorable, tanto desde la perspectiva exterior (diplomacia cultural) como interior (identidad nacional), siendo esta última la que ha vertebrado nuestra investigación.

Pese a la mencionada vinculación con aspectos favorables, el concepto «marca España» causa en ocasiones cierto escepticismo periodístico, al considerarlo un intento de proyectar una imagen demasiado optimista, sesgada o distorsionada de la realidad, algo que podría calificarse como propaganda. Este rechazo se evidencia en aquellas publicaciones que señalan la falta de correspondencia entre un discurso que se asocia a la ficción y determinados hechos que se asocian a la realidad y 
que, en ocasiones, son calificados como «verdadera marca España». No cabe duda de que el contexto en el que se creó la institución Marca España no es el más favorable para promover una iniciativa de este tipo, y la presencia habitual de enfoques negativos en los medios nacionales puede equilibrar la percepción interior basada en los aspectos positivos de la realidad.

De esta forma nos hemos aproximado a la comprensión de un concepto difuso y poliédrico como es la marca país mediante el análisis del tratamiento periodístico de un caso concreto. Este planteamiento nos permite plantear otras vías de investigación que amplíen y completen los resultados obtenidos: analizando la vinculación periodística de la marca España con otros ámbitos, ampliando la muestra cronológica y de medios, realizando un análisis cualitativo de los mensajes, analizando el tratamiento en la prensa internacional y el impacto y los efectos de las acciones llevadas a cabo a través de Marca España en el exterior.

Por último, cabe señalar que, en octubre de 2018, el gobierno de Pedro Sánchez puso fin a la figura del Alto Comisionado para la Marca España al sustituirlo por la Secretaría de Estado de la España Global (Real Decreto 1266/2018, de 8 de octubre). Este cambio, que obedece a la reestructuración del nuevo Ministerio de Asuntos Exteriores, Unión Europea y Cooperación, mantiene el objetivo de «mejorar la percepción del país en el extranjero y entre los propios españoles» (España Global, 2018). Sin embargo, cabe preguntarse si un proyecto de marca país puede tener una continuidad a largo plazo y mantener sus líneas estratégicas sin verse afectado por los cambios de gobierno, una cuestión que también abre opciones para futuros trabajos.

\section{Bibliografía}

Amela, V. M. (23 de marzo de 2015). Las apuestas y el videojuego. En: La Vanguardia, 53.

Anholt, Simon (2009a). Branding places and nations. En: Clifton, R. (ed.). Brands and Branding. Londres: Profile Books.

Anholt, Simon (2009b). Why National Image Matters. En: WTO, Handbook on Tourism Destinations Branding. Madrid: WTO/ETC.

Azpíroz, María Luisa (2012). Diplomacia pública: El caso de la 'guerra contra el terror'. Barcelona: Editorial UOC.

Batora, Jozef (2005). Public Diplomacy in Small and Medium-Sized States: Norway and Canada. La Haya: Clingendael.

Berelson, Bernard (1952). Content Analysis in Communication Research. Glencoe: Free Press.

Capriotti, Paul (2009). Branding Corporativo. Fundamentos para la gestión estratégica de la Identidad Corporativa. Santiago de Chile: Business School Universidad Mayor. 
Carcavilla, Fernando y Zugasti, Ricardo (2019). La vinculación periodística del concepto 'marca España’ con las empresas españolas. En: Ámbitos. Revista Internacional de Comunicación, Vol. 43, n ${ }^{0}$ 1. Sevilla: Universidad de Sevilla, 70-94. https:// doi.org/70-94. 10.12795/Ambitos.2019.i43.04

Casero-Ripollés, Andreu (2009). El control político de la información periodística. En: Revista Latina de Comunicación Social, $\mathrm{n}^{0}$ 64. La Laguna: Sociedad Latina de Comunicación Social, 354-366. DOI: 10.4185/RLCS-64-2009-828-354-366

Costa, Joan (2004). La imagen de marca: un fenómeno social. Barcelona: Paidós.

De San Eugenio, Jordi; Fernández-Cavia, José; Nogué, Joan y Jiménez-Morales, Monika (2013). Características y funciones para marcas de lugar a partir de un método Delphi. En: Revista Latina de Comunicación Social, n ${ }^{0}$ 68. La Laguna: Sociedad Latina de Comunicación Social 656-675. https://doi.org/10.4185/RLCS2013-995

De Toro, Juan Manuel (2009). La Marca y sus Circunstancias. Barcelona: Deusto. España Global (2018). Qué es España Global. En: https://marcaespana.es/qué-esespaña-global (Consultado el 19-07-2019).

Fan, Ying (2010). Branding the nation: Towards a better understanding. En: Place Branding and Public Diplomacy, Vol. 6, $\mathrm{n}^{\circ}$ 2. Basingstoke: Palgrave Macmillan, 97-103.

Foro de Marcas Renombradas Españolas (2016). Visión del FMRE. En: http:// www.marcasrenombradas.com/marca-espana/vision-del-fmre/ (Consultado el 1907-2019).

Guibernau, Monserrat (2009). La identidad de las naciones. Barcelona: Ariel.

Kerlinger, Fred N. (1986). Foundations of behavioral research. Nueva York: Holt, Rinehart \& Winston.

Kruckeberg, Dean y Starck, Kenneth (1998). Public relations and community: A reconstructed theory. Nueva York: Praeger.

La Porte, Teresa (2006). La diplomacia cultural americana: una apuesta por el recurso al poder blando. En: Real Instituto Elcano, ARI n ${ }^{0}$ 103. Madrid: RIE, 1-7.

La Vanguardia (21 de julio de 2013). "Margallo destituye al director adjunto de Marca España por insultar a los catalanes”. La Vanguardia, 22.

Ley 28/2010, de 3 de agosto, de modificación del artículo 6 del texto refundido de la Ley de Protección de los Animales, aprobado por el Decreto legislativo 2/2008. BOE núm. 205, de 24 de agosto.

Lynch, Dov (2005). Communicating Europe to the world: what public diplomacy for the EU?. Bruselas: European Policy Centre. 
Manfredi, Juan Luís (2011). Hacia una teoría comunicativa de la diplomacia pública. En: Comunicación y Sociedad, vol. 24, $\mathrm{n}^{\mathrm{o}}$ 2. Pamplona: Universidad de Navarra, 199-225.

Manfredi, Juan Luís y Cachinero, Jorge (2013). Diplomacia Pública y Reputación: Ideas para España. En: Informe Especial. Madrid: d+i Llorente y Cuenca.

Mannheim, Jarol B. (1994). Strategic Public Diplomacy \& American Foreign Policy. Oxford: Oxford University Press.

Ministerio de Asuntos Exteriores y Cooperación (2016). Marca España. En: http:// www.exteriores.gob.es/PORTAL/ES/POLITICAEXTERIORCOOPERACION/MARCAESP/Paginas/Inicio.aspx (Consultado el 19-07-2019).

Molina, Ignacio (2012). Independentismo e integración europea (I): la imposible adhesión automática a la UE de un territorio secesionado. En: Real Instituto Elcano, ari 80/2012. Madrid: RIE, 1-11.

Morillas, Javier (2014). La nueva diplomacia económica y la internacionalización de la economía española. Madrid: CEU Ediciones.

Noya, Javier y Prado, Fernando (2012). Marcas-país: éxitos y fracasos en la gestión de la imagen exterior. En: Real Instituto Elcano, Documento de Trabajo 13/2012. Madrid: RIE, 1-24.

Nye, Joseph S. (2004). Soft power: the means to success in world politics. Nueva York: Public Affairs.

OJD (2017). Medios Controlados. En: http://www.introl.es/medios-controlados/ (Consultado el 19-07-2019).

Olins, Wally (2005). Making a National Brand. En: Melissen, J. (ed.). The New Public Diplomacy: Soft Power in International Relations. Basingstoke: Palgrave Macmillan,.

Ónega, Fernando (8 de marzo de 2014). Mariano, y cierra España. La Vanguardia, 17.

Oviamionayi, Víctor (2004). Diplomacia pública en la bibliografía actual. En: Ámbitos, Vol. 11-12. Sevilla: Universidad de Sevilla, 215-236.

Peralba, Raúl (2010). El posicionamiento de la "Marca España” y su competitividad internacional. Madrid: Ediciones Pirámide.

Real Decreto 1266/2018, de 8 de octubre. BOE núm. 244, de 9 de octubre.

Rius, Joaquim y Martín, Mariano (2015). Spain’s nation branding project Marca España and its cultural policy: the economic and political instrumentalization of a homogeneous and simplified cultural image. En: International Journal of Cultural Policy, Vol. 21, n ${ }^{0}$ 1. Oxford: Taylor \& Francis, 20-40.

Sánchez Guitián, José Miguel (2011). Marca País: España, una marca líquida. Madrid: Esic Editorial. 
Sierra Bravo, Restituto (1997). Técnicas de investigación social. Teoría y ejercicios. Madrid: Thomson.

Suárez, O. (25 de marzo de 2013). El deporte pone de acuerdo a España. En: El Mundo, suplemento DXT, p. 1.

Taylor, Philip M. (1990). Munitions of the Mind: A history of propaganda from the ancient world to the present era. Manchester: Manchester University Press.

Xifra, Jordi (2010). Relaciones públicas y nacionalismo: una aproximación a la construcción nacional desde la perspectiva de las relaciones públicas. En: Trípodos, $\mathrm{n}^{\circ}$ 26. Barcelona: Universitat Ramon Llul, 117-131.

Wimmer, Roger D. y Dominick, Joseph R. (1996). La investigación científica de los medios de comunicación. Una introducción a sus métodos. Barcelona: Bosch Comunicación.

Zurutuza, Cristina (2012). Técnicas de investigación social en comunicación. En: Zugasti, R. (coord.): Investigar en ciencias sociales: el estudio de la comunicación. Zaragoza: Ediciones Universidad San Jorge. 
TRIBUNA: INVESTIGACIÓN Y PROFESIÓN 



\title{
Solo sé que no sé nada
}

\author{
Eugenio Martín Diéguez \\ Director General Arquetipo
}

\section{Referencia de este artículo}

Martín Diéguez, Eugenio (2019). Solo sé que no sé nada. adComunica. Revista Científica de Estrategias, Tendencias e Innovación en Comunicación, (18). 297-300. DOI: http://dx.doi.org/10.6035/2174-0992.2019.18.14

Quizá la frase más comentada de la historia y quizá el mejor slogan del conocimiento, atribuido a Sócrates, sea un buen comienzo para reflexionar sobre nuestra profesión y sobre la industria publicitaria en general, en este primer cuarto del siglo XXI.

La primera reflexión, y no es nueva, es que esta profesión está cambiando. Ahora está de moda hablar de que lo único que no cambia es el cambio, pero los publicitarios hemos estado cambiando desde que nació esta forma de ayudar a vender y de ayudar a conseguir marcas con seguidores y buena reputación. Y no hace tanto tiempo de esto. Es bueno pensar que somos una profesión muy joven, como mucho setenta años, frente a otras que llevan cientos de años y eso, hace que estemos constantemente atentos a los cambios.

Con la irrupción de Internet, todo se ha visto acelerado de forma radical y estresante, creando una verdadera convulsión en nuestra profesión, un aspecto a destacar dentro del panorama de las agencias, donde todos los actores quieren estar presentes y no todos de forma exitosa.

En este sentido, también estamos con las modas, un sinfín de posibilidades en un universo líquido que parece mucho pero que, a veces, se queda diluido en nada. Youtubers, Instagramers, influencers, un baile al que entran las marcas y no pocas 
veces salen trasquiladas, sobre todo cuando se atreven solas sin la ayuda de una pensada estratégica y profesional que centre bien los tiros.

Esa es nuestra posición: aportar cordura y profesionalidad, conduciendo discursos corporativos coherentes, sea para el mundo off o para el on.

Pero, para ello, no debemos perder nuestro rol: Pensar en los objetivos de las empresas, saber qué recursos tenemos, plantear estrategias definidas, seguir apostando por la creatividad y el arte del buen hacer y explorar todas las posibilidades que tenemos sin atiborrarse de paja.

Parece sencillo, pero es complejo. Las agencias estamos acostumbradas a los diversos campos de batalla donde conducir las tropas por terrenos hostiles y llegar a resultados con esfuerzo, imaginación y, muchas veces, pocos apoyos logísticos, pero no sabemos vender bien ese valor añadido que aportamos $\mathrm{y}$, desde fuera, parece fácil y salta la tentación de prescindir de nuestro trabajo. Es el gran error del universo empresarial, con las excepciones que nos mantienen en el ajo, porque saben todas las dificultades de nuestro trabajo multidisciplinar.

A esto también estamos acostumbrados, es más, puedo asegurar que una de nuestras disciplinas está en la parte pedagógica de enseñar a los clientes las virtudes de confiar en las agencias profesionales.

¿Tradicional o Digital? Qué más da, si ya no podemos obviar ninguno de los universos que se interpenetran. Si hay un cliente que necesita especialización, las agencias buscamos cómo establecer los mejores mecanismos para conseguir los objetivos adecuados. Por la cuenta que nos trae.

Si fuimos los pioneros en la comunicación no publicitaria, puesto que las grandes compañías publicitarias fueron las que visualizaron que había que comunicar con la credibilidad de los medios más allá de los anuncios comerciales, y se montaron las empresas de RR.PP. y Comunicación Estratégica, cómo no vamos a poder transitar los nuevos escenarios. Somos especialistas en los cambios, en adaptarnos, en tragar amargo y escupir dulces campañas y trabajos que han ayudado de forma excepcional a muchas empresas, a muchas marcas, a muchos productos.

Pasamos de la publicidad en pañales a la publicidad psicológica, para más tarde meternos en la sociológica y antropológica. Ahora estamos descubriendo las posibilidades de un nuevo mundo digital e infinito, compuesto por una sociedad líquida como ha descrito magistralmente Zygmunt Bauman y esto nos hace perder las referencias. Pero las encontraremos, ¿alguien lo duda?

Soy optimista porque esta profesión, que amo, me ha dado muchas alegrías y la posibilidad de hacer proyectos increíbles con resultados fantásticos. Siempre habrá clientes que apuesten por nuestros criterios y nos dejarán trabajar, pero no olvidemos que debemos aportar profesionalidad, visión y creatividad con coherencia.

Las nuevas generaciones están que se salen y pueden aportar mucho a la profesión, pero deben colocarse ante un rol fundamental: Tienen que ser profesionales de la 
comunicación por encima de las modas o las poses. Los que realmente construyeron esta profesión no lo hicieron con postureo, sino trabajando duro y ganándose todos los días la confianza de los clientes y la sociedad.

Propongo una mezcla generacional de experiencia y dinamismo y conocimiento de los nuevos escenarios para conseguir la mezcla explosiva que nos relance hacia una influencia perdida. Estoy seguro que lo conseguiremos, simplemente porque somos fabricantes de contenidos y sueños, ¿hay alguien que de más? 



\title{
El nuevo reto digital se llama creatividad
}

\author{
Laura Llopis \\ Directora de Estrategia y Desarrollo \\ de Negocio de Weaddyou
}

\section{Referencia de este artículo}

Llopis, Laura (2019). El nuevo reto digital se llama creatividad. adComunica. Revista Científica de Estrategias, Tendencias e Innovación en Comunicación, (18). 301304. DOI: http://dx.doi.org/10.6035/2174-0992.2018.16.15

No dejamos de escuchar que las marcas tienen nuevos retos. Estos pasan por ser culturalmente visibles, es decir, ser relevantes en un entorno donde nunca hubo tanto ruido y donde nunca fue tan fácil ignorarlo. Además, las marcas deben ser esenciales para el consumidor, pues hay tantas opciones donde elegir que, si éstas no resuelven una verdadera necesidad, no serán consideradas. Y deben crear las estructuras mentales correctas para asegurar que cuando la necesidad exista, el consumidor las tenga en su abanico de posibilidades y las escoja frente a otras.

Pero no solo eso, también se exige a las marcas que estén comprometidas con una causa interesante (lo que ya llamamos marcas con propósito) para su público porque, puestos a consumir, lo haremos a través de aquellas que nos hagan sentir que ejercemos un consumo socialmente responsable. Por eso se ha pasado de medir el top of mind a aspirar al top of heart, es decir, las marcas deben tocar el corazón de las personas si quieren tener éxito.

Es una evolución natural. Cuando las opciones se multiplican, cuando el acceso a la información de estas opciones es relativamente sencillo, cuando puedes comprar haciendo un solo click y asegurarte de que esa compra estará mañana en tu casa, 
los consumidores damos un salto más y pedimos que esa compra nos haga sentir bien, felices, comprometidos con una causa. Y no solo eso, también pedimos que toda la información de la marca nos llegue a través de una historia que nos entretenga (contenidos), que sea lo más personalizada posible (one to one) y, por supuesto, que podamos consumirla inmediatamente y a través de cualquier dispositivo (pantallas).

Porque nos comunicamos a través de pantallas (eso es el digital) y estas están siempre en nuestras manos. Según una encuesta de hábitos de consumo de YouGov, el $49 \%$ de los españoles dice chequear entre diez y cincuenta veces su móvil diariamente, mientras que un $26 \%$ se atreve a confesar que lo hace más de cincuenta veces al día. Otra encuesta de Deloitte (Encuesta Mundial de Consumidores Móviles de 2018) afirma que los estadounidenses revisan sus smartphones un promedio de 52 veces al día, mientras que el año anterior la cifra era de 47 veces por día. Más allá del número de veces, lo que parece claro es que se chequea el teléfono en busca de estímulos constantes, porque ahora el prime time es all time.

Ante este panorama, los profesionales de la comunicación que trabajamos en agencias de publicidad tenemos que hacer lo que siempre hemos hecho: ser creativos para contar historias, porque la publicidad va de eso, de historias que nos conectan con las marcas, pero también entre nosotros. Lo que ha aportado el digital es que estas historias se resuelven en un contexto algo diferente al de hace unos años. Porque la tecnología ha cambiado y con ella nuestro modo de comunicarnos. Ahora no solo queremos que las historias nos lleguen rápido y nos entretengan, queremos que sean lo suficientemente relevantes para compartirlas porque nunca fue tan fácil como hoy compartir el contenido. Y lo que compartimos habla de nosotros, nos reafirma en lo que somos y nos ayuda a mostrárselo a los demás.

En la era digital (y en la anterior también), la gente odia la mala publicidad, porque se cuela en nuestras pantallas, nos interrumpe y nos hace perder un tiempo que podríamos usar en consumir miles de contenidos interesantes. En cambio, si el mensaje nos gusta, no nos importa que la marca esté en el centro. Los chats de WhatsApp han pasado a ser un nuevo KPI en las mediciones de la eficacia.

Este contexto digital hace que las ideas que creamos se midan por raseros diferentes a los que se usaban antes de que las tecnologías lo invadieran todo. Ahora los profesionales de la comunicación tenemos que conseguir crear ideas que inspiren a los consumidores, que sean capaces de generar conversaciones, que produzcan un impacto positivo en las audiencias y que, además, generen un cambio. Además, esas ideas deben ser lo más personalizadas posible, porque queremos que las marcas nos hablen a nosotros, en primera persona.

Para conseguir este tipo de ideas y llegar a los consumidores, el uso de los datos se ha vuelto fundamental. Los datos nos permiten entender lo que hace la gente, lo que quiere, lo que necesita. Pero no el dato en sí mismo. Hoy, probablemente el mayor reto de las agencias y de sus profesionales, es ordenar esos datos y encontrar aquel o aquellos que son relevantes para nuestro trabajo, aquellos capaces de 
conectarnos realmente con las personas y ofrecerles algo significativo para ellas. Los datos nos muestran la realidad, pero nosotros tenemos que encontrar, entre todos ellos, los insights que nos permitan conectar a las marcas con las personas. Porque este negocio va de personas y la tecnología solo es un modo de acceder a ellas.

Además de esto, los profesionales de hoy tenemos que entender el digital como un medio más porque nos comunicamos a través de él. Todo es digital. Ya no tiene sentido diferenciar entre digital y otros medios. De hecho, todos los medios se conectan digitalmente desde el momento en que recibimos la información en distintas pantallas a lo largo del día. El digital en comunicación no deja de ser más que un reflejo de la sociedad, que cambia cada día los hábitos de consumo en función de lo que nos permiten las tecnologías. El reto pasa por integrar ese pensamiento digital, que todos tenemos en cuanto que somos consumidores, en los procesos de creación de la agencia. Y en ser conscientes de que, una vez la idea salga, volverá a través de diferentes interacciones con el público, que tiene más poder que nunca para opinar sobre ella, para interaccionar con ella, para hacerla grande o para ignorarla. 



\title{
Dicen que el spot ha muerto, jlarga vida al spot!
}

\author{
Josep Martí Prosper \\ Director Creativo KliperDvila
}

\section{Referencia de este artículo:}

Martí Prosper, Josep (2019). Dicen que el spot ha muerto, ¡larga vida al spot! adComunica. Revista Científica de Estrategias, Tendencias e Innovación en Comunicación, (18). 305-308. DOI: http://dx.doi.org/10.6035/2174-0992.2018.16.16

En el sector de la publicidad llevamos más de quince años vaticinando la muerte del spot. Y esto no ha sido una desaparición rápida y limpia, sino que más bien está siendo un lento decaer que nos está haciendo recapacitar a todos sobre la idea de que realmente los buenos conceptos no mueren, solo se transforman.

Pero, ¿qué ha sido de ellos? ¿Por qué decimos que están muertos si ahí siguen, acosando al usuario desde su omnipresencia en la multitud de canales actuales? Porque lo que realmente han perdido los spots no es su presencia (que también, los porcentajes de inversión publicitaria en TV convencional bajan año tras año), sino su papel protagónico como pieza principal articuladora del concepto de toda una gran campaña de comunicación. Lejos quedan esos tiempos en los que el spot barría con su presencia, mientras otros medios (la radio, la prensa, la publicidad exterior...) realizando tareas simplemente de recordatorio hacia el spot, la gran pieza madre de toda campaña.

Imaginémonos hace veinte años, cuando un aspirante a creativo decidía que quería estudiar publicidad. En general, estos estudiantes no se imaginaban articulando complicadas campañas de comunicación con multitud de fases y precisión de ciru- 
jano: se imaginaban pensando y haciendo spots: la joya de la corona y, desde luego, la más visible entonces por parte de cualquier persona ajena a nuestra profesión.

Los años pasan, y estos aspirantes a creativos se convierten, de pronto, en creativos hechos y derechos que comienzan sus andanzas en agencias valencianas. Y es en ese momento, cuando se percatan de la realidad de la publicidad valenciana: no se van a hartar de hacer spots. No es un descubrimiento fuerte, no es repentino, están tan fascinados con otras cosas que no son conscientes de que lo importante en todo esto no son los spots: es la comunicación. Es ser capaz de utilizar todas las herramientas a tu alcance, con coherencia y acierto, para que el mensaje llegue a los usuarios, y eso llega mucho más allá de poner spots en la tele.

Pero, ¿por qué era complicado realizar spots en la publicidad valenciana hace unos lustros? Analicemos las circunstancias con calma.

En primer lugar, debemos tener en cuenta las particularidades del mercado valenciano publicitario de entonces. En aquellos años, el concepto $361^{\circ}$ era una realidad absoluta en las agencias valencianas, que incorporaban servicios de publicidad, de comunicación, de diseño y de todo lo que fuera necesario para sus clientes: una realidad absolutamente necesaria para sobrevivir. Por tanto, sus profesionales debían ser absoluta y completamente versátiles, para atender desde un rebranding o un catálogo de promoción inmobiliaria, hasta una campaña con complejos conceptos de comunicación. Dentro de esto, los spots eran una rara avis al que los creativos tenían la suerte de poder enfrentarse de manera no demasiado frecuente. Además (aunque existían algunos formatos especiales) en general la televisión, como medio audiovisual por excelencia, imponía sus tiránicas normas en lo formal y casi también en lo creativo.

Por otro lado, internet lo cambió todo. Pero lo cambió de verdad. La red de redes dio lugar a una democratización de los medios en la que, por primera vez, todas las empresas podían acceder a comunicar con unos presupuestos razonables. Y estos presupuestos menguados no solían incluir la posibilidad de realizar una producción audiovisual.

Además, internet nos trajo otro maravilloso regalo: la interacción, la ruptura del sistema clásico de comunicación emisor-mensaje-receptor que se materializó en la transformación del receptor en usuario. Así se consiguió que, por primera vez, fuera posible que las marcas hablaran con sus consumidores. Con ello, llegamos al auge de las redes sociales y gracias a esto, y a los avances tecnológicos que permiten descargar formatos pesados en tiempos record, de repente la tortilla se volvió a dar la vuelta. Ahora el audiovisual no solo era imprescindible, puesto que es el formato que mejor funciona en internet, sino que su difusión ya está puesta al alcance de la gran mayoría de las marcas.

Y mientras esto ocurría, la crisis azotaba el sector. Cuando se recogieron los escombros, los supervivientes habían aprendido grandes lecciones. La más importante fue cómo maximizar los presupuestos a golpe de creatividad. Esto consiguió volver a llamar la atención de los grandes anunciantes valencianos, que poco a poco van 
volviendo a casa al comprobar que pueden confiar en una industria cargada de talento y profesionalidad.

Y así, ahora finalmente aquellos ya no tan jóvenes creativos están cumpliendo sus expectativas. Ahora ya no hacen spots, sino que integran diferentes formatos audiovisuales y de branded content dentro de estrategias transmedia de comunicación, para alcanzar los objetivos de la marca y que consiga una mejor percepción por parte de los usuarios. Es curioso como, finalmente, la comunicación tiene a convertir el audiovisual nuevamente en el formato rey. Porque cuanto más cambian las cosas, más iguales siguen.

Ahora, los estudiantes que salen de la universidad están preparados de otra manera. Ellos ya no quieren hacer spots, quieren generar conceptos. No quieren hablar a los consumidores, quieren conversar con los usuarios. No quieren hacer campañas, quieren conseguir hitos de comunicación relevantes para que los medios y las redes sociales se hagan eco de los mismos. De todas maneras, seguro que dentro de quince años el paradigma ha vuelto a cambiar por completo, y tendrán que aprovechar todo aquello que les enseñaron para construir las herramientas con las que trabajar en la nueva realidad. 



\title{
Efectos de la transformación digital en la empresa publicitaria de la Comunidad Valenciana
}

\author{
Paloma Sanz-Marcos \\ Profesora del Departamento de Comunicación Audiovisual \\ y Publicidad de la Universidad de Sevilla.
}

\section{Referencia de este artículo}

Sanz-Marcos, Paloma (2019). Efectos de la transformación digital en la empresa publicitaria de la Comunidad Valenciana. En: adComunica. Revista Científica de Estrategias, Tendencias e Innovación en Comunicación, (18). 309-312. DOI: http:// dx.doi.org/10.6035/2174-0992.2019.18.17

GONZÁLEZ OÑATE, Cristina (coord.) (2019).

El negocio publicitario en la sociedad digital de la Comunidad Valenciana.

Barcelona: UOC.

Esta obra se erige como una referencia imprescindible para conocer a fondo el ámbito de la publicidad en la Comunidad Valenciana. No obstante, lejos de presentarse como un manual de aplicación exclusivamente local, aporta una visión novedosa de los retos y cambios que ha sufrido este sector de manera global a consecuencia del desarrollo de los medios digitales. Como resultado del proyecto de investigación titulado El negocio publicitario en la sociedad digital: estructura de agencia, perfiles profesionales y nuevas tendencias creativas (Plan de Promoción Universitat Jaume I P1-1B2015-27), la coordinadora de este texto, experta en las nuevas tendencias de comunicación, realiza junto con el resto de autores una novedosa aportación acerca de las oportunidades y desafíos que supone la consolidación de las herramientas del medio online a fin de aplicar estos resultados a la realidad empresarial. 
Centrado en introducir el fenómeno de las nuevas tecnologías de la información y la comunicación, el capítulo inicial enmarca las bases y procedimientos que se han llevado a cabo para desarrollar esta investigación. En concreto, se detalla todo el proceso de trabajo; desde los participantes y herramientas empleadas, hasta las conclusiones más interesantes como resultado de la investigación. Con objeto de hacer un repaso integral de la agencia de publicidad, los capítulos siguientes, muestran cómo las estructuras de trabajo se han visto modificadas por el avance de la era digital. Así, el segundo capítulo plantea continuar con una investigación anterior cuyo objetivo se propone conocer la evolución y características de las agencias de publicidad de la Comunidad Valenciana. Se trata de un apartado interesante en tanto que explora de manera detallada no sólo las diversas tipologías de las agencias y cómo han ido cambiando, al mismo tiempo, ofrece un estudio minucioso de la estructura interna organizativa de las mismas. En este sentido, se subraya cómo internet ha renovado el modo en el que se entienden ciertos aspectos de la comunicación como el receptor, el contexto o el propio consumidor, resultando en una gestión de la publicidad que ha de ser considerada desde un enfoque sistémico e integrador. Por su parte, el capítulo tercero se centra en los perfiles profesionales del sector desde una profunda reflexión en torno a los cambios que ha supuesto la digitalización de los formatos publicitarios. No sólo se describen las consecuencias y nuevos retos de estos perfiles, asimismo, se hace un amplio repaso de las funciones y tareas a desempeñar dentro de los distintos departamentos tanto de nueva creación, como en el caso de las agencias tradicionales. Este capítulo se cierra con una serie de aptitudes reclamadas a modo de recomendaciones que han surgido por parte de los especialistas que han participado en la investigación. En su objetivo de presentar la realidad profesional del sector, el siguiente capítulo estudia la relación entre los profesionales de la publicidad y los clientes. En cuanto en la figura del anunciante, atiende de forma pormenorizada a aquellas cuestiones más cotidianas que se precisan considerar para mantener el equilibrio entre el mundo empresarial y la realidad digital, y garantizar así unos servicios equilibrados. En este caso, se advierten cuestiones como las relaciones corporativas, los servicios más demandados por las pymes valencianas o cómo la remuneración ha de ser replanteada en el entorno digital. Para finalizar, se propone una catalogación de los distintos servicios que ofrecen las agencias de publicidad en esta comunidad. La obra se cierra con un quinto capítulo dedicado al futuro de las agencias publicitarias. A través de las opiniones recogidas por parte de los profesionales entrevistados, se valora el rumbo y retos que dibujarán el futuro del sector de entre los que se destacan unas relaciones de trabajo más horizontales, la reducción de los equipos de trabajo o la búsqueda de nichos de mercado innovadores. En cuanto al carácter formal de esta obra, se trata de un texto que, a través de su estilo y presentación de los contenidos, se configura como un manual de gran utilidad que abarca las perspectivas del sector desde un punto de vista científico. Algo que resulta necesario dado que apenas existen referencias que traten las realidades profesionales desde una metodología rigurosa. 
Sin duda, nos encontramos ante un texto que ha de considerarse como un gran apoyo y servicio al mundo profesional desde el impulso académico que si bien, otras obras recientes como Empresa publicitaria de los autores Francisco J. Caro y Jorge David Fernández (Advook, 2016), o La transformación digital de la agencia de publicidad (Universidad de Navarra, 2017) del autor Jürg Kaufmann Argueta, han destacado, ofrece una novedosa aportación al incorporar una visión integradora de las consecuencias a nivel creativo y de gestión que sufren las agencias de publicidad como consecuencia de la evolución digital.

En definitiva, y a pesar de que este volumen ofrece una perspectiva práctica y cercana de la realidad y funcionamiento del caso aislado concreto del sector publicitario de la Comunidad Valenciana, podría aplicarse a otras localidades con objeto de servir de gran utilidad para la formación de los estudiantes y futuros profesionales del sector. 



\title{
Educación mediática en la era digital: hacia la formación de internautas exigentes
}

\author{
Alejandra Tirado García \\ María Rodríguez Arce
}

\section{Referencia de este artículo}

Tirado García, Alejandra y Rodríguez Arce, María (2019). Educación mediática en la era digital: hacia la formación de internautas exigentes. En: adComunica. Revista Científica de Estrategias, Tendencias e Innovación en Comunicación, (18). 313-316. DOI: http://dx.doi.org/10.6035/2174-0992.2019.18.18

JIMÉNEZ, Estefanía; GARMENDIA, Maialen y CASADO, Miguel Ángel (coords.) (2018).

Entre selfies $y$ whatsapps. Oportunidades y riesgos para la infancia

y la adolescencia conectada.

Barcelona: Gedisa.

La presencia social de la tecnología es especialmente trascendental en nuestros días entre la infancia y la adolescencia. Nuevas herramientas comunicativas y lenguajes digitales configuran a un ritmo vertiginoso una generación 3.0 que devora aplicaciones por otras más novedosas. En este contexto, ha cobrado especial valor el uso práctico de la tecnología en detrimento de las herramientas de percepción de los valores que la acompañan y los mensajes que canaliza, por lo que resulta necesaria una reflexión científica que advierta de los riesgos y oportunidades del constante contacto infantil con las pantallas.

Ante este escenario, la obra colectiva Entre selfies y whatsapps. Oportunidades y riesgos para la infancia y la adolescencia conectada, coordinada por Estefanía Jiménez, Maialen Garmendia y Miguel Ángel Casado, profesores de la Universidad 
del País Vasco, pertenecientes al EU Kids Online, ofrece un manual didáctico para padres y educadores que quieran actualizarse en las dinámicas del mundo digital. La obra está compuesta por diecisiete capítulos y cuenta con la participación de una veintena de expertos europeos y latinoamericanos que revelan con rigor las claves de la interacción actual entre los componentes del binomio infancia-tecnología.

A partir de un primer artículo introductorio de la catedrática Sonia Livingstone (London School), crucial para entender las dinámicas de uso de Internet entre los menores, cada capítulo del libro se abre paso para acometer aspectos concretos de la vida online de la infancia: el uso excesivo, el ciberbulling, el sexting, la influencia de la mediación parental y la gestión escolar de la tecnología, entre otros. Especial mención merece el artículo relacionado con el uso adictivo de la tecnología, el cual advierte de la necesidad social de distinguirlo del uso abusivo en tanto que el primero viene motivado por el grado en que la tecnología interfiere cualitativamente en la vida diaria.

En relación al contenido, resulta clave la reflexión sobre las oportunidades y los riesgos que el uso de la tecnología repercute sobre la infancia. Como apuntan Garmendia, Casado, Jiménez y Garitaonandia (Universidad del País Vasco), a mayor exposición, mayores son tanto las oportunidades como el aprendizaje del usuario, si bien es cierto que esto no le exime de los posibles riesgos como la adicción a la tecnología o los contenidos dañinos. En este sentido cobra especial importancia la figura del niño como consumidor digital. Charo Sábada, de la Universidad de Navarra, señala la importancia de promover, por tanto, la educación de los menores en relación con las nuevas tecnologías.

Por otra parte, Martínez y Casado, de la UPV, reflexionan sobre el papel de los padres a la hora de mediar en el uso de Internet y los smartphones, incidiendo en que en España estos prefieren apostar por estrategias de mediación con contenido comunicativo. En esa línea, resulta significativo el modo en que Vandoninck y Leen d’Haenens (KU Leuven de Bélgica) desarrollan en su capítulo cómo la educación contribuye a reducir los riesgos a los que se exponen los menores.

Una idea que está presente en la mayor parte del libro es la importancia que poseen tanto el núcleo familiar -no sólo los padres, sino también los hermanos mayorescomo Internet a la hora de influenciar los hábitos de los niños. No obstante, esta se materializa de forma más detallada en los dos capítulos desarrollados por Ponte, Castro y Batista, de la Universidade Nova de Lisboa, y por Rial y Gómez Salgado, de la Universidad de Santiago de Compostela.

Más allá de estas poderosas influencias, esta obra colectiva no sólo aborda la infancia, sino también profundiza en el uso que los adolescentes dan a los nuevos medios. Los autores coinciden en señalar la complejidad de estos usos. La tecnología constituye en la actualidad una herramienta clave en la formación de la personalidad el individuo, al tiempo que conlleva aspectos positivos y negativos. Tortajada, Willem y Araüna (Universitat Rovira i Virgili) advierten la conformación de cierta artificialidad y, en el caso de las adolescentes, también una autosexualización. Por 
otro lado, estas mismas herramientas otorgan una nueva visibilidad a minorías y colectivos que antes permanecían en un segundo plano, así como un nuevo empoderamiento, tal y como sugiere Antonio García Jiménez, de la Universidad Rey Juan Carlos.

Finalmente resulta necesario destacar el tratamiento del ciberacoso como extensión del acoso escolar, de la mano de Del Rey, Estévez y Ojeda, de la Universidad de Sevilla. El sexting como nueva forma de relación entre jóvenes -con sus ventajas y riesgos- abordado por Garmendia y Karrrera (Universidad del País Vasco), o las nuevas políticas de protección del menor en Internet, capítulo desarrollado por O’Neil, del Dublin Institute of Technology.

Las principales aportaciones de esta obra residen en la actual y fiable visión que ofrece del ámbito educativo en su relación con las aplicaciones tecnológicas. Los trabajos incluidos en el libro contribuyen al entendimiento de una dimensión compleja dentro del sistema comunicativo, como es la educación mediática. Como consecuencia, esta obra constituye una lectura especialmente recomendable no sólo para la comunidad científica, por su valiosa contribución, sino particularmente para educadores, padres y madres, que encontrarán en este libro un diagnóstico fiable que atiende a la identificación y la prevención de los riesgos, así como la promoción del rol crítico y la actitud exigente de los jóvenes internautas. 

CRÉDITOS I 



\section{Acerca de los promotores de adComunica Revista Científica de Estrategias, Tendencias e Innovación en Comunicación}

\section{Asociación para el Desarrollo de la Comunicación adComunica}

La Asociación para el Desarrollo de la Comunicación adComunica es una entidad sin ánimo de lucro promovida por profesores universitarios, directores de comunicación de empresas privadas, y directivos de medios de comunicación, que se dedica al fomento y el desarrollo de la comunicación en todas sus vertientes. Entre sus fines, se encuentra la edición de revistas científicas.

adComunica es una asociación abierta a particulares, empresas e instituciones que compartan el objetivo de aportar valor a la sociedad a través del de desarrollo de actividades que fomenten nuevas tendencias y procesos de innovación en comunicación.

adComunica organiza actividades presenciales dirigidas a los socios y al público en general, tales como conferencias, mesas redondas y debates en los que cuenta con la presencia de invitados que reflexionan sobre temas de interés relacionados con la comunicación como los ya mencionados.

Su ámbito territorial de actuación se limita en la actualidad a la provincia de Castellón (España).

adComunica ofrece además, entre otros servicios a las empresas asociadas, un asesoramiento gratuito y un primer nivel de asistencia, bien sea para el diagnóstico de problemas de comunicación o para actuar de intermediarios y de enlace entre la empresa y el sector de la comunicación. 


\section{Departamento de Ciencias de la Comunicación. Universitat Jaume I. Castellón. España.}

El Departamento de Ciencias de la Comunicación fue creado por el Consejo de Gobierno de la Universitat Jaume I del 17 de diciembre de 2007, y tiene adscritas el Área de Conocimiento de Comunicación Audiovisual y Publicidad y el Área de Conocimiento de Periodismo.

La docencia del Departamento de Ciencias de la Comunicación se concentra en el Grado de Publicidad y Relaciones Públicas, estudios que se implantaron en el curso 1999-2000, en el Grado de Comunicación Audiovisual, inciado en el curso 200506, y en el Grado de Periodismo, implantado en el curso 2009-10, en la Universitat Jaume I. A partir del curso 2007-08, algunos miembros del Departamento de Ciencias de la Comunicación diseñaron y pusieron en marcha el Máster Universitario en Nuevas Tendencias y Proceso de Innovación en Comunicación, título oficial verificado por la ANECA, que cuenta con tres especialidades profesionales ("Dirección estratégica de la comunicación”, "Creatividad y producción de nuevos discursos audiovisuales” y "Periodismo digital y multimedia”), además de una línea de "Iniciación a la investigación” (denominación actual del antiguo Programa de Doctorado).

Por otra parte, el Departamento de Ciencias de la Comunicación desarrolla numerosas actividades extraacadémicas que se agrupan alrededor de la "Escola de Comunicació”, como ciclos de conferencias, talleres, seminarios, congresos, etc., que ha hecho y hace posible una continuada presencia de profesionales de empresas punteras de los campos de la publicidad, del sector audiovisual y del periodismo (agencias de publicidad, centrales de medios, empresas y departamentos de comunicación, estudios de fotografía, cadenas de radio y televisión, productoras de cine y vídeo, empresas periodísticas, agencias de noticias, etc.).

Además, el Departamento tiene adscrito, desde un punto de vista académico, el Laboratorio de Ciencias de la Comunicación (LABCOM), Servicio de la Universitat Jaume I, que presta un apoyo a la docencia y a la investigación que se canaliza a través de este departamento universitario. 


\section{About the promoters of adComunica Journal of Strategies, Tendencies and Innovation in Communication}

\section{Association for the Development of Communication adComunica}

The Association for the Development of Communication adComunica is a nonprofit organisation, championed by university lecturers, communication directors in private companies and mass media managers committed to the promotion and development of all aspects of communication. One of its aims is to publish scientific journals.

adComunica is open to private individuals, businesses and institutions with a common goal of adding value to society by undertaking activities that encourage new trends and processes of innovation in communication.

adComunica organises events for its members and the general public such as lectures, round tables and debates, with guest speakers who reflect on questions of interest in the field of communication like those mentioned above.

The association's activities are currently limited to the province of Castellón (Spain).

In addition, adComunica offers a range of services to associated businesses, including free consultations and first stage assistance, whether in diagnosing communication problems or as intermediaries to provide a link between businesses and the communication sector. 


\section{Department of Communication Sciences, Universitat Jaume I, Castellón, Spain}

The Department of Communication Sciences was created by the Governing Council of the Universitat Jaume I on 17 December 2007, and consists of two knowledge areas, Audiovisual Communication and Advertising, and Journalism.

The Department of Communication Sciences offers the undergraduate degrees of Advertising and Public Relations, initiated in the academic year 1999-2000; Audiovisual Communication, running since 2005-06; and Journalism, which was introduced in the 2009-10 academic year. For the start of academic year 2007-08, members of the department designed and set up the Master's Degree in New Trends and Innovation Processes in Communication, an official qualification verified by ANECA (national quality and accreditation evaluation agency) offering three professional specialisations (strategic management of communication, creativity and production of new audiovisual discourses, and digital and multimedia journalism), as well as the Initiation in Research course of studies (the current title of the former doctoral programme).

The Department of Communication Sciences also organises numerous extracurricular activities through the Communication School, such as lecture seasons, workshops, seminars, conferences, etc., encouraging the regular and continuous presence of professionals from leading companies in the field of advertising and the audiovisual and journalism sectors (advertising agencies, media agencies, communication companies and departments, photographic studios, radio stations, cinema and video production companies, media companies, news agencies, etc.).

A further academic activity that falls under the auspices of the department is the Laboratory of Communication Sciences (LABCOM), a Universitat Jaume I service that provides support for teaching activity and research in the department. 


\section{Normas de publicación}

\section{Propuestas de textos para su publicación}

Los artículos se deben presentar en soporte electrónico, formato .DOC o .RTF, a la dirección electrónica direccion@adcomunicarevista.com o bien colgar los documentos que se solicitan en la aplicación de la página web. Los textos deben ser inéditos, estar escritos preferentemente en castellano, si bien también se admiten textos en valenciano y/o catalán (en tanto que lengua co-oficial en la Comunidad Valenciana) y en inglés, y su temática y extensión se adaptará a la sección correspondiente de la revista, lo que habrá de ser indicado por el/los autor/es del artículo:

Sección Informe: Los artículos tendrán una relación directa con la temática propuesta por la dirección de la revista, en torno al estudio de las estrategias, tendencias e innovación en los sectores de la comunicación, con una extensión entre 4.000 y 8.000 palabras, incluyendo notas al pie y bibliografía.

Sección Otras investigaciones: Los artículos versarán, de forma genérica, sobre investigaciones en el campo de las ciencias de la comunicación, con una extensión entre 4.000 y 8.000 palabras, incluyendo notas al pie y bibliografía.

Sección Tribuna: Investigación y Profesión: Esta sección, pensada principalmente para la participación de profesionales de los sectores de la comunicación, desde la perspectiva de la investigación aplicada, incluirá artículos, valoraciones críticas de novedades editoriales, noticias de la comunicación y eventos relacionados con la comunicación como congresos, encuentros, jornadas, festivales, etc., celebrados recientemente, con una extensión entre 500 y 2.000 palabras, incluyendo notas al pie y bibliografía.

Los trabajos deberán ser originales y no podrán estar en proceso de publicación por otras revistas, medios o plataformas editoriales. El cumplimiento de esta norma queda bajo la responsabilidad del/de los autor/es del artículo propuesto.

\section{Protocolo de edición de la revista}

Los manuscritos serán revisados, de forma anónima, por dos expertos, designados por la dirección de la revista, que realizarán un informe que servirá para decidir si el texto es aceptado, aceptado con condiciones o rechazado, siempre mediante una evaluación debidamente motivada. En el caso de que el manuscrito sea aceptado con condiciones, se indicará en dicho informe las modificaciones que el/los autor/es deberán introducir para su aceptación. Si el manuscrito es rechazado, el informe de evaluación deberá incluir, igualmente, las razones que motivan tal decisión, que serán comunicadas al autor/es.

En caso de que haya disparidad de valoraciones entre los dos informes de evaluación, el manuscrito será remitido a un tercer evaluador.

El plazo de respuesta de evaluación de los trabajos deberá ser inferior a 120 días. Los informes de evaluación serán remitidos a los autores. Los artículos aceptados serán enviados a sus autores que, en un plazo máximo de 15 días, deberán remitir a la revista, si procede, el manuscrito corregido.

Antes de la maquetación final del número, se enviará al autor/es el manuscrito maquetado en PDF, para que pueda revisar su artículo, que deberá remitir en un plazo máximo de 92 horas, indicando si se debe corregir alguna errata o introducir alguna pequeña modificación en el texto.

\section{Guía de presentación de manuscritos}

La propuesta de publicación del manuscrito deberá presentarse bajo la forma de tres documentos diferenciados disponibles en la página web de la revista (www.adcomunicarevista.es) que se habrán de remitir a la revista, a la dirección electrónica direccion@adcomunicarevista.com:

- Documento 1: Declaración del autor/es (Cover Letter)

- Documento 2: Portada del manuscrito (Title Page)

- Documento 3: Manuscrito (Manuscript) 


\section{Indicaciones tipográficas:}

Los manuscritos serán enviados en letra Times New Roman, cuerpo 12, interlineado simple, justificados completos y $\sin$ tabulaciones ni retornos de carro entre párrafos, con $2 \mathrm{~cm}$. en todos los márgenes de la página, que no incluirá ni numeración de páginas ni encabezados o pie de página. No se separarán con una línea los distintos bloques del manuscrito, que se describen con más detalle más adelante, para facilitar la maquetación. El uso de las comillas queda restringido a las tradicionales («»), y se emplearán, en especial, para incluir citas literales de otros documentos.

La estructura del artículo seguirá una serie de epígrafes, numerados mediante el sistema arábigo (1.; 1.1.; 1.1.1.; 2.; 2.1.; 2.1.2.; etc.), sin mayúsculas, ni subrayados ni negritas o cursivas (con la excepción de títulos de creaciones artísticas, títulos de libros, revistas, etc.).

Las tablas o figuras que se desee incluir deberán tener un mínimo nivel de calidad para su edición. Estas imágenes serán introducidas en el propio manuscrito, donde proceda su inserción, debidamente numeradas y con un título claro y breve para su identificación. En caso de que su calidad de impresión no sea suficiente, se recomienda enviar los archivos de las imágenes como ficheros adjuntos, debidamente identificados y numerados, y en formato JPEG o TIFF, con una resolución de 300 ppp. para su correcta impresión.

Las citas a otros autores deberán seguir el sistema Harvard de citación o parentético (ejemplo: Castells, 1997: 97-98), especificando la página de donde se ha extraído la cita, y la referencia completa deberá aparecer al final del texto, en un bloque dedicado a Referencias, en el que los autores se presentarán por orden alfabético, ordenados por el primer apellido del autor. Se emplearán las letras del abecedario (a, b, c...) para distinguir las publicaciones de un mismo autor y año. Las citas a otros autores se incluirán entre comillas, y en el propio texto, siempre que no excedan tres líneas: cuando sean más extensas, se insertarán con un justificado distinto (de cuatro cm.) en el texto del artículo, sin líneas de separación. Es preceptiva la inclusión de la referencia parentética en estos casos. Los fragmentos elididos en el interior de las citas textuales se indicarán con puntos suspensivos y entre corchetes [...]. A la hora de citar películas, programas de televisión, títulos de fotografías, obras pictóricas, títulos de producciones audiovisuales, etc., se empleará el título de distribución en nuestro país en cursiva, si procede, y la primera vez que se citen se incluirá la referencia entre paréntesis del título de distribución original en cursiva, seguido del director y del año de producción (cuando se trate de películas), del autor y del años de creación (fotografías, pinturas, etc.) o del nombre del productor y el año de producción (en el caso de programas de ficción para televisión como series), etc.

Las notas se incluirán al final del artículo, antes de las referencias, y seguirán un orden de numeración arábigo. Se insertarán las notas estrictamente necesarias, que aporten alguna información complementaria que no proceda introducir en el cuerpo del texto. Las notas no deben recoger referencias bibliográficas completas, puesto que éstas han de ir en el bloque final de referencias. Se podrá introducir una breve nota sobre las fuentes de financiación de la investigación, al grupo de investigación en el que se enmarca el trabajo, agradecimientos, etc., que también se incluirá como créditos en el documento 2 Portada.

Las referencias que han de aparecer al final del texto seguirán las siguientes normas de citación, con el fin de unificar criterios:

\section{Libros:}

Apellido(s), Nombre del autor/a/es (Año de Edición) [Año de publicación o Primera Edición, si procede]. Título y subtítulo. Lugar de edición: Editorial.

\section{Capítulos de Libro:}

Apellido(s), Nombre del autor/a/es (Año de Edición) [Año de publicación o Primera Edición, si procede]. Título. En: Apellido(s), Nombre del autor/a/es. Título y subtítulo. Lugar de edición: Editorial.

\section{Revistas:}

Apellido(s), Nombre del autor/a/es (Año de Edición). Título. En: Título de la Revista, Volumen, Número. Lugar de edición: Editorial, páginas. Opcionalmente, a partir de tres autores se podrá citar sólo los dos primeros autores, empleando además la fórmula et al.

\section{Documentos electrónicos:}

Para citar documentos electrónicos se seguirán las pautas anteriormente señaladas, indicando además la dirección URL y la fecha de consulta.

\section{Imágenes y figuras:}

Si se desea insertar imágenes, dibujos, tablas, gráficos, etc., y éstos provocan que el texto ocupe más de 10 Mbytes de espacio, se recomienda enviar las fotografías en uno o varios documentos aparte, en formato .TIFF o .JPEG. Estos archivos se denominarán con una numeración consecutiva, que se corresponderá con la numeración consecutiva de las figuras que aparecerá en el manuscrito. 


\section{Submission guidelines}

\section{Proposals for articles to be published}

Articles should be submitted electronically, in either .DOC or .RTF formats, to the e-mail address direccion@ adcomunicarevista.com or via the journal's online submission process, through the website. Manuscripts must be unpublished, and should preferably be written in Spanish, although articles in Valencian and/or Catalan (coofficial language in the Valencian Community) and in English will also be considered. The topic and length of the article should meet the specifications of the corresponding section of the journal, which the author(s) must specify:

Report section: articles should be directly related to the subject area proposed by the journal's editorial team, focusing on the study of strategies, tendencies and innovation in the communications sectors. Manuscripts must be between 4000 and 8000 words, including endnotes and references.

Other Research section: articles should cover generic research in the field of communication sciences. Manuscripts must be between 4000 and 8000 words, including endnotes and references.

Forum: Research and Profession: this section is conceived as a platform for contributions from professionals in the communications sectors and takes an applied research perspective. It will include articles, book reviews, communication news and recently held communication events such as conferences, meetings, lectures, festivals, etc. Articles should be between 500 and 2000 words, including endnotes and references.

All articles submitted must be original, and must not be under consideration for publication by other journals, media or publishing platforms. Authors submitting articles for publication are responsible for complying with this regulation.

\section{Journal publishing protocol}

Manuscripts will then be anonymously reviewed by two expert referees assigned by the editorial team. The referees' reports will provide the basis for the decision on whether the article is accepted unconditionally, accepted subject to revision, or rejected, by means of a duly justified evaluation. If the manuscript is accepted subject to revision, the referees' report will detail the modifications the authors should make before it can be accepted. If the manuscript is rejected, the report will include the reasons for this decision, which will be passed on to the author(s).

If the recommendations made in the two referees' reports do not coincide, the manuscript will be sent to a third referee.

The turn-around period for the peer review process will be no longer than 120 days. The referees' reports will then be forwarded to the author(s). Accepted articles will be sent to the author(s) who should return the revised manuscript, where appropriate, to the journal within 15 days.

Prior to the final typesetting of the issue, the author(s) will receive galley proofs of the manuscript in PDF format for revision. The author must return the article within a maximum of 92 hours, indicating any errata in the text or introducing any brief modifications.

\section{Guide to manuscript presentation}

Three distinct documents must be used to submit manuscript proposals, and sent to the journal at the following e-mail address direccion@adcomunicarevista.com. Templates of these documents are available on the journal's website (www.adcomunicarevista.es) for authors to use.

- Document 1: Cover Letter

- Document 2: Title Page

- Document 3: Manuscript 


\section{Text guidelines:}

Manuscript texts must be set to 12-point Times New Roman, single spaced, fully justified and with no tab stops or returns between paragraphs. All page margins must be set to $2 \mathrm{~cm}$ and pages should not be numbered or include running headers or footers. Please do not separate blocks of text with extra lines as this interferes with the typesetting process (further information is provided below). Only double angled commas («») should be used, essentially to denote quotations from other documents.

The article should be structured in a series of sections numbered using Arabic numerals (1.; 1.1.; 1.1.1.; 2.; 2.1.; 2.1.2.; etc.). Block capitals, underlining, bold or italics should not be used in headings (except in titles of artistic creations, book or journal titles, etc.).

Any tables or figures authors wish to include must meet a minimum standard of quality for publication. These images should be included in the manuscript itself, in their final position, duly numbered and identified with a clear, short title. If they are not of sufficient quality for printing, the images should be attached in separate JPEG or TIFF files, correctly identified and numbered, with a resolution of 300 ppi to ensure high print quality.

In-text references to other authors should follow the Harvard or parenthetical referencing system (e.g.: Castells, 1997: 97-98), stating the page from which the reference is taken. The full reference must appear at the end of the text in the References section, where authors are listed alphabetically by surname (first surname where appropriate). Lowercase letters should be used $(\mathrm{a}, \mathrm{b}, \mathrm{c} \ldots$ ) to differentiate publications by the same author in one year. Short quotations (fewer than three lines) from other authors must appear within inverted commas in the text; longer quotations should be indented $(4 \mathrm{~cm})$ in the text, with no blank separating lines. Parenthetical references must be included in these cases. Fragments omitted from within a quotation should be indicated by ellipses inside square brackets [...]. The first reference in the article to films, television programmes, titles and photographs, pictures, audiovisual productions, etc., should give the Spanish distribution title in italics (where appropriate), followed by a reference to the original title in italics in brackets, the name of the director and the year of production (for films), the name of the photographer or artist and the year of creation (for photographs, paintings, etc.) or the name of the production company and the year of the production (or fictional television programmes such as series), etc.

Notes should be included at the end of the article before the References section, using Arabic numerals. Automatic numbering systems offered by word processors such as Microsoft Word should be avoided as they can cause difficulties in typesetting. Authors are requested to restrict notes to a minimum, and include only those that are essential to provide additional information that is not appropriate for inclusion in the main text. Notes should not contain full bibliographical references; these must be listed in the final References section. A brief note may be included mentioning sources of funding, the Research Group that conducted the research, acknowledgements, etc., which should also appear as acknowledgements in document no. 2, Cover Letter.

The references included in the final section must follow the referencing system set out below:

\section{Books:}

Author(s) surname(s), name (Year of Publication) [Year of publication or First Edition, where appropriate]. Title and subtitle. Place: Publisher.

\section{Book Chapters:}

Author(s) surname(s), name (Year of Publication) [Year of publication or First Edition, where appropriate]. Title. In: Author(s) surname(s), name. Title and subtitle. Place: Publisher.

\section{Journals:}

Author(s) surname(s), name (Year of Publication). Title. In: Title of Journal, Volume, Issue. Place: Publisher, page numbers. Alternatively, when articles are written by three or more authors, the first two names may be cited, followed by et al.

\section{Electronic documents:}

When referencing electronic documents, the above-mentioned systems should be used, followed by the URL address and the access date.

\section{Images and figures:}

If images, drawings, tables, figures, etc. are to be included, and the document requires more than $10 \mathrm{MB}$ of space, authors are asked to send photographs in separate documents in .TIFF or .JPEG format. These files should be numbered consecutively, corresponding to the numbering of the images and figures as they appear in the manuscript. 



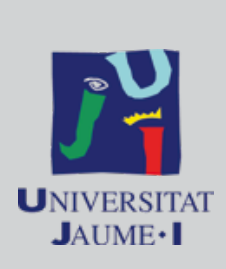

